\title{
Interictal epileptiform activity as a marker for clinical outcome
}

Citation for published version (APA):

Ebus, S. C. M. (2015). Interictal epileptiform activity as a marker for clinical outcome. [Doctoral Thesis, Maastricht University]. Maastricht University. https://doi.org/10.26481/dis.20150527se

Document status and date:

Published: 01/01/2015

DOI:

10.26481/dis.20150527se

Document Version:

Publisher's PDF, also known as Version of record

\section{Please check the document version of this publication:}

- A submitted manuscript is the version of the article upon submission and before peer-review. There can be important differences between the submitted version and the official published version of record.

People interested in the research are advised to contact the author for the final version of the publication, or visit the DOI to the publisher's website.

- The final author version and the galley proof are versions of the publication after peer review.

- The final published version features the final layout of the paper including the volume, issue and page numbers.

Link to publication

\footnotetext{
General rights rights.

- You may freely distribute the URL identifying the publication in the public portal. please follow below link for the End User Agreement:

www.umlib.nl/taverne-license

Take down policy

If you believe that this document breaches copyright please contact us at:

repository@maastrichtuniversity.nl

providing details and we will investigate your claim.
}

Copyright and moral rights for the publications made accessible in the public portal are retained by the authors and/or other copyright owners and it is a condition of accessing publications that users recognise and abide by the legal requirements associated with these

- Users may download and print one copy of any publication from the public portal for the purpose of private study or research.

- You may not further distribute the material or use it for any profit-making activity or commercial gain

If the publication is distributed under the terms of Article $25 \mathrm{fa}$ of the Dutch Copyright Act, indicated by the "Taverne" license above, 


\section{Interictal epileptiform activity as a}

\section{marker for clinical outcome}


Copyright (C) 2015 by Saskia Ebus. All rights reserved.

ISBN: 978-94-6259-619-1

Cover: Riet Ebus-Elbers

Layout: Tiny Wouters

Printed by: Ipskamp Drukkers

Financial support by Cyberonics Europe BVBA, Eisai B.V., UCB Pharma B.V., Academic Center for Epilepsy Kempenhaeghe, department research and development is gratefully acknowledged. 


\title{
Interictal epileptiform activity as a marker for clinical outcome
}

\author{
PROEFSCHRIFT \\ Ter verkrijging van de graad van doctor aan de Universiteit Maastricht, \\ op gezag van de Rector Magnificus, Prof. dr. L.L.G. Soete, \\ volgens het besluit van het College van Decanen, \\ in het openbaar te verdedigen \\ op woensdag 27 mei 2015 om 14.00 uur
}

door

Saskia Clara Mathilda Ebus 


\section{Promotores}

Prof. dr. A.P. Aldenkamp

Prof. dr. J.B.A.M. Arends (Technische universiteit Eindhoven)

Prof. dr. P.A.J.M. Boon (Universiteit Gent, België)

\section{Beoordelingscommissie}

Prof. dr. W.H. Mess (voorzitter)

Dr. F.S.S. Leijten (Universiteit Utrecht)

Dr. J. Nicolai

Prof. dr. R.J. van Oostenbrugge

Prof. dr. H. Stefan (Universiteit Erlangen, Duitsland) 
"Do not go upon what has been acquired by repeated hearing; nor upon tradition; nor upon rumour; nor upon a scripture; nor upon deduction; nor upon an axiom; nor upon dubious reasoning; nor upon another's apparent ability; nor upon the consideration, 'This is our guru.' When you yourselves know: 'These things are unwholesome; these things are blameworthy; these things are criticized by the wise; undertaken and followed, these things lead to harm and dissatisfaction', then you would be wise to abandon them... And when you yourselves know: 'These things are wholesome; these things are not blameworthy; these things are praised by the wise; undertaken and followed, these things lead to benefit and happiness', you would be wise to enter upon and dwell in them."

AN 3.65 (Kalama Sutta) 



\section{Contents}

Chapter 1 Introduction 9

Chapter 2 Can spikes predict seizure frequency ? Results of a pilot study in 21 severe childhood epilepsies treated with vagus nerve stimulation

Chapter 3 Can an early 24-hour EEG predict the response to the ketogenic diet? A prospective study in 34 children and adults with refractory epilepsy treated with the ketogenic diet

Chapter 4 Cognitive effects of interictal epileptiform discharges in children

Chapter 5 Reading performance in children with rolandic epilepsy correlates 69 with nocturnal epileptiform activity, but not with epileptiform activity while awake

Chapter 6 Changes in the frequency of benign focal spikes accompany changes in central information processing speed: A prospective 2-year follow-up study

Chapter 7 Ins and outs of quantifying spikes

Chapter 8 General discussion

Summary

Samenvatting

Valorisatie

List of publications

Dankwoord

Curriculum Vitae 



\section{Chapter 1}

Introduction 
Chapter 1 


\section{General introduction}

In the first part of this introduction, background information regarding the use of the interictal EEG (electro-encephalography) in patients with epilepsy will be presented. Some neurophysiological aspects of epileptiform discharges are explained that are necessary for a better comprehension of the research questions.

Secondly, two hypotheses that are important for this thesis are explained, and the existing knowledge on these hypotheses described.

Finally, aim and structure of the thesis are outlined.

\section{EEG in the diagnosis of epilepsy}

The diagnosis of epilepsy, a susceptibility for seizures, is primarily based on observation. Two well-observed spontaneous seizures are sufficient for the diagnosis. In patients with (suspected) epilepsy, surface EEG is used as an additional diagnostic tool. The usual questions to be answered by an EEG are:

1. Can the susceptibility for seizures be confirmed?

2. What is the epilepsy syndrome?

3. What is the severity/impact of the epilepsy ?

\section{Can the susceptibility for seizures be confirmed?}

The occurrence of interictal epileptiform discharges (IEDs) in the EEG confirms the diagnosis of epilepsy with a high probability. IEDs are only seen in $0.5 \%$ of healthy adults $^{1}$ and in $3.5 \%$ of children without seizures. ${ }^{2}$ In patients with epilepsy, the chance of finding IEDs in a 30 minute EEG in wakefulness is between $18-56 \%$ in children and $12-50 \%$ in adults, according to various studies. ${ }^{3,4}$ The sensitivity can be increased by a repeated EEG during sleep. In sleep deprived sleep about $1 / 3$ of patients with normal EEG in wakefulness will show IEDs. ${ }^{3,5}$

\section{What is the epilepsy syndrome?}

The primary step for classification is a distinction between generalized and focal seizure types. ${ }^{6}$ Knowledge on the type of interictal and/or ictal discharges in the EEG is important for this step. Generalized seizures are presumed to originate at some point within, and rapidly engaging, bilaterally distributed networks. The interictal and ictal EEG discharges have a bilateral diffuse localization. Most primarily generalized seizures have a (presumed) genetic etiology. Focal seizures have a local onset and may propagate to other regions as well as to bilaterally distributed networks. Focal seizures are observed in epilepsies with structural or metabolic etiology, but genetic causes are also possible. 
Even when underlying causes are not found initially, the EEG may point to a specific epilepsy syndrome. Particular types of epileptiform EEG abnormalities may encourage the neurologist to use advanced diagnostic tools, for example when a single localization in a certain gyrus is found, or because the type of EEG-abnormalities are recognized as those seen in epilepsies with a specific genetic cause. ${ }^{7,8}$

\section{What is the severity/impact of the epilepsy?}

The EEG can provide information on epilepsy severity that cannot otherwise be obtained. An example is the finding of ESES (electrical status epilepticus in slow wave sleep). Ictal EEG-discharges with subtle momentary effects on cognition may only be revealed with video-EEG recording in combination with close observation of cognitive performance. Long-term EEG recordings can examine the frequency of clinically difficult to detect seizures in daily life and/or in sleep (e.g. absence seizures) and this frequency may be higher than presumed.

\section{Generation and recording of IEDs}

In vitro, neurons from epileptic brain tissue exhibit aberrant behavior. They can depolarize suddenly ("paroxysmal depolarization shifts"), and do this in a repetitive, sometimes even rhythmical pattern. "Epileptic" neurons can synchronize with other neurons nearby or further away in a functional network through synaptic communication or gap junctions.

Cerebral electrical activity in the form of local field potentials in vivo can be recorded with a surface EEG. When aligning neurons of at least $6 \mathrm{~cm}^{2}$ of cortex simultaneously exhibit a depolarization shift, a graphic element called a "spike-(and slow-)wavecomplex" or "sharp-(and slow-)wave-complex" occurs in the EEG. The sharp component (spike or sharp wave) occurs within 200 milliseconds (sharp wave 70-200 ms, spike within $70 \mathrm{~ms}$ ), during which the field potential changes quickly from baseline and returns back to baseline. After this, a slow wave reflects an inhibitory phase of hyperpolarization. These graphic elements are called interictal epileptiform discharges (IEDs). ${ }^{\text {a }}$ They occur isolated or in short rhythmical bursts (Figure 1.1).

IEDs from deep sources (e.g. in deep fissures and from the inferior surfaces of the hemispheres) may not appear on the surface EEG. Field potential changes from neurons in sulci lying tangential to the skull contribute less to the surface EEG signal. New recording techniques have better abilities to localize and see propagations (magnetic encephalography $=M E G$ ) or try to reach the deeper epileptic cortical areas (intracranially recorded EEG, primarily developed to observe ictal epileptiform activity). Disadvantages are the immobilization for MEG and the invasive character and limited spatial resolution of the intra-cranial techniques.

\footnotetext{
a Note: other used terms instead of "interictal epileptiform discharge" are "interictal epileptic discharge", "interictal epileptiform activity", or sometimes the word "spike".
} 


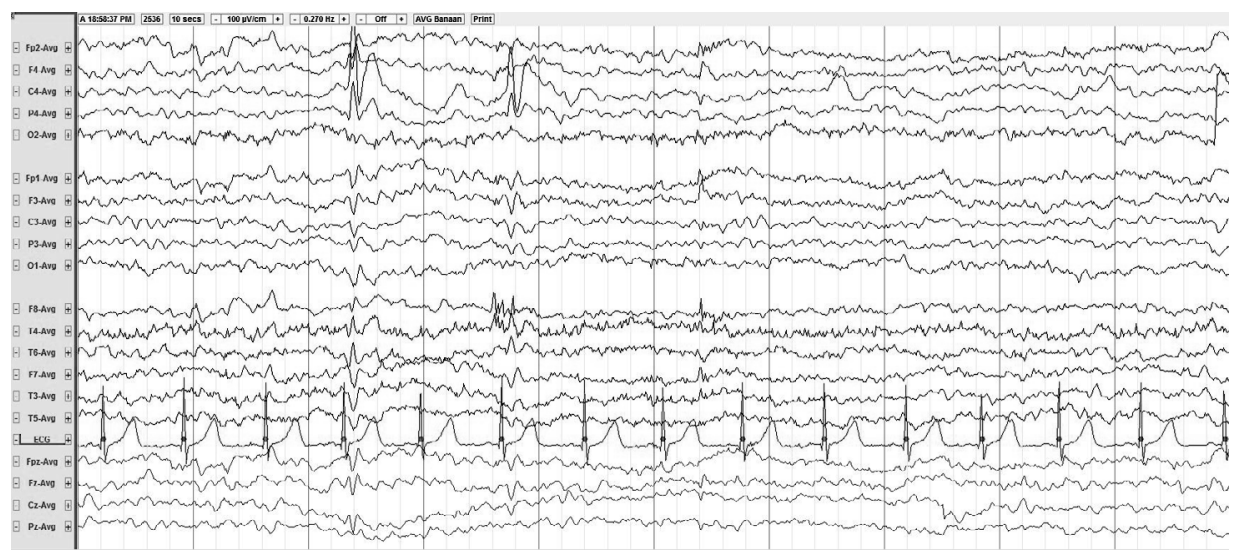

Figure 1.1 Interictal epileptiform discharges in wakefulness in a surface EEG-fragment of 10 seconds of duration. Two sharp-wave-complexes, in the third and fourth second, respectively, localized in the right central-parietal region. Common average montage.

\section{Identification of IEDs}

The identification of IEDs by visual inspection is a learned skill. An EEG-viewer (EEG technologist or neurologist/neurophysiologist) has to recognize these patterns within normal electric brain activity. He/she has to discern them from normal sharp variants that can highly resemble epileptiform activity, and from sharp artifacts. This skill is gradually trained by the observation of numerous EEGs. The difficulty of EEG interpretation is demonstrated by a study comparing the opinions of 6 experienced epileptologists to conclude to either a normal EEG pattern, an EEG with seizures or an EEG with IEDs. ${ }^{10}$ The inter-observer agreement between sets of viewers only had a mean of 0.55 (range $0.33-0.72$ ), although all individual epileptologists were quite certain of their opinion. This did not completely resemble clinical practice, as the reviewers were blinded for the indication of the EEG and comments from the EEGtechnologist.

Computerized algorithms can be developed to recognize the shape of spikes and spikewaves $^{11}$ or to recognize the morphology of a chosen template IED. Nowadays, they are mostly used to assist for focus localizations in a presurgical work-up. ${ }^{12}$ They are not often used to assist the visual detection of IEDs in clinical daily practice.

\section{IEDs and ictal discharges}

The relationship between interictal and ictal discharges is puzzling. Is the "interictal" discharge the beginning of a seizure, however not carried through, perhaps by not recruiting enough neurons to start the seizure ? This "interictal-ictal transition theory" 
seems plausible, as the localization of IEDs points to the seizure onset zone in focal epilepsies. However, the theory of a close relationship between IEDs and ictal discharges is in debate.

Tissue that creates IEDs is not always able to generate seizures. In presurgical work-up, the source with the highest IED rate not always correlates to the seizure onset zone. ${ }^{13}$ There is lack of prognostic significance of IEDs in the preoperative normal hemisphere in patients after hemispherectomy/hemispherotomy. ${ }^{14}$ IEDs can be completely suppressed in experimental settings, and despite this, the generation of ictal episodes continues. $^{15-18}$

Ictal discharges in focal epilepsies can be morphologically different from inter-ictal discharges and changes in IED-rates do not precede seizures in humans. Only a postictal increase of IED rate can be observed lasting for about 48 hours after the seizure. $^{19,20}$

\section{IED frequency and clinical correlations}

In this part of the introduction, background information is presented on two hypotheses that are important for this thesis.

The first hypothesis is the correlation between IEDs and the level of epileptogenicity.

The second hypothesis is the negative influence of IEDs on brain functions.

\section{IEDs and the level of epileptogenicity}

"Epileptogenicity" is a term to describe the capacity of neuronal tissue to generate ictal discharges. A higher level of epileptogenicity means a higher chance of seizures. There is no perfect test that defines the level of epileptogenicity of the brain or a part of the brain. The IED frequency might be a candidate. I will present the existing knowledge on the relationship between IED frequency and the risk of seizures at epilepsy onset, during the chronic phase, and when the patient has become seizure free.

\section{IEDs and epileptogenicity at the onset of epilepsy}

As already said, the occurrence of IEDs is a powerful predictor for further seizures, and it confirms the diagnosis of epilepsy with high probability. After a first seizure, the risk of seizure recurrence is about two-fold higher when IEDs are found: adults $49.5 \%$ vs. $27.4 \%$ when the EEG is normal, children $60-71 \%$ vs. $27-42 \%{ }^{3}$

\section{IEDs and epileptogenicity in chronic epilepsy}

In patients with ongoing seizures, the strength of the relationship between the momentary IED frequency and seizure frequency is best examined in a homogeneous 
group. If patients diagnosed with an epilepsy syndrome with certain characteristics of IED frequency and seizure frequency are included together with other syndromes, a correlation might not be found. For example, the high IED frequency and low seizure frequency that are generally observed in Rolandic epilepsy at first sight seems an argument against a relationship between IED frequency and seizures. However, when examined as a homogeneous group, a relationship between higher IED frequency and higher likelihood of recurrence of seizures has been reported in Rolandic epilepsy. ${ }^{21}$ Even when examined in an homogeneous group, it is difficult to find the true strength of the relationship. There are many threats:

IEDs can be missed when recordings are too short, or when IED sources are too deep. On the other hand the IED frequency will be exaggerated when the recording is in the post-ictal period, after sleep-deprivation or after drug-withdrawal.

Seizure counts may not be reliable. Patients are not always well observed or seizures may be too subtle to be recognized. Patients do not always know themselves whether they had a seizure. A study in a video-EEG unit demonstrates that $32 \%$ of all registered seizures in the awake state and $86 \%$ in sleep are not reported by the patients. ${ }^{22}$ Patients/caregivers may forget to report a seizure in the diary, even when they participate in a study.

Knowing all these caveats, it is not surprising that a study on the presence or number of IEDs in a short EEG in wakefulness and self reported retrospective seizure frequency in 192 patients with heterogeneous epilepsy syndromes with at least 2 reported seizures in history, fails to demonstrate a relationship between presence of IEDs or IED frequency and seizure frequency, despite adequate statistical power. ${ }^{23}$

\section{IEDs and epileptogenicity at the time of seizure freedom}

Many studies addressed the subject of prediction of seizure recurrence from a momentary EEG at the time of several years of seizure freedom, to decide if AEDs (antiepileptic drugs) can be safely tapered off. It appears that finding IEDs or not is not a good predictor for individual patients with focal epilepsies. ${ }^{24-28}$ It has a better prediction value in patients with primary generalized epilepsies. ${ }^{24}$

Few studies used the information of serial EEGs. This appears to be more useful. A reduced IED frequency compared to an earlier EEG, and especially normalization of the EEG when the EEG had shown IEDs before, are better predictors for seizure freedom after drug withdrawal. ${ }^{26}$ Also, re-appearance of IEDs in the period of AED withdrawal is predictive of recurrence of seizures. ${ }^{27,28}$ It is obvious, that conclusions on epileptogenicity in individual patients can be best made by observing changes in IED frequency in serial EEGs. 


\section{IEDs and brain functions}

Brain functions of patients with epilepsy are at risk. These functions are threatened by various issues: etiology-related, seizure-related, or related to side effects of drugs. IEDs may be an independent threat.

Brain functions are network functions, needing the cooperation of connected neurons in different cortical areas. Epilepsy research, especially on cognitive decline, is more and more focusing on disruptions of cerebral networks. ${ }^{29-31}$ One of the most used examinations is $\mathrm{fMRI}$ : BOLD-signals (blood-oxygenation level dependent signals) change in the regions that are functionally connected at the moment of performing certain tasks, at the moment of rest (the "default mode network"), or at the moment of occurrence of seizures or IEDs.

Although IEDs in focal epilepsies occur in a small time window, and seem to be localized in one cortical region, it is suspected that their impact on brain functions could be higher than first presumed, in time (outlasting the duration of the IED itself) as well as in space (influencing the function of remote cortical areas within cerebral networks).

Activations or de-activations (examined by BOLD-changes in fMRI-setting) can sometimes already be seen several seconds before an IED. It is suggested that this is a metabolic pre-IED phenomenon needed for synchronization of neurons, regulated by astrocytes. $^{32}$ However, the time-resolution of $\mathrm{fMRI}$ is less accurate than it is for EEG, so these short term time-relationships have to be interpreted with caution. There also seems to be a delayed effect of IEDs, demonstrated by localized EEG abnormalities in the quantitative EEG, occurring and gradually decreasing in the 6 seconds after the IED. $^{33}$

In an fMRI setting, IEDs can activate and de-activate remote brain areas outside the seizure onset zone. ${ }^{32,34,35}$ The default mode network can be deactivated in periods when frequent IEDs occur. This deactivation tends to occur ipsilateral to the IED focus and in a specific pattern for each patient/ for each IED-type in a certain patient. ${ }^{36}$ In temporal lobe epilepsy (TLE) the same networks "used" by seizures can also be activated by the IEDs: the medial temporal/limbic network, parietal/frontal or temporal/occipital network. ${ }^{37}$ These networks are important for memory and information processing. In TLE, a higher number of IEDs was shown to be correlated to lower scores on memory tests. ${ }^{38}$

The momentary effect of individual IEDs on cognition of one patient in daily life is very difficult to examine. The most referred study is from Shewmon, published in $1988^{39}$, who demonstrated slowing of visual reaction times associated with triggered occipital IEDs. It was suggested that the dysfunction was related to the slow wave (the inhibitory phase) of the IED. ${ }^{40}$ Because the momentary effect of individual IEDs is very difficult to examine, effects of IEDs on cognition are more often examined in a group, correlating IED frequency to cognitive outcome or comparing patients with different numbers of IEDs per time-unit or during the time needed for a certain cognitive task. Studies performed in a tertiary referral centre for epilepsy examining the effects of subtle ictal 
discharges versus the effects of IED frequency demonstrated that IEDs had an independent effect on cognition, however with less impact than ictal discharges. Patients with sporadic IEDs (in $<1 \%$ of the studied time) performed better than those with non-sporadic IEDs. ${ }^{41,42}$

\section{Aim and structure of this thesis}

In a tertiary epilepsy centre, most EEG-recordings are requested for patients with an established diagnosis of epilepsy, often severely affected and refractory to drugs. Neurologists seek for additional information, that will aid in medical decision making. A marker of (changes) in epileptogenicity, that can predict or at least confirm the efficacy of a chosen treatment path can be useful. Can the IED frequency be such a marker ? Furthermore, in children with learning difficulties the issue is whether IED frequency is correlated to their cognitive outcome.

In this thesis, two questions will be tested.

The first part of the thesis focuses on IEDs as a marker for epileptogenicity in the treatment of refractory patients with non-pharmacological techniques.

Chapter 2 presents the results of a prospective study in severely mentally retarded patients suffering from epilepsy syndromes known with highly frequent IEDs. This chapter focuses on the question whether an intervention (Vagus nerve stimulation) changes the IED frequency, and whether the IED frequency is reflecting the severity of the disease.

In chapter 3, a heterogeneous patient group treated with ketogenic diet is examined. It was studied whether changes in IED frequency could predict the future outcome of the diet in terms of seizure reduction.

Both studies tested the usefulness of IEDs as a marker for treatment success in refractory patient groups. Given the burden of both treatment options that require much from the patient and its caregivers, there is a need for predicting future seizure outcome as early as possible.

The second part of the thesis focuses on IEDs and cognitive outcome.

IEDs might affect brain functions, especially cognitive functions. It is however not known for which patient group, IEDs have the largest effects on cognition, independent from other epilepsy related factors. High numbers of IEDs in children are most often seen in patients with benign focal epilepsies, such as Rolandic epilepsy or Panayiotopoulos syndrome. These epilepsies are known with low seizure frequency and a self-limiting time-course. Patients with benign focal IEDs could be at risk for IEDrelated cognitive impairment during the active phase of the disease.

In chapters 4 to 6 , the thesis focuses on cognitive outcome in children with epilepsy with the IED frequency as a marker. In chapter 4, a correlation analysis between cognitive tests and IED frequency (combined with other characteristics of IEDs) in a large, heterogeneous group of children with epilepsy and/or with IEDs is presented. 
Chapter 5 shows the results of correlations between reading performance and IED frequency in a homogeneous group of patients with Rolandic epilepsy. Chapter $\mathbf{6}$ is a prospective study in children with benign focal IEDs. This study analyses whether central information processing speed improves when IEDs decrease, and whether it worsens when IEDs increase in serial EEGs.

The final chapter 7 focuses on methods of IED quantification. A current IED quantification method used in daily clinical practice in the EEG department of a tertiary referral centre for epilepsy is evaluated. For future research projects with analysis of serial EEGs from patients with benign focal IEDs, several methods are examined on their abilities to detect reliable change between successive EEGs of individual patients. 


\section{References}

1. Gregory RP, Oates T, Merry RT. Electroencephalogram epileptiform abnormalities in candidates for aircrew training. Electroencephalogr Clin Neurophysiol 1993;86:75-7.

2. Cavazzuti GB, Cappella L, Nalin A. Longitudinal study of epileptiform EEG patterns in normal children. Epilepsia 1980;21:43-55.

3. Wirrell EC. Prognostic significance of interictal epileptiform discharges in newly diagnosed seizure disorders. J Clin Neurophysiol 2010;27:239-48.

4. Baldin E, Hauser WA, Buchhalter JR, Hesdorffer DC, Ottman R. Yield of epileptiform electroencephalogram abnormalities in incident unprovoked seizures: a population-based study. Epilepsia 2014;55:1389-98.

5. Berg AT, Shinnar S. The risk of seizure recurrence following a first unprovoked seizure: a quantitative review. Neurology 1991;41:965-72.

6. Berg AT, Berkovic SF, Brodie MJ, et al. Revised terminology and concepts for organization of seizures and epilepsies: report of the ILAE Commission on Classification and Terminology, 2005-2009. Epilepsia 2010;51:676-85.

7. Vendrame M, Loddenkemper T, Zarowski M, et al. Analysis of EEG patterns and genotypes in patients with Angelman syndrome. Epilepsy Behav 2012;23:261-5.

8. Knupp K, Wirrell E. Progressive myoclonic epilepsies: it takes a village to make a diagnosis. Neurology 2014;82:378-9.

9. Cooper R, Winter AL, Crow HJ, Walter WG. Comparison of Subcortical, Cortical and Scalp Activity Using Chronically Indwelling Electrodes in Man. Electroencephalogr Clin Neurophysiol 1965;18: 217-28.

10. Grant AC, Abdel-Baki SG, Weedon J, Arnedo V, Chari G, Koziorynska E, Lushbough C, Maus D, McSween T, Mortati KA, Reznikov A, Omurtag A. EEG interpretation reliability and interpreter confidence: a large single-center study. Epilepsy Behav 2014;32:102-7.

11. Wilson SB, Turner CA, Emerson RG, Scheuer ML. Spike detection II: automatic, perception-based detection and clustering. Clin Neurophysiol 1999;110:404-11.

12. Liston AD, De Munck JC, Hamandi K, Laufs H, Ossenblok P, Duncan JS, Lemieux L. Analysis of EEG-fMRI data in focal epilepsy based on automated spike classification and Signal Space Projection. Neuroimage 2006;31:1015-24.

13. Goncharova, II, Spencer SS, Duckrow RB, Hirsch LJ, Spencer DD, Zaveri HP. Intracranially recorded interictal spikes: relation to seizure onset area and effect of medication and time of day. Clin Neurophysiol 2013;124:2119-28.

14. Wyllie E, Lachhwani DK, Gupta A, Chirla A, Cosmo G, Worley S, Kotagal P, Ruggieri P, Bingaman WE. Successful surgery for epilepsy due to early brain lesions despite generalized EEG findings. Neurology 2007;69:389-97.

15. Dorn T, Witte OW. Refractory periods following interictal spikes in acute experimentally induced epileptic foci. Electroencephalogr Clin Neurophysiol 1995;94:80-5.

16. Sherwin I. Interictal--ictal transition in the feline penicillin epileptogenic focus. Electroencephalogr Clin Neurophysiol 1978;45:525-34.

17. Jensen MS, Yaari Y. The relationship between interictal and ictal paroxysms in an in vitro model of focal hippocampal epilepsy. Ann Neurol 1988;24:591-8.

18. Avoli M, Barbarosie M. Interictal-ictal interactions and limbic seizure generation. Rev Neurol (Paris) 1999;155:468-71.

19. Gotman J. Relationships between triggered seizures, spontaneous seizures, and interictal spiking in the kindling model of epilepsy. Exp Neurol 1984;84:259-73.

20. Gotman J, Koffler DJ. Interictal spiking increases after seizures but does not after decrease in medication. Electroencephalogr Clin Neurophysiol 1989;72:7-15.

21. Kanemura H, Sano F, Ohyama T, Sugita K, Aihara M. Sequential EEG characteristics may predict seizure recurrence in rolandic epilepsy. Seizure 2014;23:646-50.

22. Hoppe C, Poepel A, Elger CE. Epilepsy: accuracy of patient seizure counts. Arch Neurol 2007;64: 1595-9.

23. Selvitelli MF, Walker LM, Schomer DL, Chang BS. The relationship of interictal epileptiform discharges to clinical epilepsy severity: a study of routine electroencephalograms and review of the literature. $J$ Clin Neurophysiol 2010;27:87-92. 
24. Caviedes BE, Herranz JL. Seizure recurrence and risk factors after withdrawal of chronic antiepileptic therapy in children. Seizure 1998;7:107-14.

25. Overweg J, Binnie CD, Oosting J, Rowan AJ. Clinical and EEG prediction of seizure recurrence following antiepileptic drug withdrawal. Epilepsy Res 1987;1:272-83.

26. Callaghan N, Garrett A, Goggin T. Withdrawal of anticonvulsant drugs in patients free of seizures for two years. A prospective study. N Engl J Med 1988;318:942-6.

27. Galimberti CA, Manni R, Parietti L, Marchioni E, Tartara A. Drug withdrawal in patients with epilepsy: prognostic value of the EEG. Seizure 1993;2:213-20.

28. Tinuper P, Avoni P, Riva R, Provini F, Lugaresi E, Baruzzi A. The prognostic value of the electroencephalogram in antiepileptic drug withdrawal in partial epilepsies. Neurology 1996;47:76-8.

29. van Diessen E, Diederen SJ, Braun KP, Jansen FE, Stam CJ. Functional and structural brain networks in epilepsy: what have we learned? Epilepsia 2013;54:1855-65.

30. Vlooswijk MC, Vaessen MJ, Jansen JF, de Krom MC, Majoie HJ, Hofman PA, Aldenkamp AP, Backes WH. Loss of network efficiency associated with cognitive decline in chronic epilepsy. Neurology 2011;77: 938-44.

31. Besseling RM, Overvliet GM, Jansen JF, van der Kruijs SJ, Vles JS, Ebus SC, Hofman PA, de Louw AJ, Aldenkamp AP, Backes WH. Aberrant functional connectivity between motor and language networks in rolandic epilepsy. Epilepsy Res 2013;107:253-62.

32. Pittau F, Levan P, Moeller F, Gholipour T, Haegelen C, Zelmann R, Dubeau F, Gotman J. Changes preceding interictal epileptic EEG abnormalities: comparison between EEG/fMRI and intracerebral EEG. Epilepsia 2011;52:1120-9.

33. Clemens B, Piros P, Bessenyei M, Varga E, Puskas S, Fekete I. The electrophysiological "delayed effect" of focal interictal epileptiform discharges. A low resolution electromagnetic tomography (LORETA) study. Epilepsy Res 2009;85:270-8.

34. Lengler U, Kafadar I, Neubauer BA, Krakow K. fMRI correlates of interictal epileptic activity in patients with idiopathic benign focal epilepsy of childhood. A simultaneous EEG-functional MRI study. Epilepsy Res 2007;75:29-38.

35. Gotman J. Epileptic networks studied with EEG-fMRI. Epilepsia 2008;49 Suppl 3:42-51.

36. Fahoum F, Zelmann R, Tyvaert L, Dubeau F, Gotman J. Epileptic discharges affect the default mode network--FMRI and intracerebral EEG evidence. PLoS One 2013;8:e68038.

37. Wiest R, Estermann L, Scheidegger O, Rummel C, Jann K, Seeck M, Schindler K, Hauf M. Widespread grey matter changes and hemodynamic correlates to interictal epileptiform discharges in pharmacoresistant mesial temporal epilepsy. J Neurol 2013;260:1601-10.

38. Mantoan MA, Caboclo LO, de Figueiredo Ferreira Guilhoto LM, Lin K, da Silva Noffs MH, de Souza Silva Tudesco I, Belzunces E, Carrete H Jr, Bussoletti RT, Centeno RS, Sakamoto AC, Yacubian EM. Correlation between memory, proton magnetic resonance spectroscopy, and interictal epileptiform discharges in temporal lobe epilepsy related to mesial temporal sclerosis. Epilepsy Behav 2009;16:447-53.

39. Shewmon DA, Erwin RJ. The effect of focal interictal spikes on perception and reaction time. I. General considerations. Electroencephalogr Clin Neurophysiol 1988;69:319-37.

40. Shewmon DA, Erwin RJ. Focal spike-induced cerebral dysfunction is related to the after-coming slow wave. Ann Neurol 1988;23:131-7.

41. Nicolai J, Ebus S, Biemans DP, Arends J, Hendriksen J, Vles JS, Aldenkamp AP. The cognitive effects of interictal epileptiform EEG discharges and short nonconvulsive epileptic seizures. Epilepsia 2012;53: 1051-9.

42. Aldenkamp A, Arends J. The relative influence of epileptic EEG discharges, short nonconvulsive seizures, and type of epilepsy on cognitive function. Epilepsia 2004;45:54-63. 


\section{Chapter 2}

Can spikes predict seizure frequency? Results of a pilot study in severe childhood epilepsies treated with vagus nerve stimulation

S.C.M. Ebus, H.J.M. Majoie, J.B.A.M. Arends, P.A.J.M. Boon

Seizure 2004;13:494-498 


\section{Summary}

We evaluated whether spike-rates are useful as an outcome parameter following Vagus Nerve Stimulation (VNS). Spikes/minute and spikebursts/minute were counted in serial electroencephalograms before and after implantation of a vagus nerve stimulator in $\mathrm{n}=19$ patients with severe childhood epilepsies. In the period of 2 years post VNS, spikerate and reported seizure frequency were significantly correlated (Spearman's $R=0.61$ ); spikebursts and seizures were correlated with $\mathrm{R}=0.74$. The response rate, counted after 6 months, was too small to detect differences in responders and non-responders as to spike-reduction. Larger samples and effect sizes are necessary to prove the hypothesis that spike reduction is useful as outcome parameter after VNS or other interventions. 


\section{Introduction}

Interictal spikes are not used as outcome parameter in the evaluation of therapies because the relationship between interictal spikes and seizures is uncertain. Sufficient data are available on acute changes in spike-rates before and following seizures as well as after acute drug administration. However, there is hardly any knowledge about possible therapeutically induced sub-acute or chronic electroencephalographic (EEG) changes related to seizure reduction. The interictal spike-rate may reflect a state of neuronal excitability, to be altered by anti-epileptic regimens. Chronic EEG changes paralleling or preceding clinical effects could be useful parameters in the development of therapies, being more objective than subjective seizure estimations. In a few previous studies spike counts have been applied. Lamotrigine significantly reduced overall interictal spike-rates comparing 24-h-EEGs pre/post 4 months of treatment (21 refractory patients) ${ }^{1}$ and in nocturnal EEGs with 3 months of treatment (13 refractory patients). ${ }^{2}$ Similar results were shown for Topiramate (23 patients, not refractory) comparing 24-hour EEGs after 4-6 months. ${ }^{3}$ In these studies, the authors did not correlate spike counts with seizure counts.

In this pilot, we assessed interictal spike-rates correlated to subjective seizure counts after intervention with vagus nerve stimulation (VNS). Spikes/minute as well as spikebursts/minute were calculated. Spikes occurring at very short intervals (spikebursts) may reflect a higher state of excitability of the epileptic cortex than isolated spikes. The clinical and neuropsychological effects of VNS after 6 months in 16 of the 19 patients were published earlier. ${ }^{4}$

\section{Method}

\section{Patients}

Nineteen children with refractory epilepsy in which VNS (by NeuroCybernetic Prosthesis developed by Cyberonics, Webster, TX) was to be introduced were included. Mean age at implantation was 11 years (6-17). Clinical syndromes are shown in Table 2.1.

\section{Data collection}

Seizures were reported from 6 months prior to 24 months post VNS. Five or more clustered seizures were counted as one seizure. Medication changes were not allowed in the first 6 months of VNS. Exceptions: patient 1, discontinuation of Valproate (450 mg) (loss of appetite) and patient 5, discontinuation of Lamotrigine (50 mg) (behavioral problems). 
Table 2.1 Demographic data.

\begin{tabular}{|c|c|c|c|c|}
\hline $\begin{array}{l}\text { Patient } \\
\text { number }\end{array}$ & Diagnosis & $\operatorname{Age}^{1} / \operatorname{Sex}$ & Etiology & $\begin{array}{c}\text { Monthly baseline seizure } \\
\text { frequency }\end{array}$ \\
\hline 1 & LGSV & $9 / \mathrm{M}$ & Perinatal anoxia & 168 \\
\hline 2 & MAstE & $11 / M$ & Atypical fever convulsion & 93 \\
\hline \multirow[t]{2}{*}{3} & MAstE & $7 / M$ & Perinatal anoxia & 289 \\
\hline & & & Father is known to have epilepsy & \\
\hline 4 & LGS & $8 / F$ & Unknown & 470 \\
\hline 5 & LGSV & $11 / \mathrm{M}$ & Viral meningoencephalitis & 74 \\
\hline 6 & LGS & $13 / F$ & Double cortex syndrome & 508 \\
\hline 7 & LGS & $6 / M$ & Perinatal anoxia & 462 \\
\hline 8 & LGS & $12 / F$ & Unknown & 283 \\
\hline 9 & LGS & $16 / M$ & Unknown & 77 \\
\hline 10 & LGS & $15 / M$ & Unknown & 470 \\
\hline 11 & MAbsE & $13 / M$ & Unknown & 162 \\
\hline 12 & LGS & $17 / M$ & Unknown & 11 \\
\hline 13 & LGSV & $8 / \mathrm{M}$ & Microcephalia & 134 \\
\hline 14 & LGSV & $14 / M$ & Perinatal anoxia and fever convulsion & 39 \\
\hline 15 & MAstE & $11 / F$ & Unknown/positive family history & 12 \\
\hline 16 & LGSV & $8 / M$ & Unknown & 14 \\
\hline 17 & SME & $6 / F$ & Unknown & 10 \\
\hline 18 & LGS & $13 / \mathrm{M}$ & Unknown & 59 \\
\hline 19 & SME & $9 / M$ & Unknown & 10 \\
\hline
\end{tabular}

LGS = Lennox Gastaut Syndrome; LGSV = Lennox Gastaut Syndrome-variant ${ }^{2} ;$ SME = Severe Myoclonic Epilepsy; MabsE = Myoclonic Absence Epilepsy; MastE = Myoclonic Astatic Epilepsy.

${ }^{1}$ At implantation of stimulator. ${ }^{2}$ Clinically resembling Lennox Gastaut syndrome, with a slow posterior rhythm in earlier EEGs but with normal posterior rhythm in the first EEG of the study.

Five wake 30-minute 32-channel EEGs were performed: one before and four each half year after VNS. The stimulator was not switched off. Spikes were detected by Persyst Spike Detector ${ }^{\circledR}$ and visually verified by author JA. A spikeburst was defined as $>3$ spikes in $\geq 4$ channels, spike-interval maximum $0.5 \mathrm{~s}$. Isolated spikes as well as spikes within spikebursts contributed to the total amount of spikes.

\section{Results}

Not every patient could be included in each analysis because of a missing EEG (patients $1,5,17,18$ ) or a failing stimulator (patient 3 , at $7^{\text {th }}$ month.)

\section{Changes in seizure frequency}

All 19 patients were on protocol. Mean monthly seizure frequency changed significantly comparing the 6 months with VNS to the baseline period ( $P=0.03$ Wilcoxon). Three patients showed more than $50 \%$ seizure reduction: patients 2,11 and 15 . They were at the lower spectrum of baseline monthly seizure frequencies (Figure 2.1a). Patient 15 
became seizure free. With exclusion of this patient the overall change in seizure frequency was still significant.

\section{EEG at 6 months of VNS}

On protocol were 16 patients (all minus 1,17,18). No overall changes in spikes/minute or spikebursts/minute were found at six months compared to the baseline EEG. Overall spike-rate in the EEG at 6 months was 20.1 (+/-35.1 range 0-132.1) compared to a baseline value of 21.7 ( \pm 25.6 range $0.2-78.2)$ spikes/minute. Overall spikeburst-rate at 6 months was 0.9 ( \pm 1.9 range $0-5.7$ ) compared to a baseline of 1.1 ( \pm 2.0 range $0-6.0$ ) spikebursts/minute. Responders had stable spike- and spikeburst-rates in baseline- and 6-months-EEG. Their spike- and spikeburst-rates were at the lower spectrum when compared to the non-responders (Figure $2.1 \mathrm{~b}$ and $\mathrm{c}$ ).

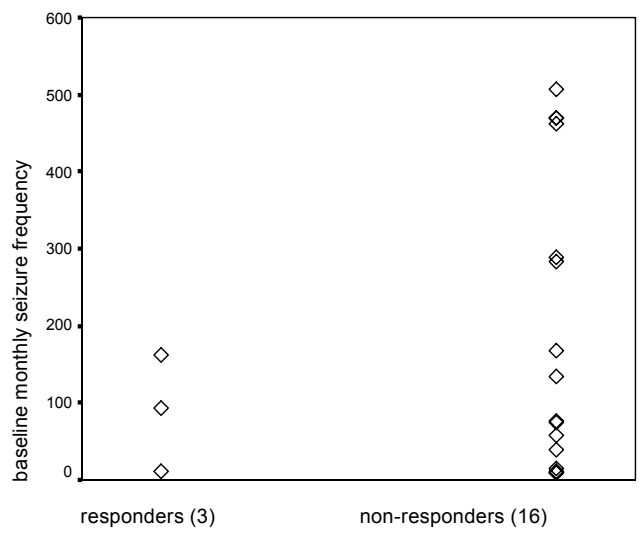

Figure 2.1a Baseline seizure frequencies of responders vs. non-responders.

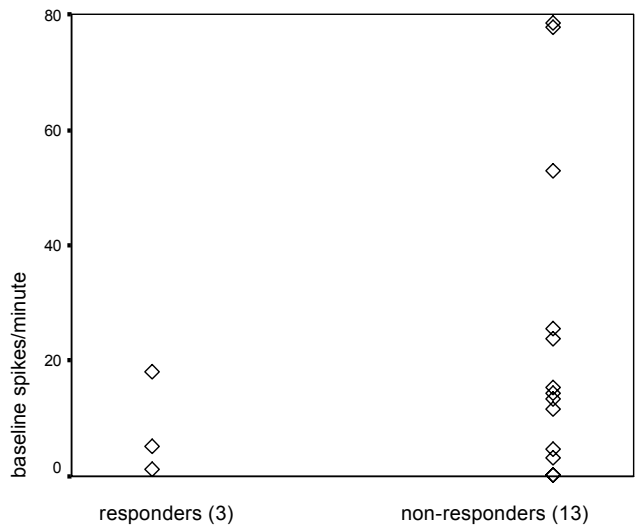

Figure 2.1b Baseline spike-rates of responders vs. non-responders. 


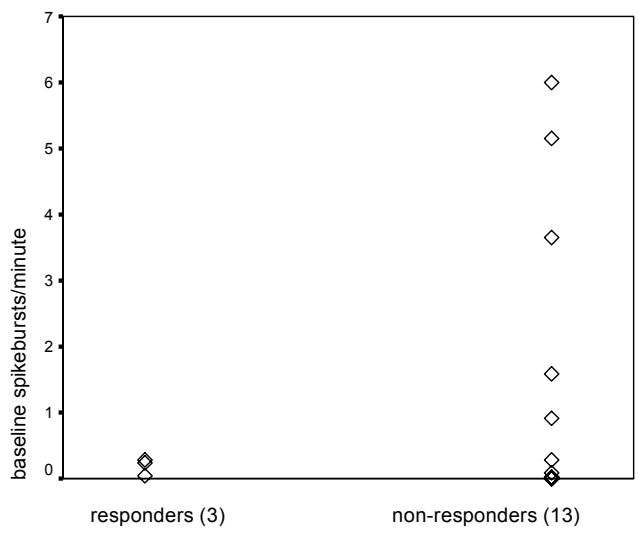

Figure 2.1c Baseline spikeburst-rates of responders vs. non-responders.

\section{Correlation analysis}

Sixteen patients (all but $1,3,5$ ) were on protocol for the correlation of mean two-year seizure frequency and mean spike/spikeburst frequency of 4 EEGs post VNS. The use of mean data was allowed because there were no significant changes in serial data post VNS (Friedman's test). Significant correlations between reported seizures and spikes (Spearman's $R=0.61$ ) and between seizures and spikebursts $(R=0.74)$ were found (Figure 2.2a and $b)$.

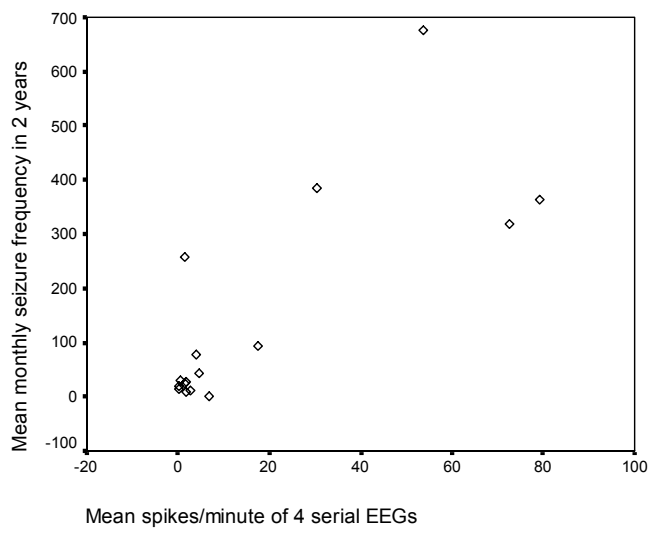

Figure 2.2a Correlation of spikes with seizures $(R=0.61)$. 


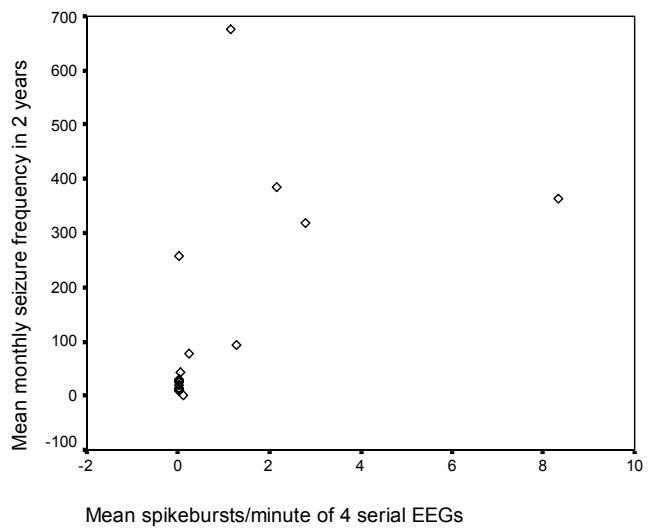

Figure 2.2b Correlation of spikebursts with seizures $(R=0.74)$.

\section{Discussion and Conclusions}

We assessed the use of interictal epileptic EEG activity as outcome parameter in 19 patients with severe childhood epilepsies. In the three responders, spike- and spikeburst rates at 6 months did not differ from baseline. Within the period of 2 years post VNS in which overall seizure-frequency and interictal epileptic activity both were stable, a significant correlation was found between spike-rate and reported seizure frequency $(R=0.61)$. Bursts of spikes predicted seizure frequency even better than spike-rates $(R=0.74)$. This seems to confirm our hypothesis that interictal epileptic activity reflects a state of neuronal excitability related to seizure frequency. The correlation of spikes with seizures could however also result from post-ictal elevation of spikes, a phenomenon shown before in refractory patients. ${ }^{5}$ An additional observation that may well fit into the hypothesis of spikes reflecting excitability was the smaller baseline interictal spike-rate together with a lower baseline seizure frequency in the three responders. Spike-rates may predict the chance of responsiveness to interventions.

In only one previous study chronic EEG-effects of VNS were examined in four EEGs within one year. ${ }^{6}$ Five patients with frequent repetitive spikes showed a gradual increase of spike-free interval duration. The other 16 showed a significant gradual decrease of spikes in the serial EEGs. The author states that "no direct correlation of the extent of seizure reduction with the degree of spike reduction" was found. One must realize that effect sizes of seizure reduction may be overestimated in open studies. Hence the true effect sizes in Koo's as well as in our pilot study may be smaller which may cause the inability to show a spike reduction related to seizure reduction, overall or in individuals (responders). 
In conclusion, the finding of a correlation between spikes and reported seizures is an encouragement to go on with trials with quantitative EEG analysis following interventions. In future studies however, the detection of post-intervention spikereduction may only be possible in larger patient groups leading to a larger effect size, preferably in a (placebo-) controlled design. 


\section{References}

1. Marciani MG, Spanedda F, Bassetti MA, Maschio M, Gigli GL, Mattia D, Bernardi G. Effect of lamotrigine on EEG paroxysmal abnormalities and background activity: a computerized analysis. British Journal of Clinical Pharmacology 1996;42:p621-7.

2. Placidi F, Marciani MG, Diomedi M, Scalise A, Pauri F, Giacomini P, Gigli GL. Effects of lamotrigine on nocturnal sleep, daytime somnolence and cognitive functions in focal epilepsy. Acta Neurologica Scandinavica 2000;102:81-6.

3. Romigi A, Placidi F, Tombini, M, Sperli F, Izzi F, Mattia D, Bollero P, Marciani M.G. Topiramate: effect on EEG interictal abnormalities and background activity (abstract). Epilepsia 2002;43:157.

4. Majoie HJ, Berfelo MW, Aldenkamp AP, Evers SM, Kessels AG, Renier WO. Vagus nerve stimulation in children with therapy-resistant epilepsy diagnosed as Lennox-Gastaut syndrome: clinical results, neuropsychological effects, and cost-effectiveness. Journal of Clinical Neurophysiology 2001;18:419-28.

5. Gotman J, Marciani MG. Electroencephalographic spiking activity, drug levels, and seizure occurrence in epileptic patients. Annals of Neurology 1985;17:597-603.

6. Koo B. EEG changes with vagus nerve stimulation. Journal of Clinical Neurophysiology 2001;18:434-41. 


\section{Chapter 3}

Can an early 24-hour EEG predict the response to the ketogenic diet? A prospective study in 34 children and adults with refractory epilepsy treated with the ketogenic diet

S.C.M. Ebus, D.A.J.E. Lambrechts, I.J.T. Herraets, M.J.M. Majoie, A.J. de Louw, P.A.J.M. Boon, A.P. Aldenkamp, J.B.A.M. Arends

Seizure 2014;23:468-474 


\section{Summary}

\section{Purpose}

We examined whether early EEG changes in a 24-h EEG at 6 weeks of treatment were related to the later clinical response to the ketogenic diet (KD) in a 6-month period of treatment.

\section{Methods}

We examined 34 patients with heterogeneous epilepsy syndromes (21 children, 13 adults) and found 9 clinical responders ( $\geq 50 \%$ seizure reduction); this is a responder rate of $26 \%$. We visually counted the interictal epileptic discharge index (IED index) in \% during $2 \mathrm{~h}$ of wakefulness and in the first hour of sleep (method 1), and also globally reviewed EEG changes (method 2), while blinded to the effect of the KD.

Results

At group level we saw a correlation between nocturnal reduction of IED index at 6 weeks and seizure reduction in the follow-up period. A proportional reduction in IED index of $30 \%$ from baseline in the sleep EEG, was associated with being a responder to the diet (Pearson Chi-square $P=0.04$ ). EEG scoring method 2 observed a significantly larger proportion of patients with EEG-improvement in sleep in KD responders than in non-responders $(P=0.03)$. At individual level, however, EEG changes did not correlate very strongly to the response to the diet, as IED reduction in sleep was also seen in $15 \%$ (method 1 ) to $26 \%$ (method 2 ) of the non-responders.

\section{Conclusion}

Nocturnal reduction of IEDs is related to the response to the $K D$, however in daily clinical practice, an early EEG to predict seizure reduction should not be advised for individual patients. 


\section{Introduction}

The KD is a high-fat, low-protein, low-carbohydrate diet used to treat patients with refractory epilepsy. The proportion of patients with $\geq 50 \%$ seizure reduction varies from $38-62 \%$ at 3 months after initiation of the KD to $27-58 \%$ at 6 months. ${ }^{1-6}$ A randomized, controlled trial showed that 28 patients of the KD group had greater than $50 \%$ seizure reduction (38\%), compared to four controls (6\%) and five of the KD group had greater than $90 \%$ seizure reduction $(7 \%)$, compared to none of the controls. ${ }^{7}$ There were no statistically significant differences in outcome between patients treated with the MCT or classical KD. ${ }^{7-9}$ The results of 30 studies with the MAD, of which one RCT demonstrated similar efficacy to the KD. ${ }^{7-9}$ Although it is traditionally children who are treated with the KD, there is also evidence of its efficacy in adults. ${ }^{6,10}$ The exact mechanisms underlying the effectiveness of the KD have not been elucidated. Because of the dietary changes, the KD is often experienced as a burden. If the response to the KD could be predicted in individual patients before or soon after its initiation, this could be helpful in selecting those patients who would potentially benefit from the KD and who should be encouraged to continue the diet.

The frequency of interictal epileptic discharges (IEDs) is a potential predictor for response to treatments. The occurrence of IEDs is correlated to seizure recurrence. ${ }^{11,12}$ IED frequency is correlated with seizure-frequency, especially in patients with severe epilepsies. $^{13}$ In a recent study Kessler et al. ${ }^{14}$ found that a response to the diet was 6 times more likely in children with a proportional IED index decline in wakefulness of $\geq 10 \%$ from baseline at one month of KD treatment.

In our centre, adults as well as children are treated with the KD. We examined whether early EEG changes during wakefulness or sleep 6 weeks after treatment initiation could be used to predict the response to the diet in subsequent months. We hypothesized that if a reduction of IEDs is seen soon after the initiation of the KD, this is related to a reduction in seizure frequency in subsequent months. Secondly, we examined whether baseline characteristics could predict the response to the KD.

\section{Method}

\section{Study design}

We compared the IED frequency in a 24-hour ambulatory EEG after 6 weeks of treatment with the KD, to the IED frequency in a baseline 24-hour EEG one week before treatment (Figure 3.1). A period of 4 weeks treatment is necessary to obtain stable ketosis. We registered at 6 weeks in order to be early in the treatment phase together with a high chance of all patients being in a steady ketosis at that moment.

A change in IED frequency was compared with the clinical outcome as defined by the mean seizure frequency during a follow-up period ranging from at least 2 to a 
maximum of 6 months compared to 2 months baseline. Seizure counts in the first month of KD introduction were not used to define clinical outcome, because this period was necessary to obtain ketosis.

Antiepileptic drugs (AED) were continued unchanged during baseline and the first six months of treatment with the KD. The only allowed exception was an urgent medical reason.

The study was approved by the Medical Ethics Committee according to Dutch Governmental Guidelines.

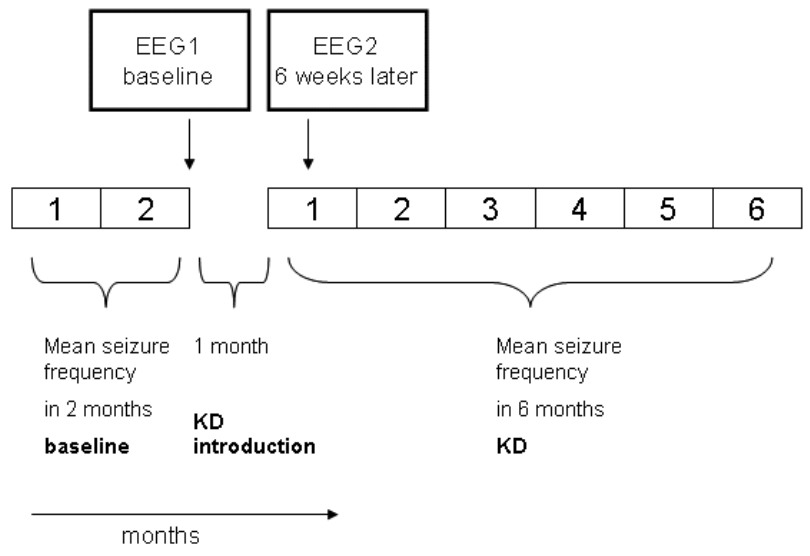

Figure 3.1 Study design.

\section{Ketogenic diet}

The KD was introduced during a 2-week hospitalization according to the Dutch guideline for $\mathrm{KD} .{ }^{15}$ This guideline does not include a fasting period. Usually the MCT (medium chain triglyceride)-diet was applied but if the insurance company did not refund the diet products, or at the subject's request, the classical diet or modified Atkins diet (MAD) was used. Changes could be made to the MCT-diet because of sideeffects and other problems during the introduction phase. When tube feeding was given, a liquid form of the classical KD was used. The start of the diet was defined as the first change made to the daily nutrition. During the KD, ketosis was frequently measured. During the second 24-hour EEG, the ketosis was measured in urine and blood or only in blood in cases of incontinence.

\section{Clinical outcome}

Patients and/or caregivers were asked to register seizures in a diary starting two months prior to the introduction of the KD. 
The mean seizure frequency during the follow-up period after the 4 weeks of KD introduction was calculated and compared to the baseline mean seizure frequency. When the mean seizure frequency was reduced by $\geq 50 \%$, the patient was defined as being a clinical responder. If seizure diaries were incomplete, the treating physician was asked to define the patient as a responder or non-responder, using patient's and/or caregiver's information.

\section{EEG analysis}

EEGs were recorded with the localizations Fp2, F4, C4, P4, O2, F8, T4, T6, Fp1, F3, C3, $\mathrm{P3}, \mathrm{O} 1, \mathrm{F7}, \mathrm{T3}, \mathrm{T5}, \mathrm{Fp0}, \mathrm{F0}, \mathrm{C0}, \mathrm{P0}$. For the comparison of the IED frequency before and after KD, two EEG scoring methods were used.

\section{EEG scoring method 1}

The number of IEDs was visually counted during 2 hours of wakefulness ( 1 hour during the day and the first hour after awakening). If possible, the selection was taken from the same hours of the day for EEG 1 and EEG 2, to minimize the effects of circadian rhythm or drug level fluctuations on the IED index. The mean number of IEDs in these two hours was used to calculate a \% of time of IEDs: (number of seconds containing IEDs / total number of seconds) * 100 (the IED index). The IED indices from 2 EEGs (baseline and EEG at 6 weeks) were combined to calculate the proportional reduction in $\%$ from the baseline index: (baseline index minus index at 6 weeks / baseline index) * 100. The IED index was also calculated for the first hour of sleep. The beginning of sleep was defined as the disappearance of the occipital rhythm during the previous 5 minutes. When patients did not have an occipital rhythm, the beginning of sleep was defined as the disappearance of eye-blinks during the previous 5 minutes. No IEDs were counted in the period of 30 minutes after any major seizure (tonic-clonic seizure, complex-partial seizure, or tonic seizure) to avoid possible post-ictal changes. Two EEGs from the same patient were scored directly after each other. The reviewer was blinded for the clinical outcomes.

\section{EEG scoring method 2}

A second EEG reviewer randomly scanned several parts throughout the EEG in the awake state and during the first hour of sleep. He concluded whether the EEG had the same, a lower, or a higher number of IEDs compared to the other EEG of the same patient. The reviewer was blinded for the clinical outcome.

We assumed that observed changes would be more reliable when the results of EEG scoring method 1 and EEG scoring method 2 would be congruent. Furthermore, EEG scoring method 2 resembles the daily practice of patient care. 


\section{Background analysis}

Because of the ambulatory registration, it was not possible to obtain artifact-free EEG fragments in the awake state with eyes closed for a spectral analysis. We only applied 3 global categories by visual inspection to describe the baseline EEG. These were: normal background, moderate background abnormalities (increased amount of diffuse slow activity with a preserved occipital rhythm with normal or decreased frequency), and severe background abnormalities (diffuse slowing of the EEG and absence of occipital rhythms).

\section{Patient selection}

We analyzed 34 patients, aged 1-45 years, included in the prospective study between January 2005 and September 2010.

Initially, 45 patients with refractory epilepsy who were candidates for the KD were included. In two patients an EEG could not be performed because of a safety helmet in one and behavioural problems in the other patient. One patient died of epilepsyrelated complications before the second EEG. In 7 patients, the second EEG was not registered because the diet was discontinued within 6 weeks after the baseline EEG, as a result of side-effects and/or the burden of the diet. In three patients, the second EEG was recorded; however the diet was discontinued before sufficient clinical follow-up had been established as was required in our study design, i.e. within two months after the 4-week introduction of the diet. Of these three, one patient had unacceptable gastro-intestinal side-effects. In the other two patients, severe seizure aggravation, not expected from earlier seizure observations (occurrence of at least twice as many seizures in both patients and additional frequent non-convulsive epileptic status in one of them), led to early discontinuation. We decided to analyze these two patients as non-responders.

\section{Statistics}

We used Mann-Whitney $U$ test (MWU) for calculating differences between groups, Spearman's correlations for correlations between 2 variables, and Pearson Chi-square test (2-sided) to test differences in proportions. Results were considered significant if alpha was $\leq 0.05$.

\section{Results}

\section{Baseline data}

The data of the 34 patients are shown in Tables 3.1a-3.1c. 
Table 3.1a Demography.

\begin{tabular}{|c|c|c|}
\hline Patients, N & & 34 \\
\hline Male/Female, $\mathrm{N}(\%)$ & & $17 / 17(50 \% / 50 \%)$ \\
\hline Mean age at KD initiation in years;months (min-max value) & & $16 ; 0(1 ; 1-45 ; 5)$ \\
\hline Number of children (age <18 years) at KD initiation, $\mathrm{N}(\%)$ & & $21(62 \%)$ \\
\hline Mean age at seizure onset in years; months (min-max value) & & $5 ; 0(0 ; 0-31 ; 6)$ \\
\hline Mean duration of epilepsy in years, months (min-max value) & & $11 ; 0(1 ; 3-44 ; 11)$ \\
\hline Number of $A E D s^{1}$ at KD initiation & & $2.4(0-5)$ \\
\hline Number of used AED before KD initiation & & $7.3(4.0-14.0)$ \\
\hline Number of patients with VNS treatment in the past & & $3(9 \%)$ \\
\hline \multirow[t]{3}{*}{ Seizure frequency at KD initiation } & Daily seizures & $19(56 \%)$ \\
\hline & $\geq 1$ seizure a week & $10(29 \%)$ \\
\hline & $\geq 1$ seizure a month & $5(15 \%)$ \\
\hline \multirow[t]{4}{*}{ Diet type } & Classic, N (\%) & $8(24 \%)$ \\
\hline & MCT N (\%) & $19(56 \%)$ \\
\hline & Atkins, N (\%) & $2(6 \%)$ \\
\hline & Mixed, N (\%) & $5(14 \%)$ \\
\hline
\end{tabular}

${ }^{1} \mathrm{AED}=$ anti-epileptic drug

Table 3.1b Syndromal diagnosis.

\begin{tabular}{|c|c|c|c|c|}
\hline Syndromal diagnosis & Subtype /aetiology & $\begin{array}{l}\text { Number of } \\
\text { patients }\end{array}$ & $\begin{array}{l}\text { Number of } \\
\text { patients } \\
\text { (total of } \\
\text { subgroup) }\end{array}$ & Percentage \\
\hline $\begin{array}{l}\text { Cryptogenic localization- } \\
\text { related epilepsy }\end{array}$ & & 17 & 17 & $50 \%$ \\
\hline \multirow{10}{*}{$\begin{array}{l}\text { Symptomatic localization- } \\
\text { related epilepsy }\end{array}$} & Perinatal asphyxia & 3 & 14 & $41 \%$ \\
\hline & Bandheterotopia & 1 & & \\
\hline & Bacterial meningo-encephalitis & 3 & & \\
\hline & Trauma & 1 & & \\
\hline & Partial trisomy 14 and 8 & 1 & & \\
\hline & Sturge Weber syndrome & 1 & & \\
\hline & CDKL-5 mutation & 1 & & \\
\hline & Perinatal intracerebral haemorrhage & 1 & & \\
\hline & Down syndrome & 1 & & \\
\hline & $1 p$-syndrome & 1 & & \\
\hline $\begin{array}{l}\text { Symptomatic generalized } \\
\text { epilepsy }\end{array}$ & $\begin{array}{l}\text { Myoclonic astatic epilepy (Doose } \\
\text { syndrome) }\end{array}$ & 2 & 2 & $6 \%$ \\
\hline $\begin{array}{l}\text { Undetermined epilepsies } \\
\text { with both generalized and } \\
\text { focal seizures }\end{array}$ & $\begin{array}{l}\text { Severe myoclonic epilepsy (Dravet } \\
\text { syndrome) }\end{array}$ & 1 & 1 & $3 \%$ \\
\hline Total & & 34 & 34 & $100 \%$ \\
\hline
\end{tabular}


Table 3.1c EEG baseline characteristics.

\begin{tabular}{|c|c|c|c|}
\hline & Categories & $\mathrm{Nr}$ of patients & Mean IED index ${ }^{1}$ \\
\hline \multirow[t]{4}{*}{ IEDs in wakefulness } & No IEDs in wakefulness & $4(12 \%)$ & $0 \%$ \\
\hline & IEDs in wakefulness & $30(88 \%)$ & $6.2 \%$ (SD $18.6 \%)$ \\
\hline & Sporadic IEDs $(\leq 1 \%)$ & $17(50 \%)$ & $0.15 \%$ (SD $0.18 \%$ ) \\
\hline & Non-sporadic IEDs (>1\%) & $13(38 \%)$ & $16.1 \%$ (SD $28.0 \%$ ) \\
\hline \multirow[t]{5}{*}{ IEDs in sleep } & No IEDs in sleep & $7(21 \%)$ & $0 \%$ \\
\hline & IEDs in sleep & $26(76 \%)$ & $15.1 \%$ (SD $25.8 \%$ ) \\
\hline & Sporadic IEDs ( $\leq 1 \%)$ & $6(17 \%)$ & $0.50 \%$ (SD $0.28 \%$ ) \\
\hline & Non-sporadic IEDs (>1\%) & 20 (59\%) & $24.7 \%$ (SD $21.5 \%$ ) \\
\hline & Missing data & 1 (3\%) & \\
\hline \multirow[t]{3}{*}{ Background abnormality } & No & $8(24 \%)$ & \\
\hline & Moderate & $18(53 \%)$ & \\
\hline & Severe & $8(23 \%)$ & \\
\hline
\end{tabular}

${ }^{1}$ Obtained by EEG scoring method 1

$62 \%$ of the patients were children. $75 \%$ had at least several seizures a week, and about half of the patients had one or more daily seizures.

24 Patients were on the KD for at least 6 months, 8 patients discontinued the diet between 2 and 6 months following the 4 weeks of KD introduction, and 2 patients discontinued the diet between the end of the 4 weeks of KD introduction and 2 months follow-up. Seizure diaries were complete for 25 patients at baseline and 23 patients at follow-up. In 11 patients the clinical response to the diet had to be defined by the treating physician because of incomplete diaries.

$88 \%$ of the patients had IEDs in the baseline awake EEG and $76 \%$ of the patients had IEDs in the baseline sleep EEG. 21 Patients had no or only sporadic IEDs $(\leq 1 \%)$ at baseline in the awake state.

There was a trend towards correlation between baseline seizure frequency and IED index (wakefulness Spearman's $R=0.37 P=0.07$; sleep Spearman's $R=0.36 P=0.09$ ). $76 \%$ of the EEGs showed a moderate to severe background abnormality. The severity of background abnormality was correlated to baseline seizure frequency (Spearman's $\mathrm{R}=0.45 P=0.02$ ), and to baseline IED index in wakefulness (Spearman's $\mathrm{R}=0.36 P=0.04$ ) and in sleep (Spearman's $\mathrm{R}=0.35 P=0.05$ ).

\section{Results after KD introduction}

\section{Seizure outcome}

$9 / 34$ patients ( $26 \%$ ) were clinical responders ( $\geq 50 \%$ seizure reduction), of whom 7 were children. In 7 of the clinical responders the response was diary-defined, in 2 physiciandefined because of an incomplete diary. They all had had a follow-up period of 6 months. The 7 responders with diaries showed a clear seizure reduction from the second month of treatment which lasted until 6 months of follow-up, resulting in a 
mean seizure reduction of $\geq 50 \%$ during 6 months, compared to the 2 months baseline period.

The mean baseline monthly seizure frequency in these 7 responders with diaries was 88.6 (SD 78.3) and in 16 non-responders with diaries 60.4 (SD 84.0). Mean seizure frequency in the follow-up period in 7 responders was 12.4 (SD 23.4) and in 16 nonresponders with diaries 68.9 (SD 85.2). Mean age of clinical responders was 10.9 (SD 12.1) and of non-responders 18.3 (SD 11.2). Mean duration of epilepsy in clinical responders was 6.6 years (SD 5.4) and in non-responders 13.0 years (SD 11.0).

There was no correlation between the clinical response to the KD and baseline seizure frequency. There was a correlation between the clinical response to the KD and younger age $(R=0.34 P=0.05)$ and a trend towards correlation between the clinical response and shorter duration of epilepsy $(R=0.31 P=0.08)$.

\section{EEG analysis at group level}

A summary of the main findings is presented in Table 3.2.

Table 3.2 Summary of findings.

\begin{tabular}{|c|c|c|}
\hline & Negative findings & Positive findings \\
\hline Group level & $\begin{array}{l}\text { No correlation between baseline IED } \\
\text { index (wakefulness/sleep) or EEG } \\
\text { background disturbance and effect of KD } \\
\text { No significant change in mean awake or } \\
\text { sleep IED index after } 6 \text { weeks KD }\end{array}$ & $\begin{array}{l}\text { Seizure reduction in follow-up period } \\
\text { correlated with IED reduction in sleep EEG } \\
\text { at } 6 \text { weeks } K D(R=0.56 P=0.04)\end{array}$ \\
\hline Individual level & See results section & 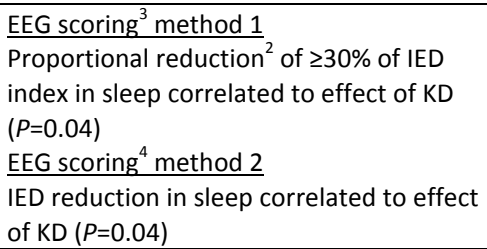 \\
\hline
\end{tabular}

${ }^{1} \mathrm{IED}=$ interictal epileptic discharges. ${ }^{2}$ proportional reduction $=$ (baseline IED index minus index at 6 weeks/baseline index) ${ }^{*} 100 .{ }^{3}$ IEDs counted in first hour of sleep. ${ }^{4}$ Global review (are IEDs reduced or not ?)

31 patients were in a ketotic state on the day of the EEG. In 2 patients ketosis was measured within the two days of the EEG and in 1 patient one week after the EEG. Since these values confirmed a ketotic state we assumed that this was also the case on the day of the EEG.

$A E D$ daily doses were unchanged between the two EEG's except for one patient with a minimal dose reduction of one AED.

We did not find correlations between the severity of EEG background slowing at baseline or the IED index at baseline and response to the KD. There was no correlation between the baseline IED index and the \% of seizure reduction. 
We found a positive correlation between the \% of IED reduction in sleep at 6 weeks and the $\%$ of seizure reduction in the follow-up period (Spearman's $R=0.56 P=0.04$ ) (see Figure 3.2) but not for IED reduction in wakefulness (Spearman's $R=0.2 P=0.4$ ).

We did not find a change in mean IED index after 6 weeks KD, in either wakefulness or in sleep ( $n=34$ patients $M W U$ wakefulness $P=0.67, n=33$ patients $M W U$ sleep $P=0.78$ ). Mean awake IED index at follow-up was $6.3 \%$ (SD $17.0 \%$ ) vs. baseline index $6.3 \%$ (SD $18.6 \%$ ) and mean sleep IED index at follow-up was $14.8 \%$ (SD 24.3\%) vs. baseline index $15.1 \%$ (SD 25.8\%).

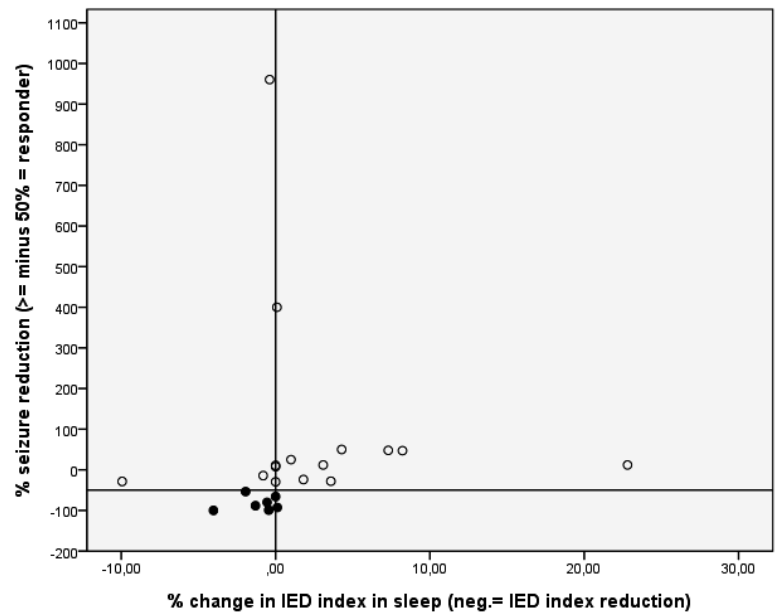

Figure 3.2 Seizure reduction versus reduction in IED index, sleep.

All (bold) dots on or below the horizontal line are patients with $\geq 50 \%$ seizure reduction (clinical responders) All dots left of the vertical line are patients with IED reduction (according to EEG scoring method 1). Spearman's $R=0,56 P=0,04$

\section{EEG analysis at individual level}

In 4/34 patients, no IEDs were seen during the 24-hour EEG at baseline or at follow-up according to EEG scoring method 1 (2 responders, 2 non-responders). In the remaining 30 patients with IEDs in wakefulness (7 clinical responders, 23 clinical non-responders), and in the 26 patients with IEDs during sleep (7 clinical responders, 19 non-responders), we analyzed which proportions of responders versus non-responders had changes in IED index at follow-up.

\section{Individual analysis of the EEG in wakefulness}

Disappearance of IEDs in wakefulness according to EEG scoring method 1 was observed in 6 patients ( 2 responders, 4 non-responders). They had very low baseline IED indices between 0.01 and $1.22 \%$. In these patients with low baseline index, there was a 
discrepancy in confirming lack of IEDs at baseline or follow-up between EEG scoring methods 1 and 2. EEG scoring method 2 confirmed the lack of IEDs at follow-up in 2 of the 6 patients identified by scoring method 1 . In these 2 patients, however, method 2 had not observed IEDs in the baseline EEG either.

Twelve out of 30 patients (2/7 responders, 10/23 non-responders) had a reduction (not disappearance) of IEDs according to method 1 . This did not distinguish responders from non-responders $(P=0.48)$. EEG scoring method 2 confirmed the reduction of IEDs in 6 of these patients with proportional reductions in excess of $20 \%$. EEG scoring method 2 did not distinguish between responders and non-responders ( $2 / 7$ responders, 4/23 nonresponders $(P=0.52)$.

Disappearance of IEDs or IED-reduction according to method 1 was observed in 4/7 responders with IEDs at baseline and in $14 / 23$ non-responders (not significant $P=0.86$ ). In order to compare our findings with the findings in the study by Kessler et al, ${ }^{14}$ we examined which patients had a proportional reduction of at least $10 \%$ in wakefulness according to method 1 . This did not distinguish the responders (4/7) from nonresponders $(13 / 23)(P=0.98)$. Nor could we distinguish between responders and nonresponders when higher proportional reductions were required.

\section{Individual analysis of the EEG in sleep}

Among the 26 patients with IEDs in sleep at baseline, there were no patients in whom IEDs disappeared. We observed a reduction of IED index according to EEG scoring method 1 in $12 / 26$ patients (5/7 responders and $7 / 19$ non-responders $(P=0.12)$. The 7 non-responders had a higher mean baseline index $(32.3 \%$ SD 24.8$)$ than the 5 responders (4.1\% SD 4.3\%), which was the attribution of 4 non-responders with high baseline index in sleep between 18.9 and $87.9 \%$. The other 3 non-responders were comparable to the responders with a mean baseline index of 3.4\% (SD 3.2\%). Although these data seem to point to a better result of the KD in patients with low IED index in sleep, this was not proved (see above "EEG analysis at group level").

EEG scoring method 2 found a reduction of IEDs in 5/7 responders and in 5/19 nonresponders, which was a significant difference $(P=0.04)$.

EEG scoring method 2 confirmed the reduction of IEDs found by method 1 in 9 of the 12 patients (4 responders, 5 non-responders). In the 3 patients in whom EEG method 2 did not confirm the IED reduction, this was explained by a very low baseline sleep index $<1 \%$ in 2 patients ( 1 responder, 1 non-responder), and by a very low IED reduction of $0.81 \%$ (proportional reduction $11.9 \%$ ) in 1 patient with baseline index $6.9 \%$.

We finally examined whether a certain proportional reduction of the IED index during sleep could identify responders. We found a significant difference between responders and non-responders when a proportional reduction of at least $30 \%$ was required, which was observed in $4 / 7$ responders versus $3 / 19$ non-responders $(P=0.04)$. All these 7 patients also had proportional reductions in wakefulness exceeding $20 \%$. The syndromal diagnoses of the 4 clinical responders with at least $30 \%$ proportional 
reduction in nocturnal IED index were: cryptogenic localisation related epilepsy $n=2$, symptomatic epilepsy after cerebral trauma $n=1$, symptomatic epilepsy after asphyxia $\mathrm{n}=1$. They were 3 children and 1 adult. They all had focal interictal epileptiform activity.

\section{Patients with increase in IED index}

We examined whether an increase in IED index would be observed more frequently in non-responders than in responders. In wakefulness this was observed in $3 / 7$ responders and in 9/23 non-responders according to EEG scoring method $1(P=0.86)$. EEG scoring method 2 identified $2 / 7$ responders with increase in IEDs in wakefulness vs. $8 / 23$ non-responders $(P=0.76)$. Increase in IED index in sleep according to EEG scoring method 1 was observed in $2 / 7$ responders and $12 / 23$ non-responders $(P=0.27)$. EEG scoring method 2 observed 11 patients (1 responder, 10 non-responders) with increase in IEDs $(P=0.16)$.

\section{Discussion}

Nine of 34 patients ( 7 children and 2 adults) were clinical responders, which represents a responder rate of $26 \%$ ( $33 \%$ in the children, $15 \%$ in adults). There were no baseline EEG features that characterized future clinical responders. At a group level we identified a correlation between a nocturnal reduction of IEDs at 6 weeks and a seizure reduction in the follow-up period. More relevant for clinical practice are changes in an early EEG at the individual level. At six weeks, EEG scoring method 1 (IED counts) found that a $30 \%$ proportional reduction of the IED index in sleep at 6 weeks, was seen more often in responders than in non-responders. EEG scoring method 2 (global reviewing) also found a significantly larger proportion of patients showing IED reduction in sleep within the group of clinical responders. The fact that the two different types of EEG scoring methods found a significant correlation between IED reduction in sleep and clinical response, adds to the reliability of finding this correlation. We observed that global reviewing is less sensitive for the detection of changes. It detected changes when spike-counts had resulted in $>20 \%$ IED reduction from baseline. The only clinical correlation we observed was correlated with $>30 \%$ IED reduction from baseline. Therefore, global reviewing (as it is performed in clinical daily practice), may be a good alternative for the time-consuming method of counting individual spikes. We found however that for individual patients the observation of reduction of IEDs in this study was not a very powerful predictor, as this was also observed in $16 \%$ (method 1 ) to $26 \%$ (method 2) of the non-responders. We conclude that this observation cannot reliably be used to advise patients whether to continue or discontinue the diet.

We included a large proportion of patients with a low baseline IED index in wakefulness. This explains why we found the highest reductions of IEDs during sleep. In patients with a low baseline index in wakefulness, there were large discrepancies in the 
findings when EEG methods 1 and 2 were compared. This illustrates that outcomes on changes in this group are less reliable and are dependent on which samples of the EEG were assessed. It is not likely that reviewing every page of the awake EEG of patients with a very low IED index, would have produced a better distinction between responders and non-responders. In patients with higher baseline index $(>1.22 \%)$ and with higher proportional decreases in IED index (above $20 \%$ ) the two scoring methods had congruent results on detecting changes.

A weakness in studies with the EEG as outcome parameter is that there is no information on fluctuations of the IED index outside the chosen duration of the EEG registration. We performed a long-term EEG, but we were not informed on day-to-day fluctuations when treatment would not be changed. We cannot exclude that a proportional reduction of at least $30 \%$ can be a result of spontaneous fluctuations. In 6 other studies, ${ }^{4,14,16-19}$ IED frequency changes after KD were analyzed and compared to a baseline. Only one study analyzed the IED index during sleep (at group level) and found a significant reduction of IEDs at 3 months, as well as a positive correlation between IED frequency reduction and seizures. This last observation corresponds to our findings. All patients in the 6 previously published studies were children. Three studies examined individual EEG changes in responders vs. non-responders during wakefulness. Remahl et al. ${ }^{17}$ described an IED reduction in 8/16 responders vs. $5 / 7$ nonresponders (not significant). Dressler et al. ${ }^{18}$ found disappearance of IEDs in 9/25 responders vs. $1 / 24$ non responders $(P=0.009)$. Kessler et al. ${ }^{14}$ found an individual IED proportional index decline of $\geq 10 \%$ of the baseline index in $12 / 26$ responders and in 2/11 non-responders (with a baseline median spike index of 7.7). The timing and analysis of the EEG in this study correspond fairly well to our method. We could not, however, reproduce the same results for the EEG in wakefulness. Our patient group had a much lower baseline median spike index of $0.2 \%$ (mean $6.2 \%$ ) compared to the patient group of Kessler. In fact most cited studies had included more patients with generalized, highly frequent IEDs in wakefulness. Especially in patients with generalized epilepsy syndromes such as Lennox-Gastaut syndrome, myoclonic astatic epilepsy and West syndrome, highly frequent IEDs in the awake state are usually observed. We only included 2/34 (6\%) of such patients, Kessler ${ }^{14} 6 / 37$ (16\%), Remahl ${ }^{17} 5 / 23$ (22\%) and Dressler $^{18} 15 / 50$ (30\%). Furthermore, Kessler classified a total of $18 / 37$ (49\%) of patients with a "generalized electroclinical syndrome". Dressler classified $46 / 50$ patients with a "generalized epilepsy syndrome". Finally, earlier studies included only children, this study also adults. The differences in the epilepsy syndromes, EEGtypes and ages probably explain the different findings in the studies.

From the combined results of all studies, it is clear that decreases in IED index can be found in a repeated EEG in individual patients on the KD with some correlation with the effect of the KD. Changes in IED index are best observed in patients with epilepsy syndromes with high baseline IED index. The studies show however that at an individual level, the method of performing an early EEG to predict whether the patient will be a responder, is not conclusive. Furthermore, in our study a clear and stable seizure 
reduction in the clinical responders could already be observed in the second month of KD treatment. Hence, in our patient group, an early EEG at 6 weeks as a predictor of future seizure reduction, was not necessary. Kessler ${ }^{14}$ commented that "the practical utility of performing an early EEG as predictor, may be limited to those patients whose seizure reduction on the KD is not immediate". The number of patients with a delayed reduction of seizures in this study was, however, not mentioned. There are several studies confirming that early seizure reduction (from the $1^{\text {st }}$ month of treatment) is seen far more often than delayed seizure reduction (Coppola et al. ${ }^{1}$ Bergvist et al. ${ }^{20}$, Mosek et al. ${ }^{21}$ ).

In our study, we did not observe complete normalization of the EEG in patients with a baseline IED index exceeding $1.22 \%$. Some studies mention abolition of frequent IEDs after KD, for example, in patients with West syndrome and hypsarrhythmia. ${ }^{22,23}$ Nikanorova et al. ${ }^{24}$ studied 4 children with CSWS (syndrome of continuous spike waves in slow wave sleep) in whom IEDs were recorded during sleep in $\geq 85 \%$ of the time. After 12 months of treatment, the EEG had normalized in one patient, slightly improved in one patient and not improved in 2 patients. The real "EEG-responder" showed a slight increase in IQ scores, disappearance of aggression and an improvement in concentration at that time. When clinical effects are subtle and not (yet) obvious, the normalization of the EEG may encourage such patients to continue the KD. The previously mentioned studies show that effects of the KD on the EEG could be more profound in certain syndromes. In patients with GLUT-1 deficiency (the best known indication for the KD), reduction of IEDs was reported in all 4 patients who showed IEDs at baseline, of whom 3 had $>90 \%$ seizure reduction (1 had never experienced seizures). ${ }^{25}$ The baseline frequency of IEDs and the magnitude of the reduction were not mentioned in this study.

\section{Conclusion}

Although we observed a correlation between seizure reduction and IED reduction during sleep at group level, we found no evidence that early EEG changes predict the efficacy of the KD in individual patients. Only in certain patients, should EEG registration before and after KD still be considered. These are patients with highly frequent interictal epileptic discharges which are a major goal of treatment, such as patients with hypsarrhythmia or ESES (electrical status epilepticus of slow wave sleep). In all other patients, the observation of seizure reduction, which will most often be noted early in the follow-up period, is the best parameter for evaluating the effect of the KD. 


\section{References}

1. Coppola G, Veggiotti P, Cusmai R, Bertoli S, Cardinali S, Dionisi-Vici C, Elia M, Lispi ML, Sarnelli C, Tagliabue A, Toraldo C, Pascotto A. The ketogenic diet in children, adolescents and young adults with refractory epilepsy: an Italian multicentric experience. Epilepsy Res 2002;48:221-7.

2. Vining EP, Freeman JM, Ballaban-Gil K, Camfield CS, Camfield PR, Holmes GL, Shinnar S, Shuman R, Trevathan E, Wheless JW. A multicenter study of the efficacy of the ketogenic diet. Arch Neurol 1998;55:1433-7.

3. Maydell BV, Wyllie E, Akhtar N, Kotagal P, Powaski K, Cook K, Weinstock A, Rothner AD. Efficacy of the ketogenic diet in focal versus generalized seizures. Pediatr Neurol 2001;25:208-12.

4. Kang HC, Kim YJ, Kim DW, Kim HD. Efficacy and safety of the ketogenic diet for intractable childhood epilepsy: Korean multicentric experience. Epilepsia 2005;46:272-9.

5. Freeman JM. Seizures, EEG events, and the ketogenic diet. Epilepsia 2009;50:329-30.

6. Sirven J, Whedon B, Caplan D, Liporace J, Glosser D, O'Dwyer J, Sperling MR. The ketogenic diet for intractable epilepsy in adults: preliminary results. Epilepsia 1999;40:1721-6.

7. Neal EG, Chaffe H, Schwartz RH, Lawson MS, Edwards N, Fitzsimmons G, Whitney A, Cross JH. The ketogenic diet for the treatment of childhood epilepsy: a randomised controlled trial. Lancet Neurol 2008;7:500-6.

8. Sharma S, Sankhyan N, Gulati S, Agarwala A. Use of the modified Atkins diet for treatment of refractory childhood epilepsy: a randomized controlled trial. Epilepsia 2013;54:481-6.

9. Kossoff EH, Cervenka MC, Henry BJ, Haney CA, Turner Z. A decade of the modified Atkins diet (20033013): Results, insights, and future directions. Epilepsy and Behavior 2013;29:437-42.

10. Payne NE, Cross JH, Sander JW, Sisodiya SM. The ketogenic and related diets in adolescents and adults-a review. Epilepsia 2011;52:1941-8.

11. Das CP, Sawhney IM, Lal V, Prabhakar S. Risk of recurrence of seizures following single unprovoked idiopathic seizure. Neurol India 2000;48:357-60.

12. Berg AT, Shinnar S. The risk of seizure recurrence following a first unprovoked seizure: a quantitative review. Neurology 1991;41:965-72.

13. Ebus SC, Majoie HJ, Arends JB, Boon PJ. Can spikes predict seizure frequency? Results of a pilot study in severe childhood epilepsies treated with vagus nerve stimulation. Seizure 2004;13:494-8.

14. Kessler SK, Gallagher PR, Shellhaas RA, Clancy RR, Bergqvist AG. Early EEG improvement after ketogenic diet initiation. Epilepsy Res 2011;94:94-101.

15. Hurk van den T. LvdE. Dieetbehandelingsrichtlijn ketogeen dieet voor kinderen (0-18) met refractaire epilepsie. Evidence based handleiding voor een multidisciplinaire behandeling. 2008.

16. Hallbook T, Kohler S, Rosen I, Lundgren J. Effects of ketogenic diet on epileptiform activity in children with therapy resistant epilepsy. Epilepsy Res 2007;77:134-40.

17. Remahl S, Dahlin MG, Amark PE. Influence of the ketogenic diet on 24-hour electroencephalogram in children with epilepsy. Pediatr Neurol 2008;38:38-43.

18. Dressler A, Stöcklin B, Reithofer E, Benninger F, Freilinger M, Hauser E, Reiter-Fink E, Seidl R, TrimmelSchwahofer $\mathrm{P}$, Feucht $\mathrm{M}$. Long-term outcome and tolerability of the ketogenic diet in drug-resistant childhood epilepsy--the Austrian experience. Seizure 2010;19:404-8.

19. Li B, Tong L, Jia G, Sun R. Effects of ketogenic diet on the clinical and electroencephalographic features of children with drug therapy-resistant epilepsy. Exp Ther Med 2013;5:611-15.

20. Bergqvist AG, Schall JI, Gallagher PR, Cnaan A, Stallings VA. Fasting versus gradual initiation of the ketogenic diet: a prospective, randomized clinical trial of efficacy. Epilepsia 2005;46:1810-9.

21. Mosek A, Natour H, Neufeld MY, Shiff Y, Vaisman N. Ketogenic diet treatment in adults with refractory epilepsy: a prospective pilot study. Seizure 2009;18:30-3.

22. Eun SH, Kang HC, Kim DW, Kim HD. Ketogenic diet for treatment of infantile spasms. Brain Dev 2006;28:566-71.

23. Hong AM, Turner Z, Hamdy RF, Kossoff EH. Infantile spasms treated with the ketogenic diet: prospective single-center experience in 104 consecutive infants. Epilepsia 2010;51:1403-7.

24. Nikanorova M, Miranda MJ, Atkins M, Sahlholdt L. Ketogenic diet in the treatment of refractory continuous spikes and waves during slow sleep. Epilepsia 2009;50:1127-31. 
Chapter 3

25. Ito $\mathrm{Y}$, Oguni $\mathrm{H}$, Ito $\mathrm{S}$, Oguni M, Osawa M. A modified Atkins diet is promising as a treatment for glucose transporter type 1 deficiency syndrome. Dev Med Child Neurol 2011;53:658-63. 


\section{Supplementary data online published at:}

http://dx.doi.org/10.1016/j.seizure.2014.03.008.

Table Summary of studies using IEDs as outcome parameter in KD.

\begin{tabular}{|c|c|c|c|c|}
\hline $\begin{array}{l}\text { Author, year, } \\
\text { Study type }\end{array}$ & $\begin{array}{l}\text { No. of patients/age/ } \\
\text { No. of patients with } \\
\mathrm{IS}^{1} \text { or } \mathrm{LGS}^{2}\end{array}$ & $\begin{array}{l}\text { Definition of } \\
\text { responders/ } \\
\text { Responder rate }\end{array}$ & $\begin{array}{l}\text { Timing and type of } \\
\text { EEG/ } \\
\text { EEG analysis }\end{array}$ & $\begin{array}{l}\text { Reported changes in } \\
\text { IEDs }^{3}\end{array}$ \\
\hline $\begin{array}{l}\text { Kang e.a. } \\
2005^{4} \\
\text { Retrospective } \\
\text { study }\end{array}$ & $\begin{array}{l}199 \text { children } \\
\text { mean age } 4.8 \\
\text { IS } n=39 \\
\text { LGS } n=75\end{array}$ & $\begin{array}{l}\geq 50 \% \text { Sz reduction at } \\
3 \mathrm{~m} ., 6 \mathrm{~m} \text { and } 12 \mathrm{~m} \\
\text { vs. baseline period } \\
\text { (duration not } \\
\text { mentioned) } \\
\text { Responder rate } \\
62 \% \text { at } 3 \mathrm{~m} \\
58 \% \text { at } 6 \mathrm{~m} \\
41 \% \text { at } 12 \mathrm{~m}\end{array}$ & $\begin{array}{l}\text { Routine awake EEG } \\
\text { somewhere between } \\
3 \text { and } 6 \mathrm{~m} . \text { in } 116 \\
\text { patients }\end{array}$ & $\begin{array}{l}\text { Pts with frequent } \\
\text { generalized IEDs: } \\
\text { improvement in } \\
41 / 71 \\
\text { Pts with frequent } \\
\text { focal IEDs: } \\
\text { improvement in } \\
15 / 45 \\
\text { Correlation with } \\
\text { seizure frequency } \\
\text { was observed (but } \\
\text { not statistically } \\
\text { analyzed). }\end{array}$ \\
\hline $\begin{array}{l}\text { Hallböök e.a. } \\
2007^{16} \\
\text { Prospective study }\end{array}$ & $\begin{array}{l}18 \text { children } \\
\text { mean age } 7.5 \\
\text { LGS } n=5\end{array}$ & $\begin{array}{l}\geq 50 \% \text { Sz reduction at } \\
3 \mathrm{~m} . \text { vs. } 3 \mathrm{~m} \text {. baseline } \\
\text { Responder rate } 67 \%\end{array}$ & $\begin{array}{l}24 \mathrm{~h} \text { EEG at } 3 \mathrm{~m} . \\
\text { Automatic spike } \\
\text { detection }\end{array}$ & $\begin{array}{l}\text { At group level } \\
\text { significant reduction } \\
\text { of IEDs in sleep. } \\
\text { Correlation between } \\
\text { IED reduction and } \\
\text { clinical seizures } R=0,6\end{array}$ \\
\hline $\begin{array}{l}\text { Remahl e.a. } \\
2008^{17} \\
\text { Prospective study }\end{array}$ & $\begin{array}{l}23 \text { children } \\
\text { mean age } 6.5 \\
\text { IS } n=1 \\
\text { LGS } n=4\end{array}$ & $\begin{array}{l}\geq 50 \% \text { Sz reduction at } \\
3 \mathrm{~m} . \text { vs. } 1 \mathrm{~m} \text {. baseline } \\
\text { Responder rate } 70 \%\end{array}$ & $\begin{array}{l}24 \text { h EEG at } 3 \mathrm{~m} \text {. } \\
\text { Semi-quantitative } \\
\text { global review ( } 6 \text { steps } \\
\text { scale of changes in } \\
\text { IED frequency) }\end{array}$ & $\begin{array}{l}\text { IED reduction in } 8 / 16 \\
\text { responders vs. } 5 / 7 \\
\text { non- responders (not } \\
\text { sign.) } \\
\text { No statements on } \\
\text { sleep EEG vs. awake } \\
\text { EEG }\end{array}$ \\
\hline $\begin{array}{l}\text { Dressler e.a. } \\
2010^{18} \\
\text { Retrospective } \\
\text { study }\end{array}$ & $\begin{array}{l}50 \text { children } \\
\text { mean age } 4.5\end{array}$ & $\begin{array}{l}\geq 50 \% \text { Sz reduction at } \\
6 \mathrm{~m} \text {. vs. } 2 \mathrm{~m} \text { baseline } \\
\text { Responder rate } 50 \%\end{array}$ & $\begin{array}{l}\text { routine awake EEG } \\
\text { between } 3 \text { and } 6 \mathrm{~m} \\
\text { Global review, of } \\
\text { disappearance of } \\
\text { IEDs }\end{array}$ & $\begin{array}{l}\text { 9/25 responders } \\
\text { disappearance of } \\
\text { IEDs vs. } 1 / 24 \text { non- } \\
\text { responders }(P=0.009)\end{array}$ \\
\hline
\end{tabular}




\begin{tabular}{|c|c|c|c|c|}
\hline $\begin{array}{l}\text { Author, year, } \\
\text { Study type }\end{array}$ & $\begin{array}{l}\text { No. of patients/age/ } \\
\text { No. of patients with } \\
\mathrm{IS}^{1} \text { or } \mathrm{LGS}^{2}\end{array}$ & $\begin{array}{l}\text { Definition of } \\
\text { responders/ } \\
\text { Responder rate }\end{array}$ & $\begin{array}{l}\text { Timing and type of } \\
\text { EEG/ } \\
\text { EEG analysis }\end{array}$ & $\begin{array}{l}\text { Reported changes in } \\
\text { IEDs }^{3}\end{array}$ \\
\hline $\begin{array}{l}\text { Kessler e.a. } \\
2011^{14} \\
\text { Prospective study }\end{array}$ & $\begin{array}{l}37 \text { children } \\
\text { mean age } 5.7 \\
\text { LGS } n=2\end{array}$ & $\begin{array}{l}\geq 50 \% \text { Sz reduction at } \\
3 \mathrm{~m} \text {. vs. } 1 \mathrm{~m} \text {. baseline } \\
\text { Responder rate } 70 \%\end{array}$ & $\begin{array}{l}30 \text { minute awake EEG } \\
\text { at } 1 \mathrm{~m} \text {. and } 3 \mathrm{~m} \text {. } \\
\text { Visual count no. of } \\
\text { seconds with IEDs -> } \\
\text { IED index in \% }\end{array}$ & $\begin{array}{l}\text { individual spike index } \\
\text { decline of } \geq 10 \% \text { at } 1 \\
\mathrm{~m} \text {. in } 12 / 26 \\
\text { responders and in } \\
2 / 11 \text { non responders } \\
\geq 10 \% \text { reduction IED } \\
\text { index }>6 x \text { more likely } \\
\text { to be responder }\end{array}$ \\
\hline $\begin{array}{l}\text { Li e.a. } \\
2013^{19} \\
\text { Prospective } \\
\text { study }\end{array}$ & $\begin{array}{l}31 \text { children } \\
\text { mean age } 2.5 \\
\text { IS } n=16 \\
\text { LGS } n=11\end{array}$ & $\begin{array}{l}\geq 50 \% \text { Sz reduction at } \\
1 \text { and } 3 \mathrm{~m} . \text { vs. } 1 \mathrm{~m} \\
\text { baseline } \\
\text { Responder rate } \\
52 \% \text { at } 1 \mathrm{w} . \\
68 \% \text { at } 1 \mathrm{~m} . \\
71 \% \text { at } 3 \mathrm{~m} .\end{array}$ & $\begin{array}{l}\geq 12 \mathrm{~h} \text { video-EEG at } 1 \\
\text { w., } 1 \mathrm{~m} \text { and } 3 \mathrm{~m} \\
\text { Visual count no. of } \\
\text { seconds containing } \\
\text { IEDs in a selection of } \\
100 \text { seconds awake } \\
\text { EEG }\end{array}$ & $\begin{array}{l}\geq 50 \% \text { reduction of } \\
\text { index in } 5 / 31 \text { at } 1 \mathrm{w}, \\
14 / 31 \text { at } 1 \mathrm{~m} \text { and } \\
16 / 31 \text { at } 3 \mathrm{~m} . \\
\text { Correlation between } \\
\text { reduction of seizures } \\
\text { not mentioned }\end{array}$ \\
\hline
\end{tabular}

${ }^{1}$ IS= infantile spasms, ${ }^{2}$ LGS=Lennox Gastaut Syndrome, ${ }^{3}$ IED=interictal epileptic discharges. 


\section{Chapter 4}

\section{Cognitive effects of interictal epileptiform discharges in children}

S.C.M. Ebus, J.B.A.M. Arends, J. Hendriksen, E. van der Horst, N. de la Parra, R. Hendriksen, E. Santegoeds, P.A.J.M. Boon, A.P. Aldenkamp

Eur J Paediatr Neurol 2012;16:697-706 


\section{Summary}

Frequent interictal epileptiform discharges (IEDs) may have effects on cognition. We analysed a group of 182 children with different epilepsy syndromes, as well as children with IEDs without observed seizures ${ }^{a}$ with 24-hour ambulatory EEG and cognitive tests. The IED index was estimated, in wakefulness and in sleep, as percentage of time in five categories $(0 \%,<1 \%, 1-10 \%, \geq 10-50 \%$ and $\geq 50 \%)$. IEDs were defined as spikes or spikewave complexes, isolated or occurring serially (in runs) without evident clinical signs of a seizure. The IED categories were correlated to cognitive test results and epilepsy characteristics. The group of patients with diurnal IEDs in $\geq 10 \%$ of the EEG record showed impaired central information processing speed, short-term verbal memory and visual-motor integration. This effect was seen independently from other EEG-related and epilepsy-related characteristics, and independently from epilepsy syndrome diagnosis. The impact of the nocturnal IEDs was of less importance; only contributing partially to the slowing of central information processing speed. We conclude that frequent IEDs (in more than $10 \%$ of the record) in the awake EEG can impair cognitive performance in children. Whether children with a high diurnal spike frequency and low seizure frequency can benefit from antiepileptic treatment should be examined in controlled trials.

\footnotetext{
${ }^{a}$ In the publication in 2012 this sentence was wrongly published as "We analysed a group of 182 children with different epilepsy syndromes, all of whom had IEDs that did not result in observed seizures". The sentence was corrected in a corrigendum in Eur J Paediatr Neurol. 2015;19(1): 104
} 


\section{Introduction}

Whether interictal epileptiform discharges (IEDs, i.e. spikes or spike-wave complexes without observed clinical seizures) can affect cognitive development is a subject that remains open to debate. ${ }^{1-4}$ Especially at an early age, frequent discharges might disturb the development and functioning of neuronal networks. Some evidences for this hypothesis arise from animal models and from research in humans. In young rabbits with abundant (penicillin-induced) focal spiking in the visual cortex, the visual network anatomically changes, and this effect is only reversible to some extent. The same procedure in the mature brain does not lead to this effect. ${ }^{5}$ In rats, a cortical area at a distance from the penicillin-induced spike focus shows reduced glucose consumption as a reflection of reduced neuronal activity, indicating the more extensive impact of localised epileptiform activity. ${ }^{6}$ Also, in children with benign focal epilepsies of childhood examined by EEG-fMRI, it was shown that the local interictal discharges can impair larger networks, because remote frontal brain areas were functionally disturbed during the occurrence of Rolandic spikes in these children. ${ }^{7}$ Several characteristics of IEDs, such as frequency and localisation of spikes, occurrence and duration of serial spike-wave complexes (i.e. runs of spike-wave discharges) could have differential effects on cognition. With respect the frequency of spikes, the occurrence of IEDs in more than $1 \%$ of the time during neuropsychological testing was associated with slowing of information processing in a previous study. ${ }^{8}$ With respect to localization, left-sided IEDs are associated with poor language abilities and right-sided or occipital IEDs with poor visuo-spatial information processing. ${ }^{9-12}$ Specialization of a hemisphere can be affected by unilateral IEDs. ${ }^{13}$ In another study, however, cognitive deficits were independent of the lateralisation of the spike focus. ${ }^{14}$ Spike-wave complexes, especially serial complexes, might have more impact than isolated spikes. An interesting study of the impact of isolated spikes indicated that isolated posterior spikes caused slowing of visual reaction times, using spike-triggered visual stimuli. ${ }^{15}$ In two children with benign childhood epilepsy with frequent diurnal centro-temporal spikes, the visual discrimination between words and pseudo-words in a reading test was shown to be impaired during intervals of five minutes with occurrence of frequent Rolandic spikes compared with spike-free periods. The authors did not state whether serial spike-wave complexes were recorded in these children but this might have been expected because of the very high index of Rolandic spikes (mean of 16 and 33 spikes/minute, respectively). ${ }^{16}$ Serial spike-wave complexes can also be associated with the so-called "transitory cognitive impairment" (TCl).,17,18 This implies that there is a brief interruption of the appropriate cognitive function because of the discharge. This should probably be defined as a subtle short ictal phenomenon. These patients may seem seizure-free unless they are closely examined with video-EEG monitoring.

Concerning nocturnal IEDs, studies have shown that in children with Rolandic epilepsy, a high nocturnal spike index is associated with poor cognitive development. ${ }^{19-21}$ Children with Rolandic epilepsy are considered to be in the benign part of a spectrum, 
in contrast to children with electrical status epilepticus of slow-wave sleep (ESES), who can be at the severe end of the spectrum. ${ }^{22-25}$ There is no doubt that children with ESES who show cognitive arrest should be treated, with the amount of epileptiform activity being used as an outcome parameter. However, such treatment is not standard for patients with Rolandic epilepsy. In epilepsy syndromes other than Rolandic epilepsy or syndromes with ESES but with high nocturnal spike frequency, the correlation between spikes and cognition has not been adequately examined.

The current situation is that IEDs may have momentary and chronic effects on brain networks; children could be especially at risk. There is growing evidence for a negative impact of IEDs on cognition. However, there are conflicting results and additional research is necessary to clarify the relationship between the discharges and cognition.

We analyzed a large group of children with different epilepsy syndromes. Our focus was on the association between the frequency of IEDs (diurnal as well as nocturnal) during 24-hour ambulatory EEG and cognition. The major factors to be analyzed were based on the existing literature: frequency, localisation, distribution and duration of runs of spike-wave complexes on the one hand and total IQ as well as several specific cognitive outcomes on the other hand. We included only children with a total IQ above 70, because lower IQs are more likely to be associated with an underlying neurological disease or disorder as a major cause of poor cognitive development.

\section{Method}

This study was approved by the medical ethics committee (MEC) Kempenhaeghe, according to Dutch governmental guidelines.

182 children, aged 6-12 years were included. All had been referred to our epilepsy centre Kempenhaeghe, The Netherlands, between 2002 and 2008 for (suspected) epilepsy and co-morbid learning and/or behavioural problems. All children had a 24-hour ambulatory EEG, 32 channel EEG and cognitive tests. The EEG and cognitive test assessment were both performed within a period of two weeks. Further inclusion criteria were: a history of at least one certain seizure or the occurrence of clear epileptiform activity in the EEG. An exclusion criterion was the occurrence of ESES, defined as $>85 \%$ duration of spike waves during slow-wave sleep. Epilepsy characteristics and caregiver-reported learning difficulties were recorded.

The index of IEDs in wakefulness and in the first hour of sleep were globally categorized by the first author (who was blinded to the results of the cognitive tests). This method is easy to apply, used in our daily practice and has been used before in publications by our group. ${ }^{8,26}$ IEDs were defined as spikes or spike-wave complexes, isolated or occurring serially (in runs) without evident clinical signs of a seizure. We used a " $1 \mathrm{~s}=10 \%$ " rule (which is also explained in Figure 4.1): if one spike or spike-wave complex occurs within one second of the page, the index is $10 \%$ on that page. An estimation in categories was made by global reviewing of at least 30 EEG pages 
throughout the recording. Sporadic IEDs (when $\leq 1$ IED/10 pages was seen) are categorized as an index of $\leq 1 \%$. If generally on each page epileptiform activity is present, this is categorized as $10-50 \%$ if less than half of the page (five seconds) contains IEDs, and as $\geq 50 \%$ if at least five seconds of each EEG page contains IEDs. If the spikes are not sporadic but not every page contains IEDs the category is set as $1-10 \%$. IED type was categorized as being focal, multi-focal or generalized. Focal IEDs were categorized as being frontal, centro-temporal-parietal or occipital, based on the electrode positions where the epileptiform activity was clearly visible in common average derivation. Laterality was recorded as being dominant or non-dominant. Serial spike-wave discharges (i.e. runs of spike-wave complexes) in the EEG in wakefulness were dichotomized into runs with a duration of at least $3 \mathrm{~s}$ and runs of a duration of less than $3 \mathrm{~s}$.

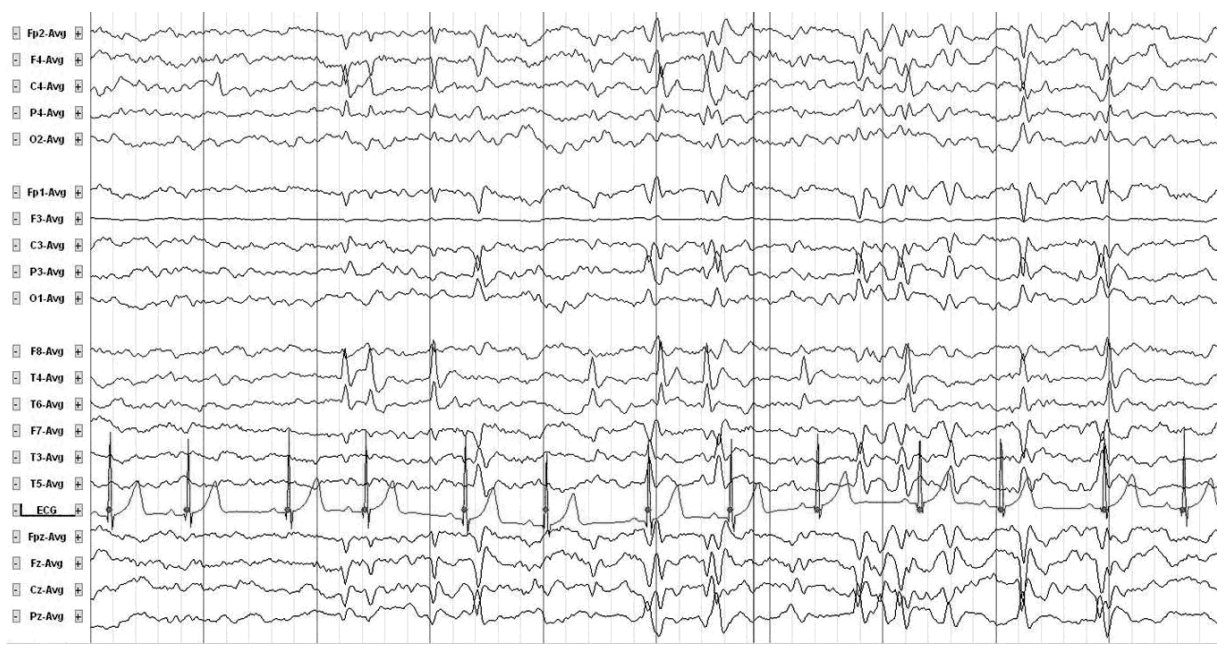

Figure 4.1 Method of estimation of the index of IEDs (interictal epileptiform discharges) in a 10-s- EEG page. Common average display montage. Eight of the $10 \mathrm{~s}$ contain one or more isolated spikewave. Only the first and last second are free of epileptic activity. The estimated index in this page is $\geq 50 \%$.

Neuropsychological tests are shown in Table 4.1. Total IQ data were placed into five categories because of the diversity of the tests used: the Wechsler Intelligence Scale for Children third and second edition (WISC-RN, WISC-IV), the Snijders Oomen nonverbal intelligence test (SON 21/2-7) and the Kaufman Assessment Battery for Children (KABC). For statistical analysis we used the Mann-Whitney- $U$ tests for comparison of groups and for correlation analysis, the Spearman's R. Alpha was set at 0.05 . 
Table 4.1 Cognitive tests.

\begin{tabular}{ll}
\hline Cognitive domain & Test \\
\hline Psychomotor speed/attention & Auditory reaction time (ART) \\
& Visual reaction time (VRT) \\
& Tapping \\
& Bourdon VOS \\
Speed of central information processing & Binary choice reaction time (BCRT) \\
& Computerized visual searching task (CVST) \\
Short term memory & Rey auditory memory task (RAMT) direct reproduction \\
& Recognition of words and figures \\
Long term memory & Rey auditory memory task (RAMT), recall \\
& Rey complex figure, recall after 20 minutes \\
Visual-spatial function & Rey complex figure, copy \\
Visual-motor integration & Beery visual motor integration (VMI) test \\
Educational achievement & \\
& Reading words and sentences at high speed \\
& Arithmetic at high speed \\
\hline
\end{tabular}

${ }^{1}$ Auditory and visual reaction times, CVST, recognition of words and figures are part of a computerized assessment battery earlier described by Alpherts WC, Aldenkamp AP (Computerized neuropsychological assessment of cognitive function in children with epilepsy. Epilepsia 1990;31 suppl. 4 S35-40). ${ }^{2}$ To measure educational achievement, the performance on the test is calculated by subtracting the determined educational level by the actual months of education that a child received in primary school (one school year consists of 10 educational months). Mean normal value is 0 in the normal healthy population. If this outcome was positive, the child has an educational delay, if the outcome is negative, the child has a lead in education. ${ }^{3}$ A Dutch screening test comparable to the Wide-Range Achievement Test in English speaking countries.

\section{Results}

96 children were male and 86 were female. The mean age was 9 years and 5 months (range 6;2-12;11 months). Tables 4.2 and 4.3 show syndrome diagnosis and seizure frequencies. Cryptogenic localization-related epilepsy was the most frequent diagnosis (101 children, 56\%). About half of the children (47\%) had a low seizure frequency (less than 1 seizure in the past year) or never had observed seizures. Sixty-one children (34\%) had a combination of partial seizure types, 62 children (34\%) had complex partial seizures as the only seizure type, twenty-two children (12\%) only had generalized seizures. Thirty-three children (18\%) were not taking antiepileptic drugs.

\section{Neuropsychological characteristics}

Total IQ data were categorized in five categories because of diversity of the tests used (WISC-III, WISC-R, SON, K-ABC). Thirty-nine children (21\%) had a total IQ between 70-79, 41 children (23\%) between 80-89, 87 (48\%) between 90-109, 14 (8\%) between 110-119 and 1 child had a total IQ above 120 . Eighty children (44\%) had a total IQ between 70 and 90 .

Symptoms of cognitive problems reported by the caregivers were recorded in $71 \%$ of all the children. Attention problems ( $40 \%$ of children) and/or problems in language 
abilities (37\% of children) were frequently reported. Within the domain of language, difficulties in language expression were most frequently reported (32 children, 18\%).

Table 4.2 Syndromal diagnosis.

\begin{tabular}{|c|c|c|c|c|}
\hline Syndromal diagnosis & Subtype / aetiology & $\begin{array}{l}\text { Number of } \\
\text { children }\end{array}$ & $\begin{array}{c}\text { Number of } \\
\text { children (total } \\
\text { of subgroup) }\end{array}$ & Percentage \\
\hline $\begin{array}{l}\text { Cryptogenic localization } \\
\text { related }\end{array}$ & & 101 & 101 & 55.5 \\
\hline Symptomatic & Perinatal asphyxia or bleeding & 8 & 20 & 11.0 \\
\hline \multirow[t]{7}{*}{ localization related } & Cortical malformation & 4 & & \\
\hline & Tuberous sclerosis & 2 & & \\
\hline & Mesiotemporal sclerosis & 2 & & \\
\hline & Arteriovenous malformation & 1 & & \\
\hline & Temporal cyst & 1 & & \\
\hline & Cerebral contusion & 1 & & \\
\hline & Meningitis & 1 & & \\
\hline \multirow[t]{2}{*}{ Benign focal epilepsy } & Rolandic $^{1}$ & 21 & & \\
\hline & Panayiotopoulos ${ }^{2}$ & 2 & 23 & 13.0 \\
\hline $\begin{array}{l}\text { Primary generalized } \\
\text { epilepsy }\end{array}$ & & 9 & 9 & 5.0 \\
\hline $\begin{array}{l}\text { Unknown syndromal } \\
\text { diagnosis }^{3}\end{array}$ & & 19 & 19 & 10.5 \\
\hline \multirow[t]{2}{*}{ No epilepsy } & $\begin{array}{l}\text { Centrotemporal (Rolandic) } \\
\text { spikes in EEG }\end{array}$ & 5 & 10 & 5.0 \\
\hline & $\begin{array}{l}\text { Other localization of spikes in } \\
\text { EEG }\end{array}$ & 5 & & \\
\hline Total & & 182 & 182 & 100.0 \\
\hline
\end{tabular}

${ }^{1}$ Rolandic epilepsy was defined as: EEG with Rolandic spikes, and typical Rolandic seizure semiology (hemifacial, hemiclonic or generalized clonic seizures). ${ }^{2}$ Panayiotopoulos syndrome was defined as: EEG with an occipital focus isolated or as one of multiple spike foci, seizure semiology with eye deviation and ictal vomiting. ${ }^{3}$ Unknown syndromal diagnosis: patients with arguments for both cryptogenic localization related epilepsy and Rolandic epilepsy (e.g. spikes in Rolandic region but lack of typical Rolandic seizure semiology) or patient with arguments for both CLRE and primary generalized seizures (e.g. absence-like seizures but focal EEG-phenomena).

Table 4.3 Seizure frequency.

\begin{tabular}{lllll}
\hline & Seizure frequency & Number of children & Percentage & Percentage/group \\
\hline No seizures & never had seizures & 10 & 5.5 & 5.5 \\
Low seizure & seizure free more than 2 years & 44 & 23.9 & 41.3 \\
frequency & $\leq 1 /$ year & 32 & 17.4 & \\
Medium to high & $\leq 6 /$ year & 14 & 7.6 & 43.9 \\
seizure frequency & every 2 months & 3 & 1.6 & \\
& monthly & 23 & 12.5 & \\
& weekly & 12 & 6.5 & \\
& several/week & 10 & 5.4 & \\
Seizure frequency & several/day & 19 & 10.3 & 9.3 \\
unknown & seizure frequency unknown & 17 & 9.3 & \\
& & 184 & 100.0 & 100.0 \\
\hline
\end{tabular}




\section{EEG characteristics}

In 130 children (71\%) IEDs were found in the awake or the sleep EEG. The percentages of patients in the different IED categories in wakefulness and sleep are presented in Figures 4.2 and 4.3 . The highest recorded category of awake index (10-50\%) was seen in $19(10 \%)$ of the 182 children. In 64 children (35\%) a sleep index of at least $10 \%$ was seen, of whom 15 had a very high index $(>50 \%)$.

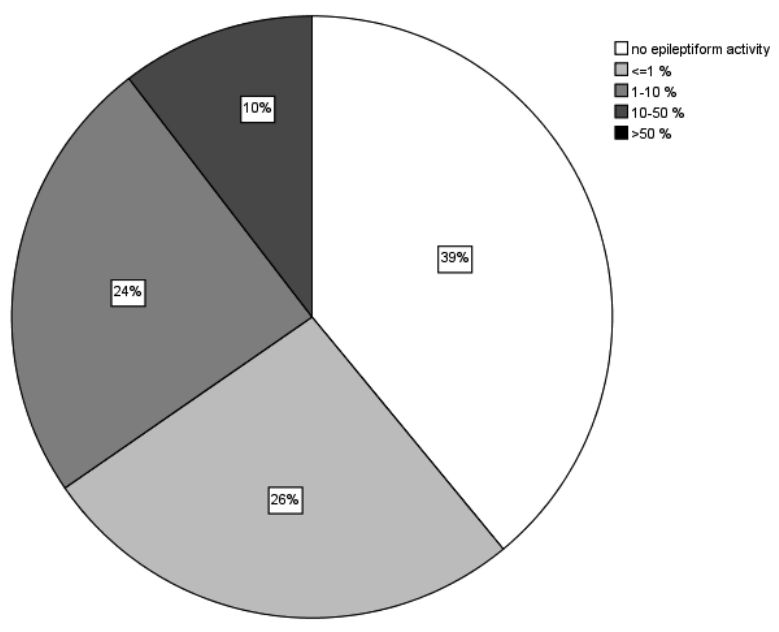

Figure 4.2 N=182 children, index of interictal epileptiform activity in the awake state (\% written within the figure $=\%$ of children)

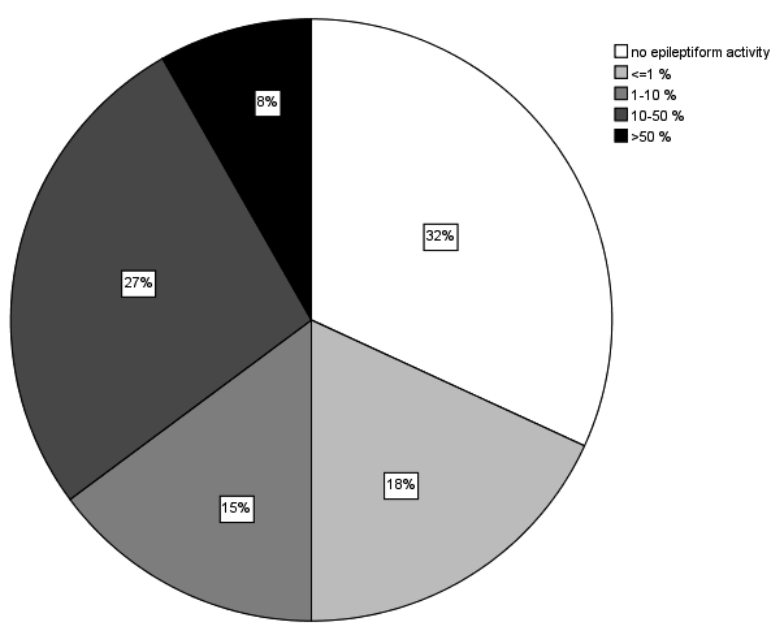

Figure 4.3 $\mathrm{N}=182$ children, index of interictal epileptiform activity in the sleep (\% written within the figure $=\%$ of children) 
Patients with cryptogenic localization-related epilepsy had a significantly lower IED index than patients with symptomatic epilepsy (awake index $P \leq 0.001$, sleep index $P=0.01$ ) and they also had a significantly lower IED index than patients with Rolandic epilepsy or with Rolandic spikes without observed seizures (awake index $P \leq 0.001$, sleep index $P \leq 0.001)$. The IED index in patients with symptomatic epilepsy did not differ ${ }^{b}$ from patients with Rolandic epilepsy/spikes. Correlation analyses between clinical and EEG characteristics and between all EEG-characteristics are presented in Tables 4.4a and $4.4 \mathrm{~b}$.

Table 4.4a Correlation-analysis between spike index and clinical characteristics (Spearman's R).

\begin{tabular}{|c|c|c|c|c|c|c|c|}
\hline & $\begin{array}{l}\text { Awake index } \\
\& \text { seizure } \\
\text { frequency }\end{array}$ & $\begin{array}{l}\text { Sleep index } \\
\& \text { seizure } \\
\text { frequency }\end{array}$ & $\begin{array}{l}\text { Awake index } \\
\& \text { seizure } \\
\text { type }^{1}\end{array}$ & $\begin{array}{l}\text { Sleep index } \\
\& \text { seizure } \\
\text { type }^{1}\end{array}$ & $\begin{array}{l}\text { Awake index } \\
\& \text { number of } \\
\text { AEDs }\end{array}$ & $\begin{array}{l}\text { Sleep index } \\
\& \text { number } \\
\text { of AEDs }\end{array}$ & $\begin{array}{l}\text { Awake or } \\
\text { sleep index } \\
\text { \& duration } \\
\text { of epilepsy }\end{array}$ \\
\hline $\begin{array}{l}\text { Cryptogenic } \\
\text { epilepsy }\end{array}$ & $\begin{array}{l}\mathrm{R}=0.46 \\
P \leq 0.001\end{array}$ & $\begin{array}{l}\mathrm{R}=0.40 \\
P \leq 0.001\end{array}$ & $\begin{array}{l}\text { Complex } \\
\text { partial } \\
\text { seizures } \\
R=0.21 \\
P=0.33\end{array}$ & - & $\begin{array}{l}\mathrm{R}=0.24 \\
P=0.02\end{array}$ & $\begin{array}{l}\mathrm{R}=0.21 \\
P=0.04\end{array}$ & - \\
\hline $\begin{array}{l}\text { Symptomatic } \\
\text { epilepsy }\end{array}$ & - & - & - & - & - & - & - \\
\hline $\begin{array}{l}\text { Rolandic } \\
\text { epilepsy/ } \\
\text { Rolandic spikes }\end{array}$ & - & - & $\begin{array}{l}\text { Secundarily } \\
\text { generalized } \\
\text { seizures } \\
R=-0.39 \\
P=0.05\end{array}$ & - & - & - & - \\
\hline
\end{tabular}

${ }^{1}$ Positive correlation $=$ more seizures of the type with higher index.

Table 4.4b Correlation between spike index and other EEG-characteristics (Spearman's R).

\begin{tabular}{lllll}
\hline & $\begin{array}{l}\text { Awake index \& } \\
\text { sleep index }\end{array}$ & $\begin{array}{l}\text { Awake index \& } \\
\text { length of discharges }\end{array}$ & $\begin{array}{l}\text { Awake index \& } \\
\text { Distribution }{ }^{1}\end{array}$ & $\begin{array}{l}\text { Sleep index \& } \\
\text { Distribution }^{1}\end{array}$ \\
\hline All children & $\mathrm{R}=0.79$ & $\mathrm{R}=0.36$ & $\mathrm{R}=0.50$ & $\mathrm{R}=0.58$ \\
& $P \leq 0.001$ & $P=0.001$ & & \\
& Children with normal & & & \\
& EEG excluded: & & & \\
& $\mathrm{R}=0.58$ & & \\
& $P<0.001$ & & & \\
& & & \\
& & & \\
\hline
\end{tabular}

\footnotetext{
${ }^{1}$ Positive correlation $=$ more multifocal or generalized distribution of spikes with higher spike index.
}

\footnotetext{
${ }^{b}$ Note. For the sake of brevity, the terms "differ" or " difference" are used to refer to statistically significant differences.
} 


\section{The effect of frequency of epileptiform activity in wakefulness}

Comparative analysis between patients with different categories of IED index was only performed in the whole patient group because of the small subgroups with the same IED index and same syndrome diagnosis. There was no difference in IQ categories or test results between groups of children with and without IEDs in wakefulness in the EEG. There was no difference between groups with $\leq 1 \%$ versus $>1 \%$ index of IEDs. There were significant differences in performance between the group with $<10 \%$ index and the group with $\geq 10 \%$ index (Table 4.5 ). The group of 19 children with $\geq 10 \%$ index in wakefulness showed impaired performance on the direct reproduction in the RAMT $(P=0.01)$, the recall in the RAMT $(P \leq 0.01)$, the trial time in the CVST $(P=0.04)$, and the Beery VMI $(P=0.01)$ compared to all other patients with $<10 \%$ index in wakefulness. In this group of 19 children with $\geq 10 \%$ index there were 7 children with cryptogenic epilepsy, 5 children with symptomatic epilepsy, 5 children with Rolandic epilepsy/ spikes, and 2 children with uncertain diagnosis (cryptogenic epilepsy or Rolandic epilepsy). Nine of these 19 children had discharges of at least 3 seconds duration. Two of the 19 children had generalized localisation of IEDs (one had generalized discharges of $\geq 3$ seconds, the other had shorter generalized discharges).

Table 4.5 Results of analysis between $\geq 10 \%$ and $<10 \%$ awake index of IEDs.

\begin{tabular}{|c|c|c|c|c|}
\hline Cognitive test & Domain & $\begin{array}{l}\text { Comparative analysis } \\
\text { between patients } \\
\text { with }<10 \% \text { vs. } \geq 10 \% \\
\text { awake index }\end{array}$ & $\begin{array}{l}\text { Regression analysis } \\
\text { EEG } \\
\text { Variables }^{1}\end{array}$ & $\begin{array}{l}\text { Regression analysis } \\
\text { Clinical variables }^{2}\end{array}$ \\
\hline & & Mann-Whitney-U & $\begin{array}{l}\text { Significant } \\
\text { contribution(s): }\end{array}$ & $\begin{array}{l}\text { Significant } \\
\text { contribution(s): }\end{array}$ \\
\hline CVST, trial time & $\begin{array}{l}\text { Central } \\
\text { information } \\
\text { processing speed }\end{array}$ & $P=0.04$ & $\begin{array}{l}\text { Awake index } \\
P=0.01 \\
\text { Sleep index } \\
P=0.03\end{array}$ & - \\
\hline $\begin{array}{l}\text { RAMT, direct } \\
\text { reproduction and } \\
\text { recall }\end{array}$ & $\begin{array}{l}\text { Short and long } \\
\text { term verbal } \\
\text { memory }\end{array}$ & $P=0.01$ & $\begin{array}{l}\text { Awake index } \\
P=0.01\end{array}$ & - \\
\hline Beery VMI & $\begin{array}{l}\text { Visual-motor } \\
\text { integration }\end{array}$ & $P=0.01$ & $\begin{array}{l}\text { Awake index } \\
P=0.03\end{array}$ & $\begin{array}{l}\text { Number of AEDs } \\
P=0.04\end{array}$ \\
\hline
\end{tabular}

${ }^{1}$ possibly predictive electro-encephalographic variables: index in wakefulness, index in sleep, distribution (focal vs. multifocal or generalized), discharge duration and lateralization (predominance for dominant hemisphere, predominance for non-dominant hemisphere, no predominance). ${ }^{2}$ possibly predictive clinical variables: syndromal diagnosis, seizure frequency, seizure type (restricted to occurrence of complex partial seizures or generalized seizures), number of AEDs used and duration of epilepsy.

Because a high IED index was associated with spike-wave discharges of longer duration, which could possibly be ictal, we observed the group of 9 children with discharges of at least 3 seconds duration and index $\geq 10 \%$ more closely. In 3 of these children additional video-EEG monitoring had later been performed and this had, indeed, shown subtle 
ictal phenomena during some but not all of their discharges: subtle myoclonia of the head/face or shoulders in two patients with cryptogenic epilepsy and short staring moments in one patient with symptomatic epilepsy. In one patient with cryptogenic epilepsy, staring associated with some of the discharges had been observed during the ambulatory EEG. In two patients (one with cryptogenic and one with symptomatic epilepsy), there was high clinical suspicion of daily staring during frequent discharges of 3-10 seconds of duration but this was not confirmed during video-EEG monitoring. One patient with cryptogenic epilepsy had discharges $<3$ seconds and eye closure sensitivity with eyelid myoclonia during some discharges. When all 7 above mentioned children with proven or suspected ictal observations were excluded from the above analysis (so that only 12 of the 19 children with index $\geq 10 \%$ were now tested against all other patients with index $<10 \%)$, the results still remained significant: direct reproduction of the RAMT $(P=0.03)$, the recall of the RAMT $(P=0.01)$, the trial time in the CVST $(P=0.02)$, and Beery VMI $(P=0.01)$. When all children with discharges of $\geq 3$ seconds of duration were excluded from both groups with either $<10 \%$ or $\geq 10 \%$ index, this did not affect the overall results: direct reproduction in the RAMT $(P=0.01)$, the recall in the RAMT $(P=0.03)$, the trial time in the CVST $(P=0.02)$, and Beery VMI $(P=0.01)$. When all children with generalized epileptiform activity were removed from both groups, this did not affect the overall results either (direct reproduction in the RAMT $(P=0.02)$, the recall in the RAMT $(P \leq 0.01)$, the trial time in the CVST $(P=0.04)$, and Beery VMI $(P=0.02)$.

\section{The effect of frequency of epileptiform discharges in sleep}

A comparative group analysis to find differences in cognitive test results or differences in IQ between patients with or without IEDs in sleep, did not show significant results. When patient groups with different categories of IED index in sleep were tested against each other ( $\leq 1 \%$ vs. $>1 \%,<10 \%$ vs. $\geq 10 \%$, and $<10 \%$ vs. $\geq 50 \%$ ) we did not find differences in cognitive test results or $I Q$, either.

\section{The effect of distribution of interictal epileptiform discharges}

Children with non-focal (multifocal or generalized) IEDs performed significantly worse than children with focal epileptiform activity on the BCRT $(P=0.04)$, the CVST (number of errors) $(P=0.04)$, the recall of the figure of Rey $(P=0.03)$, and Beery VMI $(p=0.04)$. Furthermore, they had significant problems in the three tests measuring the delay in educational achievement (reading words $(P \leq 0.01)$, reading sentences $(p \leq 0.01)$, and arithmetic $(P=0.03))$.

When patients with generalized IEDs were removed from this analysis, so that only children with multifocal IEDs were tested against children with focal IEDs, the results were still significant for the BCRT $(P \leq 0.01)$, CVST24 $(P=0.02)$, and the three tests measuring educational achievement (reading words $(P<0.01)$, sentences $(P \leq 0.001)$, and arithmetic $(P \leq 0.01)$. 
Analysis of focal versus non-focal IEDs within the groups of different syndrome diagnoses was not possible because of the low number of patients in the subgroups.

\section{The effect of localization and lateralization of interictal epileptiform discharges}

When all patients with only one IED focus were further analysed, children with a centro-temporal-parietal (CTP) localization of IEDs performed better than the combined group of children with focal IEDs in the frontal or in the occipital region, on the VRT of the dominant hand $(P=0.04)$, tapping test dominant hand $(P \leq 0.01)$, and Bourdon VOS test (number of omissions) ( $P=0.01$ ). This effect was independent of the syndrome diagnosis of Rolandic epilepsy/spikes (in which a high proportion of children had IEDs in the CTP region).

IEDs located predominantly in the non-dominant hemisphere were associated with worse performance in copying and recall of the figure of Rey $(P=0.01$ and $P=0.04$ respectively), when we compared the children with IEDs predominantly in the nondominant hemisphere to the children with IEDs located predominantly in the dominant hemisphere. Analysis of the effect of localization or lateralization within the subgroups of different syndrome diagnosis was not possible because of small numbers in the subgroups.

\section{The effect of runs of interictal epileptiform discharges}

The performance on cognitive tests in the group of children with diurnal IEDs with serial (i.e. runs of) spike-wave complexes of at least $3 \mathrm{~s}$ duration did not differ from the performance in all other children with discharges of less than $3 \mathrm{~s}$ duration.

\section{Regression analysis}

The effect of each of the EEG variables in the previous section was studied independently. However, some of these variables correlate. We analyzed the influence of the EEG variables in combination on cognitive tests, controlling for such correlations (Table 4.5). Linear regression (backward procedure) was used to test whether EEG variables had an independent effect on cognition and which variables were the best predictor of cognitive impairment.

As possibly predictive electro-encephalographic variables we included (1) the "index in wakefulness", (2) "index in sleep", (3) "distribution" (focal vs. multifocal or generalized), (4) "discharge duration" and (5) "lateralization" (predominance for dominant hemisphere, predominance for non-dominant hemisphere, no predominance).

As dependent variables we used those cognitive tests that showed most effects of the EEG factors in the previous analysis: (1) RAMT, (2) CVST and (3) Beery. For the RAMT direct reproduction the results were not statistically significant for the five characteristics combined $(P=0.25)$. After removal of three variables except discharge 
duration and index in wakefulness, these two characteristics in combination were significantly associated with performance on the RAMT $(P=0.04)$. Of these characteristics, however only "index awake" had a separate statistically significant contribution ( $P=0.01)$. For the RAMT recall, the results were not statistically significant for the five characteristics combined $(P=0.07)$. After removal of lateralization, the other characteristics in combination were associated with performance on the RAMT $(P=0.03)$. Of these characteristics, however, only "index awake" had a separate statistically significant contribution ( $p \leq 0.01$ ).

For the CVST24 test the results were not statistically significant for the five EEG variables combined $(P=0.10)$. The characteristics index awake, index in sleep and lateralization combined were associated with performance on the trial time in the CVST24 test $(P=0.04)$. Of these characteristics, only "index awake" and "index in sleep" had statistically significant associations ( $P=0.001, P=0.04$ respectively).

For the Beery visual scaled score the results were not statistically significant for the five characteristics combined $(P=0.13)$. After removal of all variables except "index awake" and "distribution" these variables were associated with performance $(P=0.03)$. However only "index awake" had a separate statistically significant contribution $(P=0.01)$.

A similar regression analysis was performed using epilepsy-related variables: syndrome diagnosis, seizure frequency, seizure type (restricted to occurrence of complex partial seizures or generalized seizures), number of AEDs used and duration of epilepsy. None of the combinations, nor individual characteristics were associated with the results of the CVST and RAMT at a statistically significant level. However for the Beery visual scaled score, regression analysis also showed a statistically significant association with the number of AEDs ( $P=0.02)$.

\section{Discussion}

Our results show an independent effect on cognition of highly frequent diurnal IEDs when they occur at least $10 \%$ of the time in the awake EEG. Our definition implies that an index of $\geq 10 \%$ represents at least one spike or spike-wave complex per 10 -s EEG. We observed diurnal IEDs in $\geq 10 \%$ of the time in $10 \%$ of the children in our study population. The high IED index was associated with slowing of central information processing speed, impairment of short-term verbal memory and impaired visual-motor integration. For visual-motor integration, however, the influence of the IED index was not independent of the effect of the number of AEDs. IEDs during sleep were not strongly associated with impaired cognition; in regression analysis they only contributed partially to the slowing of central information processing speed. However, the lack of a statistically-significant difference between the 15 patients with very high sleep index of $>50 \%$ and the other patients could have been because this study was not adequately powered. In general, detecting differences $\geq 10 \%$ requires sample sizes of more than 25 patients. We found that a multifocal/generalized distribution of IEDs as 
opposed to focal IEDs was associated with impaired cognition when examined as a separate variable. Linear regression, however, shows that for the main outcomes (central information processing speed, short-term verbal memory and visuo-motor integration) the effect of other EEG-characteristics such as distribution was not independent from the index. Clinical factors such as the epilepsy diagnosis, seizure frequency, seizure type, and other epilepsy-related variables also did not compromise these findings, at least in the regression analysis for those cognitive outcomes that were most sensitive for the effect of epileptiform EEG discharges. Concerning localization, IEDs located in the non-dominant hemisphere were associated with worse visuo-spatial function and worse long-term memory of visuo-spatial information.

The results were consistent with earlier findings from a study in which we examined children with video-EEG during cognitive testing. ${ }^{8}$ Impaired information processing speed (measured by the BCRT and the CVST) was observed in the group of 55 children with an IED index of $>1 \%$ compared to 63 children with an index of $<1 \%$. Although this study suggests a lower threshold (1\%) as to the percentage of IEDs above which cognition shows impairments than the present study, this earlier study had a larger number of children with IEDs in more than $10 \%$ of the time, namely $40 \%$ of the total study population. In the present study population only $10 \%$ of children had $\geq 10 \%$ IEDs in wakefulness. Significance with a threshold of $>1 \%$ IEDs between the groups was probably more easily obtained in the earlier study because the larger number of children with very high diurnal index.

In patients with frequent IEDs, a different aetiology defined by the syndrome diagnosis could hypothetically lead to a different magnitude or different aspect of the effects on cognition. Rolandic epilepsy can be seen as an idiopathic, probably largely genetically influenced, age-related disorder. The IEDs, often multifocal and with shifting locations over time, may be an expression of the underlying changes in widespread neuronal function caused by this age-related disorder, and not the primary cause of the neuronal dysfunction/ cognitive impairment. In symptomatic epilepsy the occurrence of IEDs results from electrophysiological changes in structurally-changed brain areas, with genetic factors probably playing a less important role. Cryptogenic localization-related epilepsy, i.e. with suspected but unknown cause, could be an intermediate, heterogeneous group. Although our results show an influence of IEDs regardless of the syndrome diagnosis, we could not adequately study differential effects of index, localization or duration of IEDs between the subgroups, because the numbers in these groups were too small.

In patients with cryptogenic epilepsy, we found a significant correlation between seizure frequency and IED frequency. Patients with Rolandic spikes and symptomatic epilepsy had higher IED frequencies but these were not correlated to seizure frequency. Especially in patients with low seizure frequency and high IED frequency, the dilemma of whether or not to "treat the EEG", i.e. to endeavour to suppress the IEDs, in an attempt to improve cognition, arises. 
In the literature there are only few prospective studies that examine the effects of treatment of IEDs with cognition as main outcome. In 1993, Marston et al. treated 10 children with generalized IEDs once every 5 minutes with add-on valproate or clobazam in a placebo-controlled cross-over design. ${ }^{27}$ The syndrome diagnosis, seizure frequencies and discharge lengths were not stated. Discharge rate was reduced with a median of $57 \%$. Global psychosocial functioning (in a rating scale assessment) improved in 8 of 10 children during the active treatment phase. Formal psychological testing, however, did not show differences. Seizure frequency was reduced as well, so that the improvement related to reduction of IEDs could not be interpreted separately from the effect of seizure reduction during the treatment phase of 3-4 months. In this study, children with ongoing seizures combined with a high IED frequency were examined. However, it is more important to study the effects of treatment on cognition in patients with low seizure frequency or without observed seizures.

Two prospective studies were performed in children with low seizure frequencies. Pressler et al. treated 48 children, of whom $77 \%$ were free from obvious seizures, with IQ $\geq 70$ and with learning and/or behaviour difficulties for three months in a placebocontrolled cross-over protocol with add-on lamotrigine. ${ }^{28,29}$ These children were not selected because of a high IED frequency, but in all children the impact of the treatment on diurnal IEDs in an ambulatory 24-hour EEG was measured. Two-thirds of the children had IEDs at baseline, with a mean rate of 9.7 discharges per hour. Fortyfour $\%$ of children had a reduced frequency of IEDs. There was a significant improvement in a global rating scale of behaviour in children with reduction of IEDs. However, there was no improvement in cognitive test results.

Mintz et al. carried out a prospective open-label study of 10 weeks treatment with levetiracetam on 6 children (monotherapy in five and add-on to ethosuximide in one child), with frequent focal diurnal IEDs and attention and/or learning difficulties. ${ }^{30}$ These children had a low seizure frequency and high diurnal spike frequency, but the observed awake index of IEDs was not stated. Four of the six patients had IEDs in the centro-temporal (Rolandic) region and the other 2 children had parietal-occipital and frontal IEDs, respectively. IEDs were reduced with treatment. Memory and concentration improved significantly in 4/6 patients, including two who had complete IED suppression.

In a retrospective analysis of 32 children treated with levetiracetam, a subgroup of 8 children without observed seizures but with Rolandic spikes and learning difficulties or behavioural problems were also included. A 20-minute sleep EEG was performed at baseline and 3 months later. ${ }^{31}$ In 2 of these children the sleep EEG was completely normalized and 3 of the children had $>90 \%$ reduction of IEDs. Four of these 5 patients with considerable EEG improvement were reported "to have gained markedly in the cognitive and behavioural domains", and the same clinical improvement was only seen in 2 of the 8 patients without EEG changes. This was concluded from a nonstandardized interview of the parents and not by neuropsychological testing (the authors focused primarily on seizures and EEG changes). Although the findings are 
interesting, it must be emphasised that open-label studies can be confounded by placebo effects as well as spontaneous fluctuations in cognition, behaviour and the EEG. One way of assessing the effects of treatment in individual patients is to perform a single-patient trial with placebo-controlled treatment. Such a study was performed in a 7-year-old boy with a bilateral frontal spike focus (28 spikes/min) in wakefulness and only a single tonic-clonic seizure at age $4 .^{32}$ This publication included no description of the nocturnal EEG. Eight treatments with valproate or placebo, each of one-week duration were given, with repeated cognitive testing. The EEG normalized while the boy was taking valproate. The results of the WISC-R coding subtest improved significantly during the valproate treatment periods. An interesting aspect of this study was the direct result of the abolition of IEDs in this child. A transitory influence of the spiking would appear to have been the main mechanism through which the IEDs impaired cognition. If chronic effects of IEDs were the origin of the school problems, such a quick recovery would probably not have been observed. How long IEDs have to be treated before clinical effects on cognition can be seen in the individual patient is generally not known. Furthermore, it is not possible to obtain complete control of IEDs in all children, as was achieved in this child. Trials in individual children are therefore difficult to interpret.

None of the studies discussed provide an adequate answer to the question of whether IEDs should be treated to improve cognition or when results of treatment can be expected. Large prospective observational studies, or controlled treatment studies in children with a low seizure frequency and a high IED frequency have not been performed so far.

Our observational prospective study has several limitations. The cognitive testing and EEG were not performed at the same time or even on the same day. In some of the children the IED frequency may have undergone major day-to-day fluctuations with the result that the effect of IED frequency on cognition could have been either underestimated or overestimated, reducing the chance of finding a correlation between IED frequency and the cognitive test results. We did not have sufficient information on earlier cognitive test results or EEGs. Better insight into the chronological relationships between EEG changes and cognitive changes can be obtained when prospective, repeated cognitive testing is compared with repeated EEG-measurements. We did not have information on the duration of the EEG disturbances. Hypothetically, IEDs in $1 \%$ of the time lasting for 5 years might have more impact on a child's brain than IEDs in $10 \%$ of the time for 2 months. A further limitation of this study is that we have grouped together spike discharges and spikewave discharges and we were consequently unable to comment on any difference in the effect between these types of epileptiform discharges.

Finally, although the examined group of 184 children was large, the number of children with frequent IEDs in wakefulness and/or sleep was limited. The numbers of children sharing the same syndrome diagnosis of Rolandic epilepsy or symptomatic epilepsy, in 
which the highest IED frequencies were observed, were small. The influence of syndrome diagnosis on the effects of IEDs could not be examined adequately.

Although our study has some limitations, our results show that IEDs can influence cognition, which is in line with several previous studies. However the results from treatment studies do not yet justify the "routine" treatment of IEDs to improve cognition. The effects of treatment in these patients should be further examined in prospective controlled trials. Even then, in individual children with low seizure frequency or without observed seizures and a high index of diurnal IEDs, antiepileptic drug treatment should only be considered when there is enough evidence for cognitive impairment related to frequent discharges. This evidence can only be obtained in a few children from video-EEG (showing transitory impairment during runs of spike-wave discharges or worse test results in periods with highly-frequent isolated spikes). In the other children objective arguments for cognitive decline should be identified, other cause of the decline should be excluded, and repeated EEG monitoring should be performed to rule out spontaneous improvement. Most important, the effect of such treatment in an individual child should be monitored not only by parental report but also with objective repeated EEGs and cognitive assessment. 


\section{References}

1. De Negri M, Baglietto MG. Cognitive impairment and epilepsy. Brain Dev 1993;15:389.

2. Galanopoulou AS, Moshe SL. The epileptic hypothesis: developmentally related arguments based on animal models. Epilepsia 2009;50 Suppl 7:37-42.

3. Stores G. Electroencephalographic parameters in assessing the cognitive function of children with epilepsy. Epilepsia 1990;31 Suppl 4:S45-9.

4. Besag FM. The therapeutic dilemma: treating subtle seizures or indulging in electroencephalogram cosmetics? Semin Pediatr Neurol 1995;2:261-8.

5. Baumbach HD, Chow KL. Visuocortical epileptiform discharges in rabbits: differential effects on neuronal development in the lateral geniculate nucleus and superior colliculus. Brain Res 1981;209:61-76.

6. Bruehl C, Kloiber O, Hossman KA, Dorn T, Witte OW. Regional hypometabolism in an acute model of focal epileptic activity in the rat. Eur J Neurosci 1995; 7:192-7.

7. Lengler U, Kafadar I, Neubauer BA, Krakow K. fMRI correlates of interictal epileptic activity in patients with idiopathic benign focal epilepsy of childhood. A simultaneous EEG-functional MRI study. Epilepsy Res 2007;75:29-38.

8. Aldenkamp A, Arends J. The relative influence of epileptic EEG discharges, short nonconvulsive seizures, and type of epilepsy on cognitive function. Epilepsia 2004;45:54-63.

9. Piccirilli M, D'Alessandro P, Sciarma T, Cantoni C, Dioguardi MS, Giuglietti M, Ibba A, Tiacci C. Attention problems in epilepsy: possible significance of the epileptogenic focus. Epilepsia 1994;35:1091-6.

10. Kasteleijn-Nolst Trenite DG, Siebelink BM, Berends SG, van Strien JW, Meinardi H. Lateralized effects of subclinical epileptiform EEG discharges on scholastic performance in children. Epilepsia 1990;31:740-6.

11. Bedoin N, Herbillon V, Lamoury I, Arthaud-Garde P, Ostrowsky K, De Bellescize J, Kéo Kosal P, Damon G, Rousselle $\mathrm{Ch}$. Hemispheric lateralization of cognitive functions in children with centrotemporal spikes. Epilepsy Behav 2006;9:268-74.

12. Wolff M, Weiskopf N, Serra E, Preissl H, Birbaumer N, Kraegeloh-Mann I. Benign partial epilepsy in childhood: selective cognitive deficits are related to the location of focal spikes determined by combined EEG/MEG. Epilepsia 2005;46:1661-7.

13. Riva D, Pantaleoni C, Milani N, Giorgi C. Hemispheric specialization in children with unilateral epileptic focus, with and without computed tomography-demonstrated lesion. Epilepsia 1993;34:69-73.

14. Volkl-Kernstock S, Willinger U, Feucht M. Spacial perception and spatial memory in children with benign childhood epilepsy with centro-temporal spikes (BCECTS). Epilepsy Res 2006;72:39-48.

15. Shewmon DA, Erwin RJ. The effect of focal interictal spikes on perception and reaction time. I. General considerations. Electroencephalogr Clin Neurophysiol 1988;69:319-37.

16. Fonseca LC, Tedrus GM, Pacheco EM. Epileptiform EEG discharges in benign childhood epilepsy with centrotemporal spikes: reactivity and transitory cognitive impairment. Epilepsy Behav 2007;11:65-70.

17. Binnie CD. Significance and management of transitory cognitive impairment due to subclinical EEG discharges in children. Brain Dev 1993;15:23-30.

18. Aldenkamp AP, Beitler J, Arends J, van der Linden I, Diepman L. Acute effects of subclinical epileptiform EEG discharges on cognitive activation. Funct Neurol 2005;20:23-8.

19. Nicolai J, van der Linden I, Arends JB, van Mil SG, Weber JW, Vles JS, Aldenkamp AP. EEG characteristics related to educational impairments in children with benign childhood epilepsy with centrotemporal spikes. Epilepsia 2007;48:2093-100.

20. Deonna T, Zesiger P, Davidoff V, Maeder M, Mayor C, Roulet E. Benign partial epilepsy of childhood: a longitudinal neuropsychological and EEG study of cognitive function. Dev Med Child Neurol 2000;42: 595-603.

21. Baglietto MG, Battaglia FM, Nobili L, Tortorelli S, De Negri E, Calevo MG, Veneselli E, De Negri M. Neuropsychological disorders related to interictal epileptic discharges during sleep in benign epilepsy of childhood with centrotemporal or Rolandic spikes. Dev Med Child Neurol 2001;43:407-12.

22. Deonna T, Davidoff V, Maeder-Ingvar M, Zesiger P, Marcoz JP. The spectrum of acquired cognitive disturbances in children with partial epilepsy and continuous spike-waves during sleep. A 4-year followup case study with prolonged reversible learning arrest and dysfluency. Eur J Paediatr Neurol 1997;1: 19-29. 
23. Rudolf G, Valenti MP, Hirsch E, Szepetowski P. From rolandic epilepsy to continuous spike-and-waves during sleep and Landau-Kleffner syndromes: insights into possible genetic factors. Epilepsia 2009;50 Suppl 7:25-8.

24. Kramer U, Sagi L, Goldberg-Stern H, Zelnik N, Nissenkorn A, Ben-Zeev B. Clinical spectrum and medical treatment of children with electrical status epilepticus in sleep (ESES). Epilepsia 2009;50:1517-24.

25. Seri S, Thai JN, Brazzo D, Pisani F, Cerquiglini A. Neurophysiology of CSWSassociated cognitive dysfunction. Epilepsia 2009;50 Suppl 7:33-6.

26. Aldenkamp AP, Arends J, Overweg-Plandsoen TC, van Bronswijk KC, Schyns-Soeterboek A, Linden I, Diepman L. Acute cognitive effects of nonconvulsive difficult-to-detect epileptic seizures and epileptiform electroencephalographic discharges. J Child Neurol 2001;16:119-23.

27. Marston D, Besag F, Binnie CD, Fowler M. Effects of transitory cognitive impairment on psychosocial functioning of children with epilepsy: a therapeutic trial. Dev Med Child Neurol 1993;35:574-81.

28. Pressler RM, Binnie CD, Coleshill SG, Chorley GA, Robinson RO. Effect of lamotrigine on cognition in children with epilepsy. Neurology 2006;66:1495-9.

29. Pressler RM, Robinson RO, Wilson GA, Binnie CD. Treatment of interictal epileptiform discharges can improve behavior in children with behavioral problems and epilepsy. J Pediatr 2005;146:112-7.

30. Mintz M, Legoff D, Scornaienchi J, Brown M, Levin-Allen S, Mintz P, Smith C. The underrecognized epilepsy spectrum: the effects of levetiracetam on neuropsychological functioning in relation to subclinical spike production. J Child Neurol 2009;24:807-15.

31. von Stulpnagel C, Kluger G, Leiz S, Holthausen H. Levetiracetam as add-on therapy in different subgroups of "benign" idiopathic focal epilepsies in childhood. Epilepsy Behav 2010;17:193-8.

32. Gordon K, Bawden H, Camfield P, Mann S, Orlik P. Valproic acid treatment of learning disorder and severely epileptiform EEG without clinical seizures. J Child Neurol 1996;11:41 


\section{Chapter 5}

\section{Reading performance in children with rolandic epilepsy correlates with nocturnal epileptiform activity, but not with epileptiform activity while awake}

S.C.M. Ebus, G.M. Overvliet, J.B.A.M. Arends, A.P. Aldenkamp

Epilepsy \& Behavior 2011;22:518-522 


\section{Summary}

Objective

An association between language impairment and rolandic epilepsy is frequently reported. This impairment could be correlated with the amount of nocturnal epileptiform activity.

Methods

We retrospectively analyzed 26 children with rolandic epilepsy and/or rolandic spikes. All had undergone a 24-hour EEG and neuropsychological assessment within 2 weeks. Reading performance (reading words and sentences) and intelligence were measured.

Results

There was a significant negative correlation between amount of nocturnal epileptiform activity and reading sentences $\mathrm{R}=-0.525(P=0.008)$. There was a trend in this correlation for reading words $\mathrm{R}=-0.398(P=0.054)$. We found a negative correlation between amount of nocturnal epileptiform activity and Verbal IQ ( $R=-0.51 P=0.08)$. No correlation was found between reading performance or Verbal IQ and amount of diurnal epileptiform activity.

\section{Conclusions}

Reading performance is impaired in children with rolandic epilepsy and is correlated to the amount of nocturnal epileptiform activity. 


\section{Introduction}

Many case reports and some studies ${ }^{1-8}$ suggest a correlation between the occurrence of frequent nocturnal epileptiform activity or frequent nocturnal epileptic seizures and the development of language impairment. This correlation is especially observed in two well known and probably genetically related childhood epilepsy syndromes: LandauKleffner syndrome and rolandic epilepsy. For Landau-Kleffner syndrome, in which there is abundant nocturnal epileptiform activity, the language impairment is most severe. ${ }^{9}$ Language impairment to a lesser degree can also be seen in rolandic epilepsy, one of the most frequently occurring epilepsy syndromes in children. ${ }^{6}$

The EEGs of patients with rolandic epilepsy reveal epileptiform sharp waves and spikewaves in the centrotemporal or centroparietal regions, which increase in number during the night. Multiple epileptiform foci can be present in both hemispheres. ${ }^{10}$ In the course of the disease, as the child grows into puberty, epileptiform activity and seizures will disappear, and therefore this epilepsy is defined as a benign focal epilepsy of childhood. Seizures are most often nocturnal and consist of hemifacial sensorimotor seizures with speech arrest and drooling, sometimes with loss of consciousness with grunting and gurgling noises. Also hemiclonic seizures or secondary generalized tonicclonic seizures are observed. ${ }^{11,12}$ The impact of the seizures is usually low because of the nocturnal occurrence and low frequency. Despite low impact of seizures, cognitive and behavioral problems can be obesrved in these children and they may cause more concern than the seizures. ${ }^{6}$ The affected cognitive domains reported in studies include attention ${ }^{13,14}$, visual perception, memory and visual-motor performance. ${ }^{15}$ Furthermore there are several reports on language impairment, especially expressive speech problems, reading problems and impaired verbal fluency ${ }^{5,16-18}$, however, language comprehension can also be affected. ${ }^{19}$ Clarke et al. assessed 55 children with rolandic epilepsy, 150 controls and their siblings and parents. They found reading disorders in $55 \%$ of the children with rolandic epilepsy, (Odds ratio 5,78) and speech sound disorders (developmentally inappropriate errors in speech production e.g. deletions and substitutions) in $37 \%$ (Odds ratio 2,47 ). Siblings of children with rolandic epilepsy were at high risk of reading disorders and speech sound disorders. ${ }^{5}$ Lundberg et al., however, showed that reading or speech problems in children with rolandic epilepsy may originate only from difficulties in correct articulation as a result of impaired tongue mobility. In the same patients speed and quality of speech as well as technique and comprehension in reading were not impaired. ${ }^{20}$

Cognitive problems in rolandic epilepsy have been reported to relate to the amount of nocturnal epileptic activity, to the occurrence of multifocality (two or more epileptiform foci), the presence of an intermittent slow-wave focus and a large nocturnal increase of epileptiform activity. ${ }^{21,22}$ Despite many reports on reading problems in children with rolandic epilepsy ${ }^{13,14}$, until now, no study has correlated the characteristics of epileptiform activity during the night in children with rolandic epilepsy with educational delay in reading performance. 


\section{Method}

In total, 26 consecutive children with rolandic epilepsy or epileptiform activity in the rolandic region (rolandic spikes), referred to the tertiary Epilepsy Centre Kempenhaeghe, Heeze, the Netherlands, in the period 2002 until 2008 were included. Theyu had to be between 6 and 12 years of age, have an intelligence quotient $>70$, and be able to speak or understand the Dutch language. They could have no neurological co-morbidity and no proven structural abnormalities on MRI. EEG recordings and neuropsychological assessments had to be performed within the same 2 weeks. The present and/or an earlier registered EEG had to show centrotemporal and/or centroparietal epileptiform activity. Observed seizure types had to be sensorimotor (hemi)facial, hemiclonic or bilaterally (tonic)-clonic. Patients with electrical status epilepticus of slow sleep (ESES) were excluded.

Electroencephalographic recordings

Twenty-four-hour, 32-channel ambulatory EEG-recordings were obtained for all children. Epileptiform activity during the first cycle of sleep was categorized as occurring none, $<1 \%, 1-10 \%, 10-50 \%$ or $50-85 \%$ of the time. Predominance of localization of the epileptiform focus/foci in the dominant or non-dominant hemisphere was determined by combining EEG results with reported and observed handedness.

\section{Academics: reading performance}

To measure possible educational delay, reading performance was calculated by subtracting the determined educational level (EL) by the actual months of education $(\mathrm{ME})$ a child received in primary school (one school year consists of 10 educational months). This was measured by the standardized Dutch tests; 'Tempo Test Woorden' (reading words) and 'Tempo Test Zinnen' (reading sentences). The mean normal value is 0 in the normal healthy population. If this outcome was positive, the child had an educational delay ${ }^{23,24}$ and vice versa, if the outcome was negative, the child had a lead in education.

\section{Intelligence}

Intelligence Quotient was measured with the Wechsler Intelligence scale (WISC-RN or WISC-III) (Dutch version).

\section{Statistical analysis}

The one sample t-test, Mann-Whitney-U test and Spearman's correlation were applied using SPSS Version 19. 


\section{Results}

Thirteen boys and thirteen girls were examined. Mean age at testing was 112.0 months (9 years 4 months, SD 18.8). Mean age at diagnosis was 83.8 months (6 years 11 months, SD 27.8). In 5 patients (19.2\%) seizures had never been observed. In the majority of patients with seizures $(n=15,68 \%)$, onset of seizures had occurred between $>1$ and 5 years ago; in 3 patients (15.8\%) onset was in the preceding year and in 3 patients (15.8\%) onset was between 6 and 10 years ago. Of the 21 children in whom seizures had been observed, 16 (76\%) had a seizure frequency of less than one seizure per 2 months (among whom 5 children had been seizure free for more than 2 years), and only 3 patients had a relatively high seizure frequency with monthly seizures. Seventeen children (65\%) used antiepileptic drugs (AEDs) in monotherapy (valproate [VPA], $n=6$, carbamazepine [CBZ], $n=3$, levetiracetam [LEV] $n=2$, clobazam [CLB] $n=1$ ), or polytherapy (CBZ/CLB $n=1$, LEV/CLB $n=1$, CBZ/VPA $n=1$, LEV/lamotrigine [LTG] $n=1$, VPA/LTG $n=1), 9$ children did not take AEDs.

Characteristics of the nocturnal epileptiform activity on the 24-hour ambulatory EEGs are summarized in Table 5.1. Fifteen patients (58\%) had a large amount of epileptiform activity during the first cycle of sleep ( $>10 \%$ of the time) in the present EEG. Only one patient no longer had epileptiform activity in the current nocturnal EEG; for this patient only one seizure had been observed in the preceding year.

Table 5.1 Characteristics of nocturnal epileptiform activity.

\begin{tabular}{lll}
\hline Group in Figures 5.1 and 5.2 & Percentage nocturnal epileptiform activity & Number (\%) of patients \\
\hline 0 & $0 \%$ & $\mathrm{n}=1(3.8 \%)$ \\
1 & $<1 \%$ & $\mathrm{n}=0$ \\
2 & $1-10 \%$ & $\mathrm{n}=5(19.2 \%)$ \\
3 & $10-50 \%$ & $\mathrm{n}=15(57.7 \%)$ \\
4 & $>50 \%-85 \%$ & $\mathrm{n}=5(19.2 \%)$ \\
Hemispheric predominance & Predominance in dominant hemisphere & $\mathrm{n}=10(38.5 \%)$ \\
& Predominance in non-dominant hemisphere & $\mathrm{n}=12(46.2 \%)$ \\
& No predominance & $\mathrm{n}=1(3.8 \%)$ \\
Number of foci & Unknown (ambidexter patient) & $\mathrm{n}=3(7.7 \%)$ \\
& Only one epileptiform focus & $\mathrm{n}=15$ \\
& Multiple ( $\geq 2)$ epileptiform foci & $\mathrm{n}=10$ \\
Intermittent slow wave focus & No epileptiform activity & $\mathrm{n}=1$ \\
& Slow wave focus & $\mathrm{n}=6$ \\
& No background changes & $\mathrm{n}=19$ \\
& No epileptiform activity & $\mathrm{n}=1$ \\
\hline
\end{tabular}

\section{Academics: reading performance}

This group of children showed delays in learning efficacy of 4.8 months (SD 10.3) for reading words and of 7.3 months (SD 14.7) for reading sentences. The one-sample $t$ test showed a significant difference in reading words $(P=0.032)$ and reading sentences 
$(P=0.023)$. This means that there is a significant differences $(P<0.05)$ in delay to reading sentences and reading words between children with rolandic epilepsy in our population and normal healthy children.

Correlation analysis revealed a correlation between larger amount of nocturnal epileptiform activity and worse performance in reading sentences in children with rolandic epilepsy/spikes ( $R=-0.525 P=0.008)$. There was a trend in this correlation between the percentage of nocturnal epileptiform activity and the performance in reading words of $-0.398(P=0.054)$. The index of epileptiform activity during wakefulness did not correlate with the performance in reading sentences $(R=-0.215$, $P=0.314)$ or performance in reading words $(R=-0.352, P=0.091)$. There was no correlation between the performance in reading sentences or reading words and seizure frequency (sentences: $R=0.096, P=0.663$, words: $R=0.01, P=0.998$ ), epilepsy duration (sentences: $R=0.320, P=0.89$, words: $R=-0.248, P=0.292$ ), or number of AEDs taken (sentences: $R=0.189, P=0.377$, words: $R=0.195, P=0.360$ ). Children who did not take AEDs did not perform worse than children who took AEDs ( $P=0.591$ sentences and $P=0.825$ words). Children using CBZ did not perform worse than children not taking CBZ ( $P=0.945$ sentences and $P=0.731$ words) and children using VPA did not perform worse than children not taking VPA ( $P=0.664$ sentences and $P=0.710$ words). Other AEDs were used too infrequently to analyze. Children with epileptiform activity in the dominant hemisphere did not show significant differences in performance in reading sentences or words compared with children with epileptiform activity predominantly in the nondominant hemisphere (both $P=0.382$ ). Children with multifocal epileptiform activity did not show differences in performance of reading sentences or words compared to children with a unilateral epileptiform rolandic focus $(P=0.336$ and $P=0.201$ respectively). Children with an intermittent slow wave focus did not show differences in performance in reading sentences or words compared to the other children $(P=0.177$ and $P=0.310$ respectively).

\section{Intelligence}

Mean Total IQ was 94.5 (SD 12.2), mean Verbal IQ 96.0 (SD 12.2), mean performal IQ 93.7 (SD 13.4). Analysis of the correlation between IQ data and EEG data revealed a correlation between a lower Verbal IQ and a higher index of nocturnal epileptiform activity ( $R=-0.51 P=0.008)$. This correlation was not observed between Performance IQ and nocturnal index $(R=-0.03 P=0.90)$ or between Verbal IQ and the diurnal index ( $\mathrm{R}=-0.13 P=0.52$ ). 


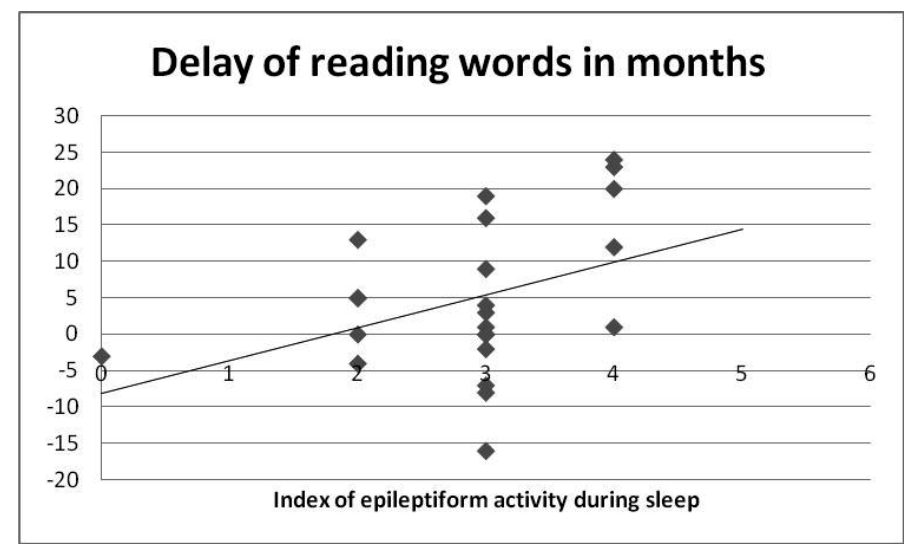

Figure 5.1 Correlation of educational delay (in months) to reading performance (reading words), with amount of nocturnal epileptiform activity as a $\%$ of time: $0=0 \%, 1=<1 \%, 2=1-10 \%, 3=10-50 \%$, 4=50-85\%.

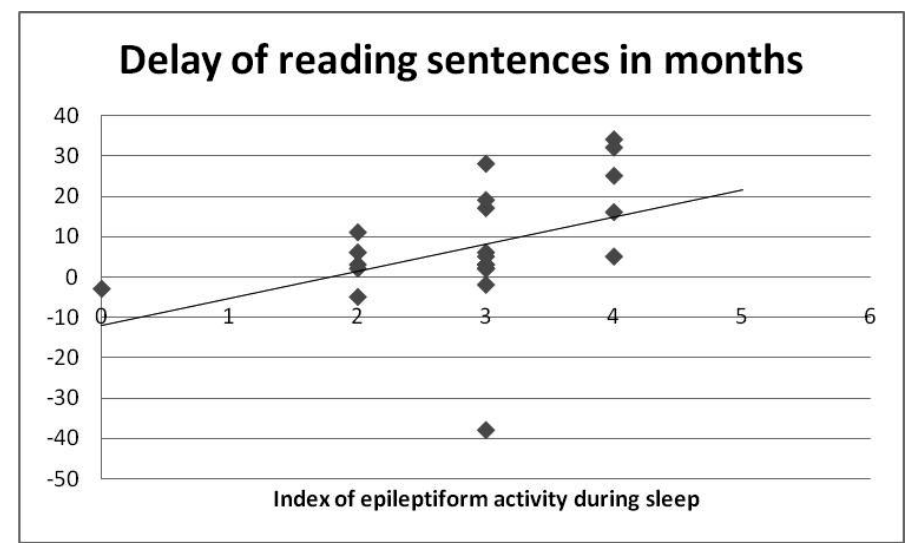

Figure 5.2 Correlation of educational delay (in months) in reading performance (reading sentences), with amount of nocturnal epileptiform activity as a $\%$ of the time: $0=0 \%, 1=<1 \%, 2=1-10 \%, 3=10$ $50 \%, 4=50-85 \%$.

\section{Discussion}

Our findings indicate that the higher the frequency of nocturnal interictal epileptiform activity in children with rolandic epilepsy or rolandic spikes, the more likely those children will have an educational delay in months to reading words and sentences.

We did not find any influence of diurnal epileptiform activity, seizure frequency, epilepsy duration, AED use or AED type on the same reading skills. The correlation was 
of moderate strength. About one third of the variability in reading performance can be explained by the amount of nocturnal epileptiform activity. Furthermore, we observed a negative correlation between Verbal IQ and frequency of nocturnal interictal epileptiform activity. For the group as a whole, this did not result in a lower mean Verbal IQ compared with the mean Performal IQ. Our study group may have been too small to detect such a difference.

A correlation between amount of nocturnal epileptiform activity and language impairment in a larger group has been reported by Overvliet et al. ${ }^{25}$ although this was in a general population of 306 children with epilepsy with an unknown proportion of children with rolandic epilepsy. In their group, mean Verbal IQ was lower than Performance IQ in patients with moderately high nocturnal index (between $1 \%$ and $10 \%$ of the time) compared with patients without nocturnal epileptiform activity. There was no difference in Verbal and Performal IQ in patients with nocturnal index $>10 \%$, probably because of more globally impaired cognition of these children. Indeed, Van Hirtum-Das et al. reported that children with a very high spike-wave index of $>50 \%$ were more likely to have global development impairment than children with a spikewave index $<50 \%$. $^{26}$

In patients in whom seizures have not bee observed but who are diagnosed with developmental language disorders there is a higher chance of finding epileptiform abnormalities in the EEG, suggesting some relationship between these abnormalities and the cognitive impairment. ${ }^{27}$ Duvelleroy-Hommet et al. examined 24 children presenting with expressive developmental dysphasia. They reported that 9 of the 24 patients had nocturnal epileptiform abnormalities in this group, among whom were 2 patients with a very high index in slow-wave sleep (around $20-60 \%$ of the time). The EEG abnormalities are not described in detail but, in some of these cases, may have had the same location and morphology as the spikes seen in benign focal epilepsies, as was the case in the 5 patients without seizures but with frequent rolandic spikes in our series. These patients may present with language problems as the only symptom. ${ }^{28}$

We compared our results with those of other studies examining reading in children with rolandic epilepsy. Northcott et al. also reported significantly lower scores on tests of basic reading and spelling (Wechsler Individual Achievement test) in 42 patients compared with controls. ${ }^{4}$ Ay et al. noted impairment in reading ability (speed and correctness) in 35 patients, compared with controls (among whom there were 7 patients in remission and after discontinuation of treatment). ${ }^{29}$ However, GoldbergStern et al. found no differences between 36 patients and controls on the Kaufmann achievement tests of technical reading (but there were problems in verbal fluency tests) ${ }^{17}$ and Lindgren et al. also did not find differences between 26 patients and controls in reading speed, comprehension and spelling, but did find problems in verbal fluency tests. ${ }^{30}$ The differences found in these studies could relate to the different tests used, but could also result from differences in study population with respect to course of disease or from selection bias (referral centre). 


\section{Cause or epiphenomenon?}

Although the amount of nocturnal EEG abnormalities is correlated to reading problems in our study, this does not prove any causality. The amount of epileptiform activity may only be a marker of the severity of the actual phase of the age-related epilepsy syndrome, being an epiphenomenon reflecting the course of the disease. ${ }^{31}$

The fact that siblings of patients with rolandic epilepsy are also at risk for developing language disturbances ${ }^{5}$, seems to point to a shared genetic disturbance independent from EEG abnormalities. However, there are still arguments that favor at least an additional effect on cognition of awake or nocturnal EEG-abnormalities. For epileptiform activity in wakefulness, it is shown that even a single spike-wave complex can have influence on momentary cognitive performance. ${ }^{32}$ In two children with rolandic epilepsy, during a reading task discriminating between words and pseudowords, a significantly greater proportion of errors was observed was observed when the awake EEG showed momentarily high density of spikes than when the EEG was spike-free. $^{33}$ In children with benign focal epilepsies of childhood examined by EEG$\mathrm{fMRI}$, remote frontal brain areas are functionally disturbed during the occurrence of rolandic spikes. ${ }^{34}$ As rolandic epilepsy is considered to be part of a spectrum ranging from age-related epilepsy syndromes with ESES, such as Landau Kleffner syndrome and atypical benign partial epilepsy of childhood on the severe and, and Rolandic epilepsy on the mild end, findings in children with these diagnoses are relevant to discuss. In children with these syndromes with ESES, large changes in metabolism not only at the site of the epileptiform activity but with inhibition at a distance were shown with PET in the acute phase of the disease. In the recovery phase (with cessation of or marked decrease in nocturnal epileptiform activity) there is major improvement or normalization of the disturbances. ${ }^{35}$ Highly frequent repetitive spikes in the nocturnal EEGs within this spectrum of diseases (including children with rolandic epilepsy), may disturb the functioning of neural networks as long as the spikes occur, and this may hypothetically cause the networks not to develop.

\section{Cognitive improvement and correlation to reduction of electroencephalographic-abnormalities}

A reduction in epileptiform activity could correlate to the improvement of cognitive skills within a certain period. The possibility of full recovery as well as the time course may be related to the duration and extent (frequency and location) of the EEG abnormalities. Soprano et al. performed a long-term follow-up study in 12 children with Landau-Kleffner syndrome. Nine of the 12 children experienced complete normalization of the EEG, and in only 3 of the 9 did language function finally normalize. The mean follow-up duration was 8 years. The time between normalization of the EEG and normalization of language functions in the individual patients was not mentioned. The authors concluded that normalization of the EEG was necessary for total language recovery; however, it is not the only predictive factor. ${ }^{2}$ Stephani and Carlsson ${ }^{36}$ did not 
find a correlation between severity of EEG changes and IQ changes in 36 children (15 of whom presented with language delay) with rolandic epilepsy, who were repeatedly examined for periods between 2.5 to 10 years. There also was no significant difference in neuropsychological development between patients who started with severely abnormal EEGs and patients who started with with fewer EEG abnormalities. ${ }^{36}$ Kossoff et al. performed a pilot study in 6 children with rolandic epilepsy who were switched to treatment with levetiracetam. In 5 of 6 children who manifested rolandic epilepsy and nocturnal epileptiform activity during treatment of carbamazepine or oxcarbamazepine, the switch to levetiracetam resulted in improvement of the EEG 6 months later, with complete normalization in 3 patients. All children experienced a subjective improvement in reading and writing. Objectively only trends toward improvement were seen in auditory comprehension and memory. It is possible that a treatment period longer than 6 months is necessary to obtain significant improvements; however, this was a small study population. ${ }^{37}$ There are no large prospective studies on language performance and treatment of interictal epileptiform activity in children with rolandic epilepsy or in children with developmental language disorders and frequent (rolandic) spikes without observed seizures. In addition, AEDs could aggravate cognitive abilities even in the language domain; this is a well-known side effect of topiramate. ${ }^{38}$ It is worth mentioning that one study ${ }^{39}$ reported worsened articulation in 11 children with rolandic epilepsy, treated with carbamazepine. They stated that children receiving this drug should be monitored for language problems. However, carbamazepine may increase epileptic activity in patients with rolandic epilepsy $^{40}$, so that it may be argued it was this effect that was manifested in this study. In the current study we did not see differences in reading performance in the (small group of) children on CBZ.

When treating patients with rolandic epilepsy and/or rolandic spikes and cognitive problems, we do not know if it is better to wait for spontaneous recovery or to treat the EEG. A recent study addressed this question. Verroti et al. tested 26 children with rolandic epilepsy at 1 year from onset and at 2 years after remission (at least 8 months from AED withdrawal). ${ }^{41}$ Each had had a unilaterally or bilaterally independent rolandic epileptiform EEG-focus that increased in sleep; patients with multiple foci or background abnormalities (slow wave foci) were excluded. Ten children with low seizure frequency were not treated with AEDs, 16 children were treated, resulting in seizure freedom. Both groups showed receptive, naming and word-retrieval problems compared to controls at 1 year from onset. Verbal IQ and Performance IQ did not change. All children experienced complete remission from the cognitive problems 2 years after remission from seizures. This study indicates that in patients without decreased IQ and without multiple EEG foci or background abnormalities, anti-epileptic treatment does not change the prognosis of the spontaneously reversible language problems. 


\section{Conclusions}

Reading performance is impaired in children with rolandic epilepsy. The larger the amount of nocturnal epileptiform activity, the more likely the reading skills will be impaired in these children. Reading sentences is more impaired than reading words. To date, we have no definite proof that children with rolandic spikes and educational delay in language performance, should be treated with antiepileptic drugs to reduce interictal nocturnal epileptiform activity and, consequently improve language performance. 


\section{References}

1. Maquet P, Hirsch E, Metz-Lutz MN, Motte J, Dive D, Marescaux C, Franck G. Regional cerebral glucose metabolism in children with deterioration of one or more cognitive functions and continuous spikeand-wave discharges during sleep. Brain 1995;118:1497-520.

2. Soprano AM, Garcia EF, Caraballo R, Fejerman N. Acquired epileptic aphasia: neuropsychologic followup of 12 patients. Pediatr Neurology 1994;11:230-5.

3. Papavasiliou A, Mattheou D, Bazigou H, Kotsalis C, Paraskevoulakos E. Written language skills in children with benign childhood epilepsy with centrotemporal spikes. Epilepsy \& Behavior 2005;6:50-8.

4. Northcott E, Connolly AM, Berroya A, Mclntyre J, Christie J, Taylor A, Bleasel AF, Lawson JA, Bye AM. Memory and phonological awareness in children with Benign Rolandic Epilepsy compared to a matched control group. Epilepsy Research 2007;75:57-62.

5. Clarke T, Strug L, Murphy PL, Bali B, Carvalho J, Foster S, Tremont G, Gagnon BR, Dorta N, Pal DK. High risk of reading disability and speech sound disorder in rolandic epilepsy families: case-control study. Epilepsia 2007; 48:2258-65.

6. Nicolai J, Aldenkamp AP, Arends J, Weber JW, Vles JSH. Cognitive and behavioral effects of nocturnal epileptiform discharges in children with benign childhood epilepsy with centrotemporal spikes. Epilepsy Behavior 2006;8:56-70.

7. Echenne B, Cheminal R, Rivier F, Negre C, Touchon J, Billiard M. Epileptic electroencephalographic abnormalities and developmental dysphasias: a study of 32 patients. Brain Dev 1992;14:216-25.

8. Overvliet GM, Besseling RM, Vles JS, Hofman PA, Backes WH, van Hall MH, Klinkenberg S, Hendriksen J, Aldenkamp AP. Nocturnal epileptiform EEG discharges, nocturnal epileptic seizures, and language impairments in children: Review of the literature. Epilepsy Behav 2010;19:550-8.

9. Landau WM, Kleffner FR. Syndrome of acquired aphasia with convulsive disorder in children. Neurology 1957; 7:523-30.

10. Berroya AM, Bleasel AF, Stevermuer TL, Lawson J, Bye AM. Spike morphology, location, and frequency in benign epilepsy with centrotemporal spikes. J Child Neurol 2005;20:188-94.

11. Lerman P. Benign partial epilepsy with centrotemporal spikes. In: Roger J, Bureau M, Dravet C, editors. Epileptic syndromes in infancy. London: John Liggey Eurotext; 1992.

12. Panayiotopoulos CP, Michael M, Sanders S, Valeta T, Koutroumanidis M. Benign childhood focal epilepsies: assessment of established and newly recognized syndromes. Brain 2008;131:2264-86.

13. Deltour L, Querné L, Vernier-Hauvette MP, Berquin P. Deficit of endogenous spatial orienting of attention in children with benign epilepsy with centrotemporal spikes (BECTS). Epilepsy Res 2008;79: $112-9$.

14. Kavros PM, Clarke T, Strug LJ, Halperin JM, Dorta NJ, Pal DK. Attention impairment in rolandic epilepsy: systematic review. Epilepsia 2008;49:1570-80.

15. Weglage J, Demsky A, Pietsch M, Kurlemann G. Neuropsychological, intellectual, and behavioral findings in patients with centrotemporal spikes with and without seizures. Dev Med Child Neurol 1997;39:646-51.

16. Chaix Y, Laguitton V, Lauwers-Cancès V, Daquin G, Cancès C, Démonet JF, Villeneuve N. Reading abilities and cognitive functions of children with epilepsy: influence of epileptic syndrome. Brain Development 2006;28:122-30.

17. Goldberg-Stern H, Gonen OM, Sadeh M, Kivity S, Shuper A, Inbar D. Neuropsychological aspects of benign childhood epilepsy with centrotemporal spikes. Seizure 2010;19:12-6.

18. Völkl-Kernstock S, Bauch-Prater S, Ponocny-Seliger E, Feucht M. Speech and school performance in children with benign partial epilepsy with centro-temporal spikes (BCECTS). Seizure 2009;18:320-6.

19. Danielsson J, Petermann F. Cognitive deficits in children with benign rolandic epilepsy of childhood or rolandic discharges: A study of children between 4 and 7 years of age with and without seizures compared with healthy controls. Epilepsy \& Behavior 2009;16:646-51.

20. Lundberg S, Frylmark A, Eeg-Olofsson O. Children with rolandic epilepsy have abnormalities of oromotor and dichotic listening performance. Dev Med Child Neurol 2005;47:603-8.

21. Nicolai J, van der Linden I, Arends JB, van Mil SG, Weber JW, Vles JS, Aldenkamp AP. EEG characteristics related to educational impairments in children with benign childhood epilepsy with centrotemporal spikes. Epilepsia 2007;48:2093-100. 
22. Massa R, de Saint-Martin A, Carcangiu R, Rudolf G, Seegmuller C, Kleitz C, Metz-Lutz MN, Hirsch E, Marescaux C. EEG criteria predictive of complicated evolution in idiopathic rolandic epilepsy. Neurology 2001;57:1071-9.

23. de vos T. Tempo-Test-Lezen (zinnen). 2nd ed. Lisse: Swets \&Zeitlinger BV; 2000.

24. de vos T. Tempo-Test-Lezen (woorden). 2nd ed. Lisse: Swets \& Zeitlinger; 2002.

25. Overvliet GM, Besseling RMH, Vles JSH, Hofman PA, Van Hall MH, Backes WH, Aldenkamp AP. Association between frequency of nocturnal epilepy and language disturbance in children. Pediatr Neurol 2011;44:333-9.

26. van Hirtum-Das M, Licht EA, Koh S, Wu JY, Shields WD, Sankar R. Children with ESES: variability in the syndrome. Epilepsy Research 2006;70:S248-58.

27. Neuschlová L, Sterbová K, Zácková J, Komárek V. Epileptiform activity in children with developmental dysphasia: quantification of discharges in overnight sleep video-EEG. Epileptic Disord 2007;9:S28-35.

28. Duvelleroy-Hommet C, Billard C, Lucas B, Gillet P, Barthez MA, Santini JJ, Degiovanni E, Henry F, De Toffol B, Autret A. Sleep EEG and developmental dysphasia: lack of a consistent relationship with paroxysmal EEG activity during sleep. Neuropediatrics 1995;26:14-8.

29. Ay Y, Gokben S, Serdaroglu G, Polat M, Tosun A, Tekgul H, Solak U, Kesikci H. Neuropsychologic impairment in children with rolandic epilepsy. Pediatr Neurology 2009;41:359-63.

30. Lindgren S, Kihlgren M, Melin L, Croona C, Lundberg S, Eeg-Olofsson O. Development of cognitive functions in children with rolandic epilepsy. Epilepsy Behav 2004;5:903-10.

31. Overvliet GM, Aldenkamp AP, Klinkenberg S, Vles JSH, Hendriksen J. Impaired language performance as a precursor or consequence of Rolandic epilepsy? J Neurol Sci 2011;304:71-4.

32. Shewmon DA, Erwin RJ. The effect of focal interictal spikes on perception and reaction time. I. General considerations. Electroencephalogr Clin Neurophysiol 1988;69:319-37.

33. Fonseca LC, Tedrus GM, Pacheco EM. Epileptiform EEG discharges in benign childhood epilepsy with centrotemporal spikes: reactivity and transitory cognitive impairment. Epilepsy Behavior 2007;11: 65-70.

34. Lengler U, Kafadar I, Neubauer BA, Krakow K. fMRI correlates of interictal epileptic activity in patients with idiopathic benign focal epilepsy of childhood. A simultaneous EEG-functional MRI study. Epilepsy Res 2007;75:29-38.

35. De Tiège X, Ligot N, Goldman S, Poznanski N, de Saint Martin A, Van Bogaert P. Metabolic evidence for remote inhibition in epilepsies with continuous spike-waves during sleep. Neuroimage 2008;40.

36. Stephani U, Carlsson G. The spectrum from BCECTS to LKS: The Rolandic EEG trait-impact on cognition. Epilepsia 2006;47:67-70.

37. Kossoff EH, Los JG, Boatman DF. A pilot study transitioning children onto levetiracetam monotherapy to improve language dysfunction associated with benign rolandic epilepsy. Epilepsy Behav 2007;11:514-7.

38. Fritz N, Glogau S, Hoffmann J, Rademacher M, Elger CE, Helmstaedter C. Efficacy and cognitive side effects of tiagabine and topiramate in patients with epilepsy. Epilepsy Behav 2005;6:373-81.

39. Park JI, Kim SJ, Kim HG. Acoustic effects of carbamazepine in benign rolandic epilepsy. Epilepsy Behav 2005;7:468-71.

40. Kochen S, Giagante B, Oddo S. Spike-and-wave complexes and seizure exacerbation caused by carbamazepine. Eur J Neurology 2002;9:41-7.

41. Verrotti A, Agostinelli S, Olivieri C, Chiarelli F, Curatolo P. Early-onset pure absence epilepsy: a distinct epileptic syndrome. Acta Paediatr 2011. 


\section{Chapter 6}

Changes in the frequency of benign focal spikes accompany changes in central information processing speed: A prospective 2-year follow-up study

S.C.M. Ebus, D.M. Ijff, J.T. den Boer, M.J.H. van Hall, S. Klinkenberg, A. van der Does, P.A.J.M. Boon, J.B.A.M. Arends, A.P. Aldenkamp Epilepsy \& Behavior 2015;43:8-15 


\section{Summary}

We prospectively examined whether changes in the frequency of benign focal spikes accompany changes in cognition. Twenty-six children with benign focal spikes (19 with Rolandic epilepsy) and learning difficulties were examined with repeated 24-hour EEG recordings, three cognitive tests on central information processing speed (CIPS) and questionnaires on cognition and behavior at baseline, 6 months and 2 years. Antiepileptic drug changes were allowed when estimated necessary by the treating physician. At baseline, a lower CIPS was correlated with a higher frequency of diurnal interictal epileptiform discharges (IEDs) and with worse academic achievement. At follow-up, there was a significant correlation between changes in CIPS and EEG changes in wakefulness (in the same direction) when the EEG-outcome was dichotomized in IED frequency "increased" or "not increased".

Behavioral problems were more often observed in patients with higher frequency of IEDs in sleep at baseline and in those with ongoing IEDs compared with those with EEG remission (without or with sporadic IEDs in the recording) at the end of the study period. No changes were observed in the results of the questionnaires. A lower diurnal IED frequency at baseline, lack of serial IEDs, and occurrence of only unilateral IEDs were correlated with a higher chance of EEG remission at 2-years follow-up. Electroencephalography remission could not be predicted from other epilepsy variables except from seizure freedom in the last six months. Our results confirm the nonbenign character of 'benign' focal spikes. Whether an early and stable EEG-remission can be achieved through antiepileptic treatment and whether this is of benefit for cognitive development should be examined in prospective placebo-controlled randomized trials. 


\section{Introduction}

In children with benign focal epilepsies, highly frequent epileptiform discharges (IEDs), the so called "benign focal spikes", are observed, in contrast with infrequent seizures. The same EEG features are also seen in children without seizures. ${ }^{1,2}$ Because of reports on cognitive and behavioral problems in relationship to the frequency of IEDs in children with Rolandic epilepsy ${ }^{3-6}$ there is an ongoing discussion regarding the significance of the frequency of benign focal spikes on cognition and behavior for an individual child.

In Rolandic epilepsy (RE) the IED frequency first increases. An increasing number of IED foci may be observed as well. When the child grows older a decreasing frequency is seen until the EEG has completely normalized, which will definitely occur when the child reaches prepuberty. ${ }^{7,8}$ The IED frequency is reflective of the course of the disease activity in combination with changes in brain maturation. It might be a better marker for the disease activity than seizure counts, since seizures are scarce, may be underreported because of nocturnal occurrence or may be suppressed by antiepileptic drugs.

Besides a phenomenon reflecting the disease course, it has been proposed that IEDs might contribute to the cognitive impairment in some of the children. The IEDs may affect cognition acutely but also (additionally) on a more chronic base. IEDs in wakefulness in RE have been associated with acute impairment of cognition, but the evidence is scarce. Fonseca ${ }^{9}$ observed a significantly higher proportion of errors on a task of discriminating words and pseudowords when spikes occurred between stimulus and response in two patients. The chronic influence of the abundant IEDs on cerebral networks is more often hypothesized as explanation for the cognitive difficulties. A specific vulnerability to IEDs could exist in sleep. Sleep could be important for learning and memory through strengthening of the cerebral network organization. ${ }^{10-12}$ Because of the nocturnal increase of IEDs, a relationship of RE with syndromes with ESES (electrical status epilepticus in slow-wave sleep) is suggested. ${ }^{13,14}$

Until now, mostly cross-sectional designs have been published, showing correlations between cognitive impairments and a higher IED frequency at one moment in time. ${ }^{3-6}$ Also, a correlation between cognitive impairment and background changes (independent of IED characteristics) was published in a cross-sectional design. ${ }^{15}$ In this study we investigated the relationships between EEG and cognition/behavior prospectively. We restricted the EEG analysis to changes in IED frequency. If a decrease of IED frequency was shown to be accompanied by cognitive improvement, this would support the development of controlled intervention trials with cognition and IED frequency as primary outcome measures.

Since our hospital is a tertiary epilepsy center, we included a group of highly affected children who were "at the top of the hill" of their disease course, at the moment of experiencing cognitive complaints in combination with an abnormal EEG and sometimes with refractory seizures as well. To examine cognition, we chose tests that 
we regard as most "fluid": most prone to quick change, mainly investigating central information processing speed and in our opinion the best candidates to show shortterm changes in cognition together with IED changes.

\section{Method}

The study was approved by the local ethics committee and all caregivers gave informed consent.

\section{Inclusion criteria}

Twenty-six patients were prospectively included between 2009 and 2012. In our center it is a standard procedure to perform a 24-hour ambulatory EEG when children are referred because of learning difficulties and epilepsy or due to learning difficulties and interictal epileptiform discharges (IEDs) in an earlier EEG. We included children with learning difficulties from this group if the 24-hour EEG showed IEDs with the characteristics of IEDs seen in benign focal epilepsies. ${ }^{16,17}$ Clinical criteria were as follows: $I Q>60$, normal $M R I$ and seizure semiology characteristic of a benign focal epilepsy $^{18, a}$ or no observed seizures.

\section{Clinical follow-up method}

Seizure frequency in the year before inclusion was estimated from an interview with the caregivers at inclusion. From inclusion until 2 years of follow-up caregivers counted seizures prospectively in a diary. Antiepileptic drug changes were allowed when deemed necessary by the treating physician. A dosage increase of at least $25 \%$ or starting/adding an AED was considered as reinforcement of the treatment. Seizure changes were determined comparing each period of 6 months with the previous 6 months (or with the retrospective baseline) and categorized as follows: remaining seizure-free, became seizure-free, with $>50 \%$ seizure reduction, with stable seizure frequency, and with $>50 \%$ seizure frequency increase.

\footnotetext{
${ }^{a}$ Criteria leading to classification of Rolandic epilepsy: focal motor seizures in the sensorimotor facial area and/or hemiclonic or bilateral clonic seizures and EEG with at least a centrotemporal IED focus, other additional focus localizations were allowed. Criteria for Panayiotopoulos syndrome: At least 1 prolonged seizure with the autonomic feature of vomiting/retching or at least 1 prolonged seizure with hypotonia and nonresponsiveness. Additional seizures with eye deviation, visual symptoms or motor seizures (hemiclonic/ bilateral clonic) were allowed. All focus localizations were allowed.
} 


\section{EEG follow-up method}

A 24-hour EEG was repeated at 6 months and at 2 years. Electroencephalograms were recorded with the standard 10-20 electrode positions. From each EEG, 30 random 10-second EEG-pages were collected from a period of 4 continuous hours from the EEG in wakefulness and from the first hour of sleep. To obtain a continuous variable for baseline description/analysis, one viewer (S.E.) counted all seconds containing IEDs in these 30 pages, allowing to calculate the \% of IEDs: (number of seconds containing IEDs/ $300 \mathrm{~s}) * 100$. Because manual IED counts are time-consuming and because a continuous variable does not allow the calculation of significant differences between individual patients, the same pages at baseline and the sets of 30 pages from both follow-up EEGs were scored in four categories by a second viewer (J.B. $)^{b}$. Each page was visually categorized as follows: (1) containing no epileptic activity, (2) $\geq 10-50 \%$ of the time, (3) IEDs $\geq 50-80 \%$ of the time or (4) IEDs $\geq 80 \%$ of the time. Each second containing 1 or more spike(wave)s was counted as $1 \mathrm{~s}(10 \%)$ of epileptic activity. Intraindividual changes between two sets of 30 category scores from successive EEGs were statistically confirmed by a Mann-Whitney $U$ test for repeated measures (alpha $<0.05$, two-sided).

EEG improvement/ worsening was defined as: statistically significant less /more IEDs between two sets of 30 scores for a serial EEG of a patient in wakefulness as well as in sleep. We decided that the EEG in wakefulness and in sleep should be both changed to have a reliable outcome on changes (or if without or with sporadic IEDs in wakefulness and non sporadic IEDs in sleep: an unchanged or normalized EEG in wakefulness was required at follow-up together with improvement in sleep for the classification of EEG improvement).

EEG remission was defined as follows: no IEDs or sporadic IEDs ( $\leq 3$ pages containing an IED within the set of 30 EEG-pages) in wakefulness and sleep.

Furthermore we determined the number or IED foci, unilateral or bilateral occurrence, and presence of $\geq 6$ s of serial spike-waves.

\section{Cognition/behavior}

\section{Cognitive tests}

If there was no recent information available about the intelligence level, the Dutch version of the Wechsler Intelligence Scale for Children - third version was used to measure the intellectual ability of children between the ages of 6 and 16 years at baseline. ${ }^{19}$ For two young children, the Dutch version of the Wechsler Preschool and Primary Scale of Intelligence third version was used. ${ }^{20}$ At baseline, 6-month follow-up and 2-year follow-up (on the day of the EEG registration), the following central information speed processing tests were used:

\footnotetext{
${ }^{b}$ Correlation of the baseline results from the two methods used by viewers S.E. and J.B.: IEDs wakefulness Spearman's $R=0.96 p<0.001$; IEDs sleep $R=0.97 P<0.001$
} 
- $\quad$ The index Processing Speed from the Wechsler Intelligence Scale.

- The binary choice reaction time measurement, which is a reaction time test with a decision component. ${ }^{21}$ The patient has to react differentially to a red square on the left side of the screen and to a green square on the right side of the screen. The reaction time reflects not only the motor speed, but also the decision-making process.

- The computerized visual searching task is adapted from Goldstein's visual searching task. ${ }^{21} \mathrm{~A}$ central grid pattern has to be compared with 24 surrounding patterns. Only one of them is identical to the target pattern. The test consists of 24 trails and gives an indication of the information processing speed and perceptual mental strategies. Reaction time, as well as the total number of errors the patients make is recorded. This task is particularly sensitive to (diurnal) cognitive effects of epileptiform EEG discharges. ${ }^{22,23}$ Of each test, a Z-score was calculated and an average Z-score of the 3 cognitive tests at baseline was computed and compared with the average $z$-score at the follow-ups. For individual patients a difference $\geq 0.5$ between the both the average Z-scores was considered to be clinically relevant. This is a generally accepted effect size in research with neuropsychological data. ${ }^{24}$

\section{QOLCE Questionnaire}

Caregivers answered a questionnaire on quality of life in childhood epilepsy (QOLCE) ${ }^{25}$ at baseline, 6 months and 2 years, which was translated (with permission) from English into Dutch to be used for this study. We did not validate the questionnaire for the use in the Dutch language. We used the four items on cognition and one item on behavior (Table 6.1). A lower QOLCE score means more problems in the domain.

\section{Category scores on academic achievement and behavior}

At baseline and at the end of the study a category score for academic underachievement as well as for behavioral problems was assigned from an interview with caregivers. This method was originally described by Massa et al. ${ }^{26}$ to examine patients for a complicated evolution of Rolandic epilepsy. It addresses the consequences of the cognitive and behavioral difficulties such as the need of special education or pharmacological or psychological treatment for behavioral problems (Table 6.1).

\section{Data analysis}

For the statistical methods to define EEG change and cognitive change in individual patients, see above. For differences between groups we applied Mann-Whitney $U$ tests or the Wilcoxon signed-rank test. For $2 \times 2$ correlation matrices we used Pearson's chisquare; for other correlation analyses, we used Spearman's rank correlation coefficient. For the correlation analysis of QOLCE items with the IED \% in wakefulness or in sleep at 
baseline (correlation matrix $5 \times 2$ ) we applied a Bonferroni correction with the new condition for significance alpha $<0.005$. We did not apply this correction for smaller correlation matrices. For multiple regressions, we used a linear approach and a backward stepwise procedure. All analyses were performed with SPSS version 21.

Table 6.1 Variables and study design.

\begin{tabular}{|c|c|c|c|c|c|c|}
\hline Variables & \multicolumn{3}{|c|}{ Information on variables } & $\begin{array}{l}\text { Base } \\
\text { line }\end{array}$ & $\begin{array}{c}6 \\
\text { months }\end{array}$ & $\begin{array}{c}24 \\
\text { months }\end{array}$ \\
\hline 24-hour EEG & \multicolumn{3}{|c|}{$\begin{array}{l}\text { Frequency of interictal epileptic activity wakefulness } \\
\text { Frequency of interictal epileptic activity sleep }\end{array}$} & $x$ & $\mathrm{x}$ & $x$ \\
\hline $\begin{array}{l}\text { Tests central } \\
\text { information } \\
\text { processing speed }\end{array}$ & \multicolumn{2}{|c|}{$\begin{array}{l}\text { Processing speed } \\
\text { Binary choice reaction time } \\
\text { Computerized visual } \\
\text { searching task }\end{array}$} & Mean Z-score & $x$ & $x$ & $x$ \\
\hline $\begin{array}{l}\text { QOLCE questionnaire } \\
\text { items on cognition } \\
\text { and behavior }\end{array}$ & $\begin{array}{l}\text { Items } \\
\text { Attent } \\
\text { Memo } \\
\text { Langu } \\
\text { Other } \\
\text { Behav }\end{array}$ & $\begin{array}{l}\text { on/concentration } \\
\text { ge } \\
\text { ognitive } \\
\text { or }\end{array}$ & $\begin{array}{l}\text { Number of questions }{ }^{1} \text { on } \\
\text { the subject } \\
5 \\
6 \\
8 \\
3 \\
15\end{array}$ & $x$ & $x$ & $x$ \\
\hline $\begin{array}{l}\text { Category scores on } \\
\text { academic } \\
\text { underachievement } \\
\text { and behavioral } \\
\text { problems }\end{array}$ & $\begin{array}{l}\text { Score } \\
0 \\
1\end{array}$ & $\begin{array}{l}\text { Academic } \\
\text { underachievement } \\
\text { Absent } \\
\text { Mild } \\
\text { (reported by } \\
\text { teachers but allowing } \\
\text { normal schooling) } \\
\text { Moderate } \\
\text { (requiring } \\
\text { individualized help) }\end{array}$ & $\begin{array}{l}\text { Behavioral } \\
\text { problems } \\
\text { Absent } \\
\text { Mild } \\
\text { (reported by parents but } \\
\text { causing minor harm to } \\
\text { others) } \\
\text { Moderate } \\
\text { (requiring } \\
\text { psychotherapeutic or } \\
\text { pharmacologic } \\
\text { interventions) } \\
\text { Severe } \\
\text { (provoking major } \\
\text { difficulties despite } \\
\text { adequate management). }\end{array}$ & $x$ & - & $x$ \\
\hline
\end{tabular}

\footnotetext{
${ }^{1}$ The answer to each question is given on a 5-point scale with increasing abnormality/problems. Maximum score (means no abnormalities) for each item $=100 .{ }^{2}$ Reasoning/solving problems, making plans/decisions, reacting slowly to things being said and done.
} 


\section{Results}

\section{Baseline data}

\section{Descriptive characteristics}

Twenty-six children (16 girls and 10 boys) were included (see Table 6.2). Nineteen of the 26 patients had Rolandic epilepsy (RE). Three patients with RE stopped after the follow-up EEG at 6 months, because of the burden of the study protocol.

Seizure frequency was not correlated with IED frequency.

Nocturnal IED frequency was correlated to diurnal IED frequency $(R=0.42, P=0.03)$.

\section{Cognitive tests and epilepsy variables}

Figure 6.1 shows the correlation between a higher diurnal IED frequency and a lower average Z-score reflecting central information processing speed $\left(R=-0.53, R^{2}=0.28\right.$, $P=0.006$ ). After removing the patient with the highest diurnal IED index (a patient with RE and multifocal bilateral centrotemporal and occipital IED foci), this correlation was still significant $(R=-0.47, P=0.02)$. Regression analysis (with 6 independent variables diurnal IED frequency, nocturnal IED frequency, epilepsy duration, seizure frequency, age at onset, and number of AEDs) revealed that 5 of these epilepsy variables in combination significantly contributed to the variability of the average Z-score $\left(R^{2}=0.50\right.$ $P=0.05)$ : diurnal IED frequency, nocturnal IED frequency, epilepsy duration, age at onset and a higher AED load. The combined variables number of AEDs (Beta -.411) and diurnal IED frequency (beta -.387) had the largest contribution $\left(R^{2}=0.46, P=0.004\right)$.

\section{Questionnaires and epilepsy variables}

We observed a correlation between a lower score on the QOLCE item behavior and a higher nocturnal IED frequency at baseline $(R=-0.77 \quad P<0.001)$. There were no correlations between cognitive QOLCE items and IED frequency.

A higher (more difficulties) category score on academic achievement was correlated with a higher diurnal IED frequency $(R=0.43 P=0.03)$. 
Table 6.2 Baseline characteristics.

\begin{tabular}{|c|c|c|c|}
\hline Age & \multicolumn{3}{|l|}{ Mean: 8.9 years (range: $5.9-12.3$ ) } \\
\hline Age at onset (first seizure) & \multicolumn{3}{|l|}{ Mean: 6.1 years (range: $2.5-10.8$ ) } \\
\hline Epilepsy duration & \multicolumn{3}{|l|}{ Mean: 2.7 years (range 4 months- 6.9 years) } \\
\hline \multirow[t]{5}{*}{ Syndromal diagnosis } & Rolandic epilepsy & \multicolumn{2}{|l|}{19} \\
\hline & Panayiotopoulos syndrome & \multicolumn{2}{|l|}{2} \\
\hline & Unclassified benign focal epilepsy ${ }^{1}$ & \multicolumn{2}{|l|}{1} \\
\hline & No observed seizures (multifocal IEDs ${ }^{2}$ ) & \multicolumn{2}{|l|}{3} \\
\hline & No observed seizures (1 IED focus) & \multicolumn{2}{|l|}{1} \\
\hline Seizure frequency & Never had observed seizures & \multicolumn{2}{|l|}{$4 / 4$} \\
\hline Last year/half year before & Seizure- free & \multicolumn{2}{|l|}{$2 / 8$} \\
\hline \multirow[t]{4}{*}{ inclusion } & Only 1 seizure & \multicolumn{2}{|l|}{$5 / 1$} \\
\hline & Several seizures but less than monthly & \multicolumn{2}{|l|}{$6 / 4$} \\
\hline & Monthly & \multicolumn{2}{|l|}{$6 / 6$} \\
\hline & Weekly & \multicolumn{2}{|l|}{$3 / 3$} \\
\hline \multirow[t]{4}{*}{ Number of AEDs } & 0 & \multicolumn{2}{|l|}{11} \\
\hline & 1 & \multicolumn{2}{|l|}{11} \\
\hline & 2 & \multicolumn{2}{|l|}{3} \\
\hline & 3 & \multicolumn{2}{|l|}{1} \\
\hline \multirow[t]{3}{*}{ IQ } & TIQ (Mean, SD, range) & \multicolumn{2}{|c|}{$91.8(16.7,68-142)$} \\
\hline & VIQ (Mean, SD, range) & \multicolumn{2}{|c|}{$93(16.6,62-142)$} \\
\hline & PIQ (Mean, SD, range) & \multicolumn{2}{|c|}{$93(13.7,71-128)$} \\
\hline Mean score & Cognition other & \multicolumn{2}{|c|}{35 (range: 0-67) } \\
\hline \multirow[t]{4}{*}{ QOLCE items } & Attention/concentration & \multicolumn{2}{|c|}{38 (range: $10-88$ ) } \\
\hline & Language & \multicolumn{2}{|c|}{51 (range 9-100) } \\
\hline & Memory & 60 (range: 17 & \\
\hline & Behavior & 62 (range: 48 & \\
\hline Category score & Academic achievement & No problems & 4 \\
\hline & (number of patients) & Mild & 5 \\
\hline & & Moderate & 9 \\
\hline & & Severe & 8 \\
\hline & Behavior (number of patients) & No problems & 13 \\
\hline & & Mild & 12 \\
\hline & & Moderate & 1 \\
\hline & & Severe & 0 \\
\hline $\begin{array}{l}\text { Mean Z-score of } 3 \text { tests on } \\
\text { central information speed }\end{array}$ & Mean: 0.15 (SD: 1.0) & & \\
\hline Mean \% epileptiform activity & Wakefulness & $14 \%$ (SD: $15 \%$ & : $0-55 \%)$ \\
\hline & Sleep & $57 \%$ (SD: 19 & : $29-93 \%)$ \\
\hline
\end{tabular}

${ }^{1}$ Occipital IED localization with typical characteristics of benign focal epilepsy and sporadic nocturnal bilateral clonic seizures. Not fulfilling the criteria for Rolandic epilepsy (no Rolandic type EEG) or Panayiotopoulos syndrome (no typical Panayiotopoulos seizure semiology). ${ }^{2}$ All three patients had least 2 foci, including 1 centrotemporal (Rolandic) focus. 


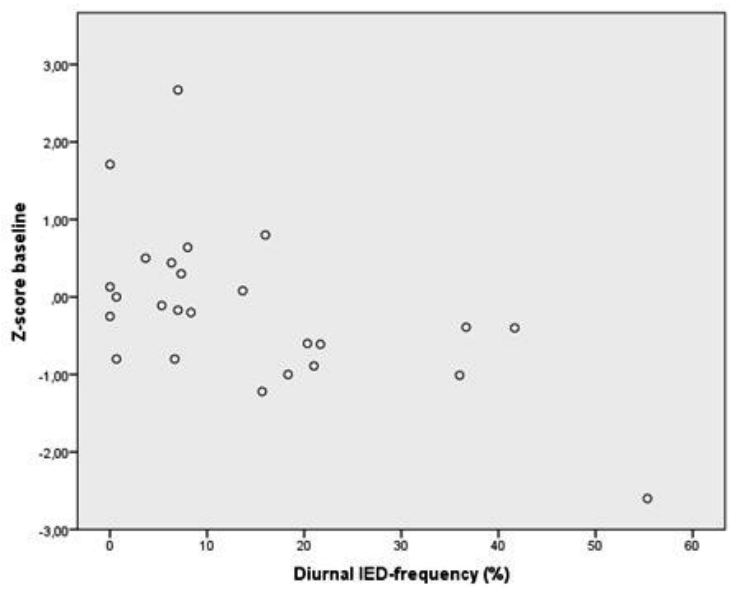

Figure 6.1 Diurnal IED frequency correlated with the average Z-score of 3 tests on information processing speed, $\mathrm{R}=-0.53 \quad P=0.006)$.

\section{Follow-up data}

\section{EEG and seizures}

As expected in the follow-up of EEGs with benign focal spikes, we observed a growing proportion of EEGs with improvement during the study period. At 6 months 7/26 patients had EEG-improvement (2 of them showed EEG-remission). At 2 years, compared with baseline in 12/23 patients, EEG improvement was observed of whom 8 had EEG remission ( 7 had RE and1 had IEDs without seizures). Combining the age at seizure onset and the moment of registration of EEG remission, we observe that, in the 7 patients with RE, EEG remission was achieved between a period of mean 3.2 years (range 0.8-7.0 years) and 4.5 years (range: 2.3 years -7.4 years) after the first observed seizure (taking into account that the moment of EEG-remission is not exactly known and could have taken place somewhere between two EEGs.

At 2-year follow-up, 19 patients with observed seizures were on protocol. The 7 patients (all had RE) with EEG-remission at 2 years were seizure-free in the last 6 months of the study compared with 7 of the 12 patients without EEG remission at 2 years (Pearson Chi-square $P=0.05$; patients with $R E 7 / 7$ vs. $4 / 9 P=0.02$ ). None of the 5 patients with ongoing seizures in the last 6 months (all had RE) had EEG remission at the end of the study. We did not find correlations between the direction of seizure changes (improvement or worsening) and the same direction of IED changes. The use of AEDs or not during the study period was not correlated with EEG improvement or remission. Electroencephalography improvement or EEG remission was not related to AED reinforcements before the registration of the EEG. 


\section{Cognition/behavioral changes and EEG changes}

The mean average Z-scores, QOLCE item scores, and category scores on academic achievement and behavior did not change during the study period. Mean QOLCE item scores did not differ between patients with EEG remission or EEG improvement at two years and the other patients. EEG remission was correlated with a lower (=less problems) category score on behavior ( $R=-0.46 P=0.03)$.

In Figure 6.2, changes in the average Z-scores are presented within the three subgroups of patients with either EEG worsening, EEG improvement, or EEG stability. At an individual level, we observed the following relationships between the directions of changes in the EEGs and average Z-scores. Cognitive improvement in central information processing speed between two EEGs was never observed in patients with worsening of the second EEG. None of the patients with EEG remission at the end of the study showed cognitive worsening in central information processing compared with the last measurement at 6 months. The above two statements were true for small patient groups and correlations were not statistically significant.

Because the Z-score was found to be correlated with the \% of IEDs at baseline in wakefulness, we additionally analyzed individual changes in the EEG in wakefulness (Figure 6.2B). The distribution did not largely differ because EEGs often changed in wakefulness as well as in sleep (with only a few patients with significant changes in wakefulness, but without change in sleep). When the EEG outcome was dichotomized in EEG worsening or not in wakefulness, there was a significant correlation between $Z$-score changes and EEG change in wakefulness (Spearman: $R=0.43, P=0.04$ )

\section{Central information processing speed and other epilepsy variables}

The variable with classification of the average Z-scores into improvement, stability, or worsening at 2 years was correlated with seizure freedom or not since the EEG at 6 months ( $R=0.45 P=0.04)$ : five of the 11 patients with ongoing seizures after this EEG at 6 months had worsening of Z-scores compared with none of the 12 patients without seizures. Antiepileptic drug reinforcement performed at some time during the study ( $n=12$ patients) was not related to Z-score changes. In only 2 patients, AEDs were (partially) tapered off; this group was too small for analysis. 
A

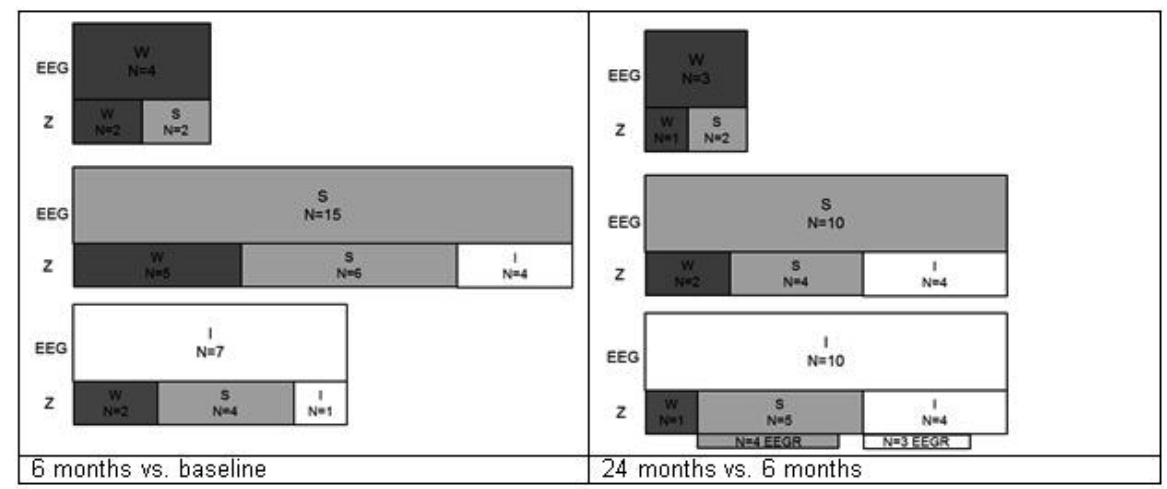

$E E G R=E E G$ remission

B

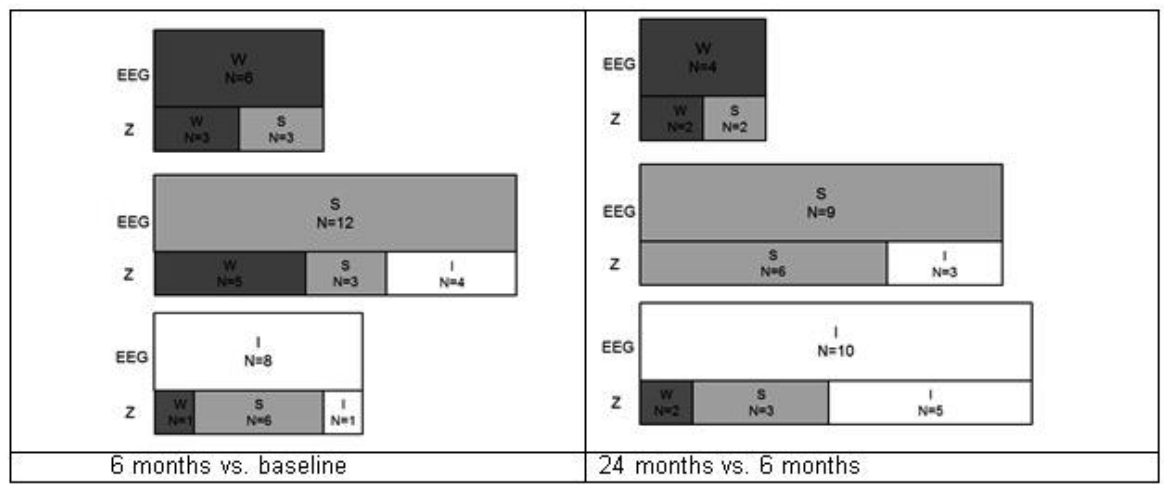

The changes in the average Z-scores are presented in the subgroups of patients with EEG-worsening, EEGstability or EEG- improvement, respectively.

Dark grey color $=$ Worsened compared to last observation,

Light grey color $=$ Stable compared to last observation

White color =Improved

Figure 6.2 EEG changes compared with average Z-score changes. A) EEG changes and average Z-score changes (when EEG had significantly changed in wakefulness as well as in sleep). B) EEG changes and average Z-score changes (when EEG had significantly changed in wakefulness).

\section{Prediction of EEG remission at 2 years}

Electroencephalography-related variables, but no other epilepsy-related variables at baseline, were correlated with EEG-remission at 2 years (Table 6.3). Figure 6.3 shows the lower baseline IED frequencies in wakefulness in the 8 patients who would obtain EEG remission 2 years later. A high diurnal IED frequency above $18 \%$ at baseline was not observed in patients with EEG remission 2 years later (Figure 6.3). Since the variables - serial IEDs, number of foci, bilateral foci and IED frequency - showed mutual 
correlations a regression analysis was performed. All the abovementioned EEG variables combined contributed $\left(R^{2}\right.$ was 0.60 for the combined factors, $\left.P=0.03\right)$. The largest contribution to EEG remission at 2 years $\left(R^{2}=0.51\right)$ was the combination of unilateral IEDs and lack of serial IEDs $(P=0.008$ for the two combined variables and $P=0.02$ for each variable in isolation).

Patients who would achieve EEG remission 2 years later, could not be identified by epilepsy-related variables at baseline such as seizure frequency in the last year or half year before baseline, the age at onset, epilepsy duration, number of AEDs, use of AEDs or not, or a syndromal diagnosis of RE vs. other syndromal diagnosis.

Table 6.3 Variables predictive of EEG-remission 2 years later.

\begin{tabular}{|c|c|c|}
\hline Variables & Baseline & Follow-up \\
\hline EEG & $\begin{array}{l}\text { Unilateral IED focus } / \text { foci }^{1} \\
\text { Lower IED frequency wakefulness } \\
\text { Lower number of IED foci }{ }^{3} \\
\text { No serial IEDs }\end{array}$ & \\
\hline Epilepsy-related ${ }^{5}$ & - & $\begin{array}{l}\text { Seizure freedom } 6 \text { months before } \\
\mathrm{EEG}^{6}\end{array}$ \\
\hline Cognition (questionnaires) & - & - \\
\hline Behavior (questionnaires) & - & - \\
\hline $\begin{array}{l}\text { Cognitive tests on central } \\
\text { information processing speed }\end{array}$ & - & - \\
\hline
\end{tabular}

${ }^{1}$ Chi-square: $P=0.009$, subgroup with RE: $P=0.04 .{ }^{2}$ Spearman: $\mathrm{R}=0.58 P=0.004$, subgroup with $\mathrm{RE}$ : $\mathrm{R}=0.59$ $P=0.02$. $^{3}$ Wakefulness Spearman: $R=0.47, P=0.02$, sleep Spearman: $R=0.47, P=0.03$. ${ }^{4}$ Spearman $R=0.52$ $P=0.009$, subgroup with RE R=0.55 $P=0.03$. ${ }^{5}$ Baseline epilepsy- related variables: seizure frequency, age, age at onset, AEDs at baseline, syndromal diagnosis RE or not. Follow-up: changes in IED frequency or lateralization at 6 months, AED changes, seizure changes. ${ }^{6}$ Chi-square $P=0.05$, subgroup with RE: $P=0.02$.

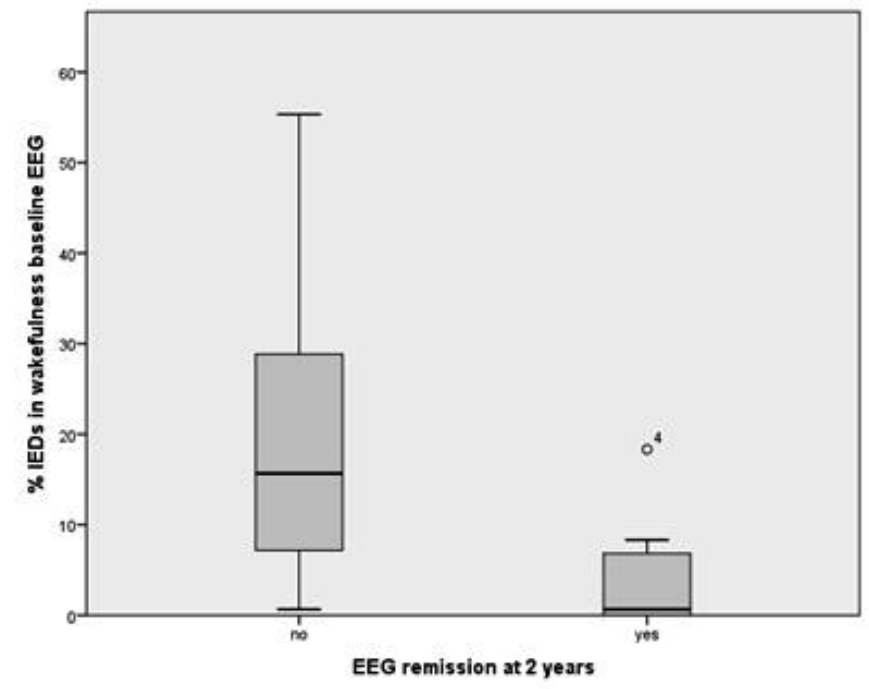

Figure 6.3 Number of IEDs at baseline in patients with and in patients without EEG remission 2 years later. 


\section{Conclusion}

The main findings were as follows:

1) Associations between IEDs and cognition/behavior:

a. A lower central information processing speed was correlated with a higher frequency of benign focal spikes in wakefulness. Patients with more spikes in wakefulness had more difficulties in academic achievement.

b. Behavioral problems were observed more in patients with higher frequency of benign focal spikes in sleep and in those with ongoing IEDs (wakefulness and/or sleep) compared with those with EEG remission.

\section{2) Changes in IEDs correlated with changes in cognition:}

a. When the EEG outcome was dichotomized in EEG worsening or not in wakefulness, there was a significant correlation between changes in central information processing speed and EEG changes in the same direction.

b. At an individual level (not significant in group analysis): children with worsening of the EEG did not show cognitive improvement; children with EEG remission did not show cognitive deterioration.

\section{3) Prediction of EEG remission}

a. Patients with IED frequency in wakefulness below $18 \%$, lack of serial IEDs, and only unilateral IEDs had a higher chance of EEG remission within 2 years.

b. Seizure freedom $\geq 6$ months before the EEG registration meant a higher chance of finding EEG remission in this registration.

\section{Discussion}

Our study confirms the relationship between the frequency of IEDs and impaired cognitive abilities as well as problematic behavior in children with benign focal spikes. Children with ongoing IEDs, especially those with an increase of IEDs in successive EEGs, were at risk for decrease of the central information processing speed, which can be a risk factor for impaired academic achievement. The frequency of IEDs in wakefulness contributed more to central information processing compared with the nocturnal IED frequency. This might partially be caused by transitory impairments as an effect of IEDs in wakefulness shown by Fonseca. ${ }^{9}$ At the other end of the EEG spectrum, we observed that patients with EEG remission (without or with only sporadic IEDs in wakefulness as well as in sleep) had no (further) cognitive deterioration and better reported behavior. In $R E$, several cognitive functions have shown to be affected in earlier studies. One domain is attention ${ }^{27,28}$, which may also relate to central information processing speed. Another frequently reported affected domain is language (reading, learning of auditory- 
verbal material, and phonologic awareness) ${ }^{29,30}$. If epilepsy syndromes with benign focal spikes can simultaneously affect several important cerebral functions in the brain of the developing child, such as language, attention and speed of processing, this is a serious threat to learning. Behavioral changes also threatened academic achievement. Central information speed could be a cognitive function with a higher chance of reversibility in relationship to IED changes, and perhaps this might be reversible at an earlier stage than language abilities. Language functions might need longer time to recover after IEDs have ceased to occur: there are indications that cortical thickness in the dominant hemisphere is reduced in patients with Rolandic epilepsy ${ }^{31}$, and structural consequences in the language network were found in MRI investigations. ${ }^{32}$ Structural changes might not be reversible or not reversible over a short time. In this study, we did not examine changes in language abilities related to IED frequency; this remains an important research topic in future prospective cohorts.

Only a few other studies have published prospective data on the direction of changes in individual children in successive evaluations of EEG and cognition. Two studies found a congruent relationship between IED reduction and cognitive improvement. Deonna ${ }^{33}$ reported data on children with benign focal spikes (19 patients with $R E$, and 3 patients with Panayiotopoulos syndrome) with 1-to 3-year follow-up and repeated examinations each 6-12 months (EEG in wakefulness and sleep, heterogeneous individual neuropsychological tests). This study found no EEG-worsening in 8 children with cognitive improvement over time (which is comparable with our findings) but did not find a certain relationship between EEG changes and cognitive deterioration in 4 other patients. The last finding is also comparable with our findings, as cognitive deterioration could also be observed in a small number of our patients with EEG improvement. In another study ${ }^{34}$, nine children with RE and seizure-freedom for at least 1 month and treated with valproic acid were followed each 3 months with EEG and cognitive tests until EEG remission. They all remained seizure-free. At the time when nocturnal IEDs were reduced to $<5 / \mathrm{min}$ (the definition of EEG remission), several cognitive tests as well as IQ were compared with baseline. In each child, full-scale IQ increased at that time (mean: 16-point increase, range: 10-29). It was not said if the patients still used VPA at the final examination. Tedrus ${ }^{35}$, however, did not find a correlation between the IQ changes and the extent of IED reduction in a group of 32 patients with RE followed for a mean of 27 months ( 6 had EEG normalization at the end of the follow-up period), when examining those with and those without $50 \%$ IED reduction compared with baseline.

We need to bring forward that the correlations between IEDs and cognition in our study were not completely isolated from the effect of the number of AEDs in a regression analysis. It is possible that treating physicians already were concerned about patients with more reported cognitive and/or behavioral problems and perhaps already had taken notice of a high amount or IEDs in an earlier registered EEG. Therefore they might have added more drugs in these patients or they might have been reluctant to 
decrease the drug load. We also cannot completely rule out that AEDs also contributed to the lower central information processing speed due to cognitive side effects.

Ongoing seizures were an additional risk factor for the worsening of the central information processing speed. The question arises if it would be possible to prevent cognitive impairment by the cessation of seizures as well as IEDs through anti-epileptic treatment. In our study, however, we could not observe that EEG remission was associated with AED treatment (the use of AEDs or not or increasing the dosage of AEDs before the final EEG). Our study design was not meant to answer this question specifically. Furthermore, there could be a selection bias in our study, because we might have included a high proportion of patients with refractory seizures in a tertiary referral center. It is, nonetheless, very important to know if AEDs would be capable of EEG normalization at an earlier stage than the time of spontaneous remission.

There is some evidence that AEDs are capable of early normalization of the EEG in RE. There are arguments in favor of AEDs compared with nontreatment with 15-55\% EEG remissions at 6 months in the various studies compared with a roughly estimated spontaneous remission rate of $15-20 \%$ at that time. ${ }^{36-40}$ Higher rates of remission are reported at 1 month of treatment (around $70 \%$ ); however, initial effects may be transient. $^{36,37,40}$

We recommend that controlled trials be performed in patients with RE with cognition as outcome. The IED frequency and possibly also EEG background changes ${ }^{15}$ can be considered as markers in such studies. However, there is risk of treating patients with a benign course and causing harm by the side effects of drugs. In 2008 a study was aborted after noticing cognitive deterioration in 6 patients treated with Sulthiame although IEDs were reduced. ${ }^{2}$ Comments have been made if this still could be the progressive cognitive deterioration because EEGs were not completely normalized. ${ }^{42}$ Trials should perhaps start first in the patients most at risk. From our study, patients with higher IED loads at presentation ( $\geq 18 \%$ of the time in wakefulness, serial IEDs, or multifocal IEDs) were more at risk of delayed EEG remission compared with others. $A$ randomized placebo-controlled trial could first be developed for the subgroup of patients with RE (and/or for patients with ongoing multifocal benign focal spikes with other syndromes), with these high IED loads, cognitive difficulties and no treatment indication for seizures (no seizures or seizure-free at least for 6 months).

A limitation of our study is the small proportion of patients with EEG worsening at 6-month follow-up and/or 24-month follow-up. This is an important subgroup in the light of our research questions. We did not observe cognitive improvement in this small group; however this was not statistically significant. A second limitation is that we only analyzed a small sample of the EEG. We, therefore, used a strict definition of EEG change (observed in the sample in wakefulness as well as in the sample from sleep), to increase the reliability of the conclusion on EEG change. We are rather confident that these conclusions were reliable; however, we did not examine this thoroughly. Next, a limitation is the selection of patients from a tertiary center. We did not include patients with the same amounts of benign focal spikes without reported difficulties in cognition 
or behavior. The found correlations between IEDs in wakefulness and central information processing speed may be driven by including subjects with very high IED load. There might be a patient subgroup that is less affected, and not referred to specialized centers, for which it is unsure if the conclusions can be extrapolated. Still we think that the value of this study is the confirmation of the nonbenign character of benign focal spikes, which should result in a general concern for all patients who present with this type of EEG finding and which should lead to the development of prospective placebo-controlled randomized trials in subgroups most at risk. 


\section{References}

1. Lerman P, Kivity-Ephraim S. Focal epileptic EEG discharges in children not suffering from clinical epilepsy: etiology, clinical significance, and management. Epilepsia 1981;22:551-8.

2. Wirrell E, Sherman EM, Vanmastrigt R, Hamiwka L. Deterioration in cognitive function in children with benign epilepsy of childhood with central temporal spikes treated with sulthiame. J Child Neurol 2008; 23:14-21.

3. Weglage J, Demsky A, Pietsch M, Kurlemann G. Neuropsychological, intellectual, and behavioral findings in patients with centrotemporal spikes with and without seizures. Dev Med Child Neurol 1997; 39:646-51.

4. Riva D, Vago C, Franceschetti S, Pantaleoni C, D'Arrigo S, Granata T, Bulgheroni S. Intellectual and language findings and their relationship to EEG characteristics in benign childhood epilepsy with centrotemporal spikes. Epilepsy Behav 2007;10:278-85.

5. Ebus SC, Overvliet GM, Arends JB, Aldenkamp AP. Reading performance in children with rolandic epilepsy correlates with nocturnal epileptiform activity, but not with epileptiform activity while awake. Epilepsy Behav 2011;22:518-22.

6. Nicolai J, van der Linden I, Arends JB, van Mil SG, Weber JW, Vles JS, Aldenkamp AP. EEG characteristics related to educational impairments in children with benign childhood epilepsy with centrotemporal spikes. Epilepsia 2007;48:2093-100.

7. Petersen J, Nielsen CJ, Gulmann NC. Atypical EEG abnormalities in children with benign partial (Rolandic) epilepsy. Acta Neurol Scand Suppl 1983;94:57-62.

8. Kanemura H, Sano F, Aoyagi K, Sugita K, Aihara M. Do sequential EEG changes predict atypical clinical features in rolandic epilepsy? Dev Med Child Neurol 2012;54:912-7.

9. Fonseca LC, Tedrus GM, Pacheco EM. Epileptiform EEG discharges in benign childhood epilepsy with centrotemporal spikes: reactivity and transitory cognitive impairment. Epilepsy Behav 2007;11:65-70.

10. Urbain C, Schmitz R, Schmidt C, Cleeremans A, Van Bogaert P, Maquet P, Peigneux P. Sleep-dependent neurophysiological processes in implicit sequence learning. J Cogn Neurosci 2013;25:2003-14.

11. Yang G, Lai CS, Cichon J, Ma L, Li W, Gan WB. Sleep promotes branch-specific formation of dendritic spines after learning. Science 2014;344:1173-8.

12. Tononi G, Cirelli C. Sleep and the price of plasticity: from synaptic and cellular homeostasis to memory consolidation and integration. Neuron 2014;81:12-34.

13. Fejerman N. Atypical rolandic epilepsy. Epilepsia 2009;50 Suppl 7:9-12.

14. Tovia E, Goldberg-Stern H, Ben Zeev B, Heyman E, Watemberg N, Fattal-Valevski A, Kramer U. The prevalence of atypical presentations and comorbidities of benign childhood epilepsy with centrotemporal spikes. Epilepsia 2011;52:1483-8.

15. Tedrus GM, Fonseca LC, Melo EM, Ximenes VL. Educational problems related to quantitative EEG changes in benign childhood epilepsy with centrotemporal spikes. Epilepsy Behav 2009;15:486-90.

16. Doose H, Neubauer B, Carlsson G. Children with benign focal sharp waves in the EEG--developmental disorders and epilepsy. Neuropediatrics 1996;27:227-41.

17. Avanzini G, Franceschetti S. Cortical excitability in benign focal epilepsies. In: Fejerman N, Caraballo RH, editors. Benign focal epilepsies in infancy, childhood and adolescence. John Libbey Eurotext 2007 p. 1528

18. Proposal for revised classification of epilepsies and epileptic syndromes. Commission on Classification and Terminology of the International League Against Epilepsy. Epilepsia 1989;30:389-99.

19. Kort S, Dekker, Verhaeghe, Compaan, Bosmans, Vermeir. WISC-III NL. Handleiding en Verantwoording.. London: The Psychological Corporation; 2005.

20. Hendriksen H. WPPSI-III NL. Wechsler Preschool and Primary Scale of Intelligence. Nederlandstalige bewerking. Afname- en scoringshandleiding. In. 3 ed. Amsterdam: Pearson. 2009.

21. FePsy: The Iron Psyche: Manual. : Heemstede, The Netherlands, Instituut voor epilepsiebestrijding. 1995.

22. Aldenkamp A, Arends J. The relative influence of epileptic EEG discharges, short nonconvulsive seizures, and type of epilepsy on cognitive function. Epilepsia 2004;45:54-63. 
23. Ebus S, Arends J, Hendriksen J, van der Horst E, de la Parra N, Hendriksen R, Santegoeds E, Boon P, Aldenkamp B. Cognitive effects of interictal epileptiform discharges in children. Eur J Paediatr Neurol 2012;16:697-706.

24. Cohen J. Statistical power analysis for the behavioral sciences. In. New York: Academic Press. 1969.

25. Sabaz M, Lawson JA, Cairns DR, Duchowny MS, Resnick TJ, Dean PM, Bye AM. Validation of the quality of life in childhood epilepsy questionnaire in American epilepsy patients. Epilepsy Behav 2003;4:680-91.

26. Massa R, de Saint-Martin A, Carcangiu R, Rudolf G, Seegmuller C, Kleitz C, Metz-Lutz MN, Hirsch E, Marescaux $C$. EEG criteria predictive of complicated evolution in idiopathic rolandic epilepsy. Neurology 2001;57:1071-9.

27. Kim EH, Yum MS, Kim HW, Ko TS. Attention-deficit/hyperactivity disorder and attention impairment in children with benign childhood epilepsy with centrotemporal spikes. Epilepsy Behav 2014;37C:54-58.

28. Deltour L, Barathon M, Quaglino V, Vernier MP, Despretz P, Boucart M, Berquin P. Children with benign epilepsy with centrotemporal spikes (BECTS) show impaired attentional control: evidence from an attentional capture paradigm. Epileptic Disord 2007;9:32-8.

29. Lindgren S, Kihlgren M, Melin L, Croona C, Lundberg S, Eeg-Olofsson O. Development of cognitive functions in children with rolandic epilepsy. Epilepsy Behav 2004;5:903-10.

30. Northcott E, Connolly AM, Berroya A, Sabaz M, Mclntyre J, Christie J, Taylor A, Batchelor J, Bleasel AF, Lawson JA, Bye AM. The neuropsychological and language profile of children with benign rolandic epilepsy. Epilepsia 2005;46:924-30.

31. Overvliet GM, Besseling RM, Jansen JF, van der Kruijs SJ, Vles JS, Hofman PA, Ebus SC, de Louw A, Aldenkamp AP, Backes WH. Early onset of cortical thinning in children with rolandic epilepsy. Neuroimage Clin 2013;2:434-9.

32. Besseling RM, Jansen JF, Overvliet GM, van der Kruijs SJ, Ebus SC, de Louw A, Hofman PA, Vles JS, Aldenkamp AP, Backes WH. Reduced structural connectivity between sensorimotor and language areas in rolandic epilepsy. PLoS One 2013;8:e83568.

33. Deonna T, Zesiger P, Davidoff V, Maeder M, Mayor C, Roulet E. Benign partial epilepsy of childhood: a longitudinal neuropsychological and EEG study of cognitive function. Dev Med Child Neurol 2000;42: 595-603.

34. Baglietto MG, Battaglia FM, Nobili L, Tortorelli S, De Negri E, Calevo MG, Veneselli E, De Negri M. Neuropsychological disorders related to interictal epileptic discharges during sleep in benign epilepsy of childhood with centrotemporal or Rolandic spikes. Dev Med Child Neurol 2001;43:407-12.

35. Tedrus GM, Fonseca LC, Castilho DP, Pacheco EM, Campregher AA, Bittar MC. Benign childhood epilepsy with centro-temporal spikes: evolutive clinical, cognitive and EEG aspects. Arq Neuropsiquiatr 2010;68:550-5.

36. Rating D, Wolf C, Bast T. Sulthiame as monotherapy in children with benign childhood epilepsy with centrotemporal spikes: a 6-month randomized, double-blind, placebo-controlled study. Sulthiame Study Group. Epilepsia 2000;41:1284-8.

37. Bast $T$, Volp A, Wolf $C$, Rating $D$. The influence of sulthiame on EEG in children with benign childhood epilepsy with centrotemporal spikes (BECTS). Epilepsia 2003;44:215-20.

38. Kwon S, Seo HE, Hwang SK. Cognitive and other neuropsychological profiles in children with newly diagnosed benign rolandic epilepsy. Korean J Pediatr 2012;55:383-7.

39. Tzitiridou M, Panou T, Ramantani G, Kambas A, Spyroglou K, Panteliadis C. Oxcarbazepine monotherapy in benign childhood epilepsy with centrotemporal spikes: a clinical and cognitive evaluation. Epilepsy Behav 2005;7:458-67.

40. Xiao F, Chen Q, Yu X, Tang Y, Luo C, Fang J, Liu L, Huang X, Gong Q, Zhou D. Hemispheric lateralization of microstructural white matter abnormalities in children with active benign childhood epilepsy with centrotemporal spikes (BECTS): a preliminary DTI study. J Neurol Sci 2014;336:171-9.

41. Mitsudome A, Ohfu M, Yasumoto S, Ogawa A, Hirose S, Ogata H, Yamada T. The effectiveness of clonazepam on the Rolandic discharges. Brain Dev 1997;19:274-8.

42. Deonna T, Roulet-Perez E, Cronel-Ohayon S, Mayor-Dubois C. Correspondence on "deterioration in cognitive function in children with benign epilepsy of childhood with central temporal spikes treated with sulthiame". J Child Neurol 2010;25:127-8. 


\section{Chapter 7}

Ins and outs of quantifying spikes 


\section{Summary}

The clinical use of a method to quantify interictal epileptiform discharges (IEDs) by visual inspection was evaluated. This method categorizes the number of IEDs in wakefulness, at sleep onset and remaining nonREM-sleep. The interobserver reliability was calculated for 128 24-hour EEGs. Furthermore, EEG-technologists and referring neurologists were questioned on their satisfaction with the method. The method had an acceptable, but moderate interobserver reliability. The time investment was small. The use of the method was most appreciated for patient groups known with high numbers of IEDs, especially to see changes at follow-up. The scoring in predefined categories was generally felt to support a global impression on change between successive EEGs, however not for all EEGs.

Secondly, it was examined which method can best be used in a research setting, to define change between the number of IEDs in 24-hour EEGs containing benign focal IEDs. The focus was on the detection of reliable and relevant changes in individual patients and the usefulness for statistical analysis. Changes had to be observed in 22 patients, using a dataset of 22 EEGs at baseline and 22 EEGs at 6-18 months followup. The method that best met all conditions was the calculation of seconds containing IEDs in 30 random pages by visual inspection, with a twice scored baseline EEG to define the limits for change. Global impression on change also met the standards for reliability and relevance, however, not for the use for statistical analysis. 


\section{Introduction}

In reaction to some of my studies several colleagues expressed their interest in the method of quantifying IEDs (interictal epileptiform discharges). Questions were focused on the method, time involved and whether such methods could also be used in daily clinical practice. Apparently more neurologists were "struggling" with quantification of IEDs in science as well as in daily clinical practice. Therefore, this chapter addresses quantification in clinical practice (7.1) and quantification of IEDs (restricted to benign focal IEDs) for a scientific purpose (7.2).

At the start of my appointment at the EEG department (2005), it was common practice to comment on the quantity of IEDs as a part of the EEG-report. Terms as "a lot of", "a fair amount", "sometimes occurring" to describe the quantity of IEDs were judged as undesirable, because it was difficult to obtain agreement when to use these terms. The frequency of IEDs was reported in a \% of the time: e.g. "IEDs occurring in 3\% of the time in wakefulness". There was a protocol how to estimate this \% (Figure 7.1). The EEG report with the amount on a scale measurement level from 0-100 \% suggested that IEDs could reliably be quantified with high precision. However, EEG-technologists felt that the interobserver agreement would probably be low, and they found the protocol difficult to handle. Often, they supplied a range of the $\%$ of the time, e.g. 5-30\%, which was less precise but more in agreement with the variability of IED frequency within an EEG.

In the same period, an automatic spike detection software program was introduced at the EEG department that enabled quantifying of IEDs/ unit of time (Persyst version 2010.02.17). Another advantage, besides quantification, was the visual representation of clustered spike-foci, allowing a quick overview of all localizations and spikepropagations. The procedure took about 20-40 minutes for quantification in 2 hours of a 24-hour EEG (added to the time needed for description of about 2-4 hours). Not in all EEGs sensitivity and/or specificity (estimated from visually identified IEDs and artifacts) were acceptable. It was a challenge to teach and maintain the skills for the use of the software for everyone working at the department. The introduction of a new EEG recording system in 2007 (not immediately compatible with the automatic detection software), forced us to reconsider the use of this software. It was decided that the efforts did not compensate for all benefits. Automatic spike detection was only used for scientific purposes from then on (focus localization, quantification).

To understand the terms "EEG-technologist" and "neurophysiologist", it is important to take notice of their different attributions in the setting of the EEG-department in which the research for this chapter was performed. In this setting, an EEG-technologist is responsible for a technically good registration of the EEG. After registration he/she is the first to observe and describe the EEG. The presumed abnormalities are marked in the EEG for presentation to the neurophysiologist. A preliminary conclusion on the clinical relevance of found abnormalities is formulated by the EEG-technologist. The 
neurophysiologist checks the report and the original EEG, makes changes if necessary, and delivers the final report to the referring neurologist.

\subsection{Is useful information supplied to referring neurologists?}

\section{Experiences with a quantification method in daily practice}

\section{Introduction}

An improved protocol was introduced for the visual quantification of IEDs in clinical practice. For clinical use the following set of ideal conditions was determined (as opposed to conditions for scientific purpose) (Table 7.1).

Table 7.1 Conditions for quantification methods.

\begin{tabular}{llcc}
\hline Condition & Description & Clinical use & Scientific use \\
\hline Simple & Easy to use & ++ & + \\
Generalizable & Applicable to each type of EEG & ++ & - \\
Reliable & Good sensitivity and specificity, good interobserver & ++ & ++ \\
& agreement/repeatability & & ++ \\
Relevant & Detection of clinically relevant changes in successive & ++ & + \\
Interpretable & $\begin{array}{l}\text { EEGs of a patient } \\
\text { Enalyzable }\end{array}$ & $\begin{array}{l}\text { physician } \\
\text { Data to be used for statistical analysis }\end{array}$ & ++ \\
\hline
\end{tabular}

The proposed improved protocol (description of it follows below) was implemented 3 years ago. At the time it had been used for 3 years it was decided to evaluate it for this thesis as well as for clinical practice.

To examine the reliability, the interobserver agreement was calculated. Furthermore EEG-technologists were asked in a questionnaire to report on their satisfaction working with this method. Referring physicians were also questioned on their satisfaction regarding the information provided in the EEG-report.

\subsubsection{Interobserver agreement}

\section{Description of the improved quantification method}

The IEDs had to be quantified in wakefulness, and (if registered) in sleep: at sleep onset (the first 15 minutes of sleep) as well as in the remaining part of non-REM sleep. 
IEDs had to be assessed on an ordinal measurement scale in 6 predefined categories (Table 7.2). For better comprehension, an explanation in text for each category was added. The protocol for the estimation of the $\%$ of the time was simplified: $10 \%$ of the time on a 10- second EEG page meant that 1 second out of 10 contained one or more IEDs and the duration of an epileptic grapho-element itself did not have to be estimated anymore. This generally meant a higher estimation of the \% of time in comparison with the old method (Figure 7.1). In patients with multi-focal benign focal spikes, the first two foci that were most present in the EEG had to be quantified separately. If the EEG-observer was uncertain, he/she was advised to score 30 pages in each state to obtain the time \% on each page, to gain more insight in the variability, and after this choose the main occurring category within these pages.

Table 7.2 Example of quantification scores in an EEG-report.

\begin{tabular}{|c|c|c|c|c|c|c|}
\hline & $\begin{array}{c}\mathbf{0 \%} \\
\text { No IEDs }\end{array}$ & $\begin{array}{c}<1 \% \\
\text { Sporadic } \\
\text { IEDs }\end{array}$ & $\begin{array}{c}\geq \mathbf{1 - 1 0 \%} \\
\text { Non-sporadic, } \\
\text { but not each } \\
\text { page contains } \\
\text { IEDs }\end{array}$ & $\begin{array}{c}\geq 10-50 \% \\
\text { Almost every } \\
\text { page contains } \\
\text { IEDs, but } \leq \\
\text { than half of } \\
\text { the page }\end{array}$ & $\begin{array}{l}\geq 50-85 \% \\
\text { Almost every } \\
\text { page contains } \\
\text { IEDs, } \geq \text { half of } \\
\text { the page }\end{array}$ & $\begin{array}{c}\geq 85 \% \\
\text { Almost } \\
\text { continuous } \\
\text { IEDs }\end{array}$ \\
\hline Wakefulness & & $x$ & & & & \\
\hline Sleep 1st $15 \mathrm{~min}$ & & & & & $X$ & \\
\hline Sleep other cycles nREM & & & & $\mathrm{X}$ & & \\
\hline
\end{tabular}

Comments:

\section{Why were the 6 categories chosen?}

It was necessary to have enough flexibility in the choices, while the different categories would represent clinically relevant differences. Though scientific evidence is lacking, a change to an adjacent category was seen as potentially clinically relevant. The highest category of $\geq 85 \%$ was chosen because this is a classical condition for the diagnosis of ESES (electrical status epilepticus in slow wave sleep). The 5 divisions within the range of $<1 \%$ to $100 \%$ IEDs of the time, are related to a normal distribution: $95 \%$ of the scores are within $\geq 1 \%$ and $<85 \%$ and the extremes are at more than 2 standard deviations (SD) of the mean. The category in the middle $(\geq 10-50 \%)$ is within + and -1 SD. However, although the thresholds can be based on such a distribution, it is known from experience that the real time \% counted in the EEGs, will not have this 'normal' distribution. E.g. patients with IEDs $\geq 85 \%$ in wakefulness are rare, while the category of $<1 \%$ is not uncommon. 


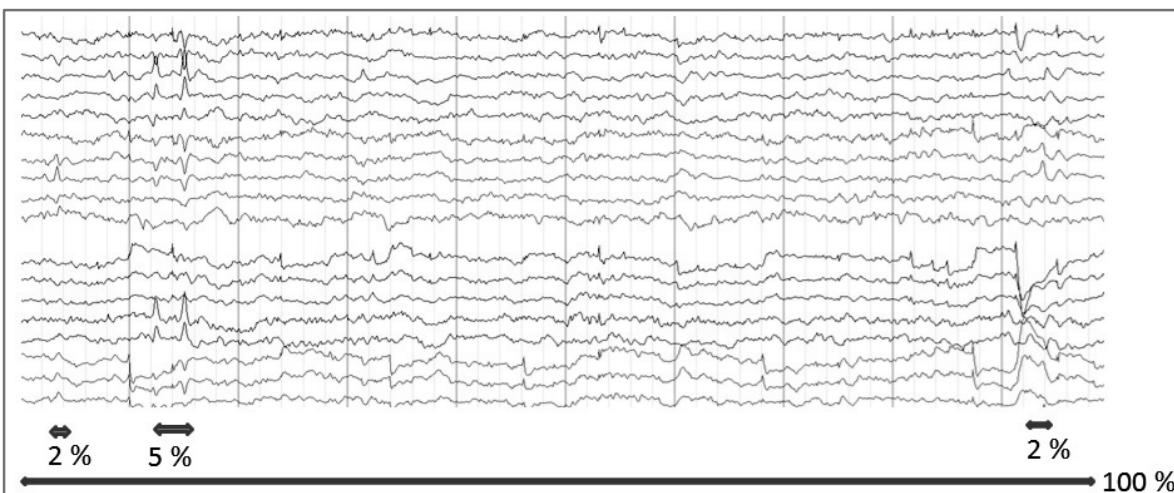

Old method: Durations of spike(waves) is estimated in \% from the whole page. When 10 seconds $=100 \%$ then the amount on this page is $9 \%$ of the time.

From estimations on several pages, the amount is assessed in the total time of registered EEG in wakefulness.

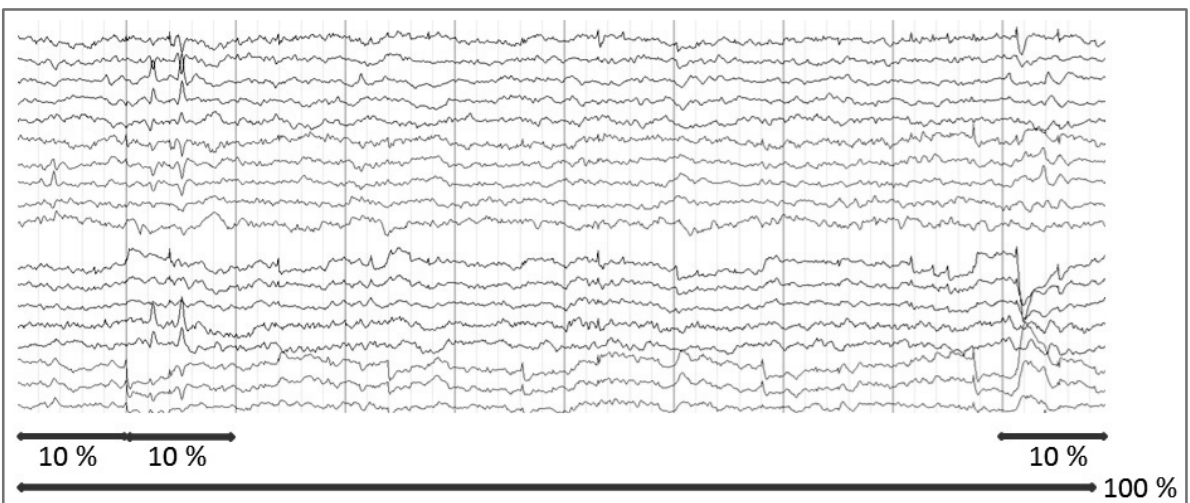

New method: 3 of the 10 seconds contain epileptiform activity. When 10 seconds $=100 \%$ then the amount on this page is $30 \%$ of the time.

From estimations on several pages, the amount is assessed within a category in the total time of registered EEG in wakefulness.

Figure 7.1 Defining the IED time \% on a 10-second EEG page, old (top) and new protocol (bottom). 


\section{Calculation of the interobserver agreement}

Two EEG observers experienced with the protocol (observer 1 S.E. (neurophysiologist) and observer $2 \mathrm{H}$. den B. (EEG-technologist) independently determined the category score of the three states (wakefulness, first 15 minutes of sleep and remaining nREM sleep) in a set of 128 ambulatory 24 hour EEGs (half of them were from children). The EEGs were randomly selected out of a set of EEGs that mentioned IEDs in the report. ${ }^{\text {a }}$ The specific question of the referring physician for EEG recording and the age of the patient were disclosed to the observers and they knew that in the original report of the EEG IEDs had been reported in wakefulness, and/or first 15 minutes of sleep and/or remaining $\mathrm{nREM}$ sleep.

Observer S.E. determined the syndromal diagnosis and type of IEDs based on the referral data and EEG features. Both observers recorded the time used to quantify each EEG.

Cohen's Kappa-scores were calculated for the three states in the complete group and in subgroups (children vs. adults and subgroups with different epilepsy characteristics). Because the variable was ordinal a weighted kappa was also calculated, using a weight of 0.25 for adjacent categories of the diagonal. ${ }^{b}$

\section{Results}

\section{Descriptive data}

Descriptive data on the syndromal diagnosis and type of IEDs are shown in Table 7.3.

Table 7.3 Frequency distribution of syndromal diagnosis and type of IEDs.

\begin{tabular}{llc}
\hline & Category & $\begin{array}{c}\mathrm{Nr} \\
\text { (nr of children) }\end{array}$ \\
\hline Syndromal diagnosis & Localization related epilepsy & $76(32)$ \\
& Generalized epilepsy & $23(8)$ \\
& Benign focal epilepsy & $18(17)$ \\
& IEDs without seizures & $7(6)^{1}$ \\
& Epileptic encephalopathy & $4(1)$ \\
& Total & 128 \\
Type of IEDs & 1 IED focus & $59(34)$ \\
& $\geq 2$ IED foci & $29(15)$ \\
& Predominantly generalized IEDs & $35(14)$ \\
& Total & $123^{3}$ \\
\hline
\end{tabular}

\footnotetext{
${ }^{1}$ Among whom 5 with benign focal IEDs. ${ }^{2}$ Defined as severely disturbed EEG background, multifocal frequent IEDs. ${ }^{3}$ Total number of cases is 123 instead of 128 because in 5 EEGs observer 1 that classified the IEDs, did not observe IEDs in any state in the EEG.
} 


\section{Time needed for quantification}

The average time used was lower for observer 1 than for observer 2 and the maximum time used was 6 minutes ${ }^{c}$. IEDs categorized above $1 \%$ of the time were always scored within 3 minutes by both observers. The time spent was negatively correlated with the amount of IEDs for both observers for all states ${ }^{d}$, indicating that more pages needed to be viewed to find low amounts of IEDs. The time used was not correlated with the type of IEDs or the syndromal diagnosis.

\section{Did the observers agree with the original reports on finding IEDs?}

The observers were aware that the original report mentioned IEDs in at least one of the 3 states, but did not know in which state of the particular 24 hour EEG.

Table 7.4 shows the \% of disagreements: not finding IEDs while the original report described IEDs. This was observed in a total of $9 \%$ for observer 1 and $10 \%$ for observer 2. The lowest chance on disagreement was at sleep onset (probably because this was a well-defined short period of 15 minutes to analyze). From the 33 cases without detected IEDs by observer $1,88 \%$ were reported as sporadically occurring IEDs in the original report. This was $91 \%$ for observer 2 . The protocol for description of a 24-hour EEG in our tertiary epilepsy centre recommends analyzing at least 5.5 hours (1980 pages) of the EEG. A sporadic IED amount in the original EEG combined with the much smaller sample reviewed by observers 1 and 2 can explain the majority of disagreements with the original report. Differences in interpretation between the EEG observers and the original reports (were the reported IEDs indeed IEDs?) could also have had some influence on these disagreements, but were probably less important.

Table 7.4 Frequencies of disagreement of 2 observers on finding IEDs compared to the original number of reports with IEDs $(n)$ for each phase.

\begin{tabular}{lcccc}
\hline \multicolumn{5}{c}{ Number (\%) of EEGs with undetected IEDs } \\
Phase \\
\hline \multirow{3}{*}{ Observer } & Wakefulness & $\begin{array}{c}\text { Sleep onset } \\
(\mathrm{n}=124)\end{array}$ & $\begin{array}{c}\text { nREM sleep } \\
(\mathrm{n}=126)\end{array}$ & $\begin{array}{c}\text { Total } \\
(\mathrm{n}=357)\end{array}$ \\
1 & $(\mathrm{n}=107)$ & $5(4 \%)$ & $15(12 \%)$ & $33(9 \%)$ \\
2 & $13(12 \%)$ & $8(6 \%)$ & $10(8 \%)$ & $34(10 \%)$ \\
\hline
\end{tabular}

\section{Distributions of IED category scores}

The distributions of the scores of both observers are shown in Figure 7.2. The distributions of both observers do not differ significantly (Wilcoxon wakefulness $P=0.08$, sleep onset $P=0.1$, rest of nREMsleep $P=0.4$ ). 


\section{Wakefulness}

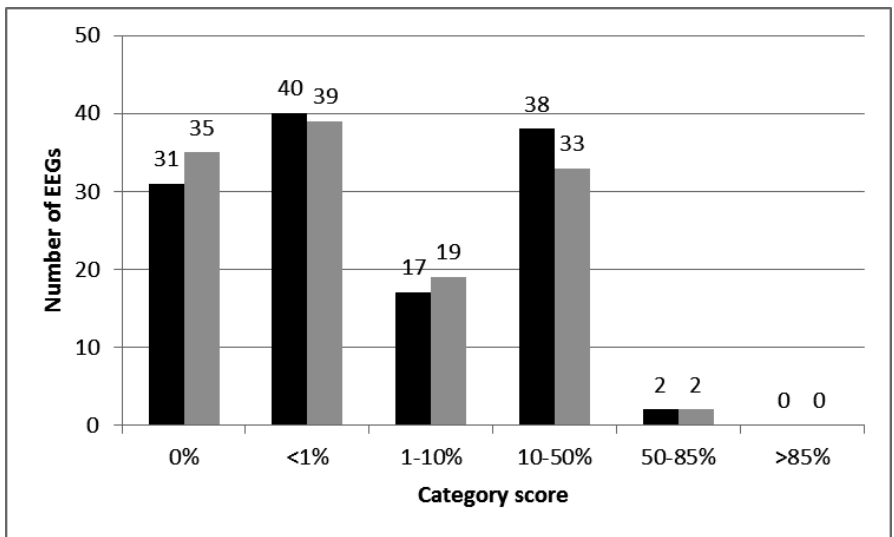

First 15 minutes of sleep

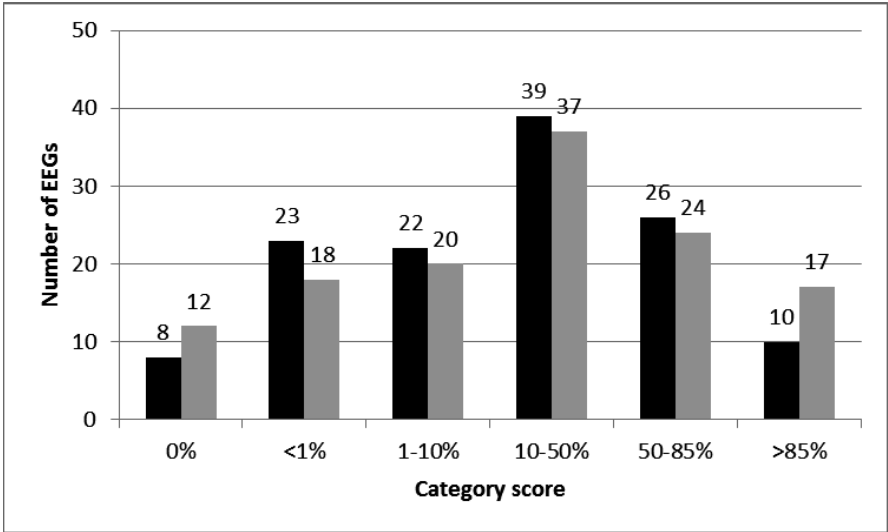

Rest of nREM-sleep

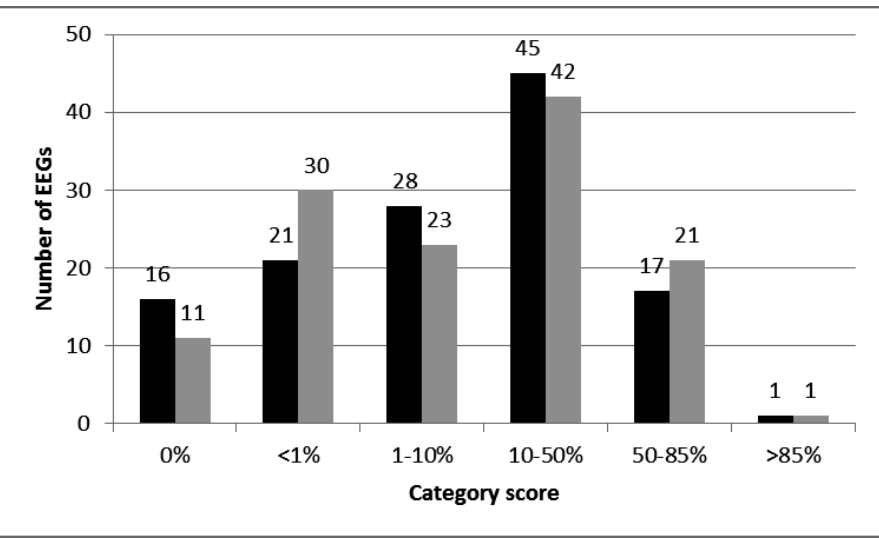

Figure 7.2 Distribution of scores of two observers each evaluating 128 EEGs in three states. Black color: observer 1. Grey color: observer 2. 


\section{Children versus adults}

The IED frequency was significantly higher in children than in adults, for both observers in all states. ${ }^{\mathrm{e}}$

When children with benign IED foci were removed (because these foci are especially known to occur with high frequency), this difference was still observed except for the scorings of observer 1 in the awake state. ${ }^{f}$

\section{Interobserver agreement}

Kappa-values showed a moderate agreement (Table 7.5). Using a weight of 0.25 for adjacent categories increased Kappa's only slightly (10\%).

Because the agreement on lack of IEDs or on finding sporadic IEDs was of less interest, EEG states in which one or both observers had not found IEDs were excluded. This did not increase the Kappa scores significantly.

Table 7.5 Cohen's Kappa values for 2 observers scoring IEDs in 3 states in either all EEGs ( $n=128)$ or a subset.

\begin{tabular}{llcc}
\hline & & State & \\
\hline & Wakefulness & Sleep (first 15 min) & Sleep (rest of nREM sleep) \\
\hline All EEGs & $0.58(n=128)$ & $0.58(n=128)$ & $0.57(n=128)$ \\
Subset & $0.64\left(n=85^{1}\right)$ & $0.60\left(n=114^{2}\right)$ & $0.59\left(n=109^{3}\right)$ \\
\hline
\end{tabular}

${ }^{1} 0 \%$ scored by 1 or both the observers excluded $\mathrm{n}=23$ both observers $0 \%$,

$\mathrm{n}=11$ observer $20 \%$, observer $1<1 \%$,

$\mathrm{n}=8$ observer $10 \%$, observer $2<1 \%$,

$\mathrm{n}=1$ observer $20 \%$, observer $11-10 \%$.

${ }^{3} 0 \%$ scored by 1 or both the observers excluded

$\mathrm{n}=8$ both observers $0 \%$,

$\mathrm{n}=3$ observer $20 \%$, observer $1<1 \%$,

$\mathrm{n}=7$ observer $10 \%$, observer $2<1 \%$,

$\mathrm{n}=1$ observer $10 \%$, observer $21-10 \%$
${ }^{2} 0 \%$ scored by 1 or both the observers excluded $\mathrm{n}=6$ both observers $0 \%$, $\mathrm{n}=5$ observer $20 \%$,observer $1<1 \%$, $\mathrm{n}=1$ observer $10 \%$, observer $2<1 \%$, $\mathrm{n}=1$ observer $20 \%$, observer $11-10 \%$, $\mathrm{n}=1$ observer $10 \%$, observer $21-10 \%$

Table 7.6 shows the ratio's of agreements and disagreements. It can be concluded that about $70 \%$ of assessments were scored in the same category by both observers.

Table 7.7 shows the Kappa values for subgroups. Agreement was the worst for generalized IEDs in wakefulness, but the IED-type "unifocal IEDs" lead to higher agreement. Agreement in children was generally higher. The agreement in the first 15 minutes of sleep was almost perfect in 23 patients with benign focal IEDs. Figure 7.3 shows the distributions in this group. 
Table 7.6 Proportions of agreement and disagreement of 2 observers scoring IEDs in 3 states in either all EEGs ( $n=128)$ or a subset.

\begin{tabular}{|c|c|c|c|c|c|c|c|c|c|}
\hline \multirow[b]{2}{*}{ Data } & \multicolumn{3}{|c|}{$\begin{array}{l}\text { Wakefulness } \\
(n=128)\end{array}$} & \multicolumn{3}{|c|}{$\begin{array}{l}\text { First } 15 \text { min. of sleep } \\
\qquad(\mathrm{n}=128)\end{array}$} & \multicolumn{3}{|c|}{$\begin{array}{l}\text { Rest of nREM sleep } \\
(n=128)\end{array}$} \\
\hline & Agr. & Adj. & $>$ Adj. & Agr. & Adj. & $>$ Adj. & Agr. & Adj. & $>$ Adj. \\
\hline \multirow[t]{2}{*}{ All } & 88 & 32 & 8 & 85 & 40 & 3 & 85 & 42 & 1 \\
\hline & (69\%) & $(25 \%)$ & $(6 \%)$ & (66\%) & (31\%) & $(2 \%)$ & (66\%) & $(33 \%)$ & $(0.1 \%)$ \\
\hline \multirow[t]{2}{*}{ Subset $^{1}$} & 65 & 19 & 1 & 79 & 34 & 1 & 77 & 32 & 0 \\
\hline & (76\%) & $(22 \%)$ & $(1 \%)$ & (69\%) & $(30 \%)$ & $(1 \%)$ & (71\%) & $(29 \%)$ & $(0 \%)$ \\
\hline
\end{tabular}

${ }^{1} 0 \%$ scored by 1 of the observers excluded. Agr.= agreement on the category. Adj.= disagreement with adjacent category chosen by the other observer. $>$ Adj. = disagreement with category further away than the adjacent category chosen by the other observer.

Table 7.7 Cohen's Kappa values for 2 observers scoring IEDs in 3 states in either all EEGs $(n=128)$ or a subset per subgroup.

\begin{tabular}{|c|c|c|c|c|c|c|c|}
\hline \multirow[b]{2}{*}{ Subgroup } & \multirow[b]{2}{*}{ Nr EEGs } & \multicolumn{2}{|c|}{ Wakefulness } & \multicolumn{2}{|c|}{ First $15 \mathrm{~min}$. of sleep } & \multicolumn{2}{|c|}{ Rest of nREM sleep } \\
\hline & & All & Subset $^{1}$ & All & Subset $^{1}$ & All & subset $^{1}$ \\
\hline All & 128 & 0.58 & 0.64 & 0.58 & 0.60 & 0.57 & 0.59 \\
\hline Adults & 64 & 0.45 & 0.55 & 0.50 & 0.54 & 0.60 & 0.62 \\
\hline Children & 64 & 0.68 & 0.70 & 0.64 & 0.63 & 0.54 & 0.51 \\
\hline $\begin{array}{l}\text { Non-generalized IEDs (= } \\
\text { focal or multifocal) }\end{array}$ & $88^{2}$ & 0.61 & 0.64 & 0.58 & 0.62 & 0.59 & 0.62 \\
\hline Uni-focal IEDs & 59 & 0.68 & 0.70 & 0.60 & 0.64 & 0.67 & 0.70 \\
\hline Generalized IEDs & 35 & 0.40 & 0.55 & 0.54 & 0.52 & 0.48 & 0.48 \\
\hline Benign focal IEDs & 23 & 0.50 & 0.68 & 0.93 & 0.93 & 0.51 & 0.53 \\
\hline
\end{tabular}

${ }^{1} 0 \%$ scored by 1 of the observers excluded. ${ }^{2} 88$ out of 123 because observer 1 did not observe IEDs in 5 EEGs.

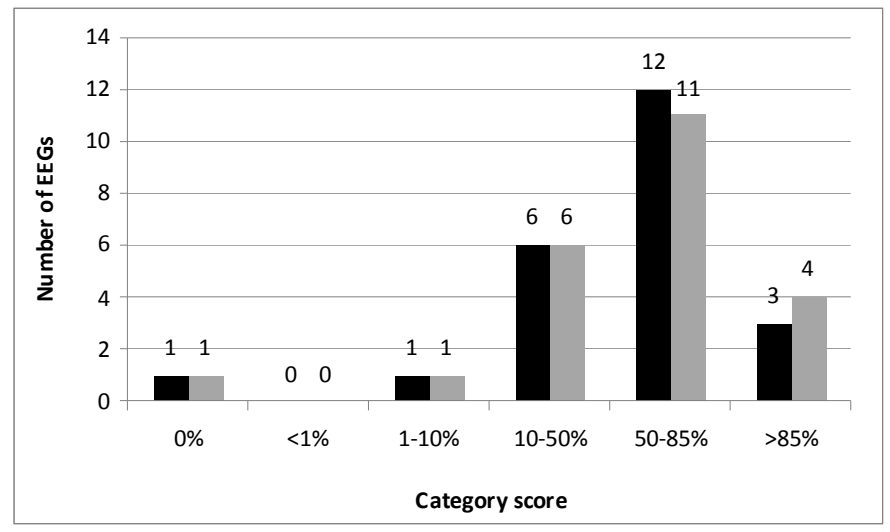

Figure 7.3 Distribution of IED categories in first 15 minutes of sleep, patients with benign focal IEDs $(n=23)$, kappa $=0.93$.

Black color: observer 1. Grey color: observer 2. 


\section{Summary of findings}

The interobserver agreement is moderate (around 0.60) and about $70 \%$ is scored in the same category.

Agreement is better in children and almost perfect in the first 15 minutes of sleep in EEGs with benign focal IEDs.

Agreement is lowest in EEGs with generalized IEDs as the predominant IED-type.

The time spent for the quantification, if IEDs are non-sporadic, was within 3 minutes.

\subsubsection{Questionnaires}

\section{Method}

Two different questionnaires were mailed, one to 27 EEG-technologists and the other to 22 neurologists working in our tertiary epilepsy centre.

Returned questionnaires were obtained from 27/27 EEG-technologists and 16/22 neurologists.

The questionnaires consisted of multiple choice questions with space for comments.

The addressed topics and questions are shown in appendix 7.1.

The results of the questionnaires were discussed in a group session with all EEGtechnologists and in a separate session with all neurologists.

\section{Results}

The answers on all questions are summarized in appendix 7.2.

EEG-technologists estimated to quantify the IEDs generally within 5 minutes. They thought that the most important clinical purpose of the quantification was to report changes between present and past EEGs. The scoring in predefined categories was generally felt to support a global impression on change between successive EEGs, however not for all EEGs. Some would like to have more categories, especially within the $10-50 \%$ range.

According to the neurologists the usefulness of the quantification method was restricted to patients with syndromes with high IED frequencies, to support the diagnosis, and to observe changes at follow-up. However neurologists appreciated the quantification table for all patients in the EEG-report, to see at one glance if they should be worried by high numbers of IEDs or a large change between successive EEGs. The interobserver agreement was generally estimated as moderate, by EEGtechnologists as well as referring neurologists. 


\subsection{And the winner is....?}

\section{A contest for scientific "benign focal spike detection" methods}

\section{Introduction}

How can an EEG best be characterized with respect to the quantity of epileptiform activity, and, more important, how is change detected in a follow-up EEG ? When a study needs the quantity of IEDs, does this mean the need of a person that is going to spend hours and hours into the donkey work of counting each IED ? Perhaps a machine could help?

Clinical case vignette:

A treating physician calls a neurophysiologist: "Could you please take a quick look at the 24-hour EEG of the child that was recorded this week ? I started to change the medication regime because she was really suffering from seizures and side effects. The previous EEG had a lot of IEDs and I'd like to know early if the EEG is now improved, to help me decide if I should go on with this medication change".

A clinical neurophysiologist can give a global impression of change within several minutes, just by running through pages from the previous and present EEG-recording. If experienced, the neurophysiologist knows which amount of change might probably be clinically relevant and related with treatment changes and which changes should be interpreted as within the range of spontaneous fluctuations of the particular type of epilepsy. However, in science, to get a paper accepted, one should better supply quantities and calculations of change with $95 \%$ confidence. Scientific confidence about a change in an EEG of one person, is a real challenge. There are no methods of this kind presented in literature. Nevertheless, in EEGs of patients with benign focal epilepsies, it is necessary to define reliable changes at individual level.

In this paragraph several methods are compared on the ability to detect changes in IED frequency in a baseline and repeated 24-hour EEG containing benign focal spikes. The methods should be of use for a scientific purpose: for observational prospective studies as well as for intervention studies. Special attention is paid to the ability to detect change in individual patients. It was also judged whether the outcome of the method on the amount and/or the change of IEDs would be suitable for statistical analyses.

More or less time-consuming methods that need visual calculation of IEDs were tested, as well as an automatic spike detector. 
Aspects included in the evaluation

1) Statistical analysis: the method can provide data to compare the EEGs of two groups.

The method should supply data to compare the EEGs of two groups that were defined by another variable (e.g. comparison of the IED frequency between a group with worse cognitive outcome to a group without cognitive problems or comparison of a group with an intervention to a non-intervention group or comparing groups with and without seizures).

2) Statistical analysis: the method can provide data for correlational analysis with other variables.

The method should supply data to correlate the IED frequency to another variable (e.g. the cognitive outcome, seizure frequency, other EEG variables).

3) The method is able to detect change between successive EEGs in individual patients.

Patients with benign focal spikes will have increase of the IED frequency at onset, then a decrease of the frequency and a disappearing of all IEDs at remission. This is an individual disease course that will cover months to years. Our condition is that the method should cover a wider spectrum of change, than only define to disappearance of IEDs. This will allow analysis between subgroups of patients with the same EEG-course. It will also allow examining whether another outcome parameter shows changes in same direction as the EEG-change for an individual patient.

4) The method shows reliable change between successive EEGs in individual patients.

A high reliability means that there is a high probability that other methods would conclude the same, and that taking another sample of the same size from the EEG would have a low chance to result in a different finding.

There are several threats to the reliability (Figure 7.4).

The first threat is a spontaneous fluctuation over time in relationship to the duration of the observed EEG sample. Furthermore a different sensitivity and/or specificity for IED detections for the first EEG compared to the second EEG is a threat. This could happen when a different EEG observer assesses the follow-up EEG, who has a different view on what is counted as an IED and what is not. This could also result from a different performance of an automatic detection algorithm in two successive EEGs, for example because of a different number of artifacts in each EEG that disturb the algorithm. When the detections from the separate 
successive EEGs are not valid, then the conclusion about change will also not be reliable. For a visual representation for the problems encountered with condition 4: see Figure 7.4.

5) The method shows a potentially clinically relevant change between successive EEGs in individual patients.

Small detected changes can be reliable, but are less likely to be clinically relevant (i.e. related with other clinical characteristics). Because there is no golden standard on what is a clinically relevant change, this condition could be turned around into the minimal condition of "it does not show clinical irrelevant change". Although there is no confirmation from literature and only clinical experience, it is hypothesized that the IED frequency does not change much from day to day in patients with benign focal spikes but only changes after a period of several months. It is also hypothesized that fluctuations of IEDs within a period of 48 hours, are of minor clinical relevance within the total disease course of several years. A condition for the method is that it should only signal changes larger than those found between two successive 24-hour periods from one patient. 
QUANTIFICATION

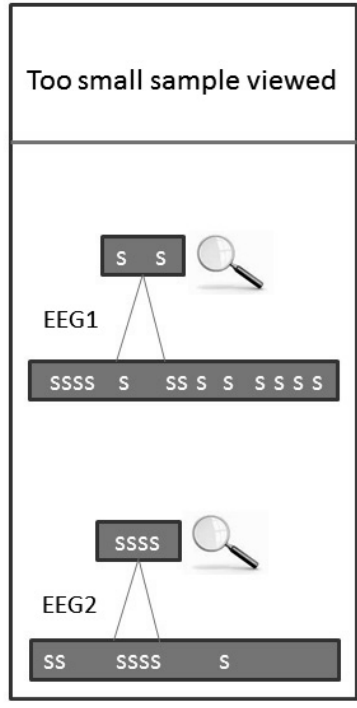

\section{DETERMINING CHANGE}
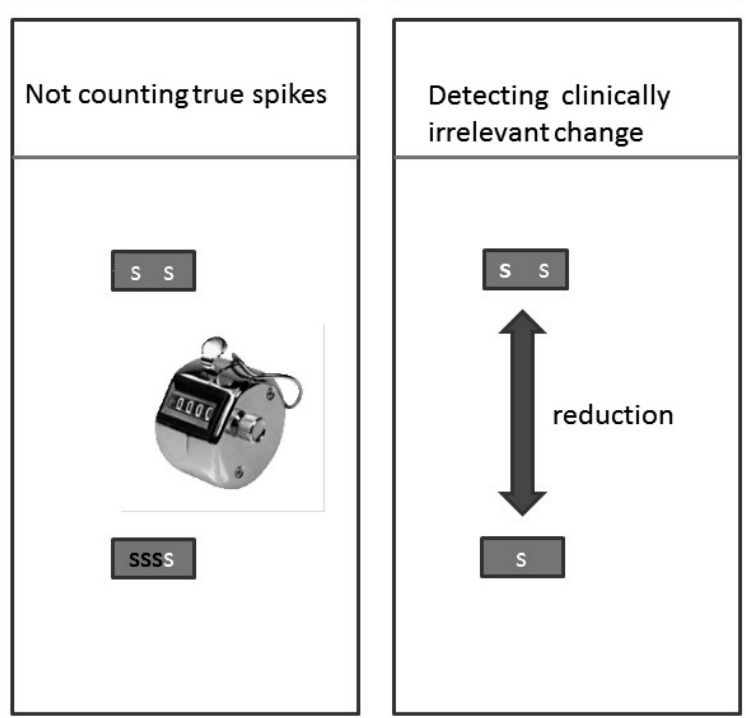

THREATS TO RELIABILITY

Figure 7.4 Threats to the decision of change in IED frequency between EEG1 and EEG2.

Blocks with "s s" written inside= EEG-fragment, length of the block is the duration of the sample and $s=$ spike. The moment of occurrence of the spike within the sample is represented by the position in the block.

Explanation of left figure: the sample out of EEG1 that is viewed, contains less spikes than the fragment from EEG2, while the original EEG 1 contained more spikes than EEG1.

Explanation of middle and right figures: when the 3 spikes in the lower sample are not counted as spikes (represented as black spikes in the middle figure), then the difference between the upper and lower sample will be defined as a reduction (right figure), while in fact this was an increase.

\section{Method}

\section{Datasets}

Two datasets were used (Table 7.8).

A 48-hour EEG was recorded in 8 children (dataset A). Because a condition for a method that detects change is that it should signal change when changes are larger than those found between two successive 24-hour periods from one patient, the methods should not conclude to change between the first and second 24 hour in dataset $A$.

The second set consisted of 22 24-hour EEGs at baseline and at follow-up in other children (dataset B). Because the follow-up EEG was at least 6 months later, it was expected to observe changes in a subset of these children. The size of this subset is 
difficult to predict. The children have different disease durations at inclusion. Since the patients were see in a tertiary centre, the dataset includes patients with a more severe course and possible longer period of highly frequent IEDs. There was no scheduled intervention in one part of this group as opposed to the other part.

Table 7.8 Datasets used to compare methods in their ability to signal changes in IEDs.

\begin{tabular}{lll}
\hline & Dataset A & Dataset B \\
\hline Nr of patients & $\mathrm{N}=8^{1}$ & $\mathrm{~N}=22^{2}$ \\
$24-$ hour EEGs & EEGA and EEGB & EEG1 and EEG2 \\
& (successive 24 hours) & (6-12 months in between) \\
\hline
\end{tabular}

${ }^{1}$ Children with benign focal spikes and diagnosed with Rolandic epilepsy. This study was approved by the local ethics commission and informed consent was obtained from all caregivers. ${ }^{2}$ These were patients with different syndromal diagnosis within the spectrum of benign focal epilepsies or with observed IEDs without seizures. This study compared EEGs at baseline with an EEG at 6 months, as well as EEGs at 6 months with EEGs at 24 months. Because changes are expected after a longer period of follow-up, we preferred to include into the EEG set the EEGs at 6 months and 24 months. If this EEG was not available, or if the EEG at 18 months showed only sporadic or no IEDs, we used the EEGs with 6 months in between. 14 were diagnosed with Rolandic epilepsy, 8 with other diagnosis ( $n=2$ Panayiotopoulos syndrome, $n=4$ epileptic foci but no observed seizures, $n=2$ occipital focus and unclear syndromal diagnosis but EEG is typical of a benign focal epilepsy).

\section{Types of IED analysis}

One automatic detection algorithm and 3 methods with visual inspection were used.

\section{Measurement scales}

Among the methods using visual inspection, there were methods with different measurement scales: nominal, ordinal or scale. The order from nominal to scale means an increase in the time needed to analyze an EEG.

\section{Sample sizes}

For the methods using visual inspection, either a sample of 30 pages, or a "sample free" method was applied.

The size of the sample (30 10-second pages for wakefulness and 3010 -second pages for sleep) was chosen based on the knowledge from daily clinical practice of the usual number of IEDs in patients with benign focal spikes. It was presumed that this number of pages would be sufficient for a reliable sample, if the pages would not be successive but randomly spread throughout a larger sample of wakefulness or the first hour of sleep. A sample of $2 \times 30$ pages for 1 EEG takes 10 minutes to analyze with the most time-consuming visual analysis method. For the whole dataset of $44 \mathrm{EEGs}$, this meant one day of work. With the same duration, the chosen automatic detection software can analyze 2 hours of each 24 hour EEG, and for this method the sample size was set at 1 hour of wakefulness and the first hour of sleep. 
"Sample free" means that the observer views as many pages as he/she thinks are needed to come to the conclusion. This resembles daily clinical practice. Hypothetically, this method will take into account the variability over time better than a predefined sample. When the variability is high, the observer will probably view more pages to come to a final conclusion on the frequency of IEDs/on change. The number of observed pages for each EEG in the sample free methods was not counted. A rough estimation from experience is that this takes about 30-100 pages for wakefulness or sleep. Because these pages do not have to be scored individually, and can be screened very quickly if the EEG observer is experienced, this is still less time-consuming than to attribute a score to every page of a set of 30 pages.

Table 7.9 shows the methods. Further explanation of the methods is shown in appendix 7.3.

From now on the following abbreviations of the used methods to obtain the IEDs quantification are used:

1. AUTO (automatic detection in sample of 1 hour)

2. MAN30 (manual counts in sample of 30 pages)

3. CAT30 (category scores in sample 30 pages)

4. CATglob (global category score, "sample free")

Table 7.9 Overview of 5 methods to define changes in IEDs between two 24-hour EEGs.

\begin{tabular}{|c|c|c|}
\hline Method $^{1}$ & Sample & Variable type \\
\hline $\begin{array}{l}\text { Automatic spike detection } \\
\text { (AUTO) }\end{array}$ & $\begin{array}{l}1 \text { hour of wakefulness and first hour } \\
\text { of sleep }\end{array}$ & $\begin{array}{l}\text { Continuous } \\
\text { (number of detections/hour) }\end{array}$ \\
\hline Manual counts & 30 random pages in wakefulness and & Continuous \\
\hline (MAN30) & $\begin{array}{l}30 \text { random pages from first hour of } \\
\text { sleep }\end{array}$ & (number of seconds with IEDs) \\
\hline Category scores, pages & 30 random pages in wakefulness and & Pseudo $^{2}$-continuous \\
\hline (CAT30) & $\begin{array}{l}30 \text { random pages from first hour of } \\
\text { sleep } \\
\text { (same pages used as for method } 2 \text { ) }\end{array}$ & $\begin{array}{l}\text { (mean score of the numbered } \\
\text { categories of set of } 30 \text { pages) }\end{array}$ \\
\hline $\begin{array}{l}\text { Category score, global } \\
\text { (CATglob) }\end{array}$ & $\begin{array}{l}\text { As many pages the observer } \\
\text { esteemed necessary to come to a } \\
\text { conclusion, in wakefulness and first } \\
\text { hour of sleep }\end{array}$ & $\begin{array}{l}\text { Ordinal } \\
\text { (category of the frequency of IEDs) }\end{array}$ \\
\hline $\begin{array}{l}\text { Global impression } \\
\text { (GLOB) }\end{array}$ & $\begin{array}{l}\text { As many pages the observer } \\
\text { esteemed necessary to come to a } \\
\text { conclusion, in wakefulness and first } \\
\text { hour of sleep }\end{array}$ & $\begin{array}{l}\text { Nominal } \\
\text { Only used to determine change } \\
\text { (improved, worsened or no change) }\end{array}$ \\
\hline
\end{tabular}

\footnotetext{
${ }^{1}$ Except for method 5 (global impression of change) the EEGs of the same patients were not scored directly after each other and the observer was not aware of the score of the other EEG of the patient if this had already been scored. The observer was not aware of the scores obtained by the other used methods if these had already been applied. " "Pseudo" because the scale variable was constructed out of an ordinal scoring method.
} 


\section{Definitions of change}

To define change between successive EEGs in 1 child is a challenging task, especially for the different methods on a scale measurement level. It is obvious that a change from 30 IEDs at baseline to 29 in 5 minutes, or from 500 to 490 in an hour, are small changes, presumably not clinically relevant. However, what reduction or increase, should be defined as change ? To define a minimum proportional \% of change, is not always adequate, especially not in cases with lower number of IEDs. E.g. a reduction from 2 to 1 seconds with IEDs in 5 minutes means a high proportional reduction of $50 \%$. The same proportional reduction in a patient with 300 seconds with IEDs at baseline is probably a more relevant change.

Our methods to determine change between two EEGs, are presented in Table 7.9 and appendix 7.3 for each method. For scale measurement levels two methods were developed: "P" and "LIM".

Method $\mathrm{P}$ uses the assumption that the IEDs would be Poisson distributed. Method P was applied, aware of the fact the IEDs would probably not follow the Poisson distribution perfectly, especially because of tendency of benign focal spikes to sometimes occur in short trains (clusters) of 2-6 IEDs on a 10-second EEG page. The software program of method $P$ is shown in appendix 7.4.

LIM uses a twice scored baseline to obtain insight in the (group) variability between two scored samples and from these scores it determines limits above/below which change in individuals at follow-up is defined. LIM was only used for the visually obtained data from method MAN30, because within a 24 hour EEG, the first hour of sleep for the automatic detection of IEDs cannot be twice analyzed. Because it is known that the IED frequency differs between sleep stages, it would be not appropriate to use the second hour of sleep that would certainly have a different mix of sleep stages than the first hour.

Appendix 7.3 shows further explanations on all methods to define change. In total, there are 5 combinations of detection methods and methods to define change and one method only deciding to change by global impression (resembling daily clinical practice).
1. AUTO
method to define change $P$
2. MAN30
method to define change $P$
3. MAN30
method to define change LIM
4. CAT30
method to define change MWU test
5. CATglob
method to define change category shift ( 2 different boundaries)
6. GLOB
method to define change global impression of change

Method LIM needed the following additional analysis of the data from method MAN30 to determine the limits. 


\section{Determination of limits for dataset A (8 successive 24 hour EEGs within 48 hour).}

The limits were determined from EEGA's twice scored. For wakefulness these limits were -22.1 and 12.6 and for sleep -29.2 and 18.7 (these values are the detected seconds with IEDs). See also the plots of the data in Figure 7.5. The differences had a normal distribution in sleep (Shapiro Wilk test for normal data). However there was no normal distribution in wakefulness $(p=0.008)$ so that the limits for wakefulness are less reliable. These limits of agreement were used to define change in EEGB in wakefulness and/or sleep:

A change of more than 22 in wakefulness and more than 30 in sleep in EEGB, would mean a reliable change between EEGA and EEGB in dataset $A$ (these values are the detected seconds with IEDs)

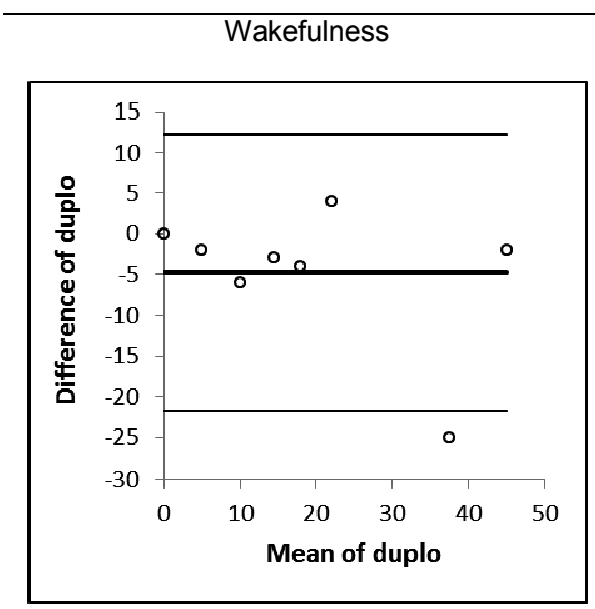

Sleep

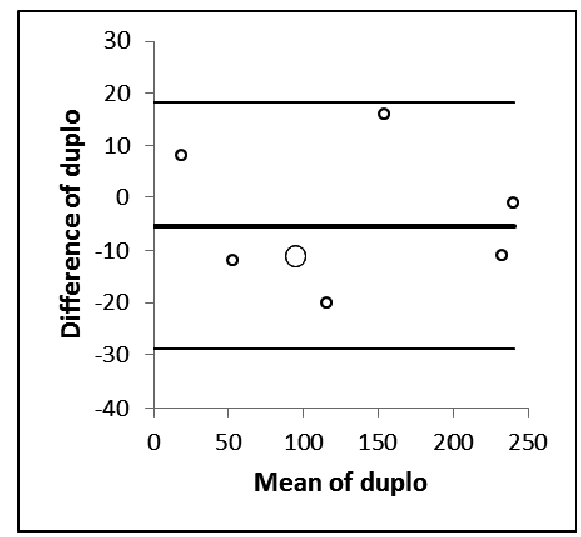

Figure 7.5 Bland-Altman plots of 8 "EEGs A" scored twice for number of seconds containing IEDs during wakefulness (left) and sleep (right).

Values on $X$ - and Y-axes are number of seconds containing IEDs. Horizontal bold line in the middle: mean difference. Top and bottom lines: mean difference \pm 2 SD (=limits). For sleep: 2 patients with same score overlap, denoted by larger circle.

\section{Determination of limits for dataset B (22 successive 24 hour EEGs with 6-18 months in between)}

The limits were determined from EEG1's scored twice. For wakefulness these limits were -16.5 and 11.8 and for sleep -34.8 and 29.1 (Figure 7.6). The differences had a normal distribution in wakefulness and sleep (Shapiro Wilk test for Normal data, which means that the distribution of the observations cannot be rejected as non-Gaussian). These limits of agreement were used to define change in EEG2 in wakefulness and/or sleep: a change of more than 17 seconds in wakefulness and more than 35 seconds in sleep would mean a reliable change between EEG1 and EEG2 in dataset B. 


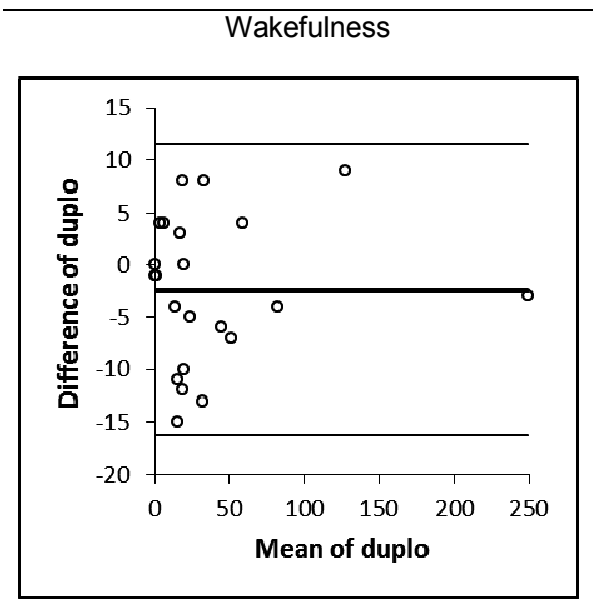

Sleep

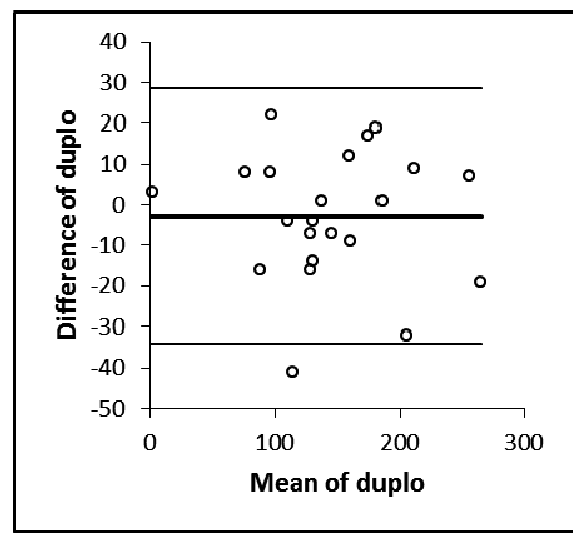

Figure 7.6 Bland-Altman plots of 22 "EEGs 1" scored twice for number of seconds containing IEDs during wakefulness (left) and sleep (right).

Values on $\mathrm{X}$ - and $\mathrm{Y}$-axes are number of seconds containing IEDs. Horizontal bold line in the middle: mean difference. Top and bottom lines: mean difference \pm 2 SD (= limits).

\section{Results}

The results are presented in the order of the predetermined conditions. In annotations illustrative cases are presented with referral to appendix 7.5 or 7.6 of this chapter in which the decisions on change of all methods in all individual EEGs can be seen.

\section{Condition 1: Statistical analysis: it can supply data to compare the EEGs of two groups.}

For the calculation of a difference in EEG abnormalities between two groups, method GLOB can only supply categories of "no change" and "change". A category of "EEG normalization" could be added. This is a rather low number of categories for comparing groups. A second negative aspect of GLOB is that it can only supply these data for the EEG at follow-up. All other methods can supply more "fine-tuned" changes/ more categories and are more suitable for group comparisons. They can also supply baseline data on the distribution of EEG abnormalities. For methods with a scale measurement (AUTO, MAN30) an advantage is that the mean and standard deviations can be calculated and presented for all compared groups. The method CAT30 resulting in a "pseudo-continuous variable" can present a mean of the category scores of the 30 pages for individuals and for groups (when categories are numbered 1-4), however, these means are difficult to interpret. 


\begin{tabular}{lc}
\hline Methods & $\begin{array}{c}\text { Comparing groups } \\
\text { Ranking }\end{array}$ \\
\hline AUTO & 1 \\
MAN30 & 1 \\
CAT30 & 2 \\
CATglob & 3 \\
GLOB & 4 \\
\hline
\end{tabular}

Condition 2: Statistical analysis: it can supply data for correlation analysis with another variable.

For correlation analysis the method should cover the whole range of the possible values and have enough values within this range. With method GLOB correlations between the frequency of IEDs and other variables may be missed and correlations can only be performed on the outcome of change. A method supplying data on a continuous scale, on baseline and at follow-up, best supports correlation analysis. The methods supplying categorical data (CAT30 and CATglob) can also be used.

\begin{tabular}{lc}
\hline Methods & $\begin{array}{c}\text { Correlation analysis } \\
\text { Ranking }\end{array}$ \\
\hline AUTO & 1 \\
MAN30 & 1 \\
CAT30 & 2 \\
CATglob & 2 \\
GLOB & 3 \\
\hline
\end{tabular}

\section{Condition 3: It is able show change in individual patients.}

All methods were primarily developed to show change in individual patients, however different methods to decide to change were used.

The CATglob method that only decides to change when the follow-up EEG is categorized further away than the adjacent category, is the least sensitive to change in dataset B (Figure 7.7). The automatic detection of IEDs (AUTO) combined with method $P$ to assign change, is the most sensitive to change. In fact, in sleep all EEGs are defined as changed by method AUTO+P.

An aspect of method LIM is the fact that the decision of change between EEGs with low number of IEDs at baseline and disappearance of IEDs at follow-up, depends on the defined limit. The higher the limit, the less sensitive the method will be in detecting change even when the EEG at follow-up truly does not contain IEDs. This could potentially lead to missing the clinically relevant change to disappearance of all IEDs. This is observed in one of the cases. ${ }^{\mathrm{g}}$

The chance of finding a difference in an individual patient is related to the amount of the proportional change from baseline. However, the range of proportional differences 
(used data from MAN30 to be viewed in appendix 7.5) from the cases in which most methods conclude to change overlaps the range of proportional differences when most methods conclude to stability. ${ }^{\text {h }}$
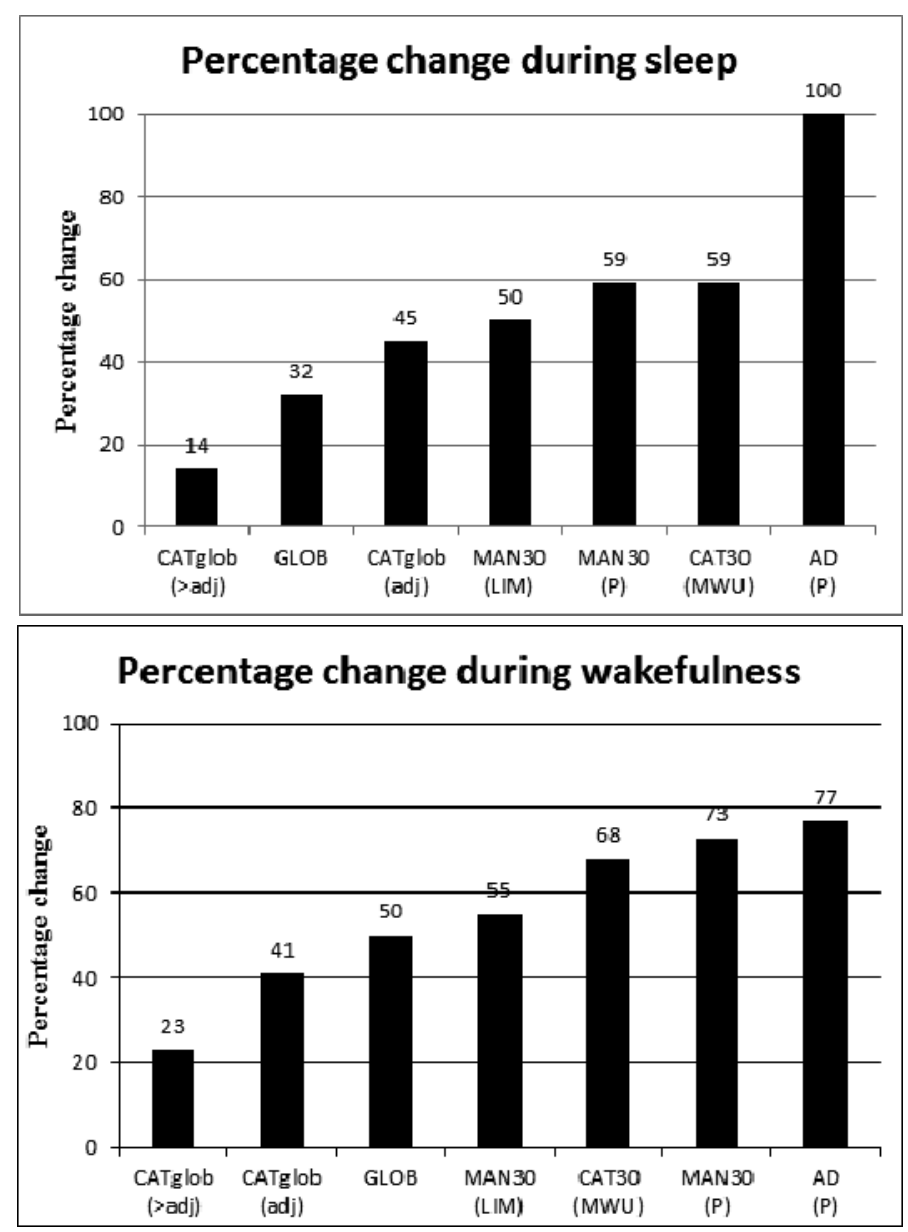

Figure 7.7 Comparison of several methods on the \% of EEGs defined as changed in dataset B (22 EEGs at baseline and $22 \mathrm{EEGs}$ at follow-up).

\section{Condition 4: It shows reliable change}

A challenge for analyzing reliability is that there is no golden standard for EEG change. One can only get an indirect impression of the reliability from the agreements and disagreements between the compared methods. E.g. if one method systematically would conclude differently from the other methods, then this method assumedly is less reliable. 
From the observations of unexpected disagreements (Table 7.10), it can be concluded that method AUTO has the lowest reliability. The most probable origin of this lower reliability is the problems with the validity in several cases. This can be concluded from appendix 7.7 in which all automatic detections are shown combined with the estimated sensitivity to detect visually identified IEDs. For a comparison in this appendix the proportional changes of the MAN30 method are shown as well. Although there is no significant difference between proportional changes from MAN30 and AUTO (Wilcoxon wakefulness $P=0.08$, sleep $P=0.6$ ), proportional changes can differ largely between method AUTO and MAN30 and may be in the opposite direction especially when sensitivity of AUTO is estimated as moderate or low. From the experience working with method AUTO, the causes of a lower sensitivity were frequent artifacts (movement or electrical) and/or low amplitude IEDs (Figure 7.8 shows examples of artifacts in the EEG that can complicate the detection of IEDs.).

The methods GLOB and MAN30 combined with method LIM seem the most reliable when unexpected results are observed in relationship to the other methods (table 10). Method MAN30 combined with LIM has success with being less sensitive to change than MAN30 combined with P: in several cases method MAN30+LIM was more adequate than combined with $\mathrm{P}$ in concluding to stability. 'The most obvious reason for that is because LIM has a compensation for the variability in the IEDs over time by scoring 2 samples at baseline.

Theoretically, a threat for method LIM as a method to define change, is the construction of the limits from the group data. A small group of patients with large variation of IEDs over time in the baseline EEG, could cause wide limits that prohibit the observation of relevant change in others. However, in this study no cases were observed in which the combination of MAN30 and method LIM concluded to stability and all other methods concluded to change. Therefore it is concluded that too wide limits were no problem in the examined group.

\begin{tabular}{lcc}
\hline Detection Methods & Methods to define change & $\begin{array}{c}\text { Reliable change } \\
\text { Ranking }\end{array}$ \\
\hline AUTO & P & 5 \\
MAN30 & P & 2 \\
& LIM & 1 \\
CAT30 & MWU & 2 \\
CATglob & $>$ adj & 3 \\
& adj & 4 \\
GLOB & GLOB & 1 \\
\hline
\end{tabular}


Table 7.10 Unexpected disagreements on the decision of one method compared to the decisions of other methods.

\begin{tabular}{|c|c|c|c|c|c|c|}
\hline \multicolumn{7}{|c|}{ Unexpected disagreements $^{1}$} \\
\hline GLOB & AUTO & MAN30 & MAN30 & САТЗ & CATglob & CATglob \\
\hline GLOB & $\mathrm{P}$ & $\mathrm{P}$ & LIM & MWU & >adj & adj \\
\hline \multicolumn{7}{|c|}{ Wakefulness } \\
\hline $\mathrm{N}=1$ & $\mathrm{~N}=2$ & $\begin{array}{l}\mathrm{N}=0 \\
(\mathrm{~N}=1)^{2}\end{array}$ & $\begin{array}{l}\mathrm{N}=0 \\
(\mathrm{~N}=1)^{2}\end{array}$ & $\begin{array}{l}\mathrm{N}=0 \\
(\mathrm{~N}=1)^{2}\end{array}$ & $N=3$ & $N=3$ \\
\hline case 4 & case 15,22 & $(\text { case } 15)^{2}$ & $(\text { case } 15)^{2}$ & $(\text { case } 15)^{2}$ & case $1,3,11$ & case $1,3,21$ \\
\hline \multicolumn{7}{|l|}{ Sleep } \\
\hline \multirow[t]{2}{*}{$\mathrm{N}=0$} & $N=6$ & $\begin{array}{l}N=0 \\
(N=1)^{2}\end{array}$ & $\mathrm{~N}=0$ & $\begin{array}{l}N=0 \\
(N=1)^{2}\end{array}$ & $\mathrm{~N}=3$ & $\mathrm{~N}=2$ \\
\hline & $\begin{array}{l}\text { case } 8,10,11, \\
14,18,21\end{array}$ & $\left(\right.$ case 20) ${ }^{2}$ & & $(\text { case } 20)^{2}$ & case $1,5,7$ & case 1,20 \\
\hline \multicolumn{7}{|l|}{ Total } \\
\hline 1 & 8 & $\begin{array}{l}0 \\
(2)^{2}\end{array}$ & $\begin{array}{l}0 \\
(1)^{2}\end{array}$ & $\begin{array}{l}0 \\
(2)^{2}\end{array}$ & 6 & 5 \\
\hline \multicolumn{7}{|c|}{$\begin{array}{l}{ }^{1} \text { Definitions and rules: Definitions of unexpected change: } 1 \text { ) one method decides differently on the change } \\
\text { between EEG1 and EEG } 2 \text { than all other methods e.g. case } 10 \text { sleep, case } 11 \text { wakefulness. } 2 \text { ) A methoc } \\
\text { unexpectedly decided to change in an opposite direction (e.g. case } 8 \text { in sleep). Rules: Agreements between } \\
\text { CATglob>adj and CATglob adj were not observed as separate scores because when CATglob>adj detects } \\
\text { change, CATglob adj will also always detect change (e.g. case } 3 \text { wakefulness). }{ }^{2} \text { Because methods that used the } \\
\text { same } 30 \text { pages have more chance on agreement, between () the cases are shown that had agreement } \\
\text { between } 2 \text { or } 3 \text { methods using the same } 30 \text { pages, but disagreed with the other methods (e.g. case } 20 \\
\text { wakefulness). }\end{array}$} \\
\hline
\end{tabular}

\section{Condition 5: It shows potentially clinically relevant change}

Because there is no golden standard on what is a clinically relevant change, the condition is that the method at least does not show clinical irrelevant change. Day-today changes are considered as irrelevant based on clinical experience. To test the methods, dataset A with 48 hour EEGs were regarded as two successive 24-hour EEGs. See appendix 7.6. This condition is best met by the method GLOB as well as MAN30 combined with LIM.

\begin{tabular}{lcc}
\hline Detection Methods & Methods to define change & $\begin{array}{c}\text { No detection of irrelevant change } \\
\text { Ranking }\end{array}$ \\
\hline AUTO & P & 6 \\
MAN30 & P & 3 \\
& LIM & 1 \\
CAT30 & MWU & 2 \\
CATglob & $>$ adj & 4 \\
& adj & 5 \\
GLOB & GLOB & 1 \\
\hline
\end{tabular}




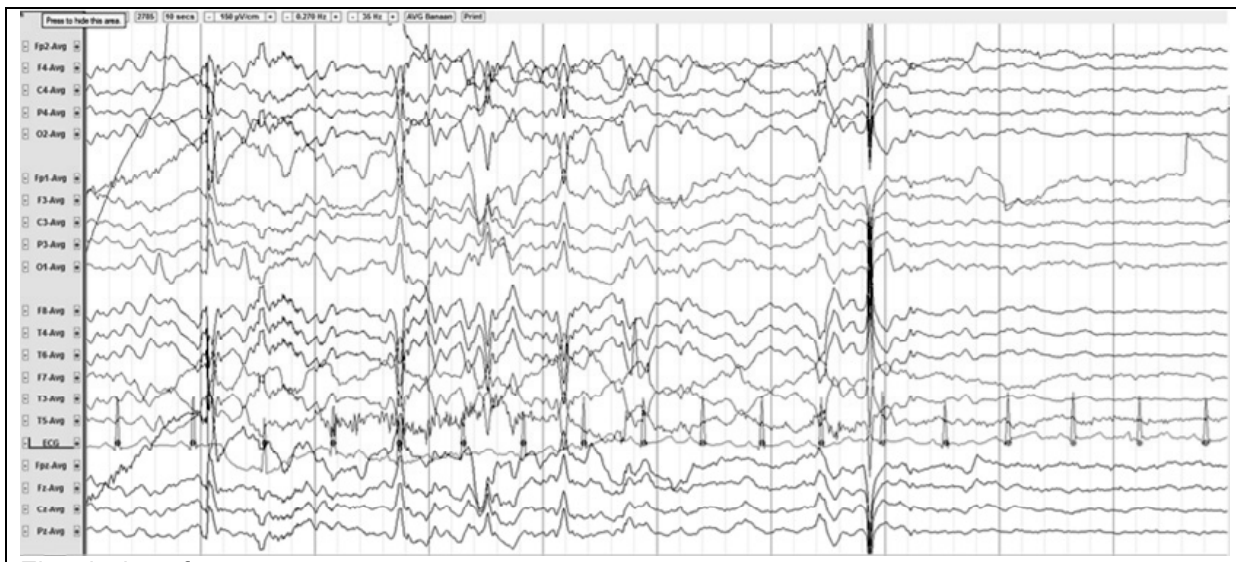

\section{Electrical artefact}

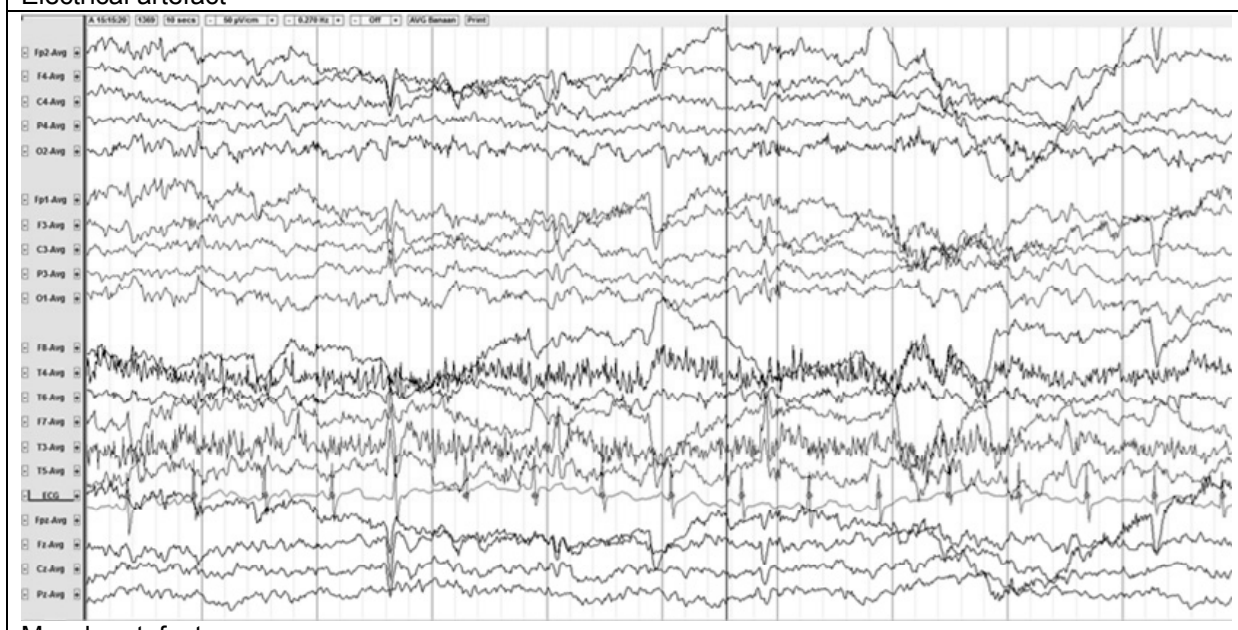

\section{Muscle artefact}

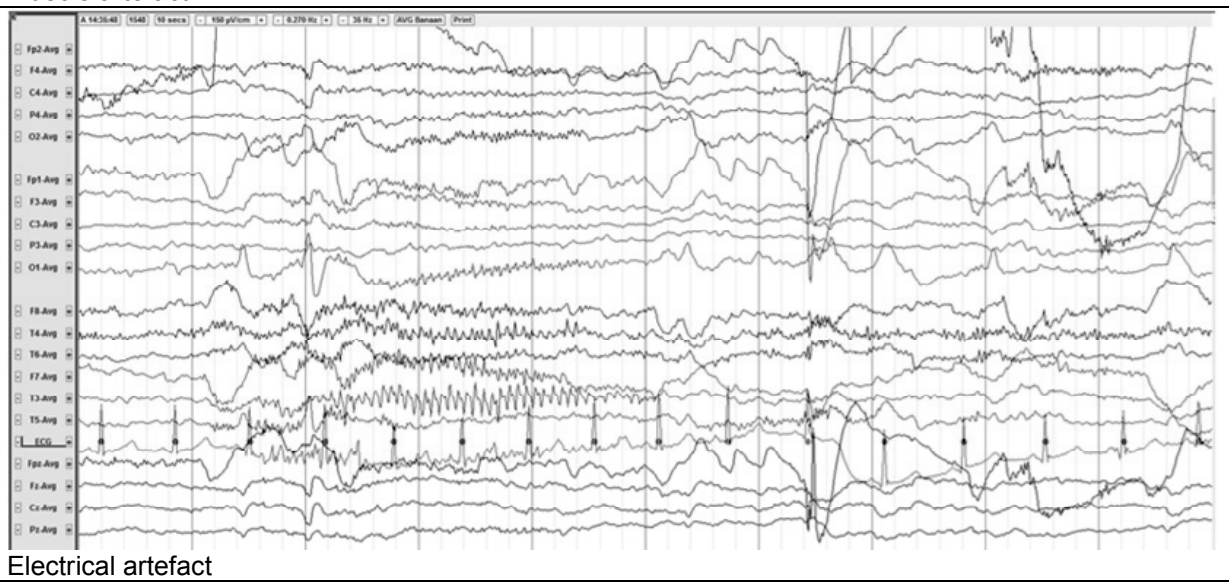

Figure 7.8 Examples of artefacts in 10-second EEG fragments (common average montage) that may disturb detection of IEDs. 


\section{Conclusion}

In the following tables the findings are summarized and the methods are finally ranked taking into account all positive and negative aspects.

\begin{tabular}{lcccc}
\hline Detection Methods & \multicolumn{2}{c}{$\begin{array}{c}\text { Properties for statistical analysis } \\
\text { Methods to define } \\
\text { change }\end{array}$} & $\begin{array}{c}\text { Group analysis } \\
\text { Correlational analysis }\end{array}$ & RANKING \\
\hline AUTO & P & 1 & 1 & 1 \\
MAN30 & P & 1 & 1 & 1 \\
& LIM & 1 & 1 & 1 \\
CAT30 & MWU & 2 & 2 & 2 \\
CATglob & $>$ adj & 3 & 2 & 3 \\
& adj & 3 & 2 & 3 \\
- & GLOB & 4 & 3 & 4 \\
\hline
\end{tabular}

\begin{tabular}{lccccc}
\hline \multirow{2}{*}{ Detection Methods } & $\begin{array}{c}\text { Methods to } \\
\text { define change }\end{array}$ & $\begin{array}{c}\text { Group } \\
\text { analysis }\end{array}$ & $\begin{array}{c}\text { Correlational } \\
\text { analysis }\end{array}$ & $\begin{array}{c}\text { Reliability/validity } \\
\text { detecting changes }\end{array}$ & RANKING \\
\hline AUTO & $\mathrm{P}$ & 1 & 1 & 5 & 4 \\
MAN30 & $\mathrm{P}$ & 1 & 1 & 2 & 2 \\
& LIM & 1 & 1 & 1 & 1 \\
CAT30 & MWU & 2 & 2 & 2 & 3 \\
CATglob & $>$ adj & 3 & 2 & 3 & 5 \\
& adj & 3 & 2 & 4 & 6 \\
- & GLOB & 4 & 3 & 1 & 5 \\
\hline
\end{tabular}

\begin{tabular}{lcc}
\hline Detection Methods & $\begin{array}{c}\text { Clinical properties (ability to detect relevant changes) } \\
\text { Methods to define change }\end{array}$ & RANKING \\
\hline AUTO & P & 6 \\
MAN30 & P & 3 \\
& LIM & 1 \\
CAT30 & MWU & 2 \\
CATglob & $>$ adj & 4 \\
& adj & 5 \\
- & GLOB & 1 \\
\hline
\end{tabular}

\begin{tabular}{lccccccc}
\hline $\begin{array}{l}\text { Detection } \\
\text { Methods }\end{array}$ & $\begin{array}{c}\text { Methods to } \\
\text { define } \\
\text { change }\end{array}$ & $\begin{array}{c}\text { Group } \\
\text { analysis }\end{array}$ & $\begin{array}{c}\text { All properties } \\
\text { Correlational } \\
\text { analysis }\end{array}$ & Reliable/valid & $\begin{array}{c}\text { relevant } \\
\text { change }\end{array}$ & $\begin{array}{c}\text { TOTAL } \\
\text { score }\end{array}$ & $\begin{array}{c}\text { FINAL } \\
\text { RANK }\end{array}$ \\
\hline AUTO & $\mathrm{P}$ & 1 & 1 & 5 & 6 & 14 & 6 \\
MAN30 & $\mathrm{P}$ & 1 & 1 & 2 & 3 & 6 & 2 \\
& LIM & 1 & 1 & 1 & 1 & 4 & 1 \\
CAT30 & MWU & 2 & 2 & 2 & 2 & 8 & 3 \\
CATglob & $>$ adj & 3 & 2 & 3 & 4 & 13 & 5 \\
& adj & 3 & 2 & 4 & 5 & 15 & 7 \\
- & GLOB & 4 & 3 & 1 & 1 & 9 & 4 \\
\hline
\end{tabular}


The best method is the MAN30 combined with LIM-method working with the calculation of limits from a twice scored baseline EEG. This method rated number 1 on all conditions. The decisions on change for individual patients with benign focal spikes are the most reliable and have the highest chance to be of clinical relevance. When the statistical analysis properties would be assessed as less important for a study design, and only individual changes in EEG should be observed, then GLOB would also be a winner. It is reassuring that this method that is used in clinical daily practice (assessing changes by global impression) is reliable. However, in science, for most study designs it will be important to describe the baseline data and to be able to do good correlational analysis and/or calculations of group differences. This is less possible with the results of method GLOB.

There are some considerations for the MAN30+LIM method. It is less sensitive than method P and CAT30 to decide to change in the subset of patients with low IED number at baseline (lower than the defined limit) and disappearance of IEDs in the follow-up EEG. Because disappearance of IEDs is a probably clinically relevant change, It is suggested to add global viewing in about 100 pages more of the follow-up EEG in these patients. The global viewing of these extra pages will increase the certainty that the EEG is indeed normalized and the decision for this patient should then be "changed" instead of "unchanged".

Furthermore, using method LIM, it is possible that the differences between first and second scored set in the baseline EEG are not normally distributed, which could make the determined limits less reliable. This will unfortunately become clear at a late moment, at the time that all baseline EEGs have been registered and scored. It is difficult to predict what effect the non-normal distribution will have on the reliability of method LIM. It seemed not to have a large influence on the reliability of the decisions for dataset $A$ (in which the differences in wakefulness were not normally distributed). However, it the distribution is not normal, it is then suggested to switch to the MAN30+P method which has obtained the second place in our contest.

Finally, in order to have the same sensitivity and specificity for the detections of IEDs, it has to be pointed out that one EEG-observer should view all EEGs within a single research project. 


\subsection{General discussion on chapter 7}

The "ins and outs" of quantification of IEDs in a clinical setting as well as for scientific purpose, were explored.

The clinically used category scoring system in our tertiary epilepsy centre was generally satisfying, with an acceptable difficulty and time-investment for EEG-technologists. However, the reliability (measured by interobserver agreement) was not perfect. The system was not always felt to support the global impression on change between successive EEGs. It became clear that it is still necessary to write parts of an EEG report instead of only scoring the EEG's characteristics. The combination will supply the best information for referring physicians.

Only in certain patient groups quantifying IEDs was seen as clinically relevant: the syndromes known with high number of IEDs, especially when the number of IEDs is an indication for treatment (ESES or hypsarrhythmia). However, there are always time restraints in clinical practice. To see the quantity at a quick glance in every EEG report was still preferred by the referring neurologists. The method adds only a few minutes to the EEG description procedure and replaces the time spend on words describing quantities. It was decided to maintain the method for all EEGs, however with some adjustments (appendix 7.8). Still, combining the findings in part 2 of the chapter on the good reliability and clinical relevance of found changes by global impression, it can be concluded that the impression of change of the EEG-technologist combined with the comments of an experienced clinical neurophysiologist on the clinical relevance of it, is in fact sufficient and the category score is not strictly needed for this purpose.

From contacts with other EEG departments, it was observed that quantification methods with clear descriptions for categories or even clear conditions for the terms as "few" or "abundant" are not used. Recently, a European taskforce of neurophysiologists published a proposed method ("SCORE") of describing EEGs in a more organized way assisted by specific software, by which most EEG-features could be scored in predefined categories. ${ }^{2}$ In this proposal a quantification method for the IEDs in categories is suggested as well. A different quantification type for single IEDs versus trains/bursts of IEDs is presented. For the single discharges the categories are: only once, <1 $\mathrm{min}, 1-3 / \mathrm{min}, 4-6 / \mathrm{min},>1 / 10$ seconds, and continuous. It is not explained why the specific categories were chosen. Interobserver agreement is not addressed. A difference between the categories of $1-3 /$ minute or $4-6 /$ minute seems not clinically relevant in our opinion, and the category of $>1 / 10$ seconds could be too broad (as the adjacent category is "continuous"). Furthermore, it is probably easier to choose "1 second containing IEDs" instead of " 1 IED" as a unit, because IEDs may exist of short trains of poly-spikes or poly-spike-waves, for which it seems not appropriate to count every spike as 1 IED. In the SCORE method, the incidence for trains/bursts of IEDs 
should be expressed as the estimated percentage of the total duration of the bursts during the recording $(<1 \%, 1-10 \%, 10-50 \%, 50-90 \%,>90 \%)$. The publication does not comment on the definition (especially the length or spatial distribution) of trains/bursts, or the method to conclude to these percentages. Therefore it seems not very practical at first sight, and a risk for a low interobserver agreement.

In the second part of the chapter, it was pointed out that it is indeed still needed to have an "unfortunate" person that is going to spend hours and hours into the donkey work of counting each IED in EEGs with benign focal spikes. The best method to define change in successive EEGs (the 30 pages scoring + method LIM to define change) even was more time-consuming than the others, because it needs to calculate two samples at baseline to supply reliable as well as relevant information on change. Furthermore, this method also met the conditions for statistical analysis, supplying data on a scale measurement level. It is important to keep in mind automatic detection methods that are able to process larger samples in the same time. From the EEG recordings in which detection algorithms failed, can be learned (can additional filters be used, can artifacts be better reduced before processing ?). With improved sensitivity and combined with method LIM an automatic algorithm might be of use, and more efficient than visual counts. It would also be interesting to examine the possibilities of software that uses the pattern of the known spikes, to find the others. We are not (yet) acquainted with the performance of such algorithms in patients with benign focal spikes.

Proportional differences are shown to be a less ideal way to present changes between EEGs, especially when IED numbers have a large variation at baseline. In studies with EEGs with a known very high frequency of IEDs at baseline in every patient this could be a good option, for example in patients with ESES (IEDs $>85 \%$ of the time in nREM sleep at baseline).

The clinical relevance of IED changes was a difficult subject to handle. In this study only the EEGs of a small number of 8 patients could be used that were willing to carry an ambulatory EEG for 48 hours. Day-to-day changes in these patients were defined as not clinically relevant, and larger changes as possibly relevant. A better (however purely hypothetical) setting to test methods to define relevant change between EEGs, would be a the use of a dataset with pre- and post-intervention EEGs from patients treated in a controlled design with an anti-epileptic therapy already known with large effect-sizes concerning IED-reduction and seizure-reduction.

It has to be pointed out that the comparison between detection methods was only performed in a dataset of patients with benign focal spikes. Perhaps other methods would be better, when other types of discharges had to be quantified, for example runs of generalized spike-waves. To study epilepsy syndromes with benign focal spikes is a 
focus in our tertiary epilepsy centre and therefore information on the best statistical analysis of the IEDs was most needed.

In literature, there were no methods described (except global impression) do detect changes between EEGs of individual patients with benign focal spikes. Appendix 7.9 summarizes 28 studies that quantified benign focal spikes or defined change between successive EEGs in patients with benign focal spikes. This appendix is not the result of a structured Pubmed search, because good search terms for IED quantification are lacking, but these are all publications identified while working on this thesis. It is observed that all but 1 study visually analyzed the frequency of IEDs. The only study that used automatic detection came from our centre. ${ }^{3}$ When IEDs were quantified (20 studies), this was mostly on a scale measurement level (IEDs/time unit) (14/20), and less frequently in categories (6/20). Group analysis calculating differences in IED numbers between 2 groups was the most performed analysis. When changes in individual patients were assessed this was only done by global impression (11/28 studies).

In conclusion, global impression is a good way to conclude to change in successive EEGs of individuals and this is a widely used method in clinical practice as well as in research. When quantification of the IEDs in a single EEG is needed in a clinical setting, a method using pre-defined categories such as used in our centre is sufficient. For research, quantification is best performed on a scale measurement level. To define change in successive EEGs, this should be combined with a reliable method. For benign focal spikes, a new method was presented, to define statistically significant and relevant change in successive EEGs of an individual patient with benign focal spikes. The IED counts should be obtained by visual counts. Automatic detection algorithms are promising because of reduction of time investment, however the examined algorithm should first be improved on reliability.

\section{Notes}

\section{Paragraph 7.1.1.}

${ }^{a}$ EEG selection method: EEG-reports of 24-hour EEGs from last 3 years were randomly selected and when the report mentioned IEDs in wakefulness or in sleep, the EEG was added to the set. We first aimed at 100 EEGs. During the selection phase it became clear that we would obtain a low proportion of children in our set. Because of the different EEG patterns in childhood that could be of importance for the interobserver agreement we tried to obtain half of the EEGs from children $\leq 12$ years. At that time we already had $n=64$ adults in the set. From then we only added randomly selected EEGs from children until we had reached a total of 64 adults and 64 children. 
b Because disagreement of more than 1 category between two observers is very undesirable we decided not to "grant" this choice with any weight compared to even worse disagreements, but only to assign a weight on the adjacent category. A moderately sized weight of 0.25 was chosen because a shift to adjacent category in successive EEGs is seen as possibly clinically relevant and disagreement on adjacent categories should not be overestimated.

c Observer 1 mean 2.2 minutes, SD 0.7, range 1.0-4.5 minutes, observer 2 mean 3.8 minutes, SD 0.9, range 1.5-6.0 minutes.

d Observer 1 wakefulness $r=-0.56 P<0.001,15$ minutes sleep $r=-0.50 P<0.0001$, rest nREM sleep $r=-0.55 P=0.0001$; observer 2 wakefulness $r=-0.34 P=0<0.001,15$ minutes sleep $r=-0.29 P=0.001$, rest nREM sleep $r=-0.34 P<0.001)$.

e Mann Whitney $U$ test wakefulness observer $1 \mathrm{p}=0.01$ observer $2 \mathrm{p}<0.01,15$ min sleep observer $1 P<0.0001$ observer $2 \mathrm{p}<0.0001$, rest of nREM sleep observer $1 P<0.0001$ observer $2 \mathrm{p}<0.0001$.

${ }^{f}$ Wakefulness observer $1 P=0.19$ observer $2 P=0.03,15$ min sleep observer $1 P<0.0001$ observer $2 P<0.01$, rest of nREM sleep observer $1 P<0.01$ observer $2 P<0.01$.

\section{Paragraph 7.1.2.}

${ }^{g}$ View appendix 7.5 case $\mathrm{nr}$. 6: no change detected by method LIM, because a difference of 16 to 0 is lower than the defined limit of 17.

${ }^{\mathrm{h}}$ We calculated the proportional change of IEDs in \% from the MAN30 method (\% are shown in appendix 7.7 for dataset B). In one case with seconds with IEDs below 20 both in wakefulness and in sleep, proportional changes were very high (case nr. 20) and still most of the methods decided to stability. After exclusion of this outlying case we calculated the proportional changes when at least 3 methods* concluded the same on change or stability. For change in wakefulness the range was $33-2800 \%$ (mean 414, median 88) and with the outlier of $2800 \%$ excluded this was 33-614\% (mean 176 median 77). When at least 3 methods concluded to stability the range in wakefulness was $8-65 \%$ (mean 36, median 35). In sleep the range for change was 13-95\% (mean 50 median 48 ) and the range for stability 5-53\% (mean 18 median 12). It is obvious that these ranges of choices for stability or change overlap. Above $65 \%$ in wakefulness and above 53\% proportional difference in sleep, most methods agreed on change. * CATglob-adj excluded because of relationship with CATglob->adj.

'View appendix 7.5. In 3 patients from dataset $B(5,18,20)$ the MAN30 +LIM method was probably adequate in concluding to stability because other methods GLOB and 
CATglob adj also concluded to stability. Methods MAN30+P and CAT30 did not have a compensation for the variability and concluded more often to change.

\section{Acknowledgements}

To be able to write this chapter, several people were of great help:

Johan Arends, neurologist/neurophysiologist for commenting on the manuscript Bert Aldenkamp, neuropsychologist for commenting on the manuscript Paul Boon, neurologist/neurophysiologist for commenting on the manuscript Hans den Boer, EEG-technologist for helping with data-acquisition

Jan Cuppen, Neiding BV for writing the software for method "P", and commenting on the manuscript and for discussions

Klaas Frankena, statistician at Wageningen University, for calculating weighted kappa values, help with determination of limits of agreements and tests of normality, lay-out of tables and figures and for commenting on the manuscript

Bert Kleine for the idea of the Blant and Altman plots

Inge van der Linde, for the idea of the questionnaires, commenting on the manuscript and helping with blinding for data-acquisition

EEG-technologists and neurologists working at Kempenhaeghe for filling in questionnaires and for discussions 


\section{Appendix 7.1}

Questionnaires used for evaluation of the clinically used IED quantification method.

\begin{tabular}{|c|c|c|}
\hline Topic & EEG-technologists & neurologists (as referring physicians) \\
\hline Time spent & $\begin{array}{l}\text { Time generally spent }(<1,1-5 \text { minutes, } \\
5-10 \text { minutes, }>10 \text { minutes) }\end{array}$ & - \\
\hline \multirow[t]{3}{*}{ Difficulty to use } & $\begin{array}{l}\text { How difficult is the use of the method } \\
\text { ( } 5 \text { point scale) }\end{array}$ & - \\
\hline & $\begin{array}{l}\text { Which type of EEGs/IEDs/syndromal } \\
\text { diagnosis is most difficult to quantify ( } 5 \\
\text { point scale) }\end{array}$ & - \\
\hline & $\begin{array}{l}\text { How often is the } 30 \text { random page } \\
\text { scoring used to assist ( } 5 \text { point scale) }\end{array}$ & - \\
\hline \multirow[t]{3}{*}{ Use for clinical practice } & $\begin{array}{l}\text { How useful is this method for clinical } \\
\text { practice ( } 5 \text { point scale) }\end{array}$ & $\begin{array}{l}\text { How useful is this method for clinical } \\
\text { practice ( } 5 \text { point scale) }\end{array}$ \\
\hline & - & $\begin{array}{l}\text { How often you specifically asked an } \\
\text { EEG registration to obtain IED } \\
\text { quantification ( } 5 \text { point scale) }\end{array}$ \\
\hline & - & $\begin{array}{l}\text { How often the quantification result is } \\
\text { used to conclude to the syndromal } \\
\text { diagnosis, assess the treatment, start } \\
\text { treatment, stop treatment (all on } 5 \\
\text { point scale) }\end{array}$ \\
\hline inter-observer agreement & $\begin{array}{l}\text { How large is the inter-observer } \\
\text { agreement ( } 5 \text { point scale) }\end{array}$ & $\begin{array}{l}\text { How large is the interobserver } \\
\text { agreement ( } 5 \text { point scale) }\end{array}$ \\
\hline Comments & $\begin{array}{l}\text { For every question additional } \\
\text { comments were possible }\end{array}$ & $\begin{array}{l}\text { For every question additional } \\
\text { comments were possible }\end{array}$ \\
\hline
\end{tabular}




\section{Appendix 7.2}

\section{Outcomes of questionnaires}

Outcomes of the questionnaire on clinical IED quantification as completed by EEGtechnologists $(n=27)$

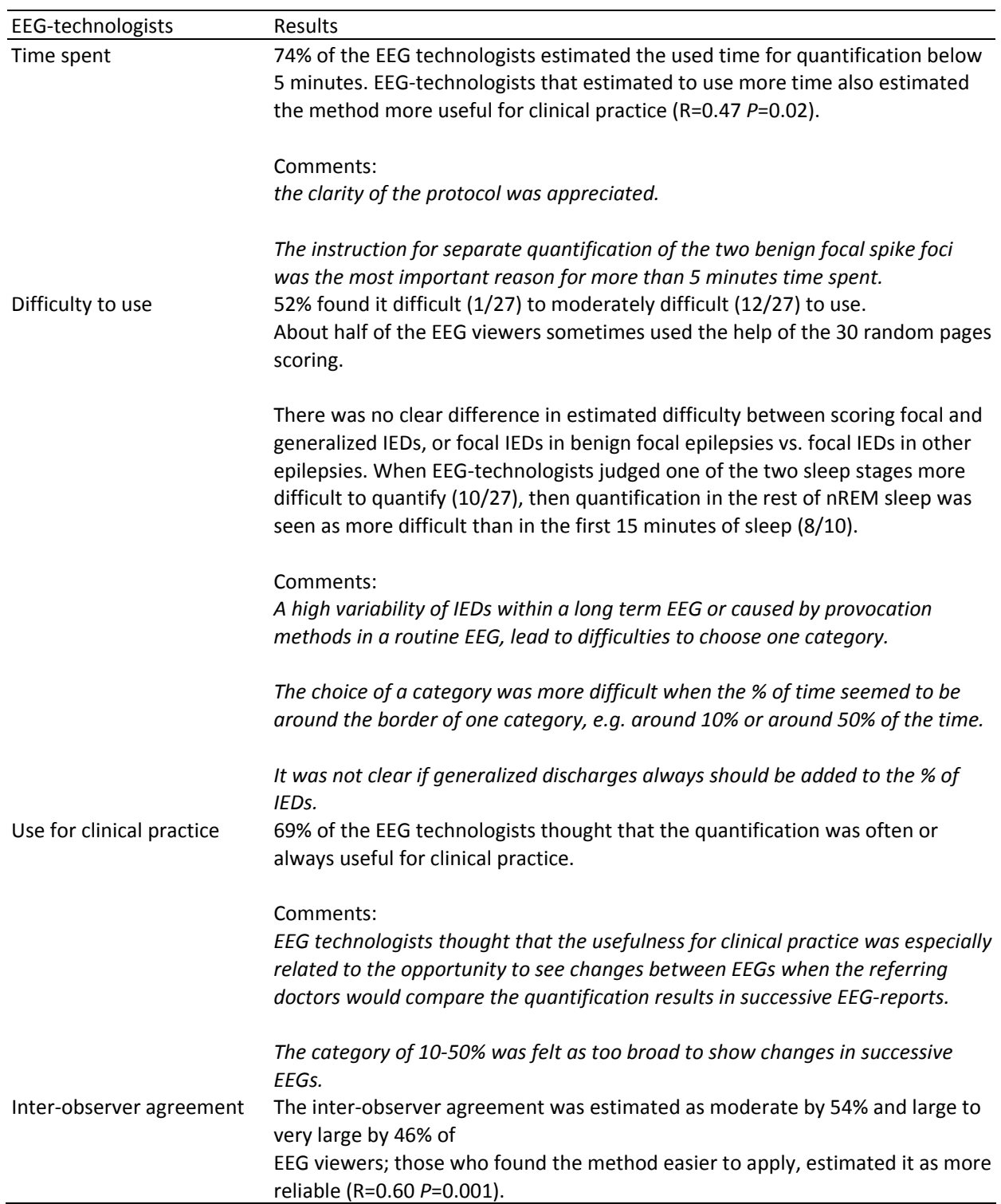


Outcomes of the questionnaire on IED quantification as completed by referring neurologists $(n=16)$.

\begin{tabular}{|c|c|}
\hline Neurologists & Results \\
\hline $\begin{array}{l}\text { Use for clinical } \\
\text { practice }\end{array}$ & $\begin{array}{l}13 / 16 \text { neurologists requested EEGs merely for quantification of IEDs. } 2 / 13 \text { did this often, } \\
10 / 13 \text { only in a minority of EEGs (defined as }<25 \% \text { of the EEGs). }\end{array}$ \\
\hline & $\begin{array}{l}\text { Half of them estimated it often or always useful for clinical practice (often } 6 \text {, always } 2 \text { ), } 5 \text { of } \\
\text { them sometimes useful, and } 3 \text { sporadically useful. The use for specific purposes is shown in } \\
\text { the table below. }\end{array}$ \\
\hline
\end{tabular}

\begin{tabular}{|l|c|c|c|c|c|l|}
\hline Use for: & Never & $\begin{array}{c}\text { Sometimes } \\
(\leq 25 \%)\end{array}$ & $\begin{array}{c}\text { Regularly } \\
(25-75 \%)\end{array}$ & $\begin{array}{l}\text { Often } \\
(\geq 75 \%)\end{array}$ & Always & $\begin{array}{l}\text { Correlation } \\
\text { with } \\
\text { variable of } \\
\text { estimated } \\
\text { usefulness }\end{array}$ \\
\hline $\begin{array}{l}\text { Syndromal } \\
\text { diagnosis }\end{array}$ & 2 & 13 & 1 & 0 & 0 & $\begin{array}{l}\mathrm{R}=0.66 \\
P=0.005\end{array}$ \\
\hline $\begin{array}{l}\text { Effect of } \\
\text { treatment }\end{array}$ & 3 & 9 & 2 & 2 & 0 & $\begin{array}{l}\mathrm{R}=0.79 \\
P<0.0001\end{array}$ \\
\hline $\begin{array}{l}\text { Start of } \\
\text { treatment }\end{array}$ & 3 & 10 & 3 & 0 & 0 & $\begin{array}{l}\mathrm{R}=0.57 \\
P=0.02\end{array}$ \\
\hline $\begin{array}{l}\text { Stop } \\
\text { treatment }\end{array}$ & 1 & 14 & 0 & 0 & 0 & $\begin{array}{l}\mathrm{R}=0.59 \\
P=0.15 \\
(\mathrm{~N} . \mathrm{S} .)\end{array}$ \\
\hline
\end{tabular}

Comments

Results were especially used to add to the probability of the syndromal diagnosis of Rolandic epilepsy or syndromes associated with ESES, or syndromes that are considered to be an epileptic encephalopathy. Follow-up EEGs for changes in IED frequency (e.g. after treatment changes), were especially requested in patients with these syndromes.

Many neurologists appreciated the fact that they were informed about on the amount of IEDs in the same way and at the same place in each EEG-report. The presented table allowed them to see at one glance if they should be worried about a patient (especially when amounts exceed $50 \%$ of the time or when a large change was seen between successive EEGs).

Several neurologists found the presentation in \% difficult to comprehend and difficult to explain to patients/caregivers.

The quantification of 2 separate foci in patients with benign focal spikes was not seen as highly clinically relevant. The same was true for separate quantification of sleep onset and rest of nonREM sleep.

Inter-observer Inter-observer agreement was estimated as moderate by $69 \%$ and large by $31 \%$ of the agreement referring neurologists. 


\section{Appendix 7.3}

\section{Descriptions of 5 methods to define changes in IEDs between two 24-hour EEGs.}

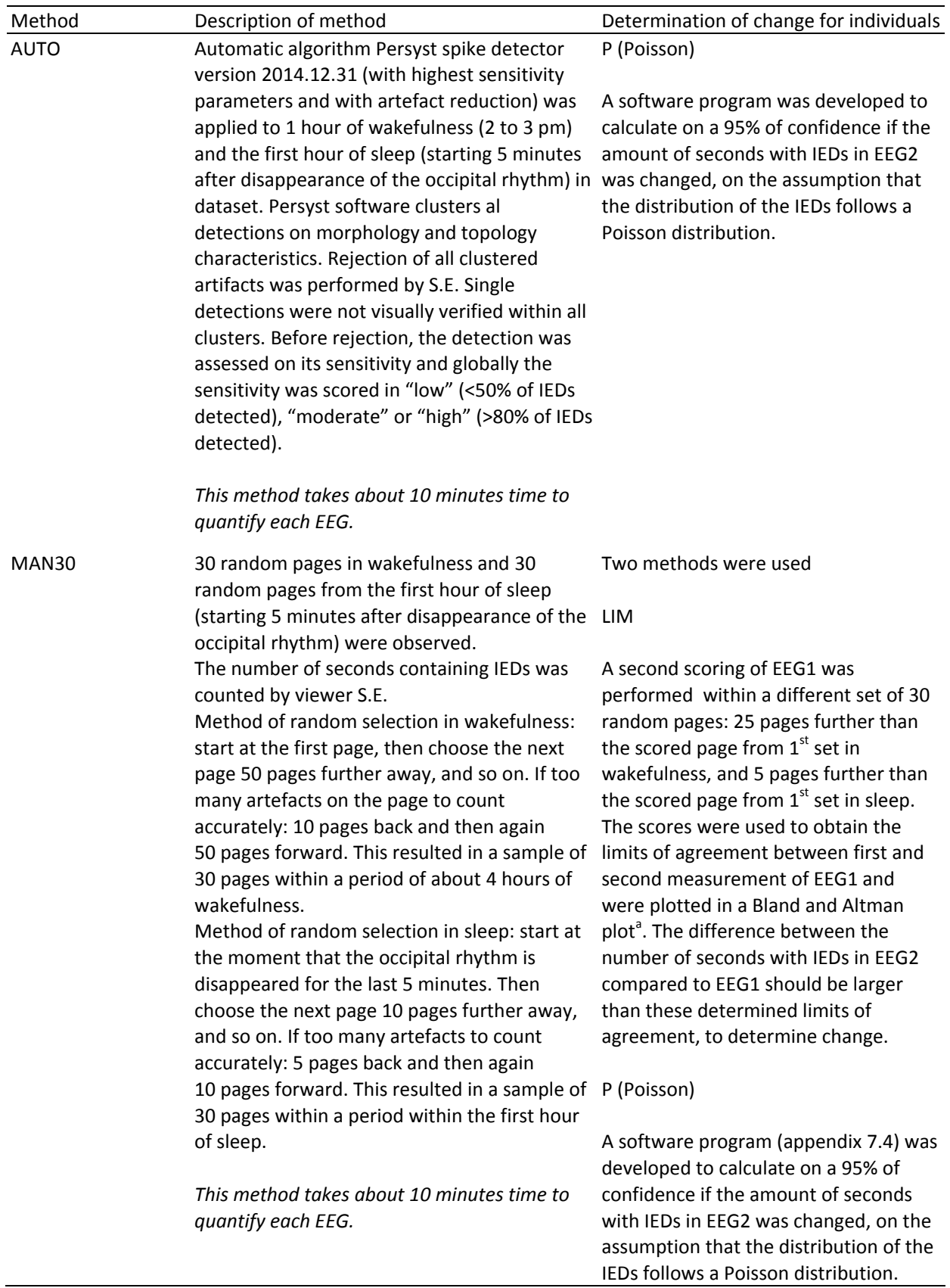




\begin{tabular}{|c|c|c|}
\hline Method & Description of method & Determination of change for individuals \\
\hline CAT30 & $\begin{array}{l}\text { The same selected } 30 \text { pages from wakefulness } \\
\text { and sleep as described for method } 1 \text { were } \\
\text { observed. } \\
\text { Viewer H.B. scored dataset A, viewer S.E. } \\
\text { scored dataset B. Each page was scored into } \\
\text { one of the categories: } 1=\text { no IEDs , } 2=\geq 10 \text { - }\end{array}$ & $\begin{array}{l}\text { The } 4 \text { categories were assigned to } \\
\text { numbers } 1 \text { to } 4 . \text { The means of the sets } \\
\text { of EEG1 and EEG } 2 \text { were compared with } \\
\text { Mann-Whitney- } U \text { test to define } \\
\text { difference between the sets (alpha } \\
0.05 \text { ). }\end{array}$ \\
\hline
\end{tabular}

$50 \%, 3=\geq 50-80 \%, 4=\geq 80 \%$ of the time within the page. One second with IED(s) on the page was defined as $10 \%$. The viewer was not aware of the result of the scoring of the other EEG of the set. The sets were not scored directly after each other. 24 hour periods dataset $\mathrm{B}$ were scored blinded.

\section{This method takes about 8 minutes time to quantify each EEG.}

CATglob

The reviewer (S.E.) was allowed to look

Two methods were used with different through the EEG for as long as it was needed/ boundaries:

in so many pages as felt necessary.

The categories for the IED frequency in

\section{CATglob-adj>} wakefulness or the first hour of sleep were: $0 \%,<1 \%, 1-10 \%, \geq 10-50 \%, \geq 50-85 \%, \geq 85 \%$ of the time. One second with IED(s) on the page was defined as $10 \%$.

The viewer was not aware of the result of the scoring of the other EEG of the set. The sets were not scored directly after each other. 24 hour periods dataset B were scored blinded.

\section{This method takes about 5 minutes time to quantify each EEG.}

GLOB

Global review (S.E.) of as many pages the reviewer esteemed necessary in wakefulness and first hour of sleep, in baseline and followup EEG.

For scoring dataset $A$ the viewer was blinded and mixed with $8 \mathrm{EEG}$ s of dataset $\mathrm{B}$, to prohibit that the viewer knew the two 24 hour EEGs came from a 48 hour EEG.

This method takes about 3 minutes time to quantify each EEG.

\footnotetext{
${ }^{a}$ This is a method published by Bland and Altman $^{1}$ primarily developed to compare two measurement instruments for the same object when both measurements result in a continuous variable. The difference between the measurements is plotted against the mean of the two measurements. The limits of agreement are the mean difference +/- 2*SD of the mean difference and these limits are used to assess how the agreement is, and if the measurement technique can be replaced by the other one. ${ }^{b}$ From the inter-observer agreement study using this method in $128 \mathrm{EEGs}$ (different epilepsy syndromes), it was shown that the interobserver agreement was moderate (around 0.60 ), with $1 / 4$ to $1 / 3$ of the EEGs scored in the adjacent category by the other viewer. In patients with non-sporadic IEDs a scoring of a category further away than the adjacent category was only seen in about $1 \%$ of the registrations. We do not know how the intra-observer agreement is (when the same EEG is blindly scored a second time by the same observer). This agreement could be better and therefore we also defined change when EEG2 was scored into the adjacent category (CATglob-adj).
} 


\section{Appendix 7.4}

\section{Software program to define difference based on Poisson distribution}

\section{Software developed by: J. Cuppen, Neiding BV}

(When the word "hours" is written, this could be replaced by any other period).

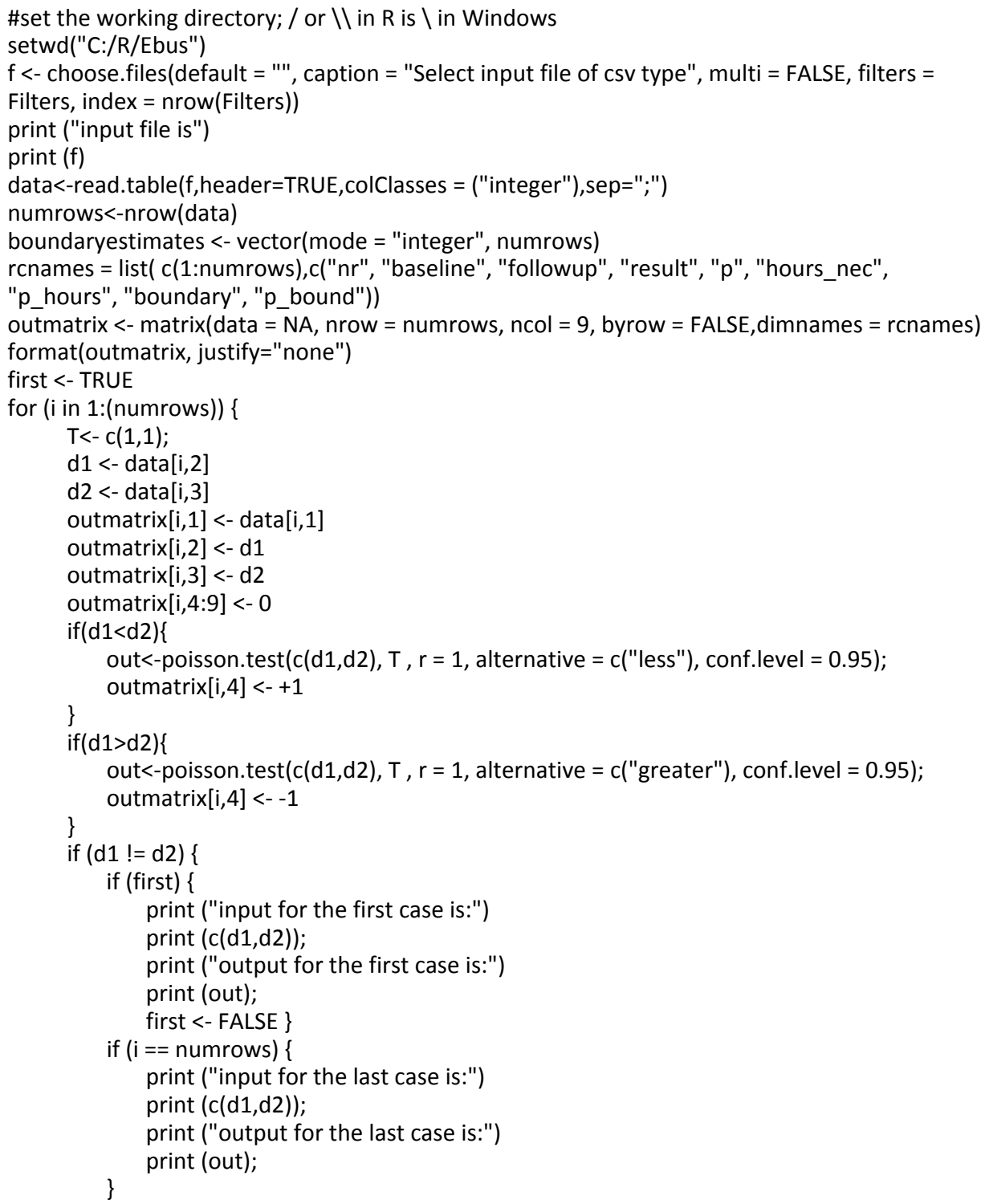




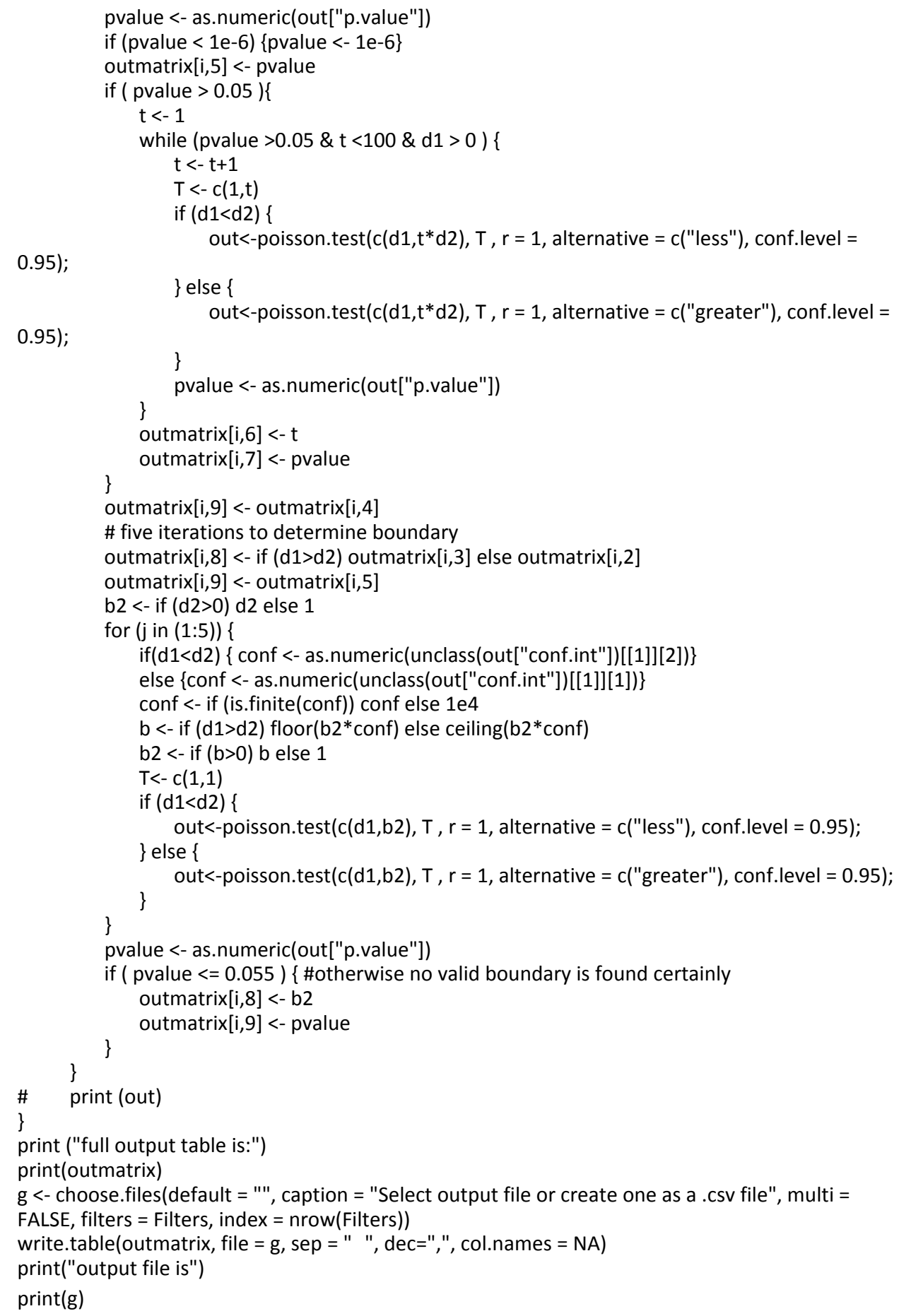




\section{Appendix 7.5}

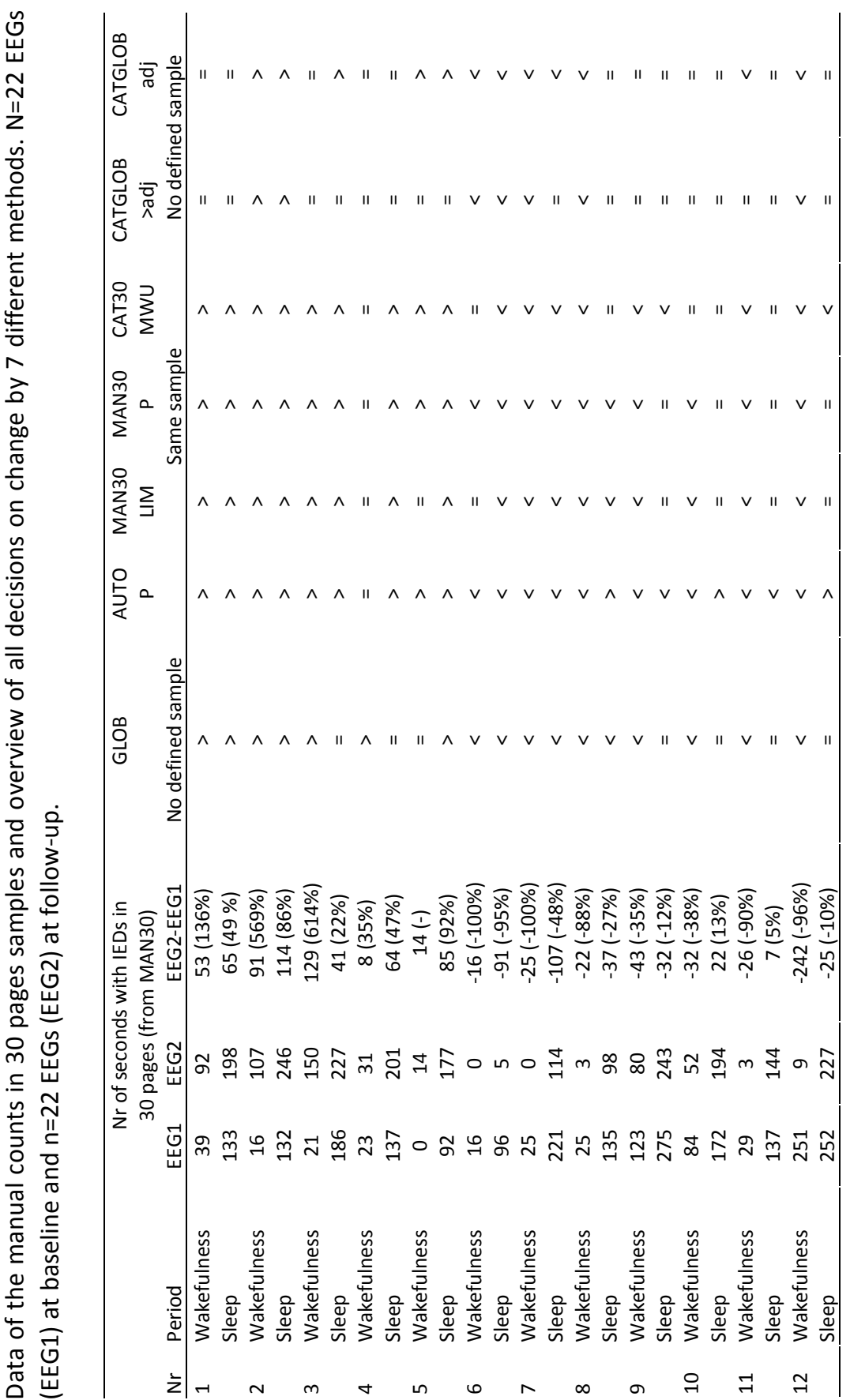




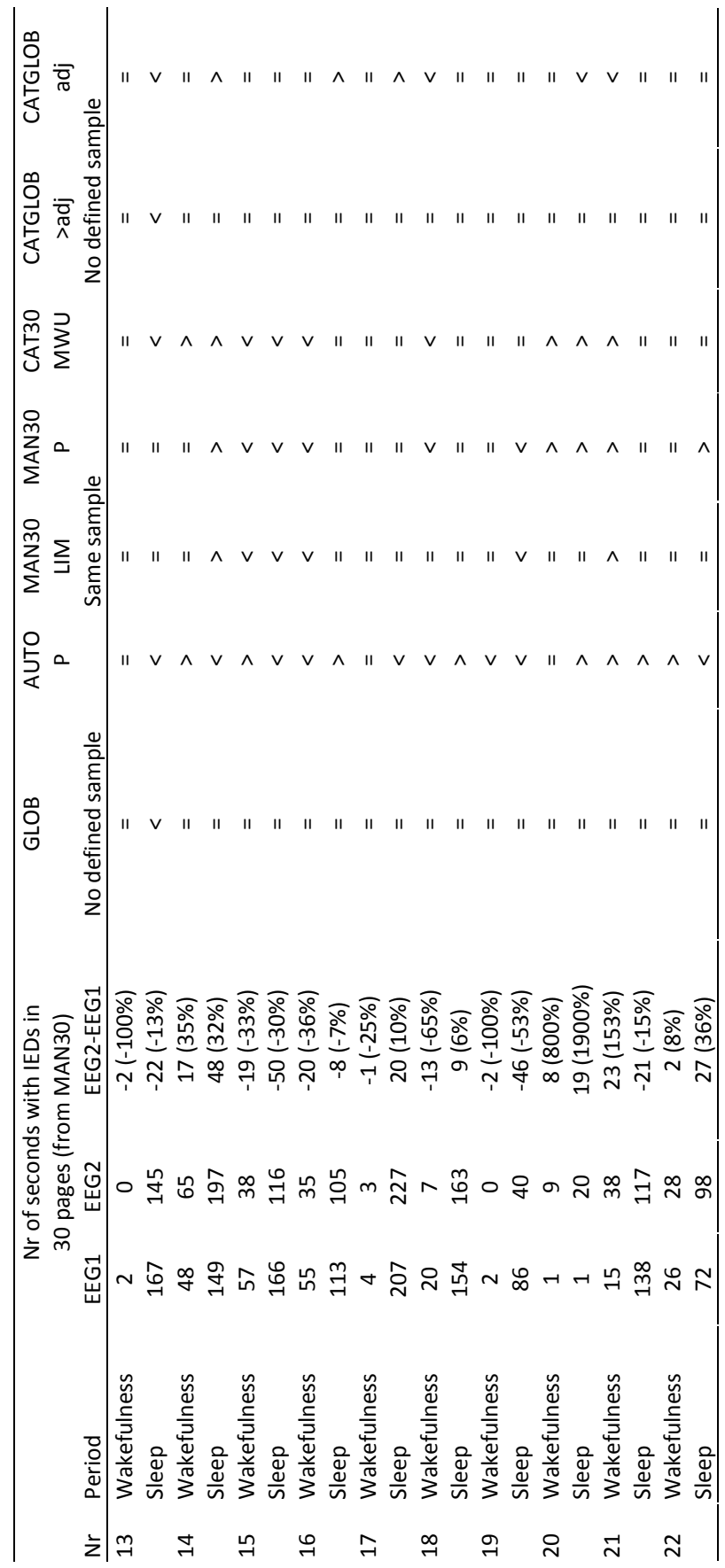




\section{Appendix 7.6}

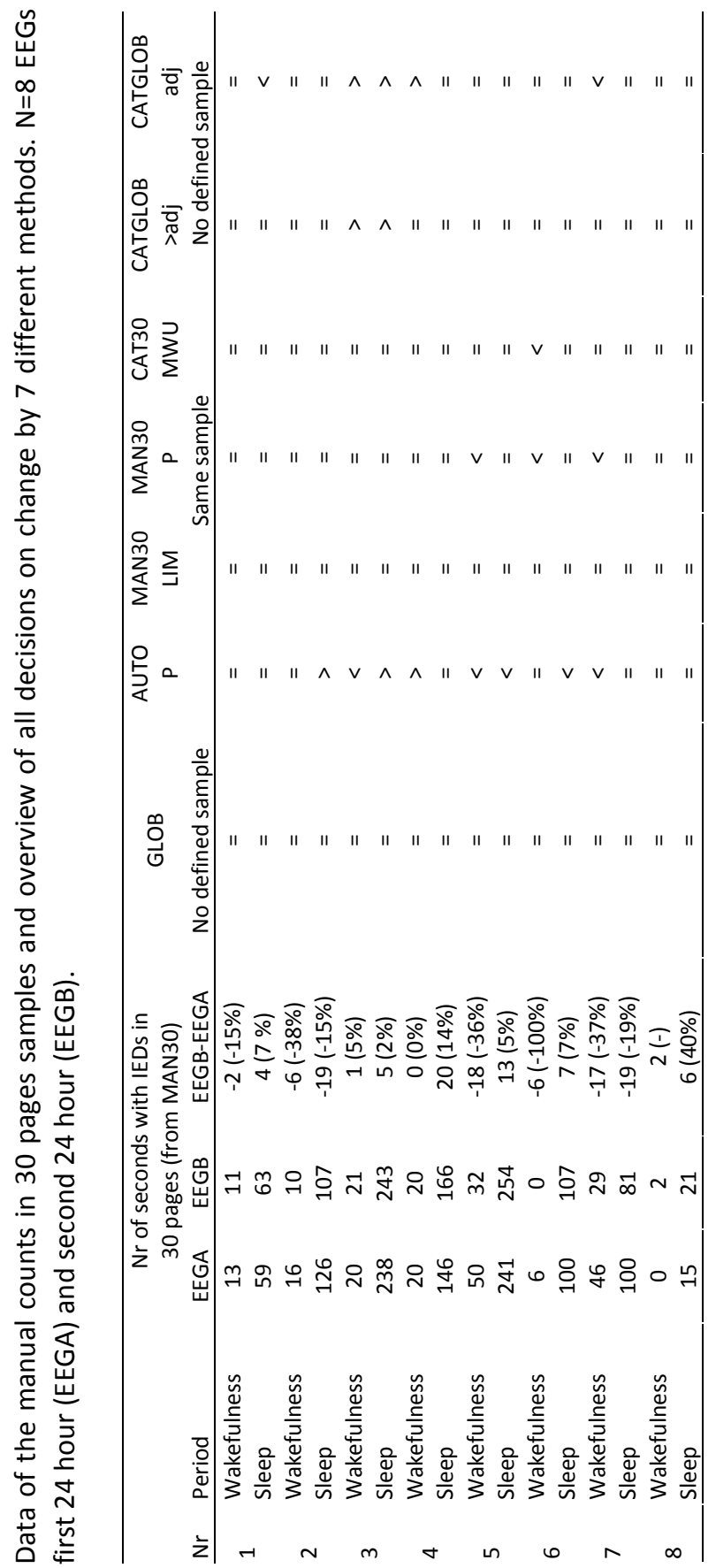




\section{Appendix 7.7}

Proportional changes of method AUTO (automatic detection in 1 hour) compared to proportional changes of MAN30 (visual detection in 30 random pages), dataset $B n=22$ EEGs baseline and 22 EEGs at follow-up.

\begin{tabular}{|c|c|c|c|c|c|c|c|c|}
\hline \multirow[t]{3}{*}{$\mathrm{nr}$} & AUTO & AUTO & AUTO\% & MAN30\% & AUTO & AUTO & AUTO\% & MAN30\% \\
\hline & \multicolumn{4}{|c|}{ Wakefulness } & \multicolumn{4}{|c|}{ Sleep } \\
\hline & EEG1 & EEG2 & $\%$ & $\%$ & EEG1 & EEG2 & $\%$ & $\%$ \\
\hline 1 & 5 & 684 & 13580 & 136 & 1858 & 3183 & 71 & 49 \\
\hline 2 & 0 & 285 & - & 569 & 255 & 1976 & 675 & 86 \\
\hline 3 & 46 & 1841 & 3902 & 614 & 2931 & 4160 & 42 & 22 \\
\hline 4 & 147 & 164 & 12 & 35 & 1916 & 2829 & 48 & 47 \\
\hline 5 & 0 & 10 & - & - & 619 & 2725 & 340 & 92 \\
\hline 6 & 62 & 0 & -100 & -100 & 1021 & 66 & -94 & -95 \\
\hline 7 & 230 & 0 & -100 & -100 & 3109 & 1662 & -47 & -48 \\
\hline 8 & 134 & 91 & -32 & -88 & 787 & 1198 & 52 & -27 \\
\hline 9 & 413 & 274 & -34 & -35 & 4551 & 2392 & -47 & -12 \\
\hline 10 & 479 & 141 & -71 & -38 & 1689 & 2185 & 29 & 13 \\
\hline 11 & 444 & 2 & -100 & -90 & 1671 & 1129 & -32 & 5 \\
\hline 12 & 3460 & 47 & -99 & -96 & 3826 & 4182 & 9 & -10 \\
\hline 13 & 3 & 0 & -100 & -100 & 2240 & 1109 & -50 & -13 \\
\hline 14 & 354 & 1315 & 271 & 35 & 2668 & 629 & -76 & 32 \\
\hline 15 & 292 & 414 & 42 & -33 & 2494 & 1699 & -32 & -30 \\
\hline 16 & 180 & 143 & -21 & -36 & 1335 & 1481 & 11 & -7 \\
\hline 17 & 35 & 39 & 11 & -25 & 2728 & 2369 & -13 & 10 \\
\hline 18 & 105 & 40 & -62 & -65 & 926 & 2357 & 155 & 6 \\
\hline 19 & 29 & 6 & -79 & -100 & 1079 & 271 & -75 & -53 \\
\hline 20 & 0 & 0 & - & 800 & 0 & 14 & - & 1900 \\
\hline 21 & 154 & 299 & 94 & 153 & 1754 & 1935 & 10 & -15 \\
\hline 22 & 52 & 170 & 227 & 8 & 1327 & 1158 & -13 & 36 \\
\hline
\end{tabular}

AUTO= automatic detections, MAN30 = manual counts $\%$ is proportional change from baseline

Dark grey filling= low sensitivity of AUTO estimated ( $<50 \%$ of visually identified IEDs detected) Light grey filling= moderate sensitivity of AUTO estimated $(50-80 \%$ of visually identified IEDs detected) No filling = good sensitivity of AUTO estimated ( $>80 \%$ of visually identified IEDs detected) 


\section{Appendix 7.8}

\section{Changes made to the quantification method after evaluation}

After combining the results of the inter-observer agreement and the questionnaires, the following decisions were made:

\section{For better interpretation:}

The presentation in \% of time was changed to "seconds containing one or more IEDs".

\section{For more efficiency/ to make the method easier to apply:}

- No separate quantification for the different foci in patients with benign focal epilepsies.

- No separate quantification for sleep onset and rest of nREM sleep.

- Generalized discharges of at least 3 seconds of duration should not be added to the IED-quantity but separately quantified in index/hour in 2 random hours and the first hour after awakening.

\section{More information on reliability:}

- We instructed the EEG-technologists to use the space for written comments when they were concerned about the reliability (e.g. "difficult choice of the category because of large variability in time, there are also several periods with IEDs in $<1 \%$ ").

- No categories were split, as this would only reduce reliability, although several EEGtechnologists would have liked this to better inform the physicians about changes between EEGs.

- We instructed the EEG-technologists that global impression on change was also important. When the same categories were chosen for the past and present EEG but they thought the EEG was changed, they should emphasize this in the conclusion of the present EEG.

Revised table to report outcomes of IED-quantification

\begin{tabular}{|c|c|c|c|c|c|c|}
\hline & $\begin{array}{l}\text { No } \\
\text { IEDs }\end{array}$ & Sporadic $^{a}$ & $\begin{array}{c}\text { Moderate } \\
\text { amount } \\
\leq 1 \mathrm{sec} . \\
\text { of } 10 \mathrm{sec} . \\
\text { page }\end{array}$ & $\begin{array}{c}\text { Large } \\
\text { amount } \\
\geq 1 \mathrm{sec} \text {. } \\
\text { of } 10 \mathrm{sec} . \\
\text { page }\end{array}$ & $\begin{array}{c}\text { Very large } \\
\text { amount } \\
\geq 5 \mathrm{sec} \text {. } \\
\text { of } 10 \mathrm{sec} \text {. } \\
\text { page }\end{array}$ & $\begin{array}{c}\text { Almost } \\
\text { continuous }^{b}\end{array}$ \\
\hline Wakefulness & & & & $x$ & & \\
\hline Sleep nREM & & & & & & $x$ \\
\hline Comments & & & & & & \\
\hline
\end{tabular}

The number of seconds with one or more IEDs per 10-second EEG page is globally estimated.

${ }^{a}$ Sporadic means globally less than one IED in 10 pages. ${ }^{b}$ Almost continuous is $>85 \%$ of the time. 


\section{Appendix 7.9}

Summary of methods used by studies that quantified benign focal spikes and/or observed changes in successive EEGs with benign focal spikes.

\begin{tabular}{|c|c|c|c|c|c|c|c|c|}
\hline $\begin{array}{l}\text { Author } \\
\text { year }\end{array}$ & $W / S$ & Sample ${ }^{a}$ & MS & FU & Anal. & $\begin{array}{l}\text { IND } \\
\mathrm{CH}\end{array}$ & $\begin{array}{c}\text { Nr.of samples } \\
\text { analyzed }\end{array}$ & $\begin{array}{c}\text { Hours } \\
\text { analyzed }\end{array}$ \\
\hline $\begin{array}{l}\text { Baglietto } \\
2001^{4}\end{array}$ & $\mathrm{~S}$ & 1 night & $\mathrm{S}$ & + & $\mathrm{G}$ & $x$ & $?$ & $?$ \\
\hline $\begin{array}{l}\text { Massa } \\
2001^{5} \\
\end{array}$ & $W+S$ & $?^{\mathrm{a}} \times 80 \mathrm{~min}$ & $S$ & + & $\mathrm{G}, \mathrm{C}$ & & $?$ & ? \\
\hline $\begin{array}{l}\text { Northcott } \\
2005^{6}\end{array}$ & $W+S$ & $\begin{array}{c}20-40 \mathrm{~min} \\
\text { Routine EEG }\end{array}$ & $S$ & - & C & & 41 & 21 \\
\hline $\begin{array}{l}\text { Berroya } \\
2005^{7}\end{array}$ & $W+1{ }^{\mathrm{c}} \mathrm{S}$ & $\begin{array}{l}2 \times 20-40 \mathrm{~min} \\
\text { Routine EEG }\end{array}$ & $S$ & + & G & & 92 & 92 \\
\hline $\begin{array}{l}\text { Tombul } \\
\text { et al } 2006^{8}\end{array}$ & $W+S$ & Routine EEG & $S$ & - & G & & 36 & 24 \\
\hline \begin{tabular}{|l|} 
Nicolai \\
$2007^{3}$ \\
\end{tabular} & $W+S$ & 24 hours & $\begin{array}{c}\mathrm{S} \\
\text { (auto) } \\
\end{array}$ & - & $\mathrm{G}, \mathrm{C}$ & & 30 & 720 \\
\hline \begin{tabular}{|l|} 
Fonseca \\
$2007^{9}$
\end{tabular} & W & $?$ & $\mathrm{~S}$ & - & $\mathrm{G}$ & & 23 & $?$ \\
\hline $\begin{array}{l}\text { Fonseca } \\
2007^{10}\end{array}$ & $W+/-S$ & $\begin{array}{c}\text { Routine } \\
\text { EEG }\end{array}$ & $S$ & - & $\mathrm{C}$ & & 42 & 28 \\
\hline $\begin{array}{l}\text { Wirrell } \\
2008^{11}\end{array}$ & $\mathrm{~S}$ & $\begin{array}{c}2 \times 60 \text { (from } 24 \mathrm{~h} \\
\mathrm{EEG} \text { ) }\end{array}$ & $\mathrm{S}$ & + & $\mathrm{G}$ & & 6 & 12 \\
\hline \begin{tabular}{|l} 
Tedrus \\
$2010^{12}$ \\
\end{tabular} & W & $\begin{array}{c}2 \times 5 \text { min (from } \\
\text { routine) }\end{array}$ & $S$ & + & $\mathrm{G}, \mathrm{C}$ & & 32 & 5 \\
\hline \begin{tabular}{|l} 
Stulpnagel \\
$2010^{13}$
\end{tabular} & $S$ & $2 \times 20$ & $S$ & + & G & & 32 & 21 \\
\hline $\begin{array}{l}\text { Sarco } \\
2011^{14} \\
\end{array}$ & $W+S$ & $\begin{array}{c}20-60 \mathrm{~min} \\
\text { SD EEG }\end{array}$ & $S$ & - & $C$ & & 21 & 14 \\
\hline $\begin{array}{l}\text { Kanemura } \\
2012^{15} \\
\end{array}$ & $W+S$ & $\begin{array}{c}? \times 20-40 \mathrm{~min} \\
\text { routine }\end{array}$ & $S$ & + & G & & $?$ & ? \\
\hline $\begin{array}{l}\text { Kwon } \\
2013^{16} \\
\end{array}$ & $S$ & $2 \times ?$ & $\mathrm{~S}$ & + & $\mathrm{G}$ & & 39 & $?$ \\
\hline $\begin{array}{l}\text { Weglage } \\
1997^{17}\end{array}$ & $W+S$ & $\begin{array}{c}\text { Routine +/-sleep } \\
\text { EEG }\end{array}$ & C & - & $\mathrm{G}, \mathrm{C}$ & & 40 & 27 \\
\hline $\begin{array}{l}\text { Engler } \\
2003^{18}\end{array}$ & $W+S$ & $2 \times$ routine & C & + & - & $x$ & 25 & 33 \\
\hline Bast $2003^{19}$ & $\mathrm{~S}$ & $3 \times$ routine & $\mathrm{C}$ & + & $\mathrm{G}$ & $x$ & 66 & 132 \\
\hline \begin{tabular}{|l} 
Riva \\
$2007^{20}$ \\
\end{tabular} & $W+S$ & $40 \mathrm{~min}$ & C & - & C & & 24 & 16 \\
\hline $\begin{array}{l}\text { Bulgheroni } \\
2008^{21} \\
\end{array}$ & $W+S$ & routine & C & - & C & & 24 & 16 \\
\hline $\begin{array}{l}\text { Verrotti } \\
2011^{22,23}\end{array}$ & $W+S$ & $? \times$ routine & $C$ & + & $\mathrm{G}$ & & 26 & $?$ \\
\hline
\end{tabular}




\begin{tabular}{|l|c|c|c|c|c|c|c|c|}
\hline $\begin{array}{l}\text { Author } \\
\text { year }\end{array}$ & W/S & Sample & MS & FU & Anal. & $\begin{array}{c}\text { IND } \\
\text { CH }\end{array}$ & $\begin{array}{c}\text { Nr.of samples } \\
\text { analyzed }\end{array}$ & $\begin{array}{c}\text { Hours } \\
\text { analyzed }\end{array}$ \\
\hline $\begin{array}{l}\text { Takahashi } \\
1991^{23}\end{array}$ & W & $?$ & - & + & - & X & 25 & $?$ \\
\hline $\begin{array}{l}\text { Mitsudome } \\
1997^{24}\end{array}$ & W+S & $2 \times$ routine & - & + & - & X & 40 & 53 \\
\hline $\begin{array}{l}\text { Verroti } \\
1999^{25}\end{array}$ & W+S & ? x routine & - & + & C & X & 40 & $?$ \\
\hline $\begin{array}{l}\text { Rating } \\
2000^{26}\end{array}$ & W+S & $4 \times$ routine & - & + & G & X & 66 & 176 \\
\hline $\begin{array}{l}\text { Deonna } \\
2000^{27}\end{array}$ & W+S & $\begin{array}{l}\text { ? } \times \text { routine (SD or } \\
\text { sleep induction) }\end{array}$ & - & + & - & X & $?$ & $?$ \\
\hline $\begin{array}{l}\text { Tzitiridou } \\
2005^{28}\end{array}$ & S & $3 \times$ routine & - & + & - & X & 70 & 140 \\
\hline $\begin{array}{l}\text { Kosoff } \\
2007^{29}\end{array}$ & W+S & $2 \times 30$ min & - & + & - & X & 6 & 6 \\
\hline $\begin{array}{l}\text { Shamdeen } \\
2012^{30}\end{array}$ & W+S (?) & $20-30$ & - & + & G, C & X & 38 & $?$ \\
\hline
\end{tabular}

a When a ? sign is shown in the column "sample" then the study analyzed retrospectively successive EEGs in patients, however not a pre-defined number per patient. ${ }^{b}$ When a - sign is written in column of the measurement scale (MS) then only descriptive data on individual cases were presented in the study. ${ }^{\mathrm{C}}$ When +/- sleep is written, this means that not all EEGs contained sleep in this study.

\section{Abbreviations}

\begin{tabular}{ll}
\hline W & Wakefulness \\
S & Sleep \\
MS & Measurement scale of quantification method \\
S (in MS column) & Scale measurement level \\
C (in MS colum) & Categories =ordinal measurement level \\
FU & Follow-up EEGs after baseline were registered \\
Anal. & Type of statistical analysis \\
G & Group differences \\
C (in Anal. Column) & Correlation analysis \\
IND CH & EEG-change in individual patients was defined \\
\hline
\end{tabular}

\section{Studies assessing individual changes}

\begin{tabular}{lccc}
\hline Author, year & \multicolumn{2}{c}{ Category of change used } & Method to define change \\
\cline { 2 - 3 } & Normalization & Decrease & \\
\hline Baglietto $2001^{4}$ & - & $\mathrm{X}$ & Global impression \\
${\text { Engler } 2003^{18}}^{\text {Bast } 2003^{19}}$ & $\mathrm{X}$ & $\mathrm{X}$ & Global impression \\
${\text { Tziridou } 2005^{28}}^{23}$ & $\mathrm{X}$ & - & Global impression \\
Takahashi $1991^{23}$ & $\mathrm{X}$ & $\mathrm{X}$ & Global impression \\
Mitsudome $1997^{24}$ & $\mathrm{X}$ & $\mathrm{X}$ & Global impression \\
Verroti $1999^{25}$ & $\mathrm{X}$ & - & Global impression \\
Rating $2000^{26}$ & $\mathrm{X}$ & - & Global impression \\
Deonna $2000^{27}$ & $\mathrm{X}$ & $\mathrm{X}$ & Global impression \\
Kosoff $2007^{29}$ & - & $\mathrm{X}$ (or increase) & Global impression \\
Shamdeen $2012^{30}$ & $\mathrm{X}$ & $\mathrm{X}$ & Global impression \\
\hline
\end{tabular}


Types of category variables used in the studies

\begin{tabular}{|c|c|c|}
\hline \multirow[t]{5}{*}{ Bast, $2003^{19}$} & 1 & $0 \%$ \\
\hline & 2 & $<25 \%$, \\
\hline & 3 & $25-50 \%$, \\
\hline & 4 & $51-70 \%$ \\
\hline & 5 & $>70 \%$ of the time \\
\hline \multirow[t]{4}{*}{ Bulgheroni, $2008^{21}$} & 1 & Absent \\
\hline & 2 & Rare (< spikes $10 / \mathrm{min})$ \\
\hline & 3 & $\begin{array}{l}\text { Intermediate ( }>10 \text { spikes } / \mathrm{min} \text { ) isolated or in brief clusters. } 10-50 \% \text { of the } \\
\text { time }\end{array}$ \\
\hline & 4 & High $(>50 \%$ of the recording \\
\hline \multirow[t]{4}{*}{ Engler, $2003^{18}$} & 1 & no discharges, \\
\hline & 2 & rare discharges, \\
\hline & 3 & frequent discharges, \\
\hline & 4 & continuous or near continuous \\
\hline \multirow[t]{4}{*}{ Riva, $2007^{20}$} & 1 & Absent \\
\hline & 2 & Rare (< spikes $10 / \mathrm{min})$ \\
\hline & 3 & $\begin{array}{l}\text { Intermediate ( }>10 \text { spikes } / \mathrm{min} \text { ) isolated or in brief clusters. } 10-50 \% \text { of the } \\
\text { time }\end{array}$ \\
\hline & 4 & High $(>50 \%$ of the recording \\
\hline \multirow[t]{5}{*}{ Verroti $2011^{25}$} & 0 & normal EEG \\
\hline & 1 & unilateral focus normal background \\
\hline & 2 & bilateral independent foci, normal background \\
\hline & 3 & $\begin{array}{l}\text { Destructed background intermittent slow wave focus, sharp waves diffusing } \\
\text { to one hemisphere or multiregional sharp waves }\end{array}$ \\
\hline & 4 & $\begin{array}{l}\text { destructed background, intermittent slow wave focus, sharp waves diffusing } \\
\text { to both hemispheres. }\end{array}$ \\
\hline \multirow[t]{3}{*}{ Weglage $1997^{17}$} & 1 & $1-5 / \min$ \\
\hline & 2 & $6-10 / \min$ \\
\hline & 3 & $>10 / \mathrm{min}$ \\
\hline
\end{tabular}




\section{References}

1. Bland JM, Altman DG. Measuring agreement in method comparison studies. Stat Methods Med Res 1999;8: 135-60.

2. Beniczky S, Aurlien H, Brogger JC, Fuglsang-Frederiksen A, Martins-da-Silva A, Trinka E, Visser G, Rubboli G, Hjalgrim H, Stefan H, Rosen I, Zarubova J, Dobesberger J, Alving J, Andersen KV, Fabricius M, Atkins MD, Neufeld M, Plouin P, Marusic P, Pressler R, Mameniskiene R, Hopfengartner R, van Emde Boas W, Wolf P. Standardized computer-based organized reporting of EEG: SCORE. Epilepsia 2013;54: 1112-24.

3. Nicolai J, van der Linden I, Arends JB, van Mil SG, Weber JW, Vles JS, Aldenkamp AP. EEG characteristics related to educational impairments in children with benign childhood epilepsy with centrotemporal spikes. Epilepsia 2007;48: 2093-100.

4. Baglietto MG, Battaglia FM, Nobili L, Tortorelli S, De Negri E, Calevo MG, Veneselli E, De Negri M. Neuropsychological disorders related to interictal epileptic discharges during sleep in benign epilepsy of childhood with centrotemporal or Rolandic spikes. Dev Med Child Neurol 2001;43: 407-12.

5. Massa R, de Saint-Martin A, Carcangiu R, Rudolf G, Seegmuller C, Kleitz C, Metz-Lutz MN, Hirsch E, Marescaux $C$. EEG criteria predictive of complicated evolution in idiopathic rolandic epilepsy. Neurology 2001;57: 1071-9.

6. Northcott E, Connolly AM, Berroya A, Sabaz M, Mclntyre J, Christie J, Taylor A, Batchelor J, Bleasel AF, Lawson JA, Bye AM. The neuropsychological and language profile of children with benign rolandic epilepsy. Epilepsia 2005;46: 924-30.

7. Berroya AM, Bleasel AF, Stevermuer TL, Lawson J, Bye AM. Spike morphology, location, and frequency in benign epilepsy with centrotemporal spikes. J Child Neurol 2005;20: 188-94.

8. Tombul T, Anlar O, Caksen H. Comparison of epileptic and nonepileptic cases with centrotemporal spikes in view of clinical findings and electroencephalographic characteristics. Int J Neurosci 2006;116: 299-313.

9. Fonseca LC, Tedrus GM, Pacheco EM. Epileptiform EEG discharges in benign childhood epilepsy with centrotemporal spikes: reactivity and transitory cognitive impairment. Epilepsy Behav 2007;11: 65-70.

10. Fonseca LC, Tedrus GM, Pacheco EM, Berretta MF, Campregher AA, Costa DM. Benign childhood epilepsy with centro-temporal spikes: correlation between clinical, cognitive and EEG aspects. Arq Neuropsiquiatr 2007;65: 569-75.

11. Wirrell E, Sherman EM, Vanmastrigt R, Hamiwka L. Deterioration in cognitive function in children with benign epilepsy of childhood with central temporal spikes treated with sulthiame. J Child Neurol 2008;23: 14-21.

12. Tedrus GM, Fonseca LC, Castilho DP, Pacheco EM, Campregher AA, Bittar MC. Benign childhood epilepsy with centro-temporal spikes: evolutive clinical, cognitive and EEG aspects. Arq Neuropsiquiatr 2010;68: 550-5.

13. von Stulpnagel C, Kluger G, Leiz S, Holthausen H. Levetiracetam as add-on therapy in different subgroups of "benign" idiopathic focal epilepsies in childhood. Epilepsy Behav 2010;17: 193-8.

14. Sarco DP, Boyer K, Lundy-Krigbaum SM, Takeoka M, Jensen F, Gregas M, Waber DP. Benign rolandic epileptiform discharges are associated with mood and behavior problems. Epilepsy Behav 2011;22: 298-303.

15. Kanemura H, Sano F, Aoyagi K, Sugita K, Aihara M. Do sequential EEG changes predict atypical clinical features in rolandic epilepsy? Dev Med Child Neurol 2012;54: 912-7.

16. Kwon S, Hwang TG, Lee J, Kim DK, Seo HE. Benign childhood epilepsy with centrotemporal spikes: to treat or not to treat. J Epilepsy Res 2013;3: 1-6.

17. Weglage J, Demsky A, Pietsch M, Kurlemann G. Neuropsychological, intellectual, and behavioral findings in patients with centrotemporal spikes with and without seizures. Dev Med Child Neurol 1997;39: 646-51.

18. Engler F, Maeder-Ingvar M, Roulet E, Deonna T. Treatment with Sulthiame (Ospolot) in benign partial epilepsy of childhood and related syndromes: an open clinical and EEG study. Neuropediatrics 2003;34: 105-9.

19. Bast T, Volp A, Wolf C, Rating D. The influence of sulthiame on EEG in children with benign childhood epilepsy with centrotemporal spikes (BECTS). Epilepsia 2003;44: 215-20. 
20. Riva D, Vago C, Franceschetti S, Pantaleoni C, D'Arrigo S, Granata T, Bulgheroni S. Intellectual and language findings and their relationship to EEG characteristics in benign childhood epilepsy with centrotemporal spikes. Epilepsy Behav 2007;10: 278-85.

21. Bulgheroni S, Franceschetti S, Vago C, Usilla A, Pantaleoni C, D'Arrigo S, Riva D. Verbal dichotic listening performance and its relationship with EEG features in benign childhood epilepsy with centrotemporal spikes. Epilepsy Res 2008;79: 31-8.

22. Verrotti A, D'Egidio C, Agostinelli S, Parisi P, Chiarelli F, Coppola G. Cognitive and linguistic abnormalities in benign childhood epilepsy with centrotemporal spikes. Acta Paediatr 2011;100: 768-72.

23. Takahashi K, Saito M, Kyo K, Gomibuchi K, Niijima S, Tada H, Honda T, Sato Y, Takahashi H, Ohtsuka C. The effects of clonazepam on rolandic discharge of benign epilepsy of children with centro-temporal EEG foci. Jpn J Psychiatry Neurol 1991;45: 468-70.

24. Mitsudome A, Ohfu M, Yasumoto S, Ogawa A, Hirose S, Ogata H, Yamada T. The effectiveness of clonazepam on the Rolandic discharges. Brain Dev 1997;19: 274-8.

25. Verrotti A, Greco R, Altobelli E, Domizio S, Sabatino G, Morgese G, Chiarelli F. Centro-temporal spikes in non-epileptic children: a long-term follow up. J Paediatr Child Health 1999;35: 60-2.

26. Rating $D$, Wolf $C$, Bast T. Sulthiame as monotherapy in children with benign childhood epilepsy with centrotemporal spikes: a 6-month randomized, double-blind, placebo-controlled study. Sulthiame Study Group. Epilepsia 2000;41: 1284-8.

27. Deonna T, Zesiger P, Davidoff V, Maeder M, Mayor C, Roulet E. Benign partial epilepsy of childhood: a longitudinal neuropsychological and EEG study of cognitive function. Dev Med Child Neurol 2000;42: 595-603.

28. Tzitiridou M, Panou T, Ramantani G, Kambas A, Spyroglou K, Panteliadis C. Oxcarbazepine monotherapy in benign childhood epilepsy with centrotemporal spikes: a clinical and cognitive evaluation. Epilepsy Behav 2005;7: 458-67.

29. Kossoff EH, Los JG, Boatman DF. A pilot study transitioning children onto levetiracetam monotherapy to improve language dysfunction associated with benign rolandic epilepsy. Epilepsy Behav 2007;11: 514-7.

30. Shamdeen MG, Jost W, Frohnhofer M, Gortner L, Meyer S. Effect of sulthiame on EEG pathology, behavior and school performance in children with Rolandic epileptiform discharges. Pediatr Int 2012;54: 798-800. 


\section{Chapter 8}

General discussion 


\section{Introduction}

The studies within this thesis were aimed at answering two main questions:

1) Can the interictal epileptiform discharge (IED) frequency be used as a marker for the outcome after therapy change ?

And:

2) Can the IED frequency be used as a marker for cognitive outcome ?

All studies were performed in the setting of a tertiary epilepsy center.

\section{IED frequency changes as a marker for outcome after therapy change}

\section{Observed correlations between seizure frequency and IED frequency}

The use of the IED frequency as a marker for clinical outcome (clinical outcome defined as the anti-epileptic effect) requires that seizure frequency and IED frequency are correlated. In several patient groups in the different studies performed, this correlation was observed (Table 8.1). The question arises, whether not finding this correlation in other groups was mainly the result of characteristics of the epilepsy syndrome, or if the finding was obscured because of methodological aspects ${ }^{a}$. Especially the limited reliability of retrospective seizure counts and measurements of IED frequencies could obscure an existing relationship, as well as examining a heterogeneous patient group. The strongest correlation was observed in the prospective study in patients with severe childhood epilepsies (most had Lennox-Gastaut syndrome). These patients are known with high IED frequencies and the high voltage IEDs in these syndromes can be clearly discerned from background. The probability that a mean IED frequency of 4 EEG samples of 30 minutes non-ambulatory (thus, fairly artifact-free) EEG, analyzed with automatic spike detection reliably reflects the IED frequency is high in this population. Postictal increase of IEDs might also have increased the correlational strength, as $74 \%$ of these patients suffered from daily seizures.

A correlation could not be calculated for idiopathic primary generalized epilepsies (PGEs). Patients with PGEs are less refractory to drugs and therefore less referred to a tertiary center. In this group, a better predictive value of ongoing IEDs for seizure recurrence is generally described. ${ }^{1-3}$

\footnotetext{
a See also general introduction in paragraph "IEDs and epileptogenicity in chronic epilepsy"
} 
Table 8.1

\begin{tabular}{|c|c|c|c|c|c|c|}
\hline Patients & 19 children $^{42}$ & 101 children $^{43}$ & 20 children $^{43}$ & $\begin{array}{l}34 \text { adults/ } \\
\text { children }^{44}\end{array}$ & 21 children $^{43}$ & 26 children $^{45}$ \\
\hline Syndrome & $\begin{array}{l}\text { Severe } \\
\text { childhood } \\
\text { epilepsies }\end{array}$ & $\begin{array}{l}\text { Cryptogenic } \\
\text { localization } \\
\text { related } \\
\text { epilepsy }\end{array}$ & $\begin{array}{l}\text { Symptomatic } \\
\text { localization } \\
\text { related } \\
\text { epilepsy }\end{array}$ & $\begin{array}{l}\text { Heterogeneous } \\
\text { syndromes }\end{array}$ & $\begin{array}{l}\text { Rolandic } \\
\text { epilepsy }\end{array}$ & $\begin{array}{l}\text { Benign focal } \\
\text { epilepsies }\end{array}$ \\
\hline Seizure counts & $\begin{array}{l}\text { Prospective, } \\
\text { mean in } \\
2 \text { year }\end{array}$ & $\begin{array}{l}\text { Retrospective, } \\
\text { category }\end{array}$ & $\begin{array}{l}\text { Retrospective, } \\
\text { category }\end{array}$ & $\begin{array}{l}\text { Prospective } \\
\text { baseline, mean } \\
\text { in } 6 \text { months }\end{array}$ & $\begin{array}{l}\text { Retrospective, } \\
\text { category }\end{array}$ & $\begin{array}{l}\text { Retrospective } \\
\text { baseline, and } \\
\text { prospective } \\
\text { follow-up } \\
\text { (category) }\end{array}$ \\
\hline IED counts & $\begin{array}{l}\text { Mean IED } \\
\text { frequency of } \\
4 \text { successive } \\
\text { EEGs ( } 120 \\
\text { min) within } \\
2 \text { year. } \\
\text { Isolated and } \\
\text { serial IEDs }\end{array}$ & $\begin{array}{l}\text { Estimation in } \\
\text { category from } \\
24 \text { h EEG }\end{array}$ & $\begin{array}{l}\text { Estimation in } \\
\text { category from } \\
24 \text { h EEG }\end{array}$ & $\begin{array}{l}\text { Mean IED } \\
\text { frequency } 2 \mathrm{~h} \\
\text { wakefulness or } \\
1 \mathrm{~h} \text { of sleep }\end{array}$ & $\begin{array}{l}\text { Estimation in } \\
\text { category from } \\
24 \text { h EEG }\end{array}$ & $\begin{array}{l}\text { Mean } \\
\text { category } \\
\text { scores of } 30 \\
\text { random pages }\end{array}$ \\
\hline \multirow{2}{*}{$\begin{array}{l}\text { Correlation } \\
\text { coefficient } \\
\text { (Spearman) }\end{array}$} & $\begin{aligned} \mathrm{W} & =0.61 \\
\mathrm{R} & =0.74^{\mathrm{a}}\end{aligned}$ & $R=0.46$ & $\begin{array}{l}\text { No } \\
\text { correlation }\end{array}$ & $\begin{array}{l}R=0.37 \\
(p=0.07 \text { N.S. })\end{array}$ & No correlation & $\begin{array}{l}\text { No } \\
\text { correlation }\end{array}$ \\
\hline & $\begin{array}{l}\text { Sot } \\
\text { examined }\end{array}$ & $R=0.40$ & $\begin{array}{l}\text { No } \\
\text { correlation }\end{array}$ & $\begin{array}{l}R=0.36 \\
(\mathrm{p}=0.09 \text { N.S. })\end{array}$ & No correlation & $\begin{array}{l}\text { No } \\
\text { correlation }\end{array}$ \\
\hline
\end{tabular}

$\mathrm{W}=\mathrm{EEG}$ in wakefulness $\mathrm{S}=\mathrm{EEG}$ in sleep. ${ }^{\mathrm{a}}$ Correlation with number of spike-bursts= IEDs occurring in a short train of spike-wave complexes.

\section{Discussion on the two studies examining IED frequency changes after therapy change}

In the studies on the non-pharmacological therapies vagus nerve stimulation (VNS) and ketogenic diet $(K D)$, respectively, no relationship, or only a specific relationship (nocturnal decrease of IEDs in responders to the KD) between IED changes and response to the therapy were observed. The prediction from nocturnal IED reduction in the KD study was not strong enough to be informative for clinical practice. The KD was not associated with full remission of all IEDs ${ }^{b}$, and the overall impact on IED change was limited. Combined methodology-related and epilepsy syndrome-related aspects influencing the correlation between changes in IED frequency and seizure frequency, might have affected the results to some extent. However, it is not expected that perfect seizure counts and different methods of EEG recording or counting of the IEDs would have changed the outcome significantly. Based on the results of these studies, it is not advised to use the EEG to confirm or predict the response to these therapies.

After our publication on VNS therapy and IED changes, two more studies on the subject were published, one retrospective study in 32 patients with heterogeneous syndromes ${ }^{4}$ and one prospective study in 15 patients with heterogeneous syndromes. ${ }^{5}$ Both studies

\footnotetext{
${ }^{b}$ In cases with a low number of IEDs at baseline treated with the ketogenic diet, the definition of IED disappearance in wakefulness was not reliable.
} 
observed IED frequency reductions for the group as a whole, however with low or no correlation with seizure reduction or seizure severity scale reduction. It is discussed if "VNS reduces IEDs and seizures at different functional levels" ${ }^{5}$ or if "VNS positively affects the EEG regardless of seizure reduction". " Methodological imperfections as another possible explanation are not discussed.

On the subject of EEG changes after initiation of the KD, a study was published soon after ours. ${ }^{6}$ It was performed in a retrospective heterogeneous patient group $(n=43)$ with short routine EEGs in wakefulness at undefined periods before the KD initiation and repeated after undefined follow-up. Responders did not differ from nonresponders regarding IED changes. The authors recommend that further studies on the subject of IEDs as outcome parameter in the ketogenic diet should be performed.

\section{Future studies with IED frequency as outcome parameter}

Should we indeed continue with the examination of IED changes as an outcome parameter for (future new) therapies ? The use of IED changes as surrogate markers in the monitoring of antiepileptic drug (AED) effects is in debate, in research - e.g. for the development of new AEDs, as well as in patient care. ${ }^{1,2,7}$ It is questionable whether new therapies will influence IED frequencies by a different mechanism and to a different extent than AEDs. The paroxysmal nature of the IED provides methodological challenges. From our studies, as well as existing literature it must be concluded that IED reduction as outcome parameter in treatment trials should be used with caution. They should best be performed in homogeneous patient groups with epilepsy syndromes known with frequent IEDs. Furthermore, in light of clinical relevance, the goal should be to predict the future therapeutic effect in individual patients in an early stage, instead of finding a correlation of IED decrease with seizure decrease for the group as a whole at further follow-up. In the latter case the focus is on the (difficult to find) correlation between seizures and IEDs. In some patient groups, the EEG could be used as a "true" outcome parameter, e.g. when ictal discharges are numerous and counts from clinical observation are not reliable. In these cases prolonged video-EEG should be recorded. Finally, IEDs can be considered as outcome parameter in research in patient groups in whom the IEDs itself are a goal of treatment. This will be further discussed when commenting on the publications addressing IEDs and cognition.

\section{Use of IED frequency changes in daily clinical practice}

In daily practice, the use of an EEG as outcome measurement still has its place. Nonetheless any referral for EEG-recording should consider all characteristics of the individual patient: the syndromal diagnosis, seizure frequency, reliability of seizure counts, expected frequency of (inter) ictal discharges. As the interviewed neurologists reported (chapter 7), IED frequency changes after therapy change are predominantly of interest when treating patients with epilepsy syndromes known with very high IED 
frequencies. They especially mentioned patients with epileptic encephalopathies and patients with electrical status epilepticus of slow wave sleep (ESES). Epilepsy syndromes regarded as epileptic encephalopathies are for example West syndrome, LennoxGastaut syndrome and Dravet syndrome. The word "epileptic encephalopathy" suggests that cognitive and /or physical deterioration is epilepsy related (although with largely unknown mechanisms, possibly partially related to highly frequent ictal and interictal discharges). ${ }^{8,9}$ Also, patients with ESES (electrical status epilepticus of slowwave sleep) in the nocturnal EEG, or patients with Landau-Kleffner syndrome (also known with highly frequent nocturnal IEDs) are considered as patients with epileptic encephalopathies. ${ }^{10,11}$ The reason for neurologists to use the EEG as additional outcome parameter in daily clinical practice for these patients is obvious from this point of view.

\section{Other markers of epileptogenicity?}

Are other markers of epileptogenicity available for the use in research or in clinical practice?

Paroxysmal high frequency oscillations (HFOs) in the EEG represent a better marker for the seizure onset zone than IEDs. ${ }^{12}$ The physiological mechanisms that give rise to HFOs and IEDs probably differ to some extent. ${ }^{13}$ The significance of HFOs has been examined almost exclusively in presurgical patients. Detecting HFOs requires a laborious procedure. They are mostly searched for in the intracranial EEG but recently it was shown that they can also be detected in a surface EEG. ${ }^{14}$ In a population of 681 children examined with nocturnal video-EEG monitoring for epilepsy surgery with surface EEG, HFOs were highly specific for the diagnosis of epilepsy, but were found in only $16 \%$ of the epilepsy patients. ${ }^{15}$ The significance of changes in paroxysmal HFOs in the evaluation of therapies could be further examined, but many practical issues as well as methodological issues can be expected, because of the similarity with the paroxysmal nature of IEDs.

Network analysis is a method increasingly used to find answers for questions in epilepsy research. Could changes in networks be related to the probability of seizure occurrence and could network characteristics be changed by therapies ? Networks can be modeled as a collection of nodes (brain regions) and edges (connections between the nodes), and doing so, the organization and also synchronization aspects can be examined. ${ }^{16}$ The diagnostic power to confirm epilepsy can be increased by combining the findings on IEDs with changes in network synchronization. Network alterations are able to predict epilepsy even if the EEG does not contain IEDs. ${ }^{17,18}$ In children with focal epilepsy, it was demonstrated that network changes during sleep deprived sleep EEG recordings were different in patients than in controls. ${ }^{19}$ The authors suggest that the type of changes indicate an increased cortical excitability in the patients, explaining why sleep deprivation leads to a higher probability of IEDs. Network analysis may be an interesting way to look at changes in epileptogenicity. 
Transcranial magnetic stimulation (TMS) is a procedure to examine the cortical excitability as well as cortical inhibitory mechanisms in the cortex of the central motor pathway. In drug naïve patients with epilepsy the intracortical inhibition is decreased, bilateral in generalized epilepsies, ipsilateral in patients with focal epilepsy. ${ }^{20,21}$ The fact that the primary motor cortex shows these changes in localization related epilepsy, implies that the excitability is increased in larger cortical regions than only in the seizure onset zone. Excitability measured by TMS is shown to be increased after sleep deprivation in patients with focal epilepsy and especially in patients with primary generalized epilepsies. ${ }^{22}$ A reduced intracortical inhibition can normalize after treatment (measured 8-12 weeks after starting therapy). ${ }^{20}$ However the prediction for future seizure freedom is best in patients with generalized epilepsies and at a group level; for individual patients with focal epilepsies the predicting value is less strong. TMS is non-invasive, easy to apply and safe, and promising as a tool to predict the efficacy of therapies. More studies should certainly be performed in this area.

\section{IED frequency changes as a marker for cognitive outcome}

\section{Relationships between IED frequency and cognition}

A correlation between higher IED frequency in wakefulness and lower scores on several cognitive test results (central information processing speed, verbal memory and visualmotor integration) was observed in children with heterogeneous epilepsy syndromes (HES). Regression analysis showed the independent influence of IEDs among other possible factors related to cognitive outcome. A limitation was the impossibility to study epilepsy syndrome specific relationships because of small subgroups. Two other publications provided information in patients with benign focal spikes (BFS). In patients with BFS the (proportionate level of the) attribution of IEDs on cognition may be larger, because of frequent IEDs in combination with low seizure frequency. A relationship between slowed central information processing speed (CIPS) and a higher diurnal IED frequency was demonstrated. Changes in CIPS were related to changes in IED frequency at follow-up. For nocturnal IEDs less correlations were found. In patients with Rolandic epilepsy (RE) the level was correlated with delayed reading skills.

\section{Other characteristics of IEDs}

Other aspects of IEDs were examined, but largest effects on cognition were shown for IED frequency. There were only few correlations with localization of IEDs (distribution in the different cortical areas or lateralization), for example a specific deficit in visualspatial skills was more frequently found in patients (with HES) with IEDs lateralized in the non dominant hemisphere. A limitation was the global localizing method and the lack of subgroups with the same localizations as well as epilepsy syndromes. Furthermore, shifting foci over time in patients with BFS may explain the inability to 
find correlations of lateralized IEDs and impairments in strongly lateralized cognitive networks (language functions or visual-spatial skills). Other studies in patients with RE have also failed to demonstrate these correlations. ${ }^{23-25}$

\section{Level of IED frequency}

A threshold above which the IED frequency should be taken into account as a risk factor is desirable when evaluating the causes for a delay in academic achievement in an individual child. The study in patients with HES suggests a level of $>10 \%$ (at least 1 IED per 10 second EEG page). However, this should be used with caution, because the interobserver agreement of the used IED frequency scoring method was later shown to be only of moderate strength. In the study of patients with BFS a level above $18 \%$ at inclusion (calculated with a more reliable visual scoring method of seconds containing IEDs) was associated with longer persistence of IEDs in the next two years. This group with ongoing IEDs at two years had less chance to improve in CIPS compared to baseline. From the combined results, but with caution, it is recommended that IEDs observed on every 10 -second page of the EEG in wakefulness should raise concern. A threshold for nocturnal IED frequency could not be proposed. A recent study tried to find such a threshold for the \% of time in nonREM sleep in patients with RE. A threshold was not found: it was observed that patients with nocturnal IED frequency below $50 \%$ (defined as a low index for the syndrome) had the same probability of verbal memory deficits at follow-up as the patients with IEDs between $50-85 \%$ of the time (although the examined groups were small). ${ }^{23}$

\section{Mechanisms}

We found the largest correlations with cognitive outcome when examining IEDs in wakefulness. However, children with frequent diurnal IEDs generally will also have more frequent nocturnal IEDs, because IED levels in wakefulness and sleep are correlated ( $R=0.79$ in the patients with HES, $R=0.42$ in the patients with BFS). Cognition could be threatened by frequent diurnal as well as nocturnal IEDs at the same time in an individual child. Mechanisms of action could be different for diurnal IEDs compared to nocturnal IEDs. There are many hypotheses regarding the mechanisms of action that causally relate IEDs to cognitive impairment. It has been hypothesized that nocturnal IEDs could interrupt sleep related neuronal processes needed for memory storage. ${ }^{26}$ It is hypothesized that focal IEDs prohibit the occurrence of normal focal slow waves in nREM sleep that are necessary for learning processes. ${ }^{27}$ Diurnal IEDs influence cognitive networks while functioning in the awake state. The neurons included in the discharge may be unavailable for the normal physiological processes. It is hypothesized that this could be related to postsynaptic inhibitory mechanisms related with the IED. ${ }^{27,28}$ The deactivations of the default mode network by single IEDs observed in $\mathrm{FMRI}$ research, could be a sign of a short disturbance of awareness. ${ }^{29,30}$ An alarming finding in animal 
models is that networks affected by IEDs may not further develop in a young brain ${ }^{31}$ and synaptic plasticity may be reduced at the site of the IED focus. ${ }^{32}$ This suggests that IED-induced functional and structural impairments co-occur in developing brains.

\section{Networks}

Outcomes on various cognitive tests were correlated with IED frequency in the HES group. Are central information processing speed (CIPS), verbal memory (VM), visualmotor integration (VMI), and reading skills (affected in the RE group) completely different or related modalities? Information processing speed tests need visual and motor skills, especially in the more complex CIPS test used in our studies (the computerized visual searching task, CVST). VM tests are related to the outcomes on CIPS tests. ${ }^{33}$ Academic achievements (reading and mathematics) are reported to be correlated with the level of $\mathrm{VMI}^{34,35}$ These findings suggest that various cognitive abilities rely on the same or connected neuronal networks. These might collapse with a domino effect, when one of them is disturbed.

The finding that the number of IEDs, but not localization or lateralization had the largest contribution to cognition is interesting. Perhaps the exact localization of IEDs is of less importance. If an IED would be able to "hit" networks, then remote effects could occur, independent from the site where the electrical discharge actually takes place. Indeed often cognitive impairments are found in children with epilepsy that do not correspond with focus localization. IED-induced network aberrations may be seen as the cause of these discrepancies. Remarkable are the findings in one recent publication on IED related network changes in 26 children. ${ }^{36}$ The acute influence of single IEDs on resting state network properties was examined with MEG (magnetoencephalography). It was demonstrated that single IEDs caused changes in the network characteristics (clustering and path length properties). These changes correlated to changes in resting state networks examined with fMRI (functional MRI), as well as to neuropsychological outcome (lower full scale IQ). A higher number of IEDs was found in children with more "IED vulnerable" networks. Also, in this study, no correlation with IED localization or other epilepsy variables (age, epilepsy duration, type of seizures) could be demonstrated.

Nevertheless, distribution of IEDs probably is still a factor that should not be neglected. IEDs being propagated to larger cortical areas could still pose a larger impact than IEDs remaining focal in a smaller cortical area. IEDs in patients with ESES (which includes bilateral synchronous IEDs), show widely spread networks changes demonstrated with EEG-fMRI. $^{30,37}$

\section{Cause or epiphenomenon?}

If IEDs are an epiphenomenon, then both the cognitive impairment and the IEDs would be signs of an underlying brain illness. Changes in IED frequency would reflect the 
course of the illness (and/or changes in "epileptogenicity", the probability of ictal discharges), but the IEDs themselves would not be the cause for the cognitive impairment. Findings supportive of this hypothesis for patients with BFS are the findings of similar cognitive deficits in siblings of children with $\mathrm{RE}^{38}$ implying that $a$ genetic underlying vulnerability may exist. Also with respect to this subject, the finding that patients with RE may show language disabilities long before seizure onset, is interesting, although the timing of "IED onset" is unknown and could still have been earlier than seizure onset. ${ }^{39}$ In few patients with Landau Kleffner syndrome, the EEG was normal when the auditory agnosia had already been observed for months. Authors who published on 3 of such cases, argued that a sampling error because of large night to night fluctuations of IEDs was more plausible than the "epiphenomenon hypothesis". ${ }^{40}$ In the before mentioned study on IED-related network changes in MEG and $\mathrm{FMRI}$, the vulnerability of the network to changes caused by IEDs, was a better predictor for IQ decline than the number of IEDs. They hypothesize that the same patients prone to more IEDs could have a higher vulnerability of networks, mediated by "dysfunctional cortical or subcortical circuitry". ${ }^{36}$ Probably the best view for now, is that the hypotheses on "epiphenomenon" and "causal relationship" could both exist at the same time. Both the underlying illness and the IEDs themselves can be independent factors threatening cognitive development. The number of IEDs can be modulated by the characteristics of the specific syndromal diagnosis. The vulnerability of cognitive networks to IEDs can be modulated by the specific syndromal diagnosis. The impact on cognitive networks may be modulated by the number, localization and propagation of IEDs within the area of the network. In Figure 8.1 all hypotheses on IEDs related to network changes are visualized.

\section{Future research}

Future research should continue to aim at pathophysiological processes related to IEDs and cognition. "Network" seems to be the key word in this type of research. As yet many questions remain unanswered. Prospective longitudinal observations of functional as well as structural changes in networks related to cognitive development are needed, both in normal children and in those suffering from epilepsy. What is the relative influence of epilepsy-related variables such as IEDs, compared to seizures, AEDs or other factors on the development of cognitive networks? What are the syndrome specific vulnerabilities of the network to IEDs and do they have underlying genetic signatures? Networks can change, can they also change back to normal? How long does that take? To what extent is recovery from cognitive disabilities possible, does this relate to the residual potential of brain plasticity and to what extent is this recovery age- or syndrome-related? This kind of research will need increasing technical and mathematical knowledge and therefore collaborations in multidisciplinary research groups are necessary. 


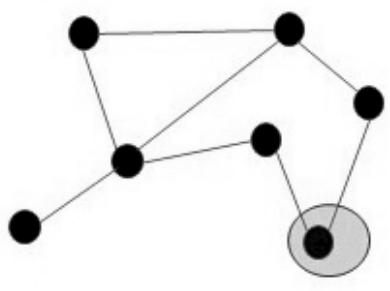

1. IEDs in one brain area of a network, may influence the function of the complete network

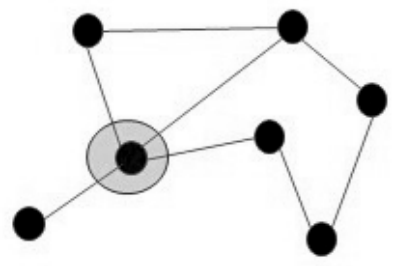

2. IEDs in another area of the same network, may influence the function of the complete network with the same outcome

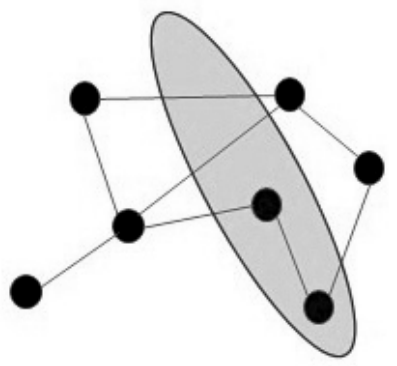

3. IEDs with further propagation may have larger influence on the function of the network

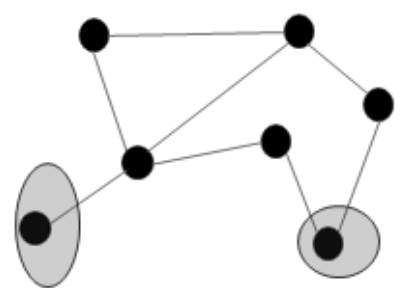

4. Multifocal IEDs may have larger influence on the function of the network

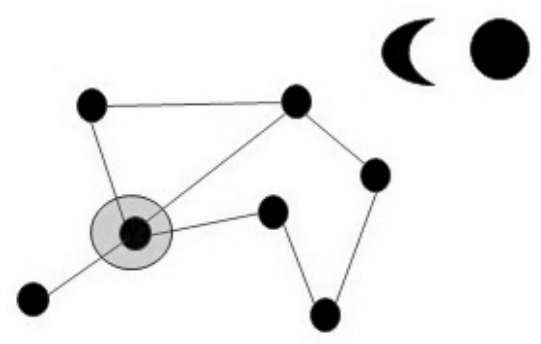

5. IEDs in wakefulness or in sleep may have a different influence

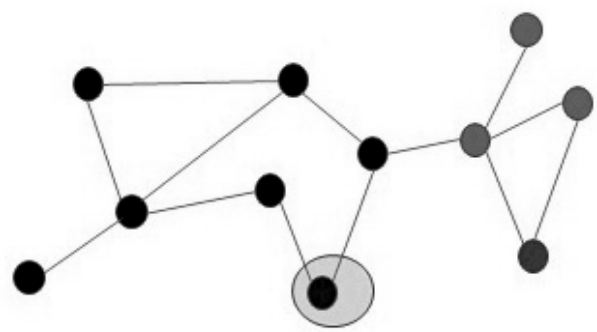

6. IEDs may be of influence on connected networks as well

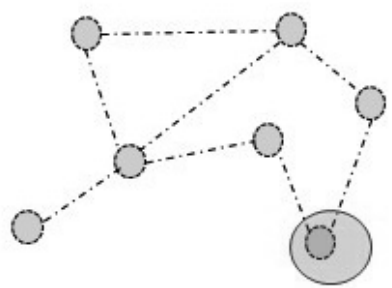

7. IEDs may have more influence on a vulnerable network

Brain area "node" within functional network Connection between brain areas

Cortical area with IEDs

Figure 8.1 Hypotheses on IEDs related to network changes 
Despite all remaining questions, the time is also ripe for controlled intervention studies in patients with cognitive impairments and frequent IEDs with cognition as main outcome parameter. There is ample evidence to suspect a causal relationship. A recent Cochrane review (2014) on the treatment of Rolandic epilepsy concludes: "regarding the area of cognitive effects, there is insufficient evidence comparing those on different AED treatments and to date no randomized controlled trials have been performed comparing the effects of treatment with no treatment/placebo". Patients that should be examined first, are those in whom other causes of cognitive impairment seem less plausible. Therefore these should be patients with low seizure frequency (even better: no seizures observed), high IED frequency and who are drug naïve. To rule out large differences in syndrome specific vulnerabilities, these patients should be diagnosed with the same epilepsy syndromal diagnosis (e.g. Rolandic epilepsy) or they should at least demonstrate similar EEG characteristics (e.g. a patient group with multifocal highly frequent IEDs, morphologically and topologically typical of benign focal IEDs). Cognition should be the main outcome parameter in relation to IED frequency. A method calculating reliable and relevant IED changes should be applied (this could be the method as suggested in chapter 7).

The treatment regimen could be an AED and the AED should be compared to placebo. The patients included in such trials must be carefully monitored for AED side effects, that itself may also deteriorate cognition. The fact that the number of AEDs used was the only other epilepsy related variable that contributed significantly to cognitive test results in regression analyses in our studies, should be conceived as a warning.

We still are waiting for the answer to this question (used as a title in an editorial by Mantovani ${ }^{41}$ written in 2000 at the occasion of a high impact publication on neuropsychological outcome in patients with Rolandic epilepsy by Deonna ${ }^{24}$ ): "Treat the patient, not the EEG ?"41 


\section{References}

1. Steinhoff BJ, Scholly J, Dentel C, Staack AM. Is routine electroencephalography (EEG) a useful biomarker for pharmacoresistant epilepsy? Epilepsia 2013;54 Suppl 2:63-6.

2. Mizrahi EM. Alternate endpoint: EEG assessment of antiepileptic drug efficacy and toxicity. Adv Neurol 1998;76:209-21.

3. Camfield C, Camfield P. Management guidelines for children with idiopathic generalized epilepsy. Epilepsia 2005;46 Suppl 9:112-6.

4. Kuba R, Nesvadba D, Brazdil M, Oslejskova H, Ryzi M, Rektor I. Effect of chronic vagal nerve stimulation on interictal epileptiform discharges. Seizure 2010;19:352-5.

5. Hallbook T, Lundgren J, Blennow G, Stromblad LG, Rosen I. Long term effects on epileptiform activity with vagus nerve stimulation in children. Seizure 2005;14:527-33.

6. Walker I, Said RR. Predictors of Ketogenic Diet Efficacy in Children Based on the Electroencephalogram (EEG). J Child Neurol 2014.

7. Richens A. Discussion. Proof of principle trials: EEG surrogate endpoints. Epilepsy Research 2001;45: 13-4.

8. Drislane FW. Overlap of encephalopathies and epileptic seizures. J Clin Neurophysiol 2013;30:468-76.

9. Lado FA, Rubboli G, Capovilla G, Avanzini G, Moshe SL. Pathophysiology of epileptic encephalopathies. Epilepsia 2013;54 Suppl 8:6-13.

10. Smith MC, Hoeppner TJ. Epileptic encephalopathy of late childhood: Landau-Kleffner syndrome and the syndrome of continuous spikes and waves during slow-wave sleep. J Clin Neurophysiol 2003;20:462-72.

11. Avanzini G, Depaulis A, Tassinari A, de Curtis M. Do seizures and epileptic activity worsen epilepsy and deteriorate cognitive function? Epilepsia 2013;54 Suppl 8:14-21.

12. Jacobs J, LeVan P, Chander R, Hall J, Dubeau F, Gotman J. Interictal high-frequency oscillations (80-500 $\mathrm{Hz}$ ) are an indicator of seizure onset areas independent of spikes in the human epileptic brain. Epilepsia 2008;49:1893-907.

13. Staba RJ, Stead M, Worrell GA. Electrophysiological biomarkers of epilepsy. Neurotherapeutics 2014;11:334-46.

14. Zelmann R, Lina JM, Schulze-Bonhage A, Gotman J, Jacobs J. Scalp EEG is not a blur: it can see high frequency oscillations although their generators are small. Brain Topogr 2014;27:683-704.

15. Wu JY, Koh S, Sankar R, Mathern GW. Paroxysmal fast activity: an interictal scalp EEG marker of epileptogenesis in children. Epilepsy Res 2008;82:99-106.

16. van Diessen E, Diederen SJ, Braun KP, Jansen FE, Stam CJ. Functional and structural brain networks in epilepsy: what have we learned? Epilepsia 2013;54:1855-65.

17. van Diessen E, Otte WM, Braun KP, Stam CJ, Jansen FE. Improved diagnosis in children with partial epilepsy using a multivariable prediction model based on EEG network characteristics. PLoS One 2013;8:e59764.

18. Douw L, de Groot M, van Dellen E, Heimans JJ, Ronner HE, Stam CJ, Reijneveld JC. 'Functional connectivity' is a sensitive predictor of epilepsy diagnosis after the first seizure. PLoS One 2010;5:e10839.

19. van Diessen E, Otte WM, Braun KP, Stam CJ, Jansen FE. Does sleep deprivation alter functional EEG networks in children with focal epilepsy? Front Syst Neurosci 2014;8:67.

20. Badawy RA, Jackson GD, Berkovic SF, Macdonell RA. Cortical excitability and refractory epilepsy: a three-year longitudinal transcranial magnetic stimulation study. Int J Neural Syst 2013;23:1250030.

21. Badawy RA, Jackson GD, Berkovic SF, Macdonell RA. Inter-session repeatability of cortical excitability measurements in patients with epilepsy. Epilepsy Res 2012;98:182-6.

22. Badawy RA, Strigaro G, Cantello R. TMS, cortical excitability and epilepsy: the clinical impact. Epilepsy Res 2014;108:153-61.

23. Filippini M, Boni A, Giannotta M, Gobbi G. Neuropsychological development in children belonging to BECTS spectrum: long-term effect of epileptiform activity. Epilepsy Behav 2013;28:504-11.

24. Deonna T, Zesiger P, Davidoff V, Maeder M, Mayor C, Roulet E. Benign partial epilepsy of childhood: a longitudinal neuropsychological and EEG study of cognitive function. Dev Med Child Neurol 2000;42:595-603. 
25. Northcott E, Connolly AM, Berroya A, Sabaz M, Mclntyre J, Christie J, Taylor A, Batchelor J, Bleasel AF, Lawson JA, Bye AM. The neuropsychological and language profile of children with benign rolandic epilepsy. Epilepsia 2005;46:924-30.

26. Sud S, Sadaka Y, Massicotte C, Smith ML, Bradbury L, Go C, Weiss SK. Memory consolidation in children with epilepsy: does sleep matter? Epilepsy Behav 2014;31:176-80.

27. Tassinari CA, Rubboli G. Cognition and paroxysmal EEG activities: from a single spike to electrical status epilepticus during sleep. Epilepsia 2006;47 Suppl 2:40-3.

28. Shewmon DA, Erwin RJ. Focal spike-induced cerebral dysfunction is related to the after-coming slow wave. Ann Neurol 1988;23:131-7.

29. Fahoum F, Zelmann R, Tyvaert L, Dubeau F, Gotman J. Epileptic discharges affect the default mode network--FMRI and intracerebral EEG evidence. PLoS One 2013;8:e68038.

30. Siniatchkin M, Groening K, Moehring J, Moeller F, Boor R, Brodbeck V, Michel CM, Rodionov R, Lemieux $L$, Stephani U. Neuronal networks in children with continuous spikes and waves during slow sleep. Brain 2010;133:2798-813.

31. Baumbach HD, Chow KL. Visuocortical epileptiform discharges in rabbits: differential effects on neuronal development in the lateral geniculate nucleus and superior colliculus. Brain Res 1981;209: 61-76.

32. Hernan AE, Alexander A, Jenks KR, Barry J, Lenck-Santini PP, Isaeva E, Holmes GL, Scott RC. Focal epileptiform activity in the prefrontal cortex is associated with long-term attention and sociability deficits. Neurobiol Dis 2014;63:25-34.

33. Fry AF, Hale S. Relationships among processing speed, working memory, and fluid intelligence in children. Biol Psychol 2000;54:1-34.

34. Sortor JM, Kulp MT. Are the results of the Beery-Buktenica Developmental Test of Visual-Motor Integration and its subtests related to achievement test scores? Optom Vis Sci 2003;80:758-63.

35. Taylor Kulp M. Relationship between visual motor integration skill and academic performance in kindergarten through third grade. Optom Vis Sci 1999;76:159-63.

36. Ibrahim GM, Cassel D, Morgan BR, Smith ML, Otsubo H, Ochi A, Taylor M, Rutka JT, Snead OC 3rd, Doesburg $\mathrm{S}$. Resilience of developing brain networks to interictal epileptiform discharges is associated with cognitive outcome. Brain 2014;137:2690-702.

37. De Tiege $X$, Goldman S, Van Bogaert P. Insights into the pathophysiology of psychomotor regression in CSWS syndromes from FDG-PET and EEG-fMRI. Epilepsia 2009;50 Suppl 7:47-50.

38. Smith AB, Kavros PM, Clarke T, Dorta NJ, Tremont G, Pal DK. A neurocognitive endophenotype associated with rolandic epilepsy. Epilepsia 2012;53:705-11.

39. Overvliet GM, Aldenkamp AP, Klinkenberg S, Vles JS, Hendriksen J. Impaired language performance as a precursor or consequence of Rolandic epilepsy? J Neurol Sci 2011;304:71-4.

40. van Bogaert P, King MD, Paquier P, Wetzburger C, Labasse C, Dubru JM, Deonna T. Acquired auditory agnosia in childhood and normal sleep electroencephalography subsequently diagnosed as LandauKleffner syndrome: a report of three cases. Dev Med Child Neurol 2013;55:575-9.

41. Mantovani J. 'Treat the patient, not the EEG'? Dev Med Child Neurol 2000;42:579.

42. Ebus SC, Majoie HJ, Arends JB, Boon PJ. Can spikes predict seizure frequency? Results of a pilot study in severe childhood epilepsies treated with vagus nerve stimulation. Seizure 2004;13:494-8.

43. Ebus S, Arends J, Hendriksen J, van der Horst E, de la Parra N, Hendriksen R, Santegoeds E, Boon P, Aldenkamp B. Cognitive effects of interictal epileptiform discharges in children. Eur J Paediatr Neurol 2012;16:697-706.

44. Ebus SC, Lambrechts DA, Herraets IJ, Majoie MJ, de Louw AJ, Boon PJ, Aldenkamp AP, Arends JB. Can an early 24-hour EEG predict the response to the ketogenic diet? A prospective study in 34 children and adults with refractory epilepsy treated with the ketogenic diet. Seizure 2014;23:468-74.

45. Ebus SC. Changes in the frequency of benign focal spikes accompany changes in central information processing speed: a prospective 2-year follow-up study. Epilepsy \& Behavior 43;2015:8-15. 
Summary 


\section{Summary}

An electroencephalogram (EEG) as applied in the routine diagnostic procedures in patients with epilepsy is usually recorded to:

- search for epileptiform discharges in order to confirm (the susceptibility for) seizures;

- analyze the localization and type of epileptiform discharges in order to obtain information on the epilepsy syndrome;

- examine the frequency of ictal discharges within a certain period in order to obtain information on the impact of the epilepsy in daily life.

The studies in this thesis examine whether the calculation of the frequency of interictal epileptiform discharges (IEDs) in an EEG can supply additional useful information. The studies are performed in the setting of a tertiary epilepsy center. It is first examined whether the IED frequency can be a marker of epileptogenicity, to be changed by vagus nerve stimulation or by a ketogenic diet as antiepileptic therapies. Can a change in IED frequency predict or at least confirm which patients respond to the therapy? Secondly, it is examined if a higher IED frequency is correlated to worse cognitive abilities in children with epilepsy. Most studies in the second part focus on children with benign focal epilepsies. These are epilepsy syndromes known with high frequency of IEDs and low seizure frequency. Learning disabilities are reported in several studies, especially in rolandic epilepsy (the most common type of benign focal epilepsies).

Chapter 1 is an introduction, providing background information and introducing the two research topics: the use of the IED frequency as a marker for the outcome after therapy change, and the use of the IED frequency as a marker for cognitive outcome.

In chapter 2 the results of a prospective study in 19 patients suffering from severe childhood epilepsies treated for 2 years with vagus nerve stimulation (VNS) are presented. For the group as a whole, no changes in IED frequency were observed in a 30-minute EEG in wakefulness at 6 months, compared to baseline. At 6 months, 3 patients were clinical responders ( $\geq 50 \%$ seizure reduction), however without clear decrease in IED frequency. Three more EEGs were recorded with intervals of 6 months, until the end of the study at 2 years VNS treatment. The IED frequency did not change. A significant correlation between the mean IED frequency (from 4 EEGs post VNS) and prospectively counted seizure frequency within 2 years was demonstrated. IEDs occurring in series of spike-waves were most strongly correlated with seizure frequency $(R=0.74)$. The study shows that the IED frequency is a candidate marker for epileptogenicity in these patients.

In chapter $\mathbf{3}$ the usefulness of calculating IED frequency in a prospectively examined heterogeneous group of 34 epilepsy patients (children and adults) treated with a ketogenic diet $(K D)$ is examined. Twenty-four hour EEG recordings pre- and post treatment enabled to examine the effects of the KD on the IED frequency in 
wakefulness as well as in sleep. The objective was the prediction of the future effect of the KD in individual patients at an early moment (at 6 weeks of treatment). Because the diet is a burden, early useful information to decide on (dis)continuing the diet, is welcome. Nocturnal decrease of IEDs at 6 weeks was related to being a responder to the KD. However, at individual level, the IED changes could not reliably predict which patients should be encouraged to continue the diet. Because a clear seizure reduction was obvious in the second month of KD treatment in all responders, seizure counts should be best used for this decision.

Chapter 4 presents the results of a cross-sectional study correlating the outcomes on several cognitive tests with IED frequency and other IED characteristics in 24 hour EEGs in 182 children with different epilepsy syndromes. A higher IED frequency in wakefulness was associated with worse performance on central information processing speed, short-term verbal memory and visual-motor integration, independently from other epilepsy-related characteristics. The frequency of nocturnal IEDs only contributed partially to a slower central information processing speed. There were no large additional effects of other IED characteristics (localization, distribution, serial spikewave complexes). The effects of IED frequency within specific syndromal diagnoses could not be examined because of too small subgroups.

In Chapter 5 a study in a homogeneous group of 26 children with rolandic epilepsy is described. Twenty-four hour EEGs, reading tests, and IQ measurements were performed. The group of children had a significant mean educational delay in reading compared to existing data on normal development. A larger delay in reading sentences was correlated to a higher nocturnal IED frequency. Verbal IQ was negatively correlated to nocturnal IED frequency. The possible causal relationship between IED frequency and language impairment is discussed.

Chapter 6 presents a 2-year prospective follow-up study in 26 children with benign focal epilepsies (mainly rolandic epilepsy), focusing on cognitive outcome and IED frequency changes over time. The cognitive function estimated to be most likely to change together with the IED frequency was chosen as outcome parameter: the central information processing speed (CIPS). At baseline, a lower CIPS was correlated with a higher IED frequency in wakefulness. At follow-up, changes in CIPS accompanied changes in IED frequency in wakefulness in the same direction. There was a higher probability of ongoing IEDs at two years follow-up in those patients that had had a baseline EEG with a high IED frequency, multifocal localization and/or serial spike-wave discharges. The chapter discusses the consequences of this finding. It is recommended that controlled intervention trials should be performed in patients with benign focal IEDs with cognition as outcome. At first patients with high IED loads, proven cognitive difficulties and without treatment indication for seizures should be included in such trials. 
In Chapter 7 methods to quantify IEDs are scrutinized. First a method used in daily clinical practice that categorizes the IED frequency is examined on efficiency, reliability and overall satisfaction. The method showed an acceptable interobserver agreement. The outcome of the quantification in the EEG report was most used for decisions on the syndromal diagnosis or to observe changes in consecutive EEGs in patients known with high IED frequencies (electrical status epilepticus of slow wave sleep (ESES), or epileptic encephalopathies). Second, for the purpose of future research, several methods to decide to change in IED frequency in successive EEGs of individual patients with benign focal IEDs were examined. Changes had to be observed in a dataset of 22 EEGs at baseline and 22 EEGs at follow-up. The method that best met all conditions was the calculation of IEDs by visual inspection, with a twice scored baseline EEG to define the limits for change.

Chapter 8 discusses the combined findings of the studies and advices on further research. Based on the results of the studies on IED change after vagus nerve stimulation and ketogenic diet, it is concluded that IED reduction is difficult to use as outcome parameter in treatment trials, because of methodological challenges and general low impact of these treatments on IED frequency. New studies should be designed with caution and are best performed in homogeneous patient groups with epilepsy syndromes known with frequent IEDs. The aim of such studies should be to predict the future therapeutic effect in individual patients. Other markers of epileptogenicity for the use in such studies should be explored, such as transcranial magnetic stimulation (TMS).

The studies on IEDs and cognition in children added to the growing evidence of a (possibly causal) relationship between IEDs and cognitive impairments. It is discussed that controlled intervention studies should be performed, with cognitive improvement as main outcome parameter in relation to IED frequency reduction. Besides intervention studies, prospective longitudinal observations of functional as well as structural changes in cognitive networks related to IEDs (and other epilepsy related variables) are needed. Syndrome specific vulnerabilities of cognitive networks to IEDs might exist. This kind of research needs technical and mathematical knowledge and therefore collaborations in multidisciplinary research groups are necessary. 
Samenvatting 


\section{Samenvatting}

Een electro-encephalografie (EEG) zoals toegepast in de routine diagnostiek bij patiënten met epilepsie wordt gebruikt om:

- naar epileptiforme ontladingen te zoeken om (de gevoeligheid voor) epileptische aanvallen te bevestigen;

- de lokalisatie en het type van de epileptiforme ontladingen te analyseren om informatie te verkrijgen over de syndroomdiagnose van de epilepsie;

- de hoeveelheid van ictale ontladingen binnen een bepaalde periode te onderzoeken om informatie te verkrijgen over de impact van de epilepsie in het dagelijks leven.

De studies in dit proefschrift onderzoeken of het bepalen van de hoeveelheid interictale epileptiforme ontladingen (interictal epileptiform discharges $=$ IEDs) in een EEG bruikbare aanvullende informatie kan opleveren. De studies werden uitgevoerd in de setting van een derdelijns epilepsiecentrum.

Als eerste werd onderzocht of de hoeveelheid IEDs een marker van epileptogeniciteit kan zijn, te veranderen door nervus vagus stimulatie of een ketogeen dieet als antiepileptische therapie. Kan een verandering in de hoeveelheid IEDs voorspellen, of tenminste bevestigen, welke patiënten goed op de therapie gaan reageren ?

Als tweede werd onderzocht of een grotere hoeveelheid IEDs gerelateerd is met slechtere cognitieve vaardigheden bij kinderen met epilepsie. De meeste studies in dit tweede deel focussen op kinderen met benigne focale kinderepilepsieën. Dit zijn epilepsiesyndromen die bekend staan om grote hoeveelheden IEDs en lage aanvalsfrequentie. Problemen met leren worden in diverse studies genoemd, vooral bij Rolandische epilepsie (het meest voorkomende type van de benigne focale kinderepilepsieën).

Hoofdstuk 1 is een introductie. Het geeft achtergrond informatie en introduceert de twee onderzoeksonderwerpen: het gebruik van de hoeveelheid IEDs als een marker voor uitkomst na verandering van therapie en het gebruik van de hoeveelheid IEDs als een marker voor uitkomst op het gebied van cognitie.

In hoofdstuk 2 worden de resultaten van een prospectieve studie bij 19 patiënten met ernstige kinderepilepsiesyndromen gepresenteerd, die 2 jaar met nervus vagus stimulatie (NVS) werden behandeld. Voor de gehele groep werden geen veranderingen in de hoeveelheden IEDs geobserveerd in een 30 minuten durend EEG in waak na 6 maanden, vergeleken met de baseline. Na 6 maanden waren 3 patiënten klinische responders ( $\geq 50 \%$ aanvalsreductie), maar zij hadden geen duidelijke daling in de hoeveelheid IEDs. Er werden nog 3 EEGs geregistreerd met intervallen van 6 maanden tot het eind van de studie na 2 jaar NVS behandeling. De hoeveelheid IEDs veranderde niet. Een significante correlatie tussen de gemiddelde hoeveelheid IEDs (van 4 EEGs na de start van de NVS behandeling) en de prospectief getelde hoeveelheid aanvallen 
werd aangetoond. IEDs die in reeksen piekgolven optraden waren het sterkst gecorreleerd met de aanvalsfrequentie $(R=0.74)$. De studie laat zien dat de hoeveelheid IEDs een kandidaat marker voor epileptogeniciteit bij deze patiënten is.

In hoofdstuk 3 wordt het nut van het bepalen van de hoeveelheid IEDs in een prospectief onderzochte heterogene groep van 34 epilepsiepatiënten (kinderen en volwassenen) behandeld met het ketogeen dieet (KD) onderzocht. Vierentwintig uur durende EEGs voor en na start van de behandeling maakten mogelijk dat zowel het effect op de hoeveelheid IEDs in waak als in slaap kon worden onderzocht. Het doel was om het toekomstige effect van het KD voor individuele patiënten op een vroeg moment (na 6 weken behandeling) te voorspellen. Omdat het dieet zwaar is om vol te houden, is vroege informatie waarop men kan baseren of het dieet al dan niet gecontinueerd moet worden, zeer welkom. Een afname van de nachtelijke hoeveelheid IEDs na 6 weken behandeling was gerelateerd met het zijn van een responder op het KD. Maar op een individueel niveau, konden de IED veranderingen niet betrouwbaar voorspellen welke patiënten aangemoedigd moesten worden om het dieet te blijven volgen. Omdat een duidelijke reductie in aanvalsfrequentie in de tweede maand van KD behandeling bij alle responders werd gezien, kunnen aanvalstellingen dus beter gebruikt worden om dit besluit te maken.

Hoofdstuk 4 presenteert de resultaten van een dwarsdoorsnede studie die de uitkomsten op verschillende cognitieve testen correleert met de hoeveelheid IEDs en andere karakteristieken van IEDs in 24 uur EEGs van 182 kinderen met verschillende epilepsiesyndromen. Een grotere hoeveelheid IEDs in waak was geassocieerd met slechter presteren op de gebieden van het tempo van centrale informatieverwerking, korte termijn verbaal geheugen en visuo-motore integratie, onafhankelijk van andere epilepsie-gerelateerde karakteristieken. De hoeveelheid nachtelijke IEDs was alleen maar deels gerelateerd aan een trager tempo van centrale informatieverwerking. Er waren geen grote effecten van andere karakteristieken van de IEDs (localisatie, distributie, reeksen piekgolfcomplexen). De effecten van de hoeveelheden IEDs per epilepsie-syndroomdiagnose konden niet goed onderzocht worden vanwege te kleine subgroepen.

In hoofdstuk 5 wordt een studie bij een homogene groep van 26 kinderen met Rolandische epilepsie beschreven. Vierentwintig uurs EEGs, leestesten en IQ metingen werden verricht. De groep kinderen had een significante gemiddelde leerachterstand bij het lezen in vergelijking met bestaande data van kinderen met een normale ontwikkeling. Een grotere achterstand voor het lezen van zinnen was gecorreleerd met een grotere hoeveelheid nachtelijke IEDs. Het verbale IQ was negatief gecorreleerd met de nachtelijke hoeveelheid IEDs. Een mogelijk causaal verband tussen de hoeveelheid IEDs en taalproblemen wordt bediscussieerd. 
Hoofdstuk 6 presenteert een 2 jaar durende prospectieve studie bij 26 kinderen met benigne focale epilepsieën (met name Rolandische epilepsie) of met IEDs typisch voor een benigne focale epilepsie maar zonder geobserveerde aanvallen, die focust op veranderingen in cognitieve uitkomst en veranderingen in IEDs in de tijd. De cognitieve functie waarvan ingeschat werd dat deze het meeste kans maakte om te veranderen tegelijkertijd met de hoeveelheid IEDs werd gekozen als uitkomst parameter: de snelheid van centrale informatieverwerking (central information processing speed=CIPS). Op de baseline was een lagere CIPS gecorreleerd met meer IEDs in waak. In het vervolg van de studie gingen de veranderingen in CIPS gepaard met veranderingen in de hoeveelheid IEDs, in dezelfde richting. Patiënten die een baseline EEG hadden met grote hoeveelheid IEDs, multifocale IEDs en/of reeksen piekgolfcomplexen hadden een grotere kans om na 2 jaar nog steeds IEDs in het EEG te hebben dan de andere patiënten. In het hoofdstuk worden de consequenties van de bevindingen bediscussieerd. Er wordt geadviseerd interventie studies te gaan opzetten bij patiënten met benigne focale IEDs, met cognitie als uitkomstmaat. Als eerste zouden patiënten met grote hoeveelheden IEDs, bewezen cognitieve problemen en zonder behandelindicatie voor aanvallen geïncludeerd moeten worden in zulke studies.

In hoofdstuk 7 worden methoden onderzocht om de hoeveelheid van IEDs vast te stellen.

Ten eerste werd een methode die gebruikt wordt in de dagelijkse praktijk en die de hoeveelheid van IEDs in categorieën indeelt, bekeken. Deze methode werd beoordeeld op efficiëntie, betrouwbaarheid en algemene tevredenheid. De methode had een acceptabele overeenkomst tussen twee verschillende beoordelaars. De uitkomst geleverd door deze methode in het EEG verslag werd vooral gebruikt om beslissingen te nemen over de epilepsie-syndroomdiagnose, of om veranderingen in opeenvolgende EEGs te beoordelen bij patiënten die bekend zijn met grote hoeveelheden IEDs (met een electrische status epilepticus in de slaap = electrical status epilepticus of slow-wave sleep = ESES, of met epileptische encephalopathieën).

Ten tweede, met het oog op gebruik voor toekomstig wetenschappelijk onderzoek, werden diverse methoden bekeken die besluiten tot verandering in de hoeveelheid IEDs in opeenvolgende EEGs van individuele patiënten met benigne focale IEDs. Veranderingen moesten worden geobserveerd in een dataset van 22 EEGs op de baseline en 22 EEGs na follow-up. De methode die het beste aan alle voorwaarden voldeed was het bepalen van de hoeveelheid IEDs door visuele inspectie, met een tweemaal gescoorde baseline om de grenzen voor verandering vast te stellen.

Hoofdstuk 8 bediscussieert de gecombineerde bevindingen van de studies en adviseert over toekomstig onderzoek. Gebaseerd op de resultaten van de studies aangaande veranderingen in de hoeveelheid IEDs na nervus vagus stimulatie en ketogeen dieet, wordt geconcludeerd dat verandering in de hoeveelheid IEDs een lastige uitkomstmaat is om te gebruiken in onderzoeken die een behandeling evalueren, omdat er 
methodologische uitdagingen zijn en er in het algemeen een lage impact van deze behandelingen op de hoeveelheid IEDs was. Nieuwe studies moeten worden ingezet met voorzichtigheid en dan het beste in homogene patiëntengroepen met epilepsiesyndromen bekend met frequente IEDs. Het doel van dergelijke studies moet het voorspellen van het toekomstige therapeutische effect zijn bij individuele patiënten. Andere markers van epileptogeniciteit voor de toepassing bij degelijke studies moeten worden bekeken, zoals transcraniële magneetstimulatie (TMS).

De studies over IEDs en cognitie bij kinderen, voegden iets toe aan het groeiende bewijs van een (mogelijk causaal) verband tussen IEDs en cognitieve problemen. Beargumenteerd wordt dat gecontroleerde interventiestudies zouden moeten worden uitgevoerd met cognitieve verbetering als belangrijkste uitkomstmaat, in relatie tot vermindering van de hoeveelheid IEDs. Naast interventiestudies, zijn prospectieve longitudinale observatiestudies van functionele en structurele veranderingen in cognitieve netwerken, gerelateerd aan IEDs (en andere epilepsie-gerelateerde variabelen), nodig. Er zouden syndroom specifieke kwetsbaarheden van cognitieve netwerken voor IEDs kunnen bestaan. Voor dit type wetenschappelijk onderzoek is technische en wiskundige kennis nodig. Daarom zijn samenwerkingsverbanden in multidisciplinaire onderzoeksgroepen noodzakelijk. 
Valorisatie 


\section{Vertaling van wetenschap naar maatschappij}

\section{Introductie}

"Kennisvalorisatie" is het maatschappelijk beschikbaar en bruikbaar maken van inzichten uit wetenschappelijk onderzoek voor eigen vakgenoten, bedrijven of maatschappelijke organisaties. Er is een groeiende maatschappelijke behoefte om vragen vanuit de samenleving en wetenschappelijk onderzoek beter op elkaar aan te laten sluiten. Het wordt wenselijk geacht dat reeds in de ontwerpfase van wetenschappelijk onderzoek door de onderzoeksgroep bewust de vraag wordt meegenomen of de voorgenomen studie wel "valoriseerbaar" is. Om de bewustwording hierover te bevorderen, is elke promovendus aan de universiteit van Maastricht verplicht een addendum over de maatschappelijke relevantie van het wetenschappelijke werk in het proefschrift op te nemen.

\section{Maatschappelijke relevantie van wetenschappelijk onderzoek op het gebied van epilepsie}

Alle onderzoeksvragen die in dit proefschrift zijn behandeld, zijn voortgekomen uit de ervaringen met de behandeling van patiënten met epilepsie in een derdelijns centrum. "Derdelijns zorg" is hooggespecialiseerde zorg. Patiënten worden verwezen naar een derdelijns epilepsiecentrum wanneer de tweedelijns zorg (geboden door specialisten in algemene ziekenhuizen) niet meer toereikend is. In het geval van patiënten met epilepsie gaat het meestal om de vraag om betere behandeling van tot dan toe niet goed behandelbaar gebleken epileptische aanvallen. Vaak zijn er bijkomende hulpvragen vanwege de praktische, psychologische en sociale impact van het hebben van een chronische epilepsie.

Epilepsie is een aandoening met een prevalentie van ca. $0.8 \%$ wereldwijd, en in Nederland zijn er ongeveer 100.000 tot 120.000 mensen bekend met epilepsie. Bij ongeveer $1 / 5$ is de epilepsie niet te genezen. Meerdere studies toonden aan dat patiënten met chronische epilepsie een lagere levenskwaliteit alsmede een lagere levensverwachting hebben. Ze presteren op lager niveau op het gebied van onderwijs, kunnen minder goed deelnemen in het beroepsleven, ze hebben problemen om sociale rollen te vervullen, mogen vaak niet autorijden, hebben vaker psychologische en cognitieve klachten en hebben een hoge consumptie van de gezondheidszorg. ${ }^{1}$ Het moge duidelijk zijn dat genezing van epilepsie of in elk geval een duidelijke aanvalsreductie voor patiënten grote voordelen zal opleveren, niet alleen voor de patiënt zelf, maar ook voor diens directe omgeving (gezin) en uiteindelijk voor de maatschappij als geheel.

Voor een derdelijns centrum als Kempenhaeghe is het belangrijk een voorloper te zijn op het gebied van de diagnostiek en behandeling van epilepsie. Het is daarom ook noodzakelijk om zowel nieuwe ontwikkelingen te blijven volgen alsook om ze zelf te 
initiëren. Het doen van wetenschappelijk onderzoek en starten van innovatieve projecten is hiervoor onontbeerlijk. Recentelijk is een samenwerkingsverband ontstaan tussen Kempenhaeghe en het Academisch Ziekenhuis Maastricht in een "Academisch Centrum voor Epileptologie", om gezamenlijk invulling te geven aan het streven om een voorloper te zijn op het gebied van epilepsiezorg.

Wetenschappelijk onderzoek waarbij de vragen direct vanuit de klinische praktijk worden gegenereerd om uiteindelijk de patiëntenzorg te verbeteren, is per definitie maatschappelijk relevant.

In hoeverre waren de onderzoeksvragen in dit proefschrift relevant in het kader van de verbetering van de behandeling van epilepsie?

\section{Maatschappelijke relevantie van de onderzoeksvragen in de eerste helft van het proefschrift}

De vraag waarop de eerste helft van het proefschrift gebaseerd is, is de vraag of het mogelijk is om een behandeling van epilepsie te evalueren met andere middelen dan alleen het observeren van toekomstige veranderingen in de hoeveelheid aanvallen, en dat liefst in een vroeg stadium van de behandeling.

De volgende veel voorkomende situatie uit de dagelijkse praktijk weerspiegelt hoe relevant deze onderzoeksvraag is voor de dagelijkse patiëntenzorg.

\footnotetext{
Neuroloog: "Omdat het medicijn A niet goed bij $\mathrm{u}$ werkt, stel ik voor om een andere behandeling te gaan uitproberen." Patiënt: "Uitproberen!!!??? Kunt u van tevoren niet even een test doen of het bij mij wel gaat werken? " Neuroloog: "Helaas, de enige manier om te weten of het werkt, is afwachten of $u$ geen aanvallen meer krijgt". Patiënt: "Maar ik heb normaal vier aanvallen per jaar. Dus als ik over een paar maanden weer een aanval krijg, dan kunnen we weer helemaal opnieuw beginnen! Ik voel me zo net een proefkonijn!".
}

Het is voor patiënten en artsen belangrijk om zo snel mogelijk een indruk te krijgen van de werkzaamheid van een nieuwe therapie. Vanuit de regels van de kansberekening, moet een patiënt ongeveer 3 maal zo lang afwachten als dat er voorheen tijd zat tussen zijn of haar aanvallen, voordat er zekerheid is dat het nieuwe anti-epileptische middel inderdaad werkt. ${ }^{2}$ Voor de patiënt uit het bovenstaande voorbeeld is er dus pas na 9 maanden duidelijkheid of het middel inderdaad werkt om verdere aanvallen te onderdrukken. Als patiënt en arts eerder zouden weten dat het nieuwe voorgestelde middel gaat werken of niet, is dat grote winst. Er kan dan eerder gestopt worden met een niet zinvolle behandeling en geswitcht worden naar een behandeling die meer kansen biedt. Zeker omdat een behandeling voor epilepsie ook gepaard kan gaan met bijwerkingen, of anderszins last kan opleveren. 
In dit proefschrift werd onderzocht of het maken van een EEG een methode is om een behandeling te evalueren. Er werd gekeken of een vermindering van de hoeveelheid interictale epileptiforme activiteit ${ }^{\mathrm{a}}$ in het EEG (electro-encephalogram) na het instellen van een behandeling, voorspelt of de aanvallen goed behandeld (gaan) worden. De onderzochte behandelingen waren niet-medicamenteus en worden voornamelijk in gespecialiseerde centra uitgevoerd: nervus vagus stimulatie en het ketogeen dieet. Vooral het ketogeen dieet is een lastig vol te houden behandeling. Bij het ketogeen dieet is specifiek gekeken naar een vroege EEG verandering om een toekomstig effect mee te beoordelen. Als dit op groepsniveau wordt aangetoond is het al belangrijk voor het begrip over de relatie tussen EEG veranderingen en aanvallen na een behandeling. In dit proefschrift is ook gekeken of het maken van een EEG voor een individuele patiënt die het dieet toepast, bruikbaar is. Als je een resultaat van een wetenschappelijk onderzoek kan toepassen in de behandeling van een individuele patiënt, is het resultaat namelijk het meest relevant.

\section{Maatschappelijke relevantie van de onderzoeksvragen in de tweede helft van dit proefschrift}

De tweede helft van het proefschrift is gebaseerd geweest op een vraag die actueel is bij de behandeling van schoolgaande kinderen met epilepsie.

De volgende situatie uit de dagelijkse praktijk beschrijft van waaruit de onderzoeksvraag voortkomt.

\footnotetext{
Moeder: “Mijn dochter heeft 2 jaar geleden een epileptische aanval gehad en daarna gelukkig nooit meer. Ze heeft op school problemen met concentreren en ook blijft de taalontwikkeling achter. Ligt dat nu toch aan de epilepsie?" Neuroloog: "We kunnen de oorzaak van haar schoolproblemen eigenlijk niet goed achterhalen. De MRI-scan is goed en ze gebruikt ook geen medicijnen die de concentratie verslechteren. Het enige dat afwijkt is het EEG waarin we wel wat veel 'vonkjes' zien optreden, een soort kortsluitinkjes waar uw dochter niets van merkt maar die aangeven dat de hersenen gevoelig zijn voor epilepsie. We weten alleen niet goed of, en in hoeverre de klachten van uw dochter eraan gerelateerd zijn. En we weten al helemaal niet of het gaat lukken de klachten te behandelen door medicijnen te geven om de vonkjes te verminderen. Ik stel voor dat we haar dus vooral ondersteunen met extra aandacht op school". Moeder: "Maar kunt $u$ dan echt niets aan die vonkjes in het EEG doen als ze misschien een oorzaak zijn?"
}

\footnotetext{
a Epileptiforme activiteit = kortdurende "vonkjes" van abnormale elektrische activiteit die zichtbaar zijn in een EEG. Interictaal betekent "tussen de aanvallen door", de hersenen van de patiënt vertonen deze afwijkingen, ook als er op dat moment geen aanval is.
} 
De vraag die we onszelf tijdens multidisciplinair overleg over kinderen met leerstoornissen en epilepsie steeds stellen, is in hoeverre een kind met frequente interictale epileptiforme activiteit ("vonkjes" in bovenstaand klinisch voorbeeld) in het EEG last heeft van deze afwijkingen, in de zin van cognitieve klachten. De ultieme vraag is, of een poging gedaan moet worden om deze epileptiforme activiteit te onderdrukken met (extra) medicatie zodat de cognitieve ontwikkeling van het kind zal verbeteren.

In het algemeen is de cognitieve ontwikkeling bij kinderen met epilepsie wel iets om zorgen over te hebben. In een grote studie die 282 kinderen met epilepsie vanaf de eerste aanval vervolgde en vergeleek met kinderen zonder epilepsie, werd aangetoond dat al vanaf het debuut van de epilepsie (de eerste aanval) bij ongeveer een kwart van de kinderen cognitieve problemen aanwezig waren. Het krijgen van meerdere aanvallen alsmede gebruik van medicatie zijn belangrijke redenen waardoor nog een groter percentage kinderen uiteindelijk problemen krijgt met leren. Ook frequente interictale epileptiforme activiteit in het EEG is een mogelijke factor ${ }^{3}$. Ongeveer de helft van de kinderen met epilepsie heeft problemen op school, en een groot aantal kinderen daarvan heeft ook extra hulp op school nodig ${ }^{4}$. Als de cognitieve ontwikkeling van een kind niet optimaal verloopt, betekent dit kosten voor extra begeleiding alsmede minder kansen om later een "goed beroep" te kunnen uitvoeren. Meer te weten komen over de oorzaken en behandelmogelijkheden van leerproblemen bij kinderen met epilepsie is dus van groot maatschappelijk belang. In dit proefschrift is onderzocht in hoeverre de interictale epileptiforme activiteit in het EEG gerelateerd is met leerstoornissen bij kinderen met epilepsie of bij kinderen die nooit aanvallen hadden, maar wel interictale epileptiforme activiteit in het EEG laten zien.

\section{Delen van de resultaten en toekomst}

De resultaten van de verrichte onderzoeken zijn gedeeld met andere onderzoekers op wetenschappelijke congressen. Meerdere hoofdstukken van dit proefschrift zijn gepubliceerd in internationale tijdschriften die gelezen worden door vakgenoten (behandelaars en wetenschappers) in de epilepsiezorg. Tegenwoordig is het opzoeken van deze gepubliceerde artikelen eenvoudig door een voor iedereen toegankelijk zoeksysteem op internet (Pubmed). Andere onderzoekers kunnen op basis van de resultaten gerichter nieuw onderzoek initiëren, om steeds beter bij de antwoorden op de overgebleven vragen te kunnen komen. Ofwel zij kunnen op basis van de resultaten besluiten dat een vraag voldoende is beantwoord en geen verder onderzoek meer behoeft. Op basis van de beschreven resultaten in dit proefschrift is het bijvoorbeeld aannemelijk dat toekomstige onderzoekers terughoudend zullen zijn om het effect van het ketogeen dieet met een EEG te evalueren in een nieuwe studie. Daarentegen, is de vraag over cognitie en epileptiforme afwijkingen in het EEG nog onvoldoende 
beantwoord in dit proefschrift en zullen in dit gebied ongetwijfeld nieuwe studies opgezet worden.

Ook binnen Kempenhaeghe zelf wordt "voortgeborduurd" op de resultaten van dit proefschrift en op de ervaringen die zijn opgedaan tijdens het doen van dit promotieonderzoek. Enkele nieuwe studies zijn in de fase van voorbereiding. Mogelijk zal er in de toekomst ook een interventiestudie ontwikkeld kunnen worden voor een specifieke doelgroep van kinderen met hoogfrequente interictale epileptiforme afwijkingen. Het ontwerpen van een interventiestudie bij dergelijke kinderen is een lastige klus en het vergt een denkproces binnen een multidisciplinaire groep onderzoekers en clinici.

Dat brengt mij bij het noemen van een laatste valorisatie-aspect van wetenschappelijk onderzoek doen in een klinische setting. Dergelijk onderzoek is voor onderzoekers en alle betrokken clinici in de onderzoeksgroep een bijzonder bevredigend proces, omdat het gaat om het beantwoorden van die vragen "waar iedereen mee zit" in de dagelijkse confrontatie met mensen met epilepsie. Werknemers die zinvolheid en plezier ervaren bij wat ze doen, stimuleren elkaar binnen het creatieve proces van wetenschappelijk onderzoek doen, en dit zal niet alleen de kwaliteit van het onderzoek zelf vergroten: de positieve energie die eruit voortkomt is aanstekelijk voor iedereen in hun omgeving en een onmisbare factor voor een centrum voor epileptologie om het vuur waarmee iedereen blijft zoeken naar verbeterde epilepsiezorg, brandende te houden.

\section{Referenties}

1. Laxer KD, Trinka E, Hirsch L, Cendes F, Langfitt J, Delanty N, Resnick T, Benbadis SR. The consequences of refractory epilepsy and its treatment. Epilepsy Behav. 2014;37:59-70.

2. Westover MB, Cormier J, Bianchi MT, Shafi M, Kilbride R, Cole AJ, Cash SS. Revising the "Rule of Three" for inferring seizure freedom. Epilepsia 2012;53:368-76.

3. Fastenau PS, Johnson CS, Perkins SM, Byars AW, deGrauw TJ, Austin JK, Dunn DW. Neuropsychological status at seizure onset in children: risk factors for early cognitive deficits. Neurology 2009;18;73:526-34.

4. Beghi M, Cornaggia CM, Frigeni B, Beghi E. Learning disorders in epilepsy. Epilepsia 2006;47 Suppl 2: 14-8. 
List of publications 


\section{List of publications}

S.C.M. Ebus, H.J.M. Majoie, J.B.A.M. Arends, P.A.J.M. Boon

Can spikes predict seizure frequency ? Results of a pilot study in severe childhood epilepsies treated with vagus nerve stimulation

Seizure 2004;13:494-498

S.C.M. Ebus, G.M. Overvliet, J.B.A.M. Arends, A.P. Aldenkamp

Reading performance in children with rolandic epilepsy correlates with nocturnal epileptiform activity, but not with epileptiform activity while awake.

Epilepsy \& Behavior 2011;22:518-522

S.C.M. Ebus, J.B.A.M. Arends, J. Hendriksen, E. van der Horst, N. de la Parra, R. Hendriksen, E. Santegoeds, P.A.J.M. Boon, A.P. Aldenkamp Cognitive effects of interictal epileptiform discharges in children

Eur J Paediatr Neurol. 2012;16(6): 697-706

Corrigendum: Eur J Paediatr Neurol. 2015;19:104

Nicolai J, Ebus S, Biemans DP, Arends J, Hendriksen J, Vles JS, Aldenkamp AP

The cognitive effects of interictal epileptiform EEG discharges and short nonconvulsive epileptic seizures.

Epilepsia 2012;53:1051-9

Besseling RM, Overvliet GM, Jansen JF, van der Kruijs SJ, Vles JS, Ebus SC, Hofman PA, de Louw AJ, Aldenkamp AP, Backes WH

Aberrant functional connectivity between motor and language networks in rolandic epilepsy.

Epilepsy Res. 2013;107:253-62

Besseling RM, Jansen JF, Overvliet GM, van der Kruijs SJ, Ebus SC, de Louw A, Hofman PA, Vles JS, Aldenkamp AP, Backes WH

Reduced structural connectivity between sensorimotor and language areas in rolandic epilepsy.

PLoS One 2013;8:e83568

Overvliet GM, Besseling RM, Jansen JF, van der Kruijs SJ, Vles JS, Hofman PA, Ebus SC, de Louw A, Aldenkamp AP, Backes WH

Early onset of cortical thinning in children with rolandic epilepsy.

Neuroimage Clin. 2013;2:434-9 
Besseling RM, Jansen JF, Overvliet GM, van der Kruijs SJ, Vles JS, Ebus SC, Hofman PA, Louw Ad, Aldenkamp AP, Backes WH

Reduced functional integration of the sensorimotor and language network in rolandic epilepsy.

Neuroimage Clin. 2013;2:239-46

Overvliet GM, Besseling RM, van der Kruijs SJ, Vles JS, Backes WH, Hendriksen JG, Ebus SC, Jansen JF, Hofman PA, Aldenkamp AP

Clinical evaluation of language fundamentals in Rolandic epilepsy, an assessment with CELF-4.

Eur J Paediatr Neurol. 2013;17:390-6

S.C.M. Ebus ${ }^{1}$, D.A.J.E. Lambrechts ${ }^{1}$, I.J.T.Herraets, H.J.M. Majoie, A.J. de Louw, P.A.J.M. Boon, A.P. Aldenkamp, J.B.A.M. Arends

Can an early 24-hour EEG predict the response to the ketogenic diet?

A prospective study in 34 children and adults with refractory epilepsy

treated with the ketogenic diet

Seizure 2014;23:468-474

${ }^{1}$ both first authors

Besseling RM, Jansen JF, Overvliet GM, van der Kruijs SJ, Ebus SC, de Louw AJ, Hofman PA, Aldenkamp AP, Backes WH

Delayed convergence between brain network structure and function in rolandic epilepsy.

Front Hum Neurosci. 2014;8:704

S.C.M. Ebus, D.M. IJff, J.T. den Boer, M.J.H. van Hall, S. Klinkenberg, A. van der Does, P.A.J.M. Boon, J.B.A.M. Arends, A.P. Aldenkamp

Changes in the frequency of benign focal spikes accompany changes in central information processing speed: A prospective 2-year follow-up study.

Epilepsy \& Behavior 2015;43:8-15 
Dankwoord 


\section{Dankwoord}

Mijn promotietraject was lang en dus ook mijn dankwoord.

Terugkijkend, besef ik hoeveel gebeurtenissen (toevallig of niet toevallig) voor deze promotie in elkaar hebben moeten grijpen. En hoeveel goede wil en werk van andere mensen eraan heeft bijdragen. Ik ben blij dat mijn wens om te promoveren die al zo lang "broeide", uiteindelijk vervuld is. Velen weten hoeveel twijfels ik heb gehad. Het is moeilijk om de draad vast te houden van een langdurig promotietraject en om steeds het plezier daarvan te blijven voelen, ook bij tegenspoed. Vooral in het laatste jaar waarin de draad steviger begon te worden en ik hem minder vaak hoefde los te laten; en waarin ik bovendien met steeds meer enthousiaste mensen ging samenwerken, heb ik de "wetenschapsvreugde" ervaren zoals ik mij dat tevoren had voorgesteld. In een groep ideeën uitwisselen voor onderzoek, gebaseerd op klinische vraagstellingen en met elkaar uitkomsten van onderzoeken interpreteren.

Ook al is het werk natuurlijk nooit zo baanbrekend als je je, jong en ambitieus, aan het begin van het traject nog voorstelt, ik denk wel dat ik voor wat betreft het doel van een promotie: "leren een onderzoeker te worden", geslaagd ben. Alles wat ik heb meegemaakt heeft me zowel een beetje meer geleerd als ook wijzer gemaakt.

Ik wil iedereen bedanken die mij in al de voorgaande jaren heeft geholpen. Als eerste alle patiënten en hun begeleiders die moeite hebben gedaan om deel te nemen aan de wetenschappelijke projecten. De volgende mensen wil ik persoonlijk bedanken:

Als eerste mijn drie promotoren die gezamenlijk een continue drijfveer en goede raadgevers waren.

Johan Arends, ik denk dat er niemand is (vooral ook ikzelf niet) die het gepresteerd heeft om zo'n rotsvast vertrouwen te blijven hebben in het slagen van deze promotie. Vanaf het prille begin (we spraken al met elkaar over een promotie op het gebied van neurofysiologie toen ik nog amper een piekgolf van een andere golf kon onderscheiden) ben je van onschatbare waarde geweest. Je onvoorwaardelijke positieve manier van aanmoediging was een van deze "schatten". Daarnaast had ik veel aan je grote (visionaire) kennis die ook mij richting gegeven heeft. Ondanks dat ik mijn eigen weg wilde gaan met mijn onderzoeksvragen. Je wekelijkse tijd die je voor mij vrij maakte voor zo nodige afstemming (jaar in jaar uit...) en je topsnelheden van denken bij zulk overleg: wonderbaarlijk en heel handig. Dat je recent hoogleraar bent geworden is zeer terecht en ik ben trots dat je daardoor nu een van mijn promotoren kan zijn. Bedankt ook voor je vriendschap en het samen muziek maken.

Bert Aldenkamp, ik heb je ooit gezegd: "zonder jou kan en wil ik niet promoveren" en dat is vanwege je inspirerende aanwezigheid, het plezier van samen met jou over vraagstukken rond cognitie en EEG te spreken, zowel in de dagelijkse praktijk als op het wetenschappelijk gebied. Vooral voor het tweede deel van mijn promotie waarbij de "cognitie" om de hoek kwam kijken, was jij als neuropsycholoog en ervaren wetenschapper op gebied van cognitie en EEG, onmisbaar en heb je me veel inzichten gegeven. Ook heb ik je statistische hulp gewaardeerd en je perfecte leiding in de 
eindfase in jouw rol als eerste promotor. Ik heb je lang "aan het lijntje" gehouden als klinische promovendus (vele jonge promovendi die jij tegelijkertijd begeleidde waren stukken eerder klaar), ook voor promotoren is het lastig om zo'n draad lang vast te moeten houden. Bedankt dat je dat voor mij gedaan hebt.

Paul Boon, jij stond aan de wieg van dit gebeuren, want de eerste wensen voor een promotie heb ik uitgesproken tegen jou, in je positie van directeur onderzoek en ontwikkeling van Kempenhaeghe. Je hebt de poort voor mij opengezet ("kom eerst maar eens een half jaar in Kempenhaeghe werken en dan kan je alvast nadenken over onderzoek doen"). Het heeft niet alleen geleid tot een wetenschappelijk traject maar ook tot een plezierige baan. Vanaf het allereerste begin heb je mijn traject, dat gepaard ging met veel vallen en weer opstaan, gevolgd. Je hebt als een zeer ervaren onderzoeker steeds een goede inbreng gehad wanneer ik er om vroeg. Ik ben trots dat iemand met zo'n grote kennis en bekendheid als het gaat om onderzoek bij epilepsie, met mij mee heeft gedacht.

Voor hulp bij het schrijven van de publicaties wil ik eerst bedanken mijn mede "eerste auteur" van het artikel over ketogeen dieet Danielle Lambrechts (die ook nog heel goed werk leverde als proefdruk-lezende paranimf !), en als medeauteur van het prospectieve artikel over cognitie en EEG Dominique ljff. Ook dank voor de mede auteurs Mariëtte Debeij, Sylvia Klinkenberg, Geke Overvliet, Marian Majoie en Anton de Louw. Voor inspirerende discussies: Hans Vles, Joost Nicolai, Jan Cuppen, Bert Kleine en alle mensen die werken bij de "leerstoornissengroep" van Kempenhaeghe. Geke Overvliet en René Besseling, fijn dat ik kon meedenken bij enkele publicaties bij jullie promoties. Voor het verzetten van bergen werk wil ik vooral Hans den Boer bedanken (KNF-laborant) voor zijn consciëntieuze, tijdrovende EEG-scoringen, en daarnaast ook Ariadne van der Does (onderzoeksverpleegkundige) voor het strak in de hand houden van de prospectieve dataverzameling bij de studie over cognitie en EEG; Inge van der Linden (physician assistant KNF) voor vele adviezen en werkzaamheden, en verder de (toenmalige) geneeskundestudenten Ingrid Herraets en Erwin Teuniszen, statisticus Klaas Frankena, medisch fysicus Pauly Ossenblok en secretaresse Ankie van Oyen. Diverse medewerkers (destijds of nog steeds) werkend bij de gedragswetenschappelijke dienst voor het invoeren en mee interpreteren van neuropsychologische data: Dominique ljff, Nora de la Parra, Els van der Horst, Ruben Hendriksen, Eric Santegoeds, en voor de goede begeleiding daarvan: Jos Hendriksen en Bert Aldenkamp. Alle KNF-laboranten voor hun aanmoediging en medewerking bij mijn promotietraject. Nynke Bodde voor haar adviezen vanuit haar eigen ervaring als "klinische promovendus".

Voor het overnemen van KNF taken mijn collega neurologen op de KNF alsmede Inge van der Linden. Voor het zorgdragen voor patiënten tijdens mijn afwezigheid veel dank voor mijn collega neurologen Inge Gommans en Jurgen Schelhaas, verpleegkundig specialist Bea Martens en misschien wel een van de beste secretaresses van de wereld Dorian Niessen. En natuurlijk alle andere collega's of verpleegkundig specialisten die werk overnamen terwijl ik "lekker zat te schrijven". Voor technische ondersteuning: 
Roy Krijn (medisch technoloog), voor het trouw aanleveren van resultaten uit het EPD André Kamping en voor het aanleveren van artikelen zo snel dat het Overtoom wel leek: Irene Gijselhart (bibliothecaresse). De mensen van de helpdesk en met name Alex Buenen voor de ondersteuning bij computer- en vooral SPSS problemen. Alle mensen van de beoordelingscommissie, prof. dr. W.H. Mess, dr. F.S.S. Leijten, dr. J. Nicolai, prof. dr. R.J. van Oostenbrugge en prof. dr. H. Stefan, veel dank voor jullie bijdrage en Tiny Wouters voor meehelpen met de lay-out.

Voor het weerbaar maken van mijn lichaam - danwel het weer uit de knoop halen van vastzittende onderdelen ervan- bij de (te) vele computer uurtjes: Matthew Deal (Pilates- en Franklin methode instructeur). Voor het ontwikkelen van wijsheid, die je zeker als promovendus goed kan gebruiken: Gestalttherapeut Hans Loeffen.

Lidy, bedankt voor jouw "Tolliaanse" manier van paranimf zijn ! Rieneke en Mascha: bedankt voor jullie steun en opp-app-ende apps. Mijn mindfulle styling-adviseur en vriendin Stephanie: dankjewel!

Papa en mama, jullie kennen mijn "honger" om te leren als geen ander en jullie hebben de vervulling ervan altijd mee helpen waarmaken, als er mensen zijn die daadwerkelijk "aan de wieg" hebben gestaan van deze promotie, zijn jullie het! Bedankt voor alles! Mama, zo bijzonder is het dat jij de prachtige kaft van mijn proefschrift hebt gemaakt. Joost, Janine, Jane en Judie, Marieke, Wout, Bas, Gijs, Rose, papa, mama en mijn lieve oma, wat fijn dat jullie er zijn en met mij het leven meeleven en meevieren. Al mijn andere vrienden, familie en kennissen en Kempenhaeghe-genoten die ik hierboven niet heb genoemd en die mij steunden tijdens mijn promotie, heel veel dank. 
Curriculum Vitae 


\section{Curriculum Vitae}

\section{English}

Saskia Ebus was born on November 2nd, 1972 in Nijmegen.

After secondary school (Stedelijk Gymnasium Nijmegen), she studied medicine at the Radboud University Nijmegen from 1991-1998. From 1998-2005 she was a neurology resident at the department of neurology at the Canisius Wilhelmina Hospital Nijmegen (dr. C.W.G.M Frenken and later dr. W.I.M. Verhagen, for clinical neurophysiology dr. J. Meulstee). Half way this residency, she worked for six months in the epilepsy center Kempenhaeghe and during this period the first plans for a thesis in the field of epilepsy were made.

Since 2005 until now, she works as a neurologist at epilepsy center Kempenhaeghe. Her main pursuits are the clinical diagnosis and treatment of adult patients with epilepsy as well as electroencephalography (EEG) in children and adults with epilepsy. She is also active in education programs for nurses and EEG- technologists. Gradually her neurophysiological interest focused on video-EEG monitoring in mentally retarded patients and on school-aged children and correlations between epileptiform EEG abnormalities and learning disabilities. In the thesis this last growing interest is reflected by the change of topic from "EEG as outcome parameter for epilepsy treatment", to the "EEG as outcome parameter for cognition".

Saskia lives in Eindhoven and she is an enthusiastic amateur singer in choir ensembles (Collegium Vocale Eindhoven and ensemble "I Fortunelli"). Furthermore she is obsessed by Pilates as a way to improve the awareness and strength of the body and in the practice of Buddhism to do the same with the mind.

\section{Nederlands}

Saskia Ebus werd geboren op 2 november 1972 in Nijmegen.

$\mathrm{Na}$ de middelbare school (Stedelijk Gymnasium Nijmegen), studeerde ze geneeskunde aan de Radboud Universiteit Nijmegen van 1991-1998. Van 1998-2005 was ze in opleiding tot neuroloog in het Canisius Wilhelmina Ziekenhuis te Nijmegen (opleiders dr. C.W.G.M Frenken en later dr. W.I.M. Verhagen, voor klinische neurofysiologie dr. J. Meulstee). Halverwege deze opleiding werkte ze zes maanden in epilepsiecentrum Kempenhaeghe en gedurende deze periode werden de eerste plannen voor een promotie op het gebied van epilepsie al gesmeed.

Sinds 2005 tot heden, werkt ze als neuroloog in het epilepsiecentrum Kempenhaeghe. Haar belangrijkste werkzaamheden liggen op het vlak van de diagnostiek en behandeling van epilepsie bij volwassenen, alsmede electroencephalografie (EEG) bij kinderen en volwassenen met epilepsie. Ze is ook actief in onderwijsprogramma's voor verpleegkundigen en EEG-laboranten. Gaandeweg focuste de neurofysiologische interesse zich vooral op video-EEG monitoring bij patiënten met ernstige verstandelijke 
handicap en op schoolgaande kinderen en relaties tussen epileptiforme EEGafwijkingen en leerproblemen. In het proefschrift wordt deze laatste groeiende interesse weerspiegeld in de verandering van het onderwerp "EEG als uitkomstparameter bij de behandeling van epilepsie" naar "EEG als uitkomstparameter voor cognitie".

Saskia woont in Eindhoven en ze is een enthousiaste amateur zanger in koorensembles (Collegium Vocale Eindhoven en ensemble "I Fortunelli"). Verder is ze gegrepen door Pilates als een manier om de aandacht voor de kracht van het lichaam te verbeteren en door het praktiseren van Boeddhisme als een manier om hetzelfde te doen met de geest. 